Florida International University FIU Digital Commons

5-11-2012

\title{
Assessment of Biodegradable Magnesium Alloys for Enhanced Mechanical and Biocompatible Properties
}

Puneet Kamal S. Gill

Florida International University, Pgillo01@fiu.edu

DOI: $10.25148 /$ etd.FI12080610

Follow this and additional works at: https://digitalcommons.fiu.edu/etd

\section{Recommended Citation}

Gill, Puneet Kamal S., "Assessment of Biodegradable Magnesium Alloys for Enhanced Mechanical and Biocompatible Properties" (2012). FIU Electronic Theses and Dissertations. 714.

https://digitalcommons.fiu.edu/etd/714 


\section{FLORIDA INTERNATIONAL UNIVERSITY \\ Miami, Florida}

\section{ASSESSMENT OF BIODEGRADABLE MAGNESIUM ALLOYS FOR ENHANCED MECHANICAL AND BIOCOMPATIBLE PROPERTIES}

A dissertation submitted in partial fulfillment of the

requirements for the degree of

DOCTOR OF PHILOSOPHY

in

MATERIAL SCIENCE AND ENGINEERING

by

Puneet Kamal Singh Gill

2012 
To: Dean Amir Mirmiran

College of Engineering and Computing

This thesis, written by Puneet Kamal Singh Gill, and entitled Assessment of Biodegradable Magnesium Alloys for Enhanced Mechanical and Biocompatible Properties, having been approved in respect to style and intellectual content, is referred to you for judgment.

We have read this dissertation and recommend that it be approved.

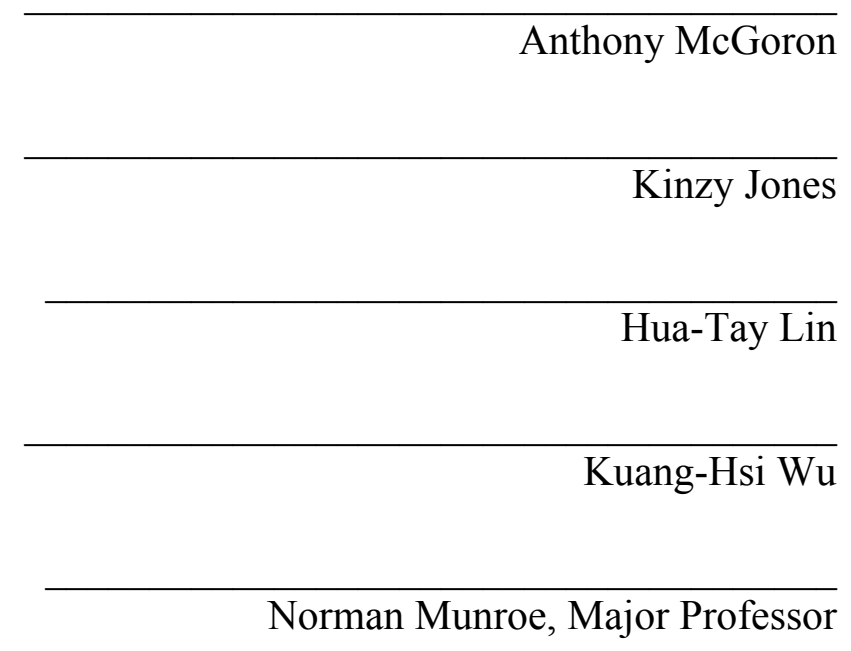

Date of Defense: May 11, 2012

The dissertation of Puneet Kamal Singh Gill is approved.

Dean Amir Mirmiran

College of Engineering and Computing

Dean Lakshmi N. Reddi University Graduate School

Florida International University, 2012 


\section{DEDICATION}

This dissertation is dedicated to ever loving memory of my father. He would have been extremely proud of this moment. I dedicate this dissertation to my parents, brother and wife - without their energetic support and love, it would have been impossible to complete this research. 


\section{ACKNOWLEDGMENTS}

I take this opportunity to express my sincere gratitude towards Dr. Norman Munroe (Faculty Advisor) for his support, motivation and valuable discussions during this entire research work. His continuous guidance helped me immensely in the research. His untiring support and encouragement throughout my Ph.D. has made the path very clear and easy. I thank him for long discussion hours he dedicated just to clear the knots in this research. His ideas always gave a new dimension to the research, and proposed many different aisles of solution. He taught us of doing things efficiently and to achieve maximum output. His ever-enthusiastic spirit, critical perspicacity, and energetic approach were the sole motivation of my persistence. He has taught me to challenge myself and stretch my limitations. I am thankful for his efforts, time and dedication for completion of my dissertation and developing my career.

My sincere thanks go to Dr. Kinzy W. Jones, Dr. Kuang-Hsi Wu, Dr. Anthony McGoron and Dr. H.T Lin for serving on my thesis committee and for their valuable suggestions. Their vast experience shared during my proposal defense has helped me to undertake more research strategies. Dr. Jones has been always very supportive and encouraging and provided a big help with his research facilities. Dr. Wu has always been very supportive and was always available to guide me through my research. Much learning was gained through attending his classes and his ability to make challenging topics easy and clear to understand. I sincerely thank Dr. McGoron and Dr. Lin for their encouragement, support and timely feedback.

I thank Dr. Sharan Ramaswamy for allowing me to use his facility for bio studies.

I thank Amit Datye for his support throughout this research and also in performing 
mechanical tests. He always encouraged me on employing critical thinking in my analyses. By mimicking his personality, of constructive criticism and a tireless work ethic, I was able to conduct my research in a more efficient and systematic manner. I would like to thank Mr. Ryszard Rokicki from Electrobright ${ }^{\circledR}$ for sample preparation, Dr. Hari-Babu Nadendla from Brunel University for providing samples and Neal Ricks in assisting the Advanced Materials Engineering Research Institute (AMERI) facilities. I would also like to thank Dr. Jose R. Almirall and Ms. Tatiana Trejos from International Forensic Research Institute for the use of their Inductively Coupled Mass Spectrometer (ICP-MS). I sincerely thank Dr. Debrupa Lahiri, Dr. Indranil Lahiri, Dr. Srinivasa R. Bakshi, Dr. Waseem Haider, Dr. Anoop Keshri and Dr. Kantesh Balani for their informative discussions and spears of ideas.

Special words of thanks go to Rupak Dua who provided extensive assistance in bio related studies. I would like thank our group members Sushma Amruthaluri, Ebony Daniels, Chandan Pulletikurthi, Smit Pandya and Vishal Musaramthota. I thank my friends for their everlasting moral support, Amardeep Mann, Gurjashan Singh, Gurjiwan Singh, Varun Pennmatsa, Mandar Zope, Utkarsh Bhatt, Srikanth Korla and many more for all their help and support.

I would like to acknowledge the Mechanical Materials Engineering Department (MME), Advanced Materials Engineering Research Institute (AMERI), Florida Center for Analytical Electron Microscopy (FCAEM), Center for the Study of Matter at Extreme Conditions (CESMEC), International Forensic Research Institute and Oak Ridge National Lab (ORNL) for laboratory support. I thank the University Graduate School for extending a Doctoral Evidence Acquisition (DEA) and Dissertation Year Fellowship 
(DYF) to support my research. I also acknowledge the financial support from National Institute of General Medical Sciences Award Number SC3GM084816.

Last but not least, I would like to thank my lovely parents and brother who supported me with their love, in every moment, during ups and downs of this research. Above all, I would like to thank my wife Zinki, without her moral support and love I would not have been able to complete my thesis work successfully. 


\author{
ABSTRACT OF THE DISSERTATION \\ ASSESSMENT OF BIODEGRADABLE MAGNESIUM ALLOYS FOR ENHANCED \\ MECHANICAL AND BIOCOMPATIBLE PROPERTIES \\ by \\ Puneet Kamal Singh Gill \\ Florida International University, 2012 \\ Miami, Florida \\ Professor Norman Munroe, Major Professor
}

Biomaterials have been used for more than a century in the human body to improve body functions and replace damaged tissues. Currently approved and commonly used metallic biomaterials such as, stainless steel, titanium, cobalt chromium and other alloys have been found to have adverse effects leading in some cases, to mechanical failure and rejection of the implant. The physical or chemical nature of the degradation products of some implants initiates an adverse foreign body reaction in the tissue. Some metallic implants remain as permanent fixtures, whereas others such as plates, screws and pins used to secure serious fractures are removed by a second surgical procedure after the tissue has healed sufficiently. However, repeat surgical procedures increase the cost of health care and the possibility of patient morbidity. This study focuses on the development of magnesium based biodegradable alloys/metal matrix composites (MMCs) for orthopedic and cardiovascular applications. The $\mathrm{Mg}$ alloys/MMCs possessed good mechanical properties and biocompatible properties. Nine different compositions of $\mathrm{Mg}$ alloys/MMCs were manufactured and surface treated. Their degradation behavior, ion leaching, wettability, morphology, cytotoxicity and mechanical 
properties were determined. Alloying with $\mathrm{Zn}, \mathrm{Ca}, \mathrm{HA}$ and $\mathrm{Gd}$ and surface treatment resulted in improved mechanical properties, corrosion resistance, reduced cytotoxicity, lower $\mathrm{pH}$ and hydrogen evolution. Anodization resulted in the formation of a distinct oxide layer (thickness 5-10 $\mu \mathrm{m}$ ) as compared with that produced on mechanically polished samples $(\sim 20-50 \mathrm{~nm})$ under ambient conditions. It is envisaged that the findings of this research will introduce a new class of Mg based biodegradable alloys/MMCs and the emergence of innovative cardiovascular and orthopedic implant devices. 
ABBREVIATIONS

ASTM

ATP

ANOVA

$\mathrm{Ca}$

CA

DP

DPBS

EDS

EIS

FBS

FP

Gd

$\mathrm{H}_{2}$

HA

HCP

HCP

HUPAC

ICP-MS

ISO

K

$\mathrm{Mg}$
American Society for Testing Materials

Adenosine Triphosphate

Analysis of Variance

Calcium

Contact Angle

Diamond Paste

Dulbecco's Phosphate Buffered Saline

Energy Dispersive Spectroscopy

Electrochemical Impedance Spectroscopy

Fetal Bovine Serum

Fractional Polarity

Gadolinium

Hydrogen

Hydroxyapatite

Hexagonal Closed Packed

Hexagonal Close Packed

Human Pulmonary Artery Endothelial Cells

Inductively Coupled Mass Spectroscopy

International Organization for Standardization

Potassium

Magnesium 


\begin{tabular}{ll} 
MgO & Magnesium Oxide \\
NSF & Nephrogenic Systemic Fibrosis \\
O & Oxygen \\
PBS & Phosphorous \\
rpm & Phosphate Buffer Saline \\
SEM & Revolutions Per Minute \\
SFE & Scanning Electron Microscopy \\
SRB & Surface Free Energy \\
XRD & Sulforhodamine B Assay \\
Zn & X-ray Diffraction \\
\hline
\end{tabular}




\section{NOMENCLATURE}

\begin{tabular}{|c|c|}
\hline $\mathrm{A}^{\mathrm{o}}$ & Angstrom \\
\hline $\mathrm{At} \%$ & Atomic Percentage \\
\hline $\mathrm{C}_{\mathrm{dl}}$ & Capacitance Double Layer \\
\hline${ }^{\mathrm{o}} \mathrm{C}$ & Celsius \\
\hline $\mathrm{R}_{\mathrm{ct}}$ & Charge Transfer Resistance \\
\hline$\theta_{\mathrm{i}}$ & Contact Angle Between Solid and Liquid \\
\hline $\mathrm{Cu}$ & Copper \\
\hline $\mathrm{I}_{\text {corr }}$ & Corrosion Current \\
\hline $\mathrm{E}_{\text {corr }}$ & Corrosion Potential \\
\hline $\mathrm{C}$ & Cysteine \\
\hline$\rho$ & Density \\
\hline $\mathrm{d}$ & Dispersion \\
\hline$\gamma_{i}^{d}$ & Dispersion Portion of Surface Tension (testing drop, i) \\
\hline$\gamma_{s}^{d}$ & Dispersion Portion of Surface Tension (testing surface, s) \\
\hline EW & Equivalent Weight \\
\hline $\mathrm{y}$ & Film Thickness \\
\hline $\mathrm{y}$ & Film Thickness \\
\hline FP & Fractional Polarity \\
\hline $\mathrm{G}$ & Gibbs Free Energy \\
\hline Q & Glutamine \\
\hline $\mathrm{h}$ & Hydrogen bond \\
\hline
\end{tabular}




\begin{tabular}{|c|c|}
\hline Z" & Impedance (imaginary) \\
\hline Z' & Impedance (real) \\
\hline $\mathrm{V}$ & Molar Volume \\
\hline M & Molecular Mass \\
\hline $\mathrm{L}$ & Ostwald solubility coefficient \\
\hline $\mathrm{R}_{\mathrm{PB}}$ & Pilling-Bedworth Ratio \\
\hline$v$ & Poisson's Ratio \\
\hline $\mathrm{p}$ & Polar \\
\hline Rs & Solution Resistance \\
\hline A & Surface Area \\
\hline$\gamma_{i}^{-}$ & Surface Tension Contributed by Base (testing drop, i) \\
\hline$\gamma_{s}^{-}$ & Surface Tension Contributed by Base (testing surface, s) \\
\hline$\gamma_{i}^{+}$ & Surface Tension Contribution by Acid (testing drop, i) \\
\hline$\gamma_{s}^{+}$ & Surface Tension Contribution by Acid (testing surface, $s$ ) \\
\hline$\gamma_{s}$ & Surface Tension of Solid Sample \\
\hline$\gamma_{i}$ & Surface Tension of Testing Drop \\
\hline $\mathrm{t}$ & Time \\
\hline W & Tryptophan \\
\hline$\lambda$ & Wavelength \\
\hline $\mathrm{Wt} \%$ & Weight Percentage \\
\hline $\mathrm{E}$ & Young's Modulus \\
\hline
\end{tabular}




\section{TABLE OF CONTENTS}

CHAPTER

1.0 INTRODUCTION

1.1 History of Biomaterials 3

1.2 Classification of Biomaterials 3

1.3 Magnesium Alloys for Implant Applications 5

$\begin{array}{lll}1.4 & \text { Why Magnesium Alloys? } & 7\end{array}$

$\begin{array}{lll}\text { 1.4.1 Crystal Structure of Magnesium } & 10\end{array}$

1.4.2 Beneficial Effects of Alloying Elements 11

$\begin{array}{lll}1.5 & \text { Research Objective } & 14\end{array}$

$\begin{array}{ll}2.0 & \text { LITERATURE REVIEW } \\ & 17\end{array}$

2.1 Biodegradable Magnesium - Current Research 17

3.0 MATERIALS AND METHODS 28

3.1 Synthesis of Mg Biodegradable Materials 28

$\begin{array}{ll}3.2 & \text { Sample Preparation } \\ 3.3 & \text { Reagent }\end{array}$

3.3 Reagents 31

4.0 ELECTROCHEMICAL STUDIES 33

4.1 Corrosion Behavior of Medical Implants 33

4.2 Magnesium - Corrosion Mechanism 33

$\begin{array}{lll}4.3 & \text { Factors Affecting Corrosion } & 38\end{array}$

$\begin{array}{ll}\text { 4.3.1 Pilling-Bedworth Ratio } & 40\end{array}$

4.3.2 Corrosion Kinetics 41

4.4 Corrosion Testing $\quad 42$

4.4.1 Electrochemical Test 43

4.4.2 Immersion Test 45

4.5 Corrosion Results and Discussion $\quad 47$

4.5.1 Potentiodynamic Polarization Test 47

4.5.2 Electrochemical Impedance Spectroscopy (EIS) 54

4.5.3 Static Immersion Test 63

$\begin{array}{ll}\text { 4.5.4 Dynamic Immersion Test } & 70\end{array}$

4.5.5 Dissolved Ions Released During Immersion Test 75

5.0 SURFACE CHARACTERIZATION 79

$\begin{array}{ll}\text { 5.1. Material Characterization } & 79\end{array}$

5.1.1 SEM/EDS: Mechanically Polished and Anodized Samples 79

5.1.1.1 SEM/EDS of Mechanically Polished Alloys/MMCs after

Potentiodynamic Corrosion in PBS and PBS with Amino Acids 85

5.1.1.2 SEM/EDS of Mechanically Polished Alloys/MMCs in PBS after Static Immersion Tests 89

5.1.1.3 SEM/EDS of Mechanically Polished Alloys/MMCs in PBS after Dynamic Immersion Test 
5.1.1.4 SEM/EDS of Anodized Mg Alloys/MMCs after

Potentiodynamic Corrosion in PBS 96

5.1.1.5 SEM/EDS of Anodized Mg Alloys/MMCs in PBS after Static Immersion Test

5.1.1.6 SEM/EDS of Anodized Mg Alloys/MMCs in PBS after Dynamic Immersion Test

5.1.2 X-Ray Diffraction of Mg Alloy/MMCs Before and After Corrosion

5.2 Grain Size Determination

5.3 Density Measurement

5.4 Wettability

5.4.1 Wettability Measurements of Mg Alloys/MMCs

6.0 DETERMINATION OF MECHANICAL PROPERTIES

123

6.1 Elastic Modulus and Hardness Via Nanoindentation

123

6.2 Vicker's Hardness

124

6.3 Results and Discussions of Mechanical Properties

125

6.4 Ultimate Tensile Strength

7.0 BIOCOMPATIBILITY STUDIES

7.1 Endothelial Cell Proliferation on Mg Alloys/MMCs

132

7.2 Cytotoxicity of Leached Ions on Endothelial Cells by SRB Assay

135

7.3 Osteoblast Cell Proliferation on Mg Alloys/MMCs

7.4 Cytotoxicity of Leached Ions on Osteoblast Cells by SRB Assay

7.5 Monitoring Osteoblast Cell Growth on Mg Alloys/MMCs Electrochemical Impedance Spectroscopy

8.0 EFFECT OF SURFACE ROUGHNESS

8.1 Effect of Surface Roughness on Electrochemical Behavior and Wettability

8.1.1 Roughness Effect - Results and Discussion 154

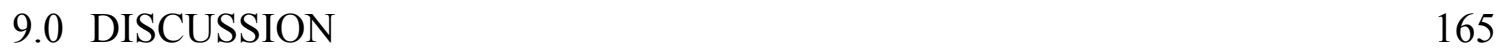

$\begin{array}{ll}\text { 10.0CONCLUSION } & 176\end{array}$

11.0 RECOMMENDATIONS FOR FUTURE RESEARCH 179

$\begin{array}{ll}\text { REFERENCES } & 180\end{array}$

$\begin{array}{ll}\text { APPENDICES } & 195\end{array}$ 


\section{LIST OF TABLES}

TABLE PAGE

Table 1.1: Biomaterials used in human body [5,25,145] 4

Table 1.2: Role of selected alloying elements and blood serum content [70,89,90,91] 14

Table 2.1: Summary of (approximate) properties of some of the potential Mg based alloys for bone and stent applications. [70,71,85,89,92,94,96,99,121] 25

Table 3.1: Nominal and analyzed compositions of the materials in weight percentage $(\mathrm{wt} \%)$

Table 3.2: Lubricants and abrasives used during sample preparation 30

Table 3.3: Chemical composition of PBS solution in $\mathrm{g} / \mathrm{L}$.

Table 4.1: Calculated Pilling-Bedworth ratio for the elements used in this investigation 41

Table 4.2: Average potentiodynamic polarization data for mechanically polished samples in PBS at $37^{\circ} \mathrm{C}$

Table 4.3: Average potentiodynamic polarization data from three test values in PBS and PBS containing amino acids

Table 4.4: Average potentiodynamic polarization data for anodized samples in PBS at 37 ${ }^{\mathrm{o}} \mathrm{C}$

Table 4.5: Ostwald solubility coefficient $\mathrm{L}$ ( $\mathrm{ml}$ gas per $\mathrm{ml}$ medium) for hydrogen in biological media at various temperatures $\left({ }^{\circ} \mathrm{C}\right)[70,122]$

Table 4.6: Comparison between the corrosion rates depicted for mechanically polished and anodized samples via immersion test

Table 4.7: Corrosion rates of mechanically polished and anodized samples under dynamic conditions.

Table 4.8: ICP-MS acquisition parameters for the analysis of the samples

Table 5.1: Acid-Base, average values of surface free energy components $\left(\mathrm{mJ} / \mathrm{m}^{2}\right)$ for mechanically polished samples 
Table 5.2: Acid-Base, average values of surface free energy components $\left(\mathrm{mJ} / \mathrm{m}^{2}\right)$ for anodized samples

Table 7.1: Composition of F-12K medium used for endothelial cells [74]

Table 7.2: Composition of DMEM/F-12 medium used for osteoblast cells $[195,196,197,198,199]$

Table 7.3: The electrochemical impedance parameters of $\mathrm{Mg} 1 \mathrm{Zn}$ in cell culture media with osteoblast cells at different time intervals

Table 8.1:Lubricants and abrasives used during sample preparation and average roughness parameters

Table 8.2: Results of potentiodynamic corrosion tests of the samples in PBS at $37{ }^{\circ} \mathrm{C} 157$

Table 8.3: $\mathrm{R}_{\text {corr }}$ and $\mathrm{C}_{\mathrm{dl}}$ values of $\mathrm{Mg} 1 \mathrm{Zn} 1 \mathrm{Ca}$ alloys in PBS at $37^{\circ} \mathrm{C}$

Table 8.4: Surface free energy and fractional polarity components

Table A.1: Kitazaki Hata, average values of surface free energy components $\left(\mathrm{mJ} / \mathrm{m}^{2}\right)$ mechanically polished samples

Table A.2: Kitazaki Hata, average values of surface free energy components $\left(\mathrm{mJ} / \mathrm{m}^{2}\right)$ anodized samples

Table A.3: Acid-Base, average values of mechanically polished samples: contact angle, interfacial free energy and work of adhesion

Table A.4: Kitazaki Hata, average values of mechanically polished samples: contact angle, interfacial free energy and work of adhesion

Table A.5: Acid-Base, average values of anodized alloys: contact angle, interfacial free energy and work of adhesion

Table A.6: Kitazaki Hata, average values of anodized alloys: contact angle, interfacial free energy and work of adhesion

Table A.7: Acid-Base, average values of mechanically polished samples at different roughness: contact angle, interfacial free energy and work of adhesion

Table A.8: Acid-Base, average values of surface free energy components $\left(\mathrm{mJ} / \mathrm{m}^{2}\right)$ of mechanically polished samples at different roughness

Table A.10: Properties of elements used in this study 
Table A.11: Mean concentration values of $\mathrm{Ca}, \mathrm{Mg}, \mathrm{Zn}$ and Gd measured by ICP-MS. All concentrations and standard deviations were estimated for 3 replicates. Concentrations are reported in ppm $(\mu \mathrm{g} / \mathrm{mL})$ 


\section{LIST OF FIGURES}

FIGURE $\quad$ PAGE

Figure 1.1: World market of biomaterials [9]. 2

Figure 1.2: Schematic showing the ideal conditions of reduced load on implant over time of healing process $[6,128]$.

Figure 1.3: Magnesium connectors designed by Payr for vessel anastomosis [29,30]. Method (A) used an extravasal magnesium ring, which ensures an open postoperative anastomosis. Method (B) uses a two-part extravasal connector with a male and female part.

Figure 1.4: Newspaper article on the importance of magnesium in diet.

Figure 1.5: Approximate magnesium distribution [31]. $\quad 8$

Figure 1.6: Intracellular distribution of $\operatorname{Mg}[32,33] . \quad 9$

Figure 1.7: Hypothetical model demonstrating magnesium in cell proliferation control $[33,35]$.

Figure 1.8: Mg unit cell crystal: (a) Principal planes [ $\left.\begin{array}{llll}1 & -2 & 1 & 0\end{array}\right]$, basal plane, face plane (b) Principal $\left[\begin{array}{llll}1 & 1 & 0 & 0\end{array}\right]$ planes. (c) Principal directions [37,38]. 11

Figure 1.9: Schematic representation of the research summary. 16

Figure 2.1: TEM micrograph of extruded composite after aging: (a) refined grains, 100$200 \mathrm{~nm}$; and (b) nano-rods distributed in the grain boundaries [94]. 20

Figure 2.2: The solid solution time effect on grain size and hardness at $525{ }^{\circ} \mathrm{C}$ [95]. 21

Figure 2.3: Corrosion rates variation with concentration of $\mathrm{Gd}$ in $\mathrm{Mg}$ [99]. 23

Figure 2.4: Flouroscopic images of cross-sections of: (a) degradable polymer and (b) magnesium rod in a guinea pig femura, performed $10 \mathrm{~mm}$ below trochanter. The specimens were harvested 18 weeks postoperatively and images were taken in-vivo by staining the new bone with calcein green. Bar $=1.5 \mathrm{~mm}$; $\mathrm{I}=\mathrm{implant}$ residual; $\mathrm{P}=$ periosteal bone formation; $\mathrm{E}=$ endosteal bone formation [104].

Figure 2.5: Schematic representation of (approximate) properties of potential $\mathrm{Mg}$ based alloys for biomedical applications (corrosion rate (CR), $\mathrm{mm} /$ year) $[70,71,85,89,92,94,96,99,121]$.

Figure 3.1: Schematic representation of Brunel alloy manufacturing process [37]. 28 
Figure 3.2: Typical anodization setup.

Figure 4.1: Potential-pH (Pourbaix) diagram for Mg-zinc in water at $25^{\circ} \mathrm{C}$, showing the theoretical domains of corrosion, immunity and passivation.

Figure 4.2: $\mathrm{Ca}^{2+}$ and $\mathrm{Mg}^{2+}$ concentration as a function of clotting time of human plasma [73].

Figure 4.3: Factors affecting the corrosion behavior of implant materials.

Figure 4.4: Classification of three different techniques used for corrosion studies for magnesium alloys.

Figure 4.5: Potentiostat corrosion cell arrangement.

Figure 4.6: MPM custom corrosion cell kit.

Figure 4.7: Schematic representation of immersion test setup.

Figure 4.8: Typical potentiodynamic polarization curves of mechanically polished $\mathrm{Mg}$ samples in PBS at $37^{\circ} \mathrm{C}$.

Figure 4.9: Typical potentiodynamic polarization curves of mechanically polished $\mathrm{Mg}$ alloys in PBS containing amino acids at $37^{\circ} \mathrm{C}$.

Figure 4.10: Typical potentiodynamic polarization curves of anodized Mg samples in PBS at $37^{\circ} \mathrm{C}$.

Figure 4.11: Comparison of corrosion rates between mechanically polished and anodized samples.

Figure 4.12: Equivalent circuit of the corrosion cell: $\mathrm{R}_{\mathrm{s}}=$ electrolyte resistance, $\mathrm{R}_{\mathrm{ct}}=$ charge transfer resistance and $\mathrm{C}_{\mathrm{dl}}=$ capacitance double layer [201].

Figure 4.13: Nyquist plots (log-log representation) for mechanically polished samples in PBS at $37^{\circ} \mathrm{C}$.

Figure 4.14: Bode plot (phase Vs frequency) for mechanically polished alloys in PBS at $37^{\circ} \mathrm{C}$.

Figure 4.15: Variation of the concentration of counter ions with distance from the surface.

Figure 4.16: Bode plot (impedance modulus Vs frequency) for mechanically polished alloys in PBS at $37^{\circ} \mathrm{C}$. 
Figure 4.17: Equivalent circuit for filmed corrosion surfaces [201].

Figure 4.18: Nyquist plots (log-log representation) for anodized samples in PBS at $37{ }^{\circ} \mathrm{C}$.

Figure 4.19: Schematic demonstrating the factors influencing the filiform corrosion [131].

Figure 4.20: Bode plot (phase Vs frequency) for anodized samples in PBS at $37^{\circ} \mathrm{C}$.

Figure 4.21: Bode plots (impedance modulus Vs frequency) for anodized alloys in PBS at $37{ }^{\circ} \mathrm{C}$.

Figure 4.22: Hydrogen evolutions from mechanically polished samples immersed in PBS for 192 hours at $37^{\circ} \mathrm{C}($ mean $\pm \mathrm{SD}, \mathrm{n}=3)$.

Figure 4.23: Hydrogen evolution from anodized samples immersed in PBS for 192 hours at $37^{\circ} \mathrm{C}($ mean $\pm \mathrm{SD}, \mathrm{n}=3)$.

Figure 4.24: The $\mathrm{pH}$ for mechanically polished samples immersed in $\mathrm{PBS}$ at $37{ }^{\circ} \mathrm{C}$ (mean $\pm \mathrm{SD}, \mathrm{n}=3$ ).

Figure 4.25: The $\mathrm{pH}$ for anodized samples immersed in $\mathrm{PBS}$ at $37^{\circ} \mathrm{C}(\mathrm{mean} \pm \mathrm{SD}, \mathrm{n}=3$ ).

Figure 4.26: The $\mathrm{pH}$ of mechanically polished samples immersed in $\mathrm{PBS}$ at $37^{\circ} \mathrm{C}$ under dynamic conditions (mean $\pm \mathrm{SD}, \mathrm{n}=3$ ).

Figure 4.27: The $\mathrm{pH}$ of anodized samples immersed in PBS at $37^{\circ} \mathrm{C}$ under dynamic conditions (mean $\pm \mathrm{SD}, \mathrm{n}=3$ ).

Figure 4.28: Effect of velocity on the rate of degradation of a metal under diffusioncontrolled cathodic process [162].

Figure 4.29: ICP-MS analysis showing the concentration of $\mathrm{Mg}$ and $\mathrm{Ca}$ ions in corrosion extract obtained from mechanically polished samples during static immersion (mean $\pm \mathrm{SD}, \mathrm{n}=3$ ).

Figure 4.30: ICP-MS analysis showing the concentration of $\mathrm{Mg}$ and $\mathrm{Ca}$ ions in corrosion extract (PBS + amino acids) obtained from mechanically polished samples during static immersion (mean $\pm \mathrm{SD}, \mathrm{n}=3$ ).

Figure 4.31: ICP-MS analysis showing the concentration of $\mathrm{Mg}$ and $\mathrm{Ca}$ ions in corrosion extract obtained from anodized samples during static immersion (mean $\pm \mathrm{SD}, \mathrm{n}=3$ ). 
Figure 4.32: ICP-MS analysis showing the concentration of $\mathrm{Mg}$ and $\mathrm{Ca}$ ions in corrosion extract obtained from anodized samples during dynamic immersion $($ mean $\pm \mathrm{SD}, \mathrm{n}=$ $3)$.

Figure 5.1: SEM photomicrographs and EDS analysis (inset): (a) Mg1Zn (ACI); (b) Mg1Zn1Ca (ACI); (c) Mg1Zn1Ca8Gd (ACI); (d) Mg1Zn1Ca; (e) Mg1Zn1Ca1HA; (f) Mg1Zn1Ca3HA; (g) Mg5Zn1Ca; (h) Mg5Zn1Ca1HA; and (i) Mg5Zn1Ca3HA.

Figure 5.2: SEM photomicrographs and EDS analysis (inset) for anodized samples: (a) Mg1Zn (ACI); (b) Mg1Zn1Ca (ACI); (c) Mg1Zn1Ca8Gd (ACI); (d) Mg1Zn1Ca; (e) Mg1Zn1Ca1HA; (f) Mg1Zn1Ca3HA; (g) Mg5Zn1Ca; (h) Mg5Zn1Ca1HA; (i) Mg5Zn1Ca3HA; and (j) cross-section of the anodized Mg1Zn1Ca (ACI) alloy.

Figure 5.3: Scanning electron microscopy image of alloys after potentiodynamic corrosion: (a) MgZn, PBS; (b) MgZn, PBS+C; (c) MgZn, PBS+Q; (d) MgZn, $\mathrm{PBS}+\mathrm{W}$ and (e) composition of the surface layers formed on Mg alloys during accelerated corrosion tests in PBS and PBS with amino acids.

Figure 5.4: Scanning electron microscopy image of alloys after potentiodynamic corrosion: (a) MgZnCa, PBS; (b) MgZnCa, PBS+C; (c) MgZnCa, PBS+Q; (d) $\mathrm{MgZnCa}, \mathrm{PBS}+\mathrm{W}$ and (e) composition of the surface layers formed on Mg alloys during accelerated corrosion tests in PBS and PBS with amino acids.

Figure 5.5: Scanning electron microscopy image of alloys after potentiodynamic corrosion: (a) MgZnCaGd, PBS; (b) MgZnCaGd, PBS+C; (c) MgZnCaGd, PBS+Q; (d) $\mathrm{MgZnCaGd}, \mathrm{PBS}+\mathrm{W}$ and (e) composition of the surface layers formed on $\mathrm{Mg}$ alloys during accelerated corrosion tests in PBS and PBS with amino acids.

Figure 5.6: SEM photomicrographs of mechanically polished samples after 192 hours of immersion in PBS at $37^{\circ} \mathrm{C}$.

Figure 5.7: (a) Plot showing composition of the surface layers formed on mechanically polished $\mathrm{Mg}$ samples after immersion and (b) microstructure of $\mathrm{Mg} 5 \mathrm{Zn} 1 \mathrm{Ca}$ corroded in PBS, showing $\alpha$ and $\beta$ phases (Right inset SEM of human bone of 22 year old male [132] and left inset change of surface composition during corrosion, where (A) is the initial surface and (B) is the surface after corrosion [69]) .

Figure 5.8: SEM photomicrographs of mechanically polished alloys after dynamic immersion test in PBS.

Figure 5.9: Photomicrographs of anodized samples after potentiodynamic polarization test in PBS at $37^{\circ} \mathrm{C}$. 
Figure 5.10: SEM photomicrographs of anodized sample after 192 hours of immersion in PBS at $37^{\circ} \mathrm{C}$.

Figure 5.11: Photomicrographs of anodized samples after dynamic immersion for 192 hours in PBS at $37^{\circ} \mathrm{C}$.in PBS at $37^{\circ} \mathrm{C}$.

Figure 5.12: Plot showing composition of the surface layers formed on anodized $\mathrm{Mg}$ samples: (a) static immersion and (b) dynamic immersion.

Figure 5.13: XRD spectra of mechanically polished samples: (a) Mg1Zn (ACI); Mg1Zn1Ca (ACI); Mg1Zn1Ca8Gd (ACI) and (b) Mg1Zn1Ca; Mg1Zn1Ca1HA; Mg1Zn1Ca3HA; Mg5Zn1Ca; Mg5Zn1Ca1HA; and Mg5Zn1Ca3HA.

Figure 5.14: XRD spectra of anodized samples.

Figure 5.15: XRD spectra of mechanically polished samples after corrosion in PBS. 110

Figure 5.16: XRD spectra of anodized samples after corrosion in PBS.

Figure 5.17: XRD spectra of anodized samples after dynamic corrosion in PBS at $37^{\circ} \mathrm{C}$.

Figure 5.18: Average grain size of $\mathrm{Mg}$ samples.

Figure 5.19: Experimental and theoretical densities of mechanically polished samples.114

Figure 5.20: (a) Kyowa contact angle meter, DM-CE1 and (b) Schematic representing interfacial forces and contact angle of a liquid drop on a solid surface.

Figure 5.21: Schematic illustrating various layers in metals effecting interfacial free energy and polarity.

Figure 5.22: Acid-Base theory contact angle, interfacial free energy and work of adhesion components for mechanically polished samples (mean $\pm \mathrm{SD}, \mathrm{n}=10)$.

Figure 5.23: Kitazaki-Hata surface free energy components of mechanically polished samples (mean $\pm \mathrm{SD}, \mathrm{n}=10)$.

Figure 5.24: Acid-Base theory contact angle, interfacial free energy and work of adhesion components for anodized samples (mean $\pm \mathrm{SD}, \mathrm{n}=10$ ).

Figure 5.25: Kitazaki-Hata surface free energy components of anodized surfaces (mean \pm $\mathrm{SD}, \mathrm{n}=10)$.

Figure 6.1: Schematic of indentation dimensions during Vicker's hardness test [181]. 125 
Figure 6.2: Nanoindentation: (a) Typical load Vs displacement curves for $200 \mathrm{mN}$ peak load, (b) Peak load Vs modulus; Mg1Zn, Mg1Zn1Ca and Mg1Zn1Ca8Gd and (c) Peak load Vs modulus; Mg1Zn1Ca, Mg1Zn1Ca1HA, Mg1Zn1Ca3HA, Mg5Zn1Ca, $\mathrm{Mg} 5 \mathrm{Zn} 1 \mathrm{Ca} 1 \mathrm{HA}$ and $\mathrm{Mg} 5 \mathrm{Zn} 1 \mathrm{Ca} 3 \mathrm{HA}(\operatorname{mean} \pm \mathrm{SD}, \mathrm{n}=10)$.

Figure 6.3: Hardness calculated by Oliver Pharr approach: (a) $\mathrm{Mg} 1 \mathrm{Zn}, \mathrm{Mg} 1 \mathrm{Zn} 1 \mathrm{Ca}$ and Mg1Zn1Ca8Gd and (b) Mg1Zn1Ca, Mg1Zn1Ca1HA, Mg1Zn1Ca3HA, Mg5Zn1Ca, Mg5Zn1Ca1HA and Mg5Zn1Ca3HA (mean \pm SD, $\mathrm{n}=10$ ).

Figure 6.4: Load Vs hardness calculated from Vicker's hardness (mean \pm SD, $n=5) .129$

Figure 6.5: Approximate tensile properties of $\mathrm{Mg}$ alloys/MMCs adopted from Zibiao $\mathrm{Li}$, M. Phil thesis at Brunel University, Brunel Center for Advanced Solidification Technology (BCAST), August 2010 [119].

Figure 7.1: Schematic representation of procedure adopted for biocompatibility studies.

Figure 7.2: Net growth rate of endothelial cells exposed to leached ions from mechanically polished samples during static immersion test (mean $+\mathrm{SD}, \mathrm{n}=3$ ): (a) Mg1Zn (ACI); (b) Mg1Zn1Ca (ACI); (c) Mg1Zn1Ca8Gd (ACI); (d) Mg1Zn1Ca; (e) Mg1Zn1Ca1HA; (f) Mg1Zn1Ca3HA; (g) Mg5Zn1Ca; (h) Mg5Zn1Ca1HA; and (i) Mg5Zn1Ca3HA. Statistical significance $(p<0.05)$ was analyzed using the Tukey test.

Figure 7.3: Net growth rate of osteoblast cells exposed to leached ions from mechanically polished samples during static immersion test (mean $+\mathrm{SD}, \mathrm{n}=3$ ): (a) $\mathrm{Mg} 1 \mathrm{Zn}$ (ACI); (b) Mg1Zn1Ca (ACI); (c) Mg1Zn1Ca8Gd (ACI); (d) Mg1Zn1Ca; (e) Mg1Zn1Ca1HA; (f) Mg1Zn1Ca3HA; (g) Mg5Zn1Ca; (h) Mg5Zn1Ca1HA; and (i) $\mathrm{Mg} 5 \mathrm{Zn} 1 \mathrm{Ca} 3 \mathrm{HA}$. Statistical significance $(\mathrm{p}<0.05)$ was analyzed using the Tukey test.

Figure 7.4: Optical morphologies of osteoblast cells that were cultured in the control (C) and $10 \%$ extract (E) concentrations of $\mathrm{MgZn}, \mathrm{MgZnCa}$ and $\mathrm{MgZnCaGd}$ alloys from corrosion test runs in PBS for (a) 2 days, 4 days and (c) 7 days.

Figure 7.5: Net growth rate of osteoblast cells exposed to leached ions from anodized samples during dynamic immersion test (mean $+\mathrm{SD}, \mathrm{n}=3$ ): (a) $\mathrm{Mg} 1 \mathrm{Zn}(\mathrm{ACI})$; (b) Mg1Zn1Ca (ACI); (c) Mg1Zn1Ca8Gd (ACI); (d) Mg1Zn1Ca; (e) Mg1Zn1Ca1HA; (f) $\mathrm{Mg} 1 \mathrm{Zn} 1 \mathrm{Ca} 3 \mathrm{HA}$; (g) Mg5Zn1Ca; (h) Mg5Zn1Ca1HA; and (i) Mg5Zn1Ca3HA.Statistical significance $(p<0.05)$ was analyzed using the Tukey test.

Figure 7.6: Effect of time on osteoblast cells growth on Mg1Zn by electrochemical impedance spectroscopy: (a) without cells and (b) with cells. 
Figure 8.1: Interference microscope image representation of $\mathrm{Mg} 1 \mathrm{Zn} 1 \mathrm{Ca}$, scan area (640 x $860 \mu \mathrm{m})$.

Figure 8.2: SEM micrographs of Mg1Zn1Ca alloys for different surface roughness. 155

Figure 8.3: Potentiodynamic polarization curves of $\mathrm{Mg} 1 \mathrm{Zn} 1 \mathrm{Ca}$ alloys at different roughness in PBS at $37^{\circ} \mathrm{C}$.

Figure 8.4: Equivalent circuit of the corrosion cell: $R_{s}=$ electrolyte resistance, $R_{\text {corr }}=$ charge transfer resistance and $\mathrm{C}_{\mathrm{dl}}=$ capacitance double layer.

Figure 8.5: Nyquist plots of $\mathrm{Mg} 1 \mathrm{Zn} 1 \mathrm{Ca}$ alloys, with different surface roughness, tested in PBS at $37^{\circ} \mathrm{C}$.

Figure 8.6: Bode representation of: (a) impedance modulus and (b) phase shift for $\mathrm{Mg} 1 \mathrm{Zn} 1 \mathrm{Ca}$ with different surface roughness in PBS at $37^{\circ} \mathrm{C}$.

Figure 8.7: Plot showing the effect of roughness on corrosion rate (CR) and contact angle (CA).

Figure A.1: Corrosion rates attained from immersion test on mechanically polished and anodized samples in PBS at $37^{\circ} \mathrm{C}$.

Figure A.2: Plot depicting the fractional polarity values for mechanically polished and anodized samples.

Figure A.3: Contact angle (water) and SFE values for both mechanically polished and anodized samples. 


\subsection{INTRODUCTION}

Biocompatibility has been defined as "the study and knowledge of the interactions between living and non-living materials", and a biomaterial is defined as: " $a$ material intended to interface with biological systems to evaluate, treat, augment or replace any tissue, organ or function of the body" [1]. Biomaterials have been used for more than a century in the human body to improve body functions and replace damaged tissues [2]. Over the last 30 years, biomaterials have received a considerable amount of attention as a means of treating diseases and easing suffering by no longer focusing on a conventional pharmaceutical formulation but rather a combination of device-integrated biomaterial and the necessary therapeutic treatment. Biomaterials have found applications in approximately 8000 different kinds of medical devices [4], which have been used in repairing skeletal systems, returning cardiovascular functionality, replacing organs, and repairing or returning senses [5]. Even though biomaterials have had a pronounced impact in medical treatment, there still exists a need for better polymers, ceramics, and metallic systems. Common examples in the medical industry of medical devices include: sutures, supportive meshes, needles, orthopedic, osteosynthetics, vascular grafts, stents, etc. The biomaterials employed must possess good mechanical integrity, non-toxicity and pronounced chemical stability [6].

In recent years, the demand for biomaterials has been increasing with relative proportion of senior citizens in society as a result of the demand for replacement of failed tissue and organs with biomaterials and artificial devices [3]. For example, an $8 \%$ annual growth is anticipated in the orthopedic industry from $\$ 6$ billion in 2007 to $\$ 13$ billion by 
2017 [7]. It is projected that by 2015, there will be 133 million Americans over 45, the age at which the incidence of heart diseases is documented. Many will require stents (small metal-mesh sleeves implanted in unclogged arteries by angioplasty). Figure 1.1 shows the world market of bioimplants where, the largest share is for orthopedic (38\%) and cardiovascular applications (37\%). The total number of hip replacements was 152,000 in 2000 , which was a $33 \%$ increase from 1990 and a little over half is projected towards 2030 i.e. 272,000 . Unfortunately, these all hip replacements are not successful, as on an average the total lifetime of hip replacement is only about $10-15$ years, which is an issue in case of young patients. To meet this demand, a wide variety of biomaterials comprising of polymers, ceramics and metals are being developed.

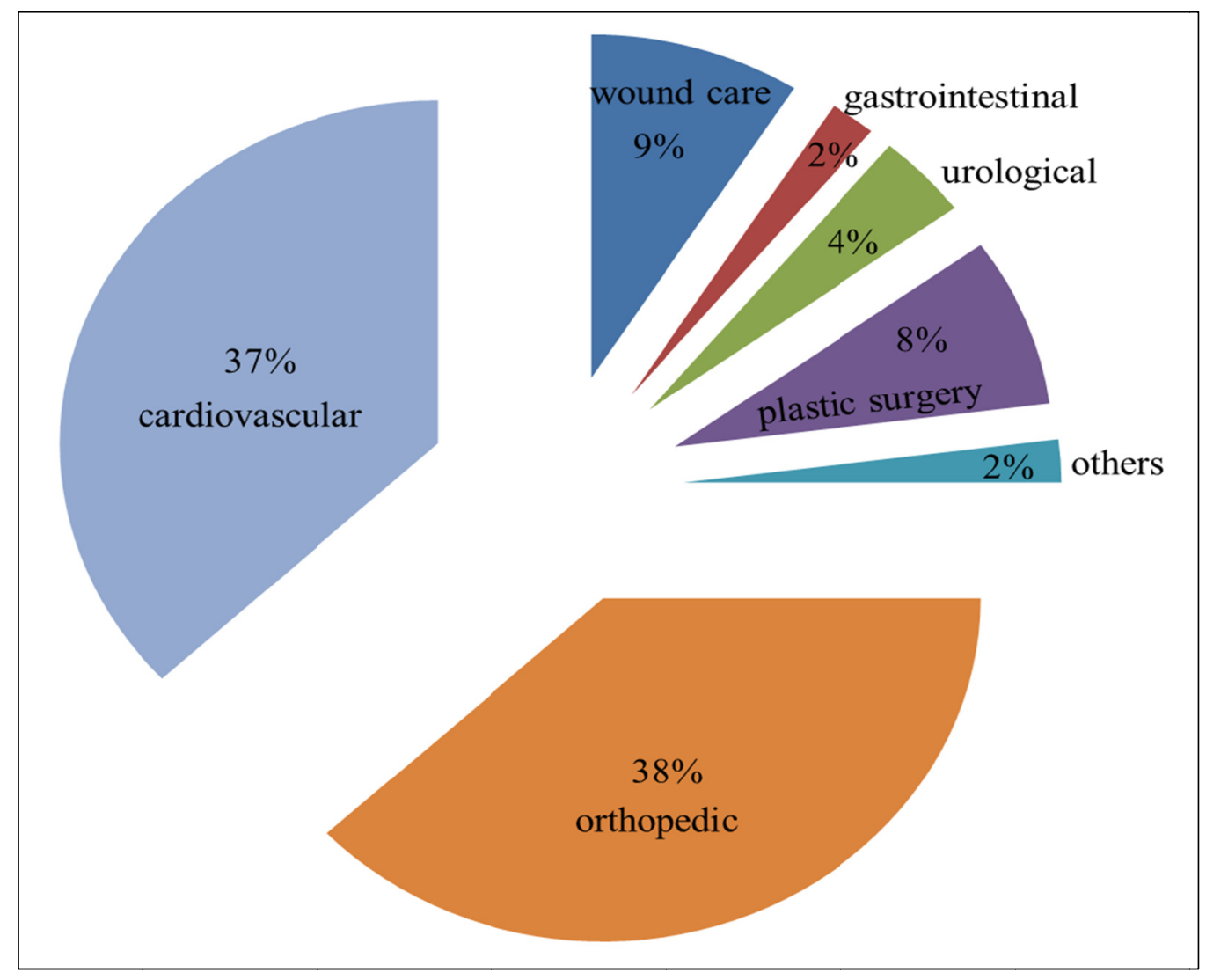

Figure 1.1: World market of biomaterials [9]. 


\subsection{History of Biomaterials}

The use of biomaterials for the manufacturing of implant devices is not new. It has been reported that the substitution of bone parts in the body has been practiced since the pre Christian era, where copper and bronze were the main materials used. The major concern faced with those implants was copper ion leaching, which further lead to poisoning in the body. Until the mid-nineteenth century, there were no other materials suitable for implantation other than copper and bronze. [9].

By the mid-nineteenth century, serious attempts had already been made to repair body parts with foreign materials. In 1880, Gluck, used ivory prosthesis as implants in the body. The involvement of biomaterials earlier were unsuccessful due to occurrence of infection or toxicity and in 1860 , Dr. J. Lister developed an antiseptic surgical technique [6]. In 1902, gold was used as the interphase between the articular heads of the implant. This experiment proved to be successful, which lead to further studies on chemically inert and stable materials [6].

\subsection{Classification of Biomaterials}

Biomaterials are categorized into three classes: class I materials [8, 10], which have no direct contact with bodily tissues; class II materials that are intermittently in contact with tissues; and class III materials that are constantly in contact with tissue and are prone to unwanted ion leaching [8]. The latter can be categorized into three types: bio-inert, bioactive and biodegradable. Currently approved and commonly used Class III metallic biomaterials include stainless steels, titanium and cobalt-chromium based alloys 
[8]. A limitation of these current metallic biomaterials, is the possible release of toxic metallic ions through corrosion or wear processes $[11,12,13,14,15]$ that leads to inflammatory cascades, reduced biocompatibility and possible tissue loss $[16,17,17,19,19,21,22]$. Furthermore, these metallic biomaterials are essentially neutral in vivo, remaining as permanent fixtures, which in the case of plates, screws and pins that are used to secure serious fractures, must be removed by a second surgical procedure after the tissue has healed sufficiently [24]. Repeat surgical procedures increase health care costs and possible morbidity of patients. Table 1.1 summarizes the various types of biomaterials and their applications.

Table 1.1: Biomaterials used in human body [5,25,139]

\begin{tabular}{|c|c|c|}
\hline Type of material & Examples & Application \\
\hline Polymers & $\begin{array}{l}\text { Nylon, silicones, teflon, } \\
\text { polyester fibers, high strength } \\
\text { acrylics, polyurethane, hydro- } \\
\text { gels, polycarbonate, } \\
\text { polypropylene }\end{array}$ & $\begin{array}{l}\text { contact lenses, vascular grafts, wound } \\
\text { dressings, maxillo facial operations, } \\
\text { absorbable sutures, drug- release } \\
\text { systems, reneal dialysis cartridges, } \\
\text { trocars, extra cellular matrices }\end{array}$ \\
\hline Metals & $\begin{array}{l}\text { Nitinol, titanium alloys, cobalt- } \\
\text { chromium alloys, } 316 \text { L stainless } \\
\text { steels, platinum alloys, silver, } \\
\text { magnesium alloys, iron alloys }\end{array}$ & $\begin{array}{c}\text { joint replacements, dental root } \\
\text { implants, bone screws, bone plates, } \\
\text { bone grafts, cardiac stents, electrodes, } \\
\text { anti-bacterial material }\end{array}$ \\
\hline Ceramics & $\begin{array}{c}\text { Alumina, zirconia, } \\
\text { hydroxyapatite, bio-glass }\end{array}$ & $\begin{array}{l}\text { joint replacements, bone spacers, } \\
\text { tooth implants, bone bonding } \\
\text { applications, bone cement fillers, } \\
\text { cardiac stents }\end{array}$ \\
\hline Composites & $\begin{array}{l}\text { Carbon-carbon, calcium } \\
\text { phosphate cement }\end{array}$ & joint implants, heart valves \\
\hline
\end{tabular}




\subsection{Magnesium Alloys for Implant Applications}

Degradable materials are of value in short term applications, such as in sutures, supportive meshes, drug delivery, orthopedic, osteosynthesis, vascular graft, stents, etc. where they can minimize the number of invasive procedures. Such materials should exhibit good mechanical properties and homogeneous degradation with non-toxic degradation products. Additionally, in the case of orthopedic implants their densities and elastic moduli should be similar to that of human bone $[24,26]$, which continuously undergoes remodeling due to changes in its mechanical load environment that could lead to stress shielding. Resultantly, the implant bears most of the load causing the bone beneath to experience a reduced load, which leads to reduced bone density and new complications [26]. Figure 1.2 shows the load transfer process during the degradation of material, which further leads to healing and remodeling process.

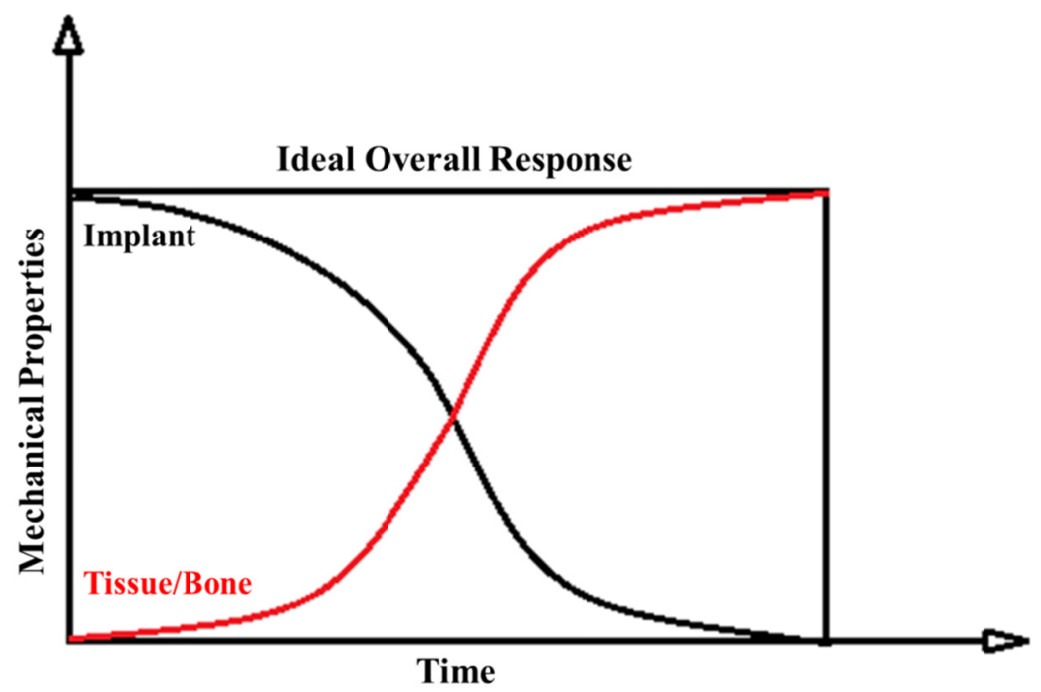

Figure 1.2: Schematic showing the ideal conditions of reduced load on implant over time of healing process $[6,122]$. 
Payr in 1900 proposed $\mathrm{Mg}$ as a potential implant for musculoskeletal applications, such as fixator pins, nails, wires, cramps, sheets and plates [29,31]. Figure 1.3 shows magnesium tubular connectors designed by Payr. In 1906, Lambotte, a French surgeon, first implanted $\mathrm{Mg}$ as fracture fixation plates, which faced the problem of gas cavity formation due to rapid corrosion [29]. However, total absorption in rabbits and dogs was observed after 7 to 10 months without any pain [29]. In 1934, Henschen and Gerlach referred to $\mathrm{Mg}$ as an ideal osteosynthesis material [29], followed by Verbrugge who in 1937 indicated that implanted $\mathrm{Mg}$ was neither toxic, nor an irritant and reported that slow corrosion promoted callus formation [29].

A

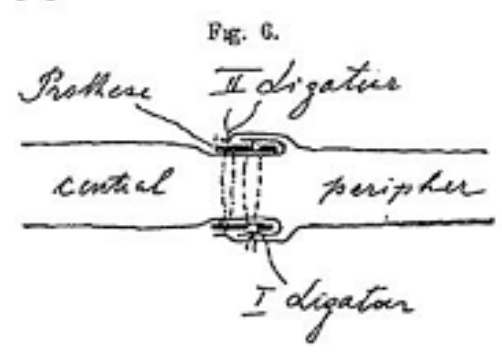

Wig. $6 \mathrm{a}$.

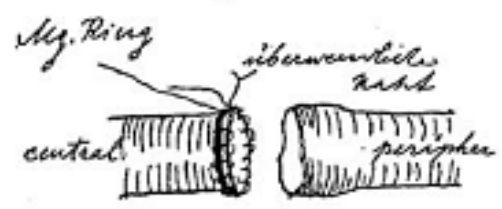

Fig. 5.
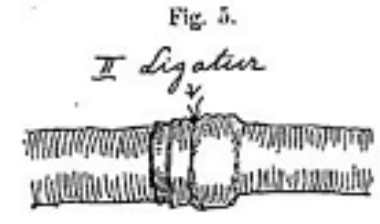

B

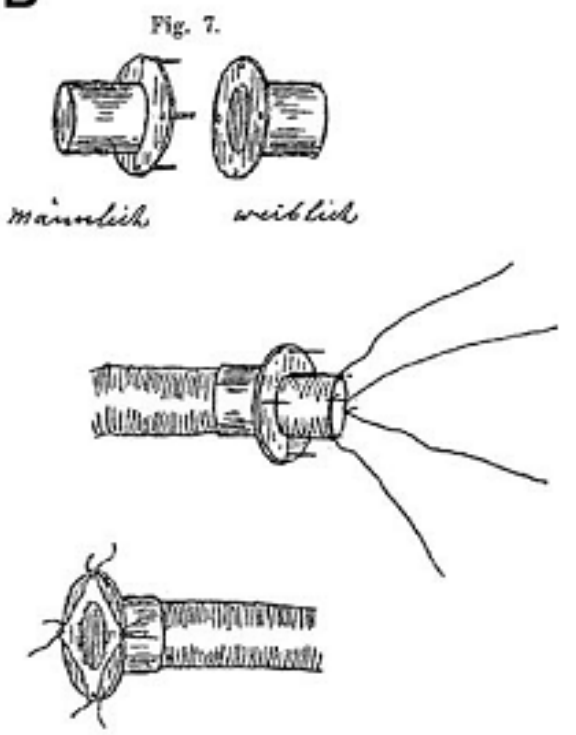

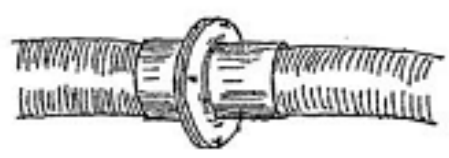

Figure 1.3: Magnesium connectors designed by Payr for vessel anastomosis [29]. Method (A) used an extravasal magnesium ring, which ensures an open postop-erative anastomosis. Method (B) uses a two-part extravasal connector with a male and female part. 
In both methods, the $\mathrm{Mg}$ connector was extravasal and anastomosis was achieved by duplication of the intima. Thus, no foreign material was located intravasal after the anastomosis.

\subsection{Why Magnesium Alloys?}

Sunday, May 23, $2004 \quad$ Houston Chronicle $\quad \star \star \quad$ 3E

\section{Importance of magnesium in diet often underestimated}
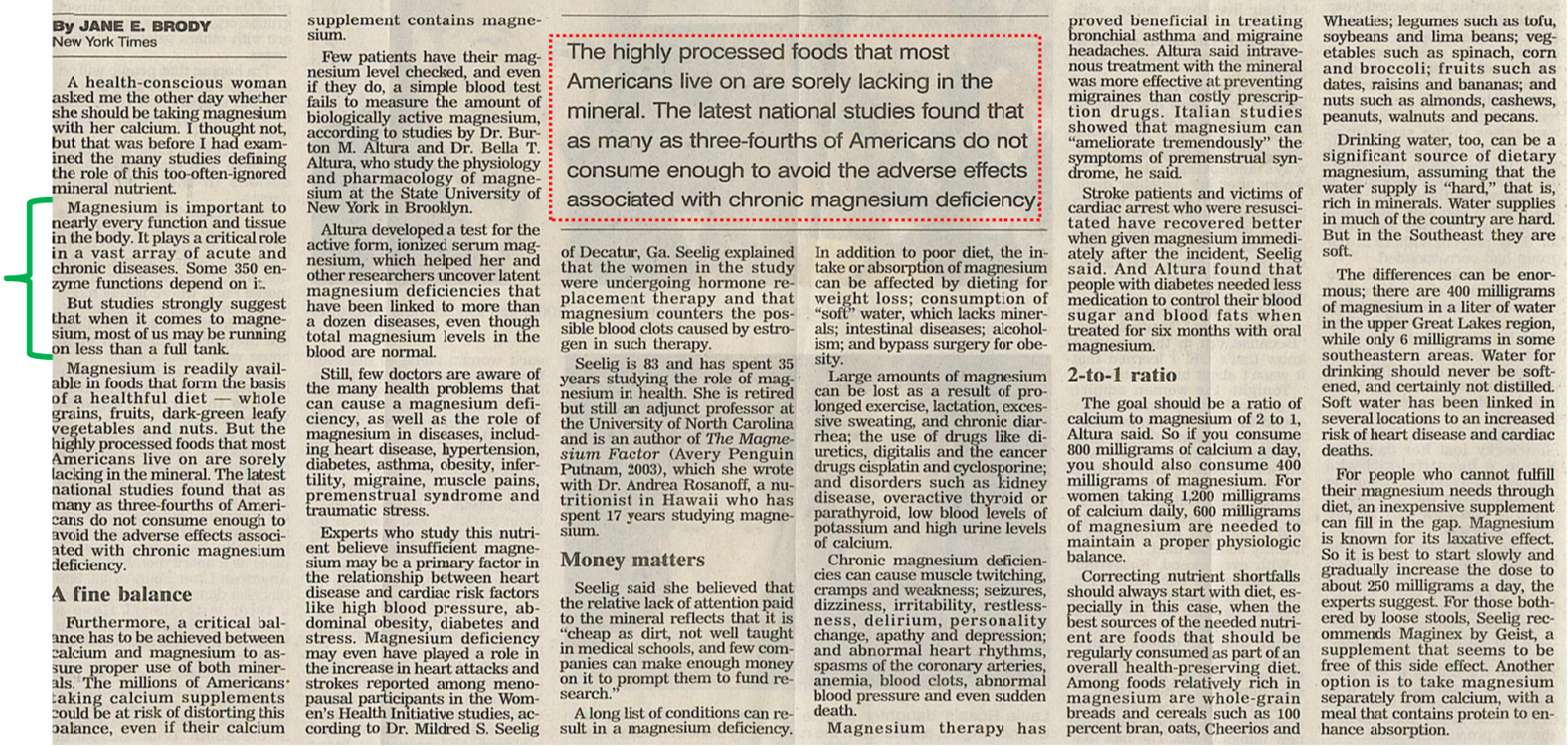

Figure 1.4: Newspaper article on the importance of magnesium in diet [30].

Figure 1.4 shows the newspaper cutting discussing the importance of $\mathrm{Mg}$, which

is often underestimated in dietary supplement. $\mathrm{Mg}$ is the fourth most abundant element in

the human body $(\approx 21-28 \mathrm{~g})$; approximately $50 \%$ is found in bone and the remainder is found in cells of tissue and organs (see Figure 1.5) [31, 32, 33]. 


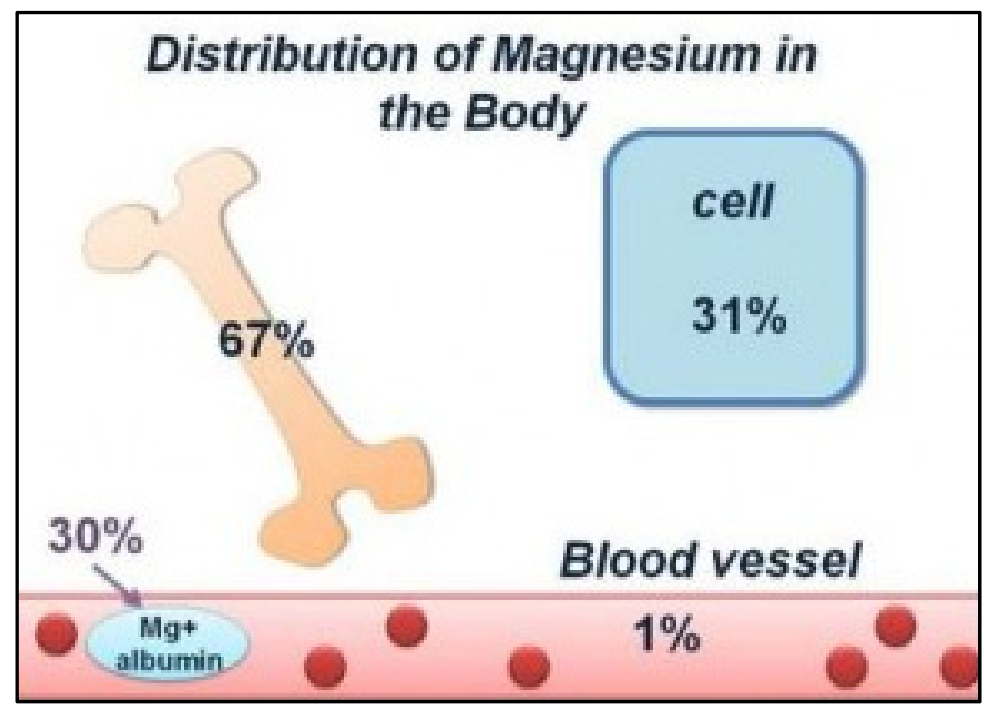

Figure 1.5: Approximate magnesium distribution [31].

$\mathrm{Mg}$ is required in more than 325 biochemical reactions in the body (especially for those enzymes that use nucleotides as cofactors or substractes) $[44,45,46,47,48]$. It helps to maintain normal muscle (contraction of muscles), steady heart rhythm, healthy immune system, strong teeth and bones and transmits nerve impulses (neurological) $[44,43,49,50]$. The intracellular concentration of $\mathrm{Mg}$ is $14-20 \mathrm{mmol} / \mathrm{l}$ the majority of which is bound to nucleic acids, phospholipids in cell membranes, enzymes, ATP (adenosine triphosphate) and proteins, see Figure $1.5[33,35] . \mathrm{Mg}$ also helps to regulate blood sugar levels, promotes normal blood pressure and is known to be involved in energy metabolism and protein synthesis $[34,35] . \mathrm{Mg}$ is primarily absorbed in the ileum and colon and is excreted through the kidneys [36,42,46,50].

Common magnesium compounds include $\mathrm{Mg}$ amino acid chelate, $\mathrm{Mg}$ carbonate, Mg oxide, $\mathrm{Mg}$ oxide dolomite and $\mathrm{Mg}$ sulfate (used to prevent eclamptic seizures [54]). Mg alloys are lightweight (density $1.7 \mathrm{~g} / \mathrm{cc}$ ) which is $\sim 1 / 3$ as dense as titanium alloys [27, 
57]. The formation of $\mathrm{Mg}$ alloys is dependent on the element's liquid solubility in molten $\mathrm{Mg}$ and any interference between alloying elements [55].

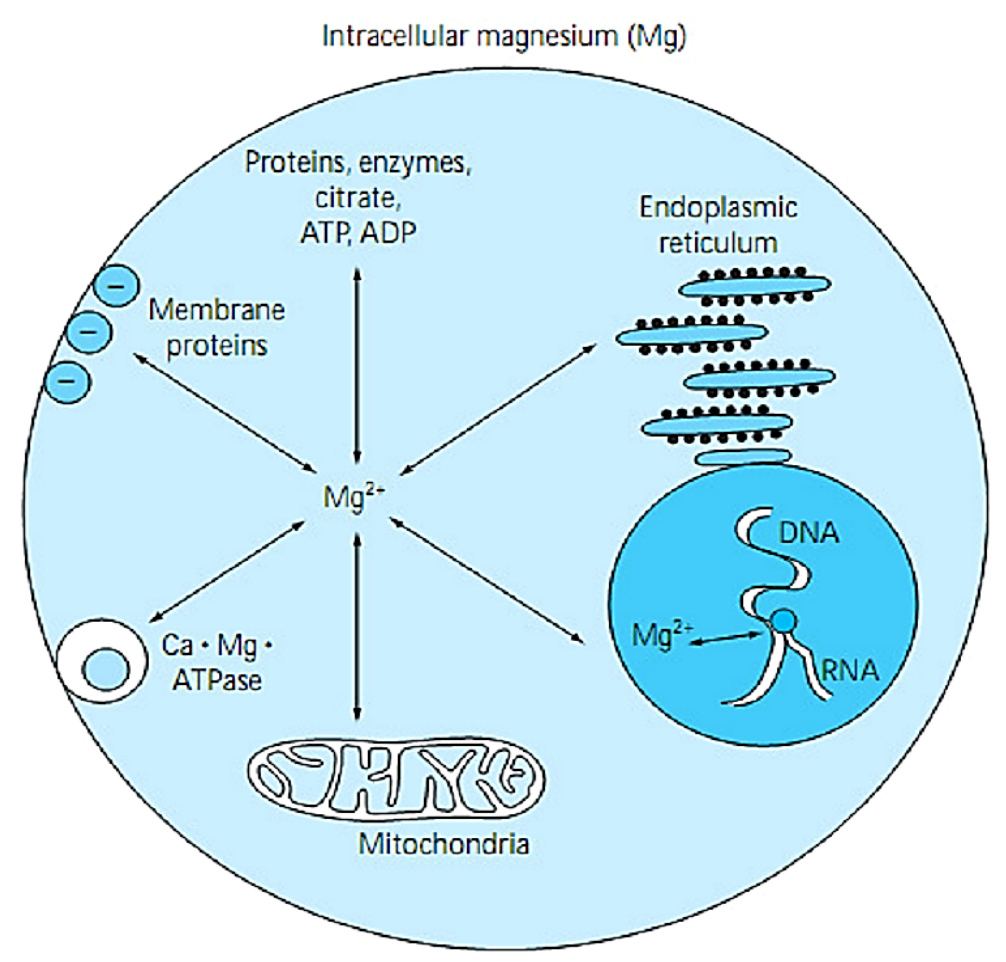

Figure 1.6: Intracellular distribution of $M g$ [32, 33].

Rubin et al. (2005) modeled the role of Mg in regulating cell cycle control, Figure 1.6 [34], where intracellular Mg promotes polysome formation, protein synthesis and a number of Mg-ATP dependent reactions [33,34,35]. $\mathrm{Mg}^{++}$ions also promote DNA synthesis and cell division. A hypothetical model showing the role of $\mathrm{Mg}$ in cell proliferation is shown in Figure 1.7. 

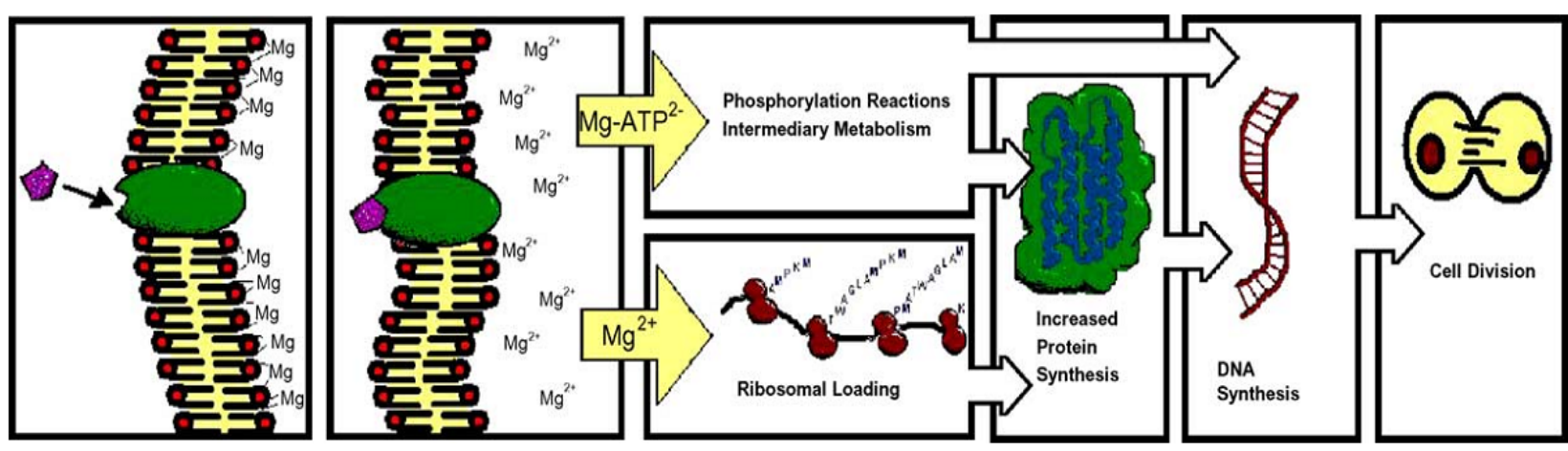

Figure 1.7: Hypothetical model demonstrating magnesium in cell proliferation control $[33,35]$.

\subsubsection{Crystal Structure of Magnesium}

The element $\mathrm{Mg}$ received its name from the Greek word Magnesia a district in Thessaly. Mg is the seventh most abundant element in the earth crust by mass. It has an hexagonal closed packed (HCP) crystal structure with lattice parameters: $a=0.321 \mathrm{~nm}$ and $\mathrm{c}=0.521 \mathrm{~nm}$. Figure 1.8 shows the principal planes and directions in a $\mathrm{Mg}$ unit cell. Slip deformation mainly occurs along the (0001) basal plane and in the $<11 \overline{2} 0>$ direction on the vertical face plane $\{10 \overline{1} 0\}[37,38]$. At elevated temperatures, slip occurs in the $<11 \overline{2} 0>$ direction on the pyramidal planes $\{10 \overline{1} 1\}$. 

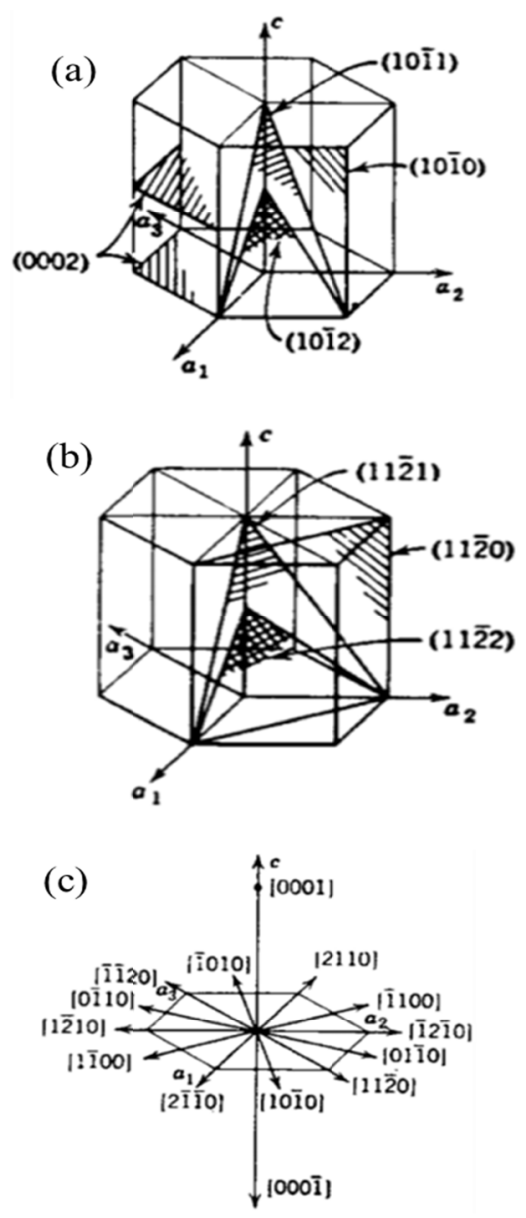

Figure 1.8: $M g$ unit cell crystal: (a) Principal planes [1 -2 1 0], basal plane, face plane (b) Principal [1 1100$]$ planes. (c) Principal directions [37,38].

Chemically, $\mathrm{Mg}$ alloys are relatively unstable and are susceptible to corrosion. Mg alloys have excellent specific strength and stiffness, low density, very good machinability, dimensional stability, high damping capacity and good weldability under a controlled atmosphere [39,40,41].

\subsubsection{Beneficial Effects of Alloying Elements}

Alloying elements not only enhance the mechanical properties of $\mathrm{Mg}$, but also impart significant effects on its corrosion resistance and biocompatibility. Uniform and 
controlled corrosion rates are of particular importance for bioabsorbable materials, the absence of which could lead to an excessive release of dissolved metal ions and biological medical complications. Below is a list of common alloying elements.

Calcium: The most abundant element in the body, calcium is required for a variety of physiological reactions [69]. 99\% of calcium is stored in bones and teeth with less than $1 \%$ in blood, muscle and intercellular fluids [70]. As an alloying element, calcium is generally added in small amounts in order to control the metallurgical properties by controlling oxidation in the molten condition as well as serving as a grain-refining agent [55]. Calcium apatite (hydroxyapatite) a form of calcium is also used for biodegradable implant applications. HA is basically a calcium phosphate, which is chemically similar to the mineral crystallites present in human bone [56].

Iron: Iron is essential for maintaining good health and is an integral part of many proteins and enzymes. It acts as an oxygen carrier to muscle and enzymes for biochemical reactions (myoglobin) $[53,72]$ and is important for the regulation of cell growth and differentiation $[73,74]$. However, excessive amounts of iron can result in acute toxicity and even death [77].

Manganese: Manganese is found in the pancreas, bone, liver and kidneys and is important in skeletal and connective tissue development. It acts as a catalyst and cofactor for many enzymatic processes (in the mitochondria) involving in the synthesis of fatty acids and cholesterol and is an actual component of manganese super oxide dismutase enzyme. As an alloying element with magnesium, manganese does not induce any significant effect on its tensile strength but slightly increases the yield strength. Generally, manganese has relatively low solubility in magnesium [55]. 
Rare earth metals: Rare earths are normally added as mischmetal $(\sim 50 \%$ cerium, $25 \%$ lanthanum and small amounts of neodymium and praseodymium) or as didymium (praseodymium and neodymium). The addition of these metals increases the strength of magnesium alloys [55] and no significant toxicity was reported [115].

Gadolinium: Gadolinium is one the most abundant of all rare earth elements and is the least expensive. It has no known biological role, but is said to stimulate the metabolism, and could be detrimental in concentrations in excess of $8 \mathrm{wt} \%$. Nevertheless, gadolinium has a high solubility in magnesium and improves its strength and creep resistance $[78,79,80]$. Due to its high affinity for oxygen, several oxides $\left(\mathrm{Gd}_{2} \mathrm{O}_{3}\right.$, spinel $\left.\mathrm{MgGd}_{2} \mathrm{O}_{4}\right)$ are produced which act as a diffusion barrier for further oxidation.

Zinc: Zinc is an important element for development and growth in humans, and is involved catalytically in approximately 100 enzymes, wound healing, cell division and protein/DNA synthesis $[53,81]$. As an alloying element, zinc results in solid solution hardening with magnesium and with other alloying elements, improves its strength and corrosion resistance [55].

Zirconium: Zirconium has no known biological role and the human body contains, on average, 1 milligram. As an alloying element, it imparts good corrosion resistance [63], and grain-refinement to magnesium alloys. Due to similar lattice parameters $(\alpha-Z r: a=$ $0.323 \mathrm{~nm}, \mathrm{c}=0.514 \mathrm{~nm}$ and $\mathrm{Mg}: \mathrm{a}=0.320 \mathrm{~nm}, \mathrm{c}=0.520 \mathrm{~nm}$ ), a zirconium-rich solid solution is produced early in the freezing of the melt, which provide sites for heterogeneous nucleation of magnesium grains during solidification.

Yttrium: Yttrium has no known biological role, but is found in the liver, kidney, spleen, lungs, and bones [100], for a total amount of 0.5 milligrams in the entire human body. As 
an alloying element, yttrium has relatively high solubility in magnesium (12.4 wt $\%)$ and is added with other rare elements to promote creep resistance at temperatures up to 300 ${ }^{\circ} \mathrm{C}[55]$.

Table 1.2: Role of selected alloying elements and blood serum content [64,83,84,85]

\begin{tabular}{|c|c|c|}
\hline Elements & $\begin{array}{c}\text { Concentration in } \\
\text { Blood Serum, mmol/L }\end{array}$ & Role \\
\hline Calcium & $1.3 \mathrm{mmol} / \mathrm{L}$ & $\begin{array}{c}\text { muscle contraction, blood vessel expansion and } \\
\text { contraction, insurance of maximum bone } \\
\text { strength and transmission of impulses } \\
\text { throughout the central nervous system }\end{array}$ \\
\hline Iron & $0.005-0.023 \mathrm{mmol} / \mathrm{L}$ & $\begin{array}{c}\text { enables cell respiration, energy production, } \\
\text { production of red blood cells (haematopoiesis), } \\
\text { oxygen and carbon dioxide transport, } \\
\text { production of hemoglobin in RBC }\end{array}$ \\
\hline Magnesium & $0.73-1.06 \mathrm{mmol} / \mathrm{L}$ & $\begin{array}{l}\text { required for more than } 325 \text { biochemical } \\
\text { reactions, regulate blood sugar level, keeps } \\
\text { heart rhythm steady, healthy immune system } \\
\text { and maintains bone and teeth health }\end{array}$ \\
\hline Manganese & $0.001 \mathrm{mmol} / \mathrm{L}$ & $\begin{array}{l}\text { required in enzymatic processes involved in the } \\
\text { synthesis of fatty acids and cholesterol, } \\
\text { synthesis of glycoproteins, which coat body } \\
\text { cells and protect against viruses }\end{array}$ \\
\hline Rare earth metals & $<0.047 \mathrm{mg}$ & compound of drugs for cancer treatment \\
\hline Gadolinium & - & $\begin{array}{l}\text { no known biological role, but is said to } \\
\text { stimulate the metabolism }\end{array}$ \\
\hline Zinc & $0.012-0.017 \mathrm{mmol} / \mathrm{L}$ & $\begin{array}{c}\text { required for more than } 100 \text { biochemical } \\
\text { reactions, wounds healing, DNA synthesis and } \\
\text { cell division }\end{array}$ \\
\hline Zirconium & $0.00011 \mathrm{mmol} / \mathrm{L}$ & $\begin{array}{l}\text { no known biological role and compounds are of } \\
\text { low toxicity }\end{array}$ \\
\hline
\end{tabular}

\subsection{Research Objective}

The current research focuses on the development of new biodegradable $\mathrm{Mg}$ alloys, in an effort to improve the corrosion resistance, biocompatibility and mechanical 
properties. The alloys were subjected to anodization in order to reduce their initial degradation rate. The following are the main objectives of current research:

- Investigate the overall effect of the addition of alloying elements on biocompatibility and mechanical properties.

- Determine the role surface treatment on metallurgical and biocompatibility properties.

A schematic representation of the research tasks conducted is shown in Figure 1.9. 


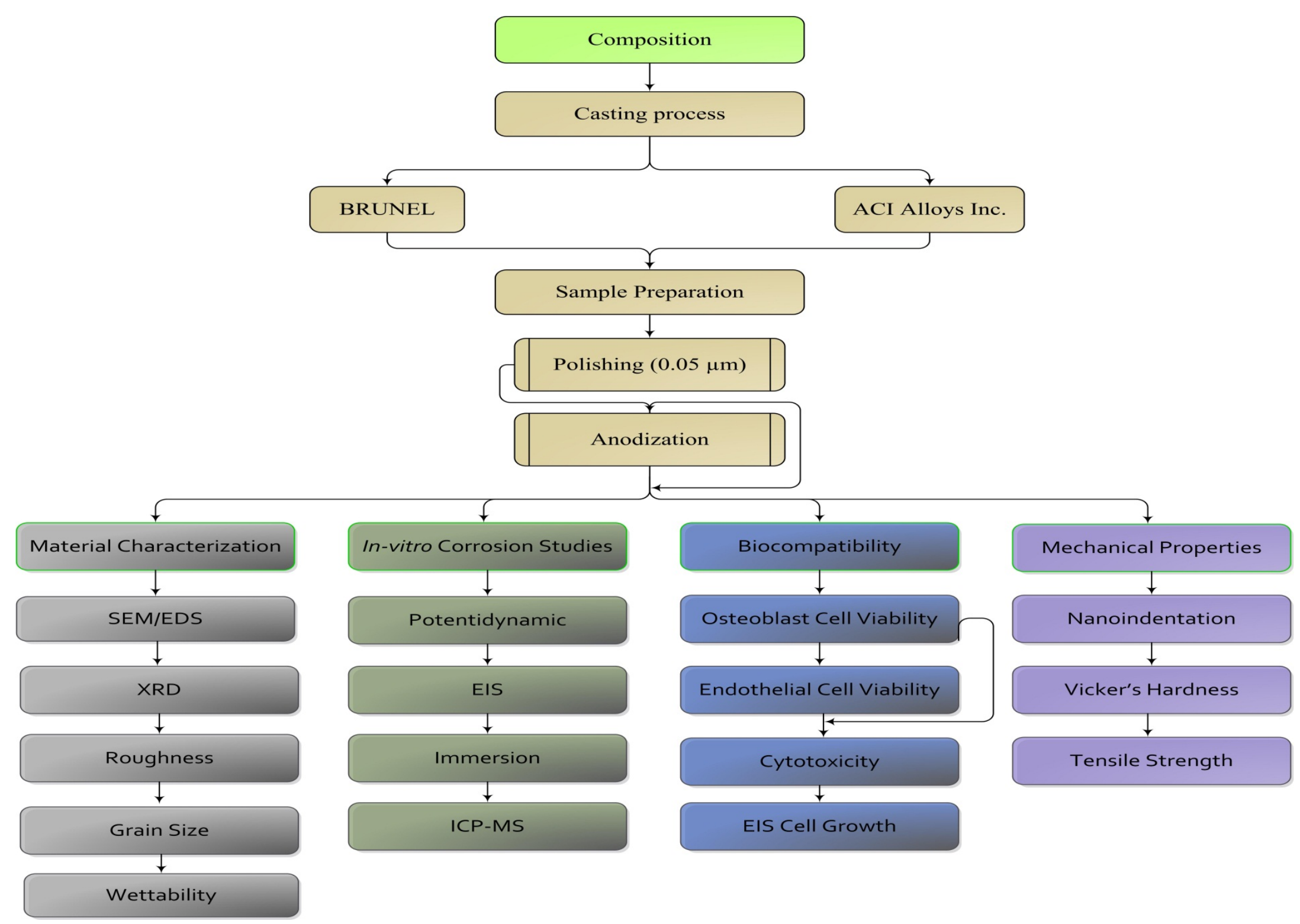

Figure 1.9: Schematic representation of the research summary. 


\subsection{LITERATURE REVIEW}

\subsection{Biodegradable Magnesium - Current Research}

Development of $\mathrm{Mg}$ based biodegradable alloys is a challenge due to limitations of controlled and uniform degradation, as well as prolonged mechanical integrity in some applications. The main function of a biodegradable alloy is continuous dissolution as new tissue develops. As already discussed, $\mathrm{Mg}$ is one of the most suited candidates for this application because of its degradation behavior and its assimilation in the human body as an essential element. This has prompted a significant amount of research on the development of biodegradable alloys consisting mainly of $\mathrm{Mg}$ in combination with other potential elements in various compositions. Although advances have been made on the rate of degradation of some alloys, there is still a dearth of information on their biocompatibility. However, most $\mathrm{Mg}$ alloys have their own characteristic corrosion behavior as a result of their unique microstructure or the existence of intermetallics. Table 2.1, summarizes properties of selected $\mathrm{Mg}$ based alloys for biomedical applications.

Pure magnesium (as-cast) has low overall yield strength $(\mathrm{YS} \sim 27 \mathrm{MPa}$ ), tensile strength (TS $\sim 90 \mathrm{MPa}$ ) and is easily susceptible to pitting corrosion, which can lead to loss of mechanical integrity before the tissue has fully healed [115]. Alloying is one method of preserving the mechanical integrity, corrosion resistance and biocompatibility of $\mathrm{Mg}$ [66]. For biodegradable applications, the alloying element must be non-toxic and biocompatible, so that once implanted the concentration of the dissolved ions do not 
exceed the concentration normally found in human blood or tissue depending on the application. Tao et al. (2008) [87], manufactured $\mathrm{Mg}-6 \mathrm{Zn}-\mathrm{xCa}(\mathrm{x}=3,5,7.5,10$ weight percentage, $w \mathrm{t} \%$ ) alloys by twin-roll rapid solidification that were subjected to rapid solidification and annealing at $200{ }^{\circ} \mathrm{C}$ for 1 hour. A dendritic structure developed with a grain size of 1-5 $\mu \mathrm{m}$ [87], which improved strength, creep resistance and moderate ductility observed during age-hardening were attributed to the formation of various phases such as: $\mathrm{Mg}_{2} \mathrm{Ca}, \mathrm{Mg}_{2} \mathrm{Zn}_{3}, \mathrm{MgZn}_{2}$ and $\mathrm{Ca}_{2} \mathrm{Mg}_{6} \mathrm{Zn}_{3}$ [87]. Peng et al. (2009) [89] prepared $\mathrm{Mg} 12 \mathrm{Gd} 4 \mathrm{Y} 2 \mathrm{Nd} 0.3 \mathrm{Zn} 0.6 \mathrm{Zr}$ wt $\%$ alloy by casting technology and after age hardening, were able to achieve improved mechanical properties (room temperature, YS $=280 \mathrm{MPa}$ and $\mathrm{TS}=310 \mathrm{MPa}$ ) due to a microstructure composed of fine metastable precipitates dispersed in the matrix. Enhanced mechanical properties were attributed to a fine grain size of 70-100 $\mu \mathrm{m}$ and a stable microstructure, that consisted of fine precipitates of $\beta$ '-Mg15RE3, dispersed precipitates of Mg24RE5 (sheet-shaped) and Mg5RE (polygon-shapes). Zhang et al. (2010) [90] manufactured MgZn alloys by melting and casting, where $\alpha$ and $\gamma-\operatorname{MgZn}$ phases were observed to precipitate along the grain boundary. Hort et al. (2010) investigated Mg2Gd, Mg5Gd, Mg10Gd, Mg15Gd (wt \%) manufactured by casting, where Gd was used to enhance the mechanical properties [93]. The yield strength and tensile strength of the as-cast alloy (YS $=37.99-127.65 \mathrm{MPa}$ and $\mathrm{TS}=103.73-175.22 \mathrm{MPa}$ ) increased with $\mathrm{Gd}$ content and solid solution formation [93].

Bruno Zberg et al. (2009), used various compositions of Mg-Zn-Ca alloys prepared by melt-spinning and determined various corrosion states [86]. The extended solubility of $\mathrm{Zn}$ in the amorphous structure of $\mathrm{Mg}-\mathrm{Zn}-\mathrm{Ca}$, displayed limited hydrogen 
evolution. This was confirmed by in vivo tests, where no inflammation was observed in the animal (abdominal walls and cavities) [86]. Zhoui Tao et al., manufactured ternary Mg-Zn-Ca alloys by twin-roll rapid solidification that were exposed to two different treatments, rapid solidification and annealing at $200{ }^{\circ} \mathrm{C}$ for 1 hour, which exhibited a dendritic structure with a grain size of 1-5 micrometer [87]. An increase in strength, creep resistance and moderate ductility were reported, which could be attributed to the formation of various phases such as: $\mathrm{Mg}_{2} \mathrm{Ca}, \mathrm{Mg}_{2} \mathrm{Zn}_{3}, \mathrm{MgZn}_{2}$ and $\mathrm{Ca}_{2} \mathrm{Mg}_{6} \mathrm{Zn}_{3}$ during age hardening [87].

Xinyu Ye et al. (2009) [88], fabricated Mg-Zn-Zr with 1 wt $\%$ nanohydroxyapatite (n-HA) as reinforcement by casting and without n-HA as a baseline. The refined grains of the $\mathrm{Mg}-\mathrm{Zn}-\mathrm{Zr}$ matrix, $100-200 \mathrm{~nm}$ in size were obtained by extrusion and dynamic recrystallization (Figure 2.1). The tests were conducted in simulated body fluid (SBF), where a protective layer of $\mathrm{Mg}(\mathrm{OH})_{2} \cdot \mathrm{nH}_{2} \mathrm{O}$ forms on the $\mathrm{Mg}$ alloy, which prevents direct exposure of the medium on Mg. Thus, the alloy degrades at a controlled rate. The formation of a protective layer on the samples leads to continuous absorption of acid ions in $\mathrm{SBF}\left(\mathrm{CO}_{3}{ }^{2-}, \mathrm{PO}_{4}{ }^{3-}\right.$ and $\left.\mathrm{Cl}^{-}\right)$[88]. The reinforced $\mathrm{Mg}$ alloy exhibited enhanced corrosion resistance and in vitro cytocompatibility, where n-HA particles adsorb acid ions, which also form a new protective layer that essentially prevents pitting corrosion. The average corrosion rate in SBF after immersion test for 20 days was $0.75 \mathrm{~mm} /$ year and maximum osteoblast cell density achieved after 5 days was $(1.85 \pm 0.15) \mathrm{X} 10^{4} / 1$. 


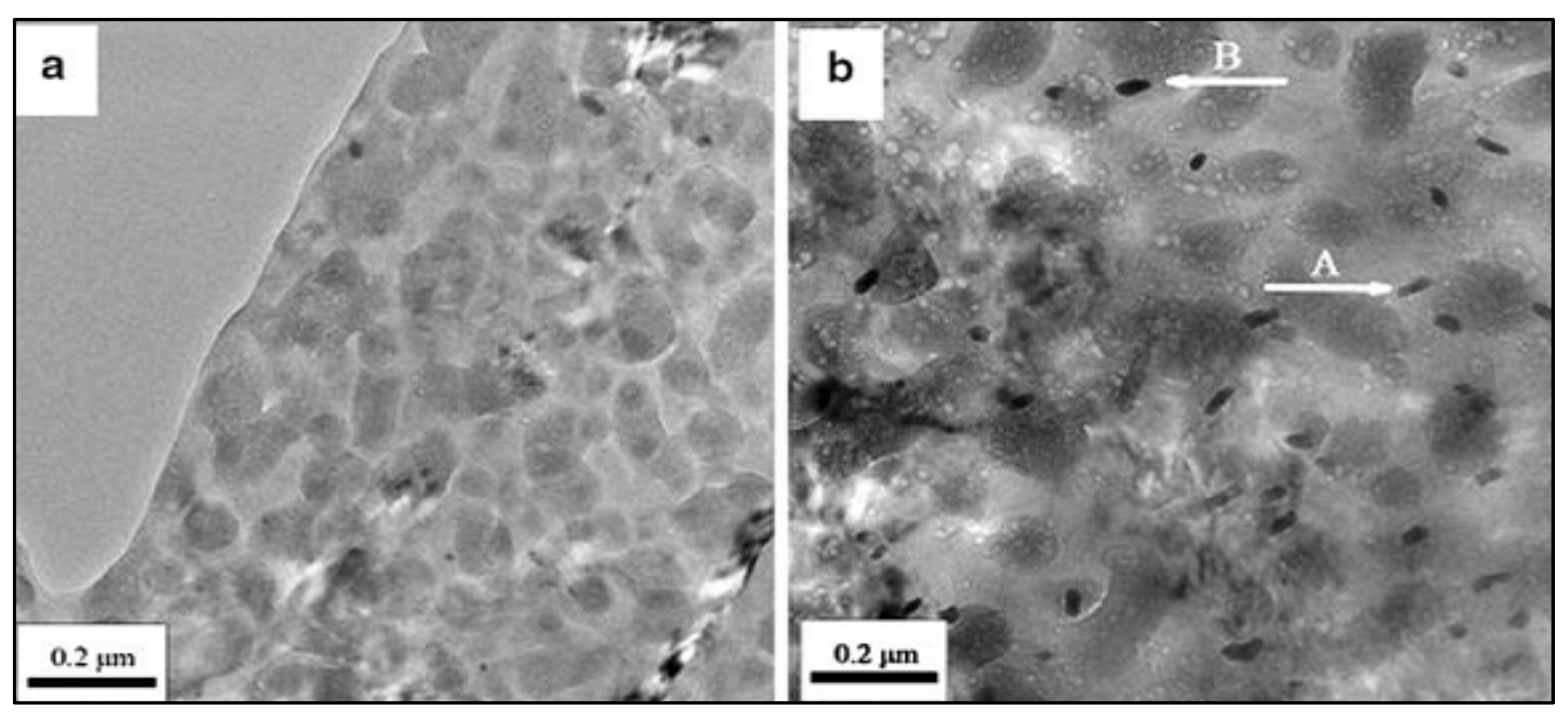

Figure 2.1: TEM micrograph of extruded composite after aging: (a) refined grains, 100$200 \mathrm{~nm}$; and (b) nano-rods distributed in the grain boundaries [88].

Qiuming Peng et al. (2009) [89] manufactured Mg-12Gd-4Y-2Nd-0.3Zn-0.6Zr (wt\%) alloy by casting technology and after age hardening were able to achieve high mechanical properties (see Table 2.1) due to fine microstructure, fine metastable precipitates and dispersed precipitates in the matrix. Figure 2.2 shows the effect of solid solution time on grain size and hardness [89]. The enhanced mechanical properties were attributed to the fine grain size and stable microstructure, composed of fine precipitates of $\beta^{\prime}-\mathrm{Mg}_{15} \mathrm{RE}_{3}$ and dispersed precipitates $\mathrm{Mg}_{24} \mathrm{RE}_{5}$ (sheet-shaped) and $\mathrm{Mg}_{5} \mathrm{RE}$ (polygonshaped). 


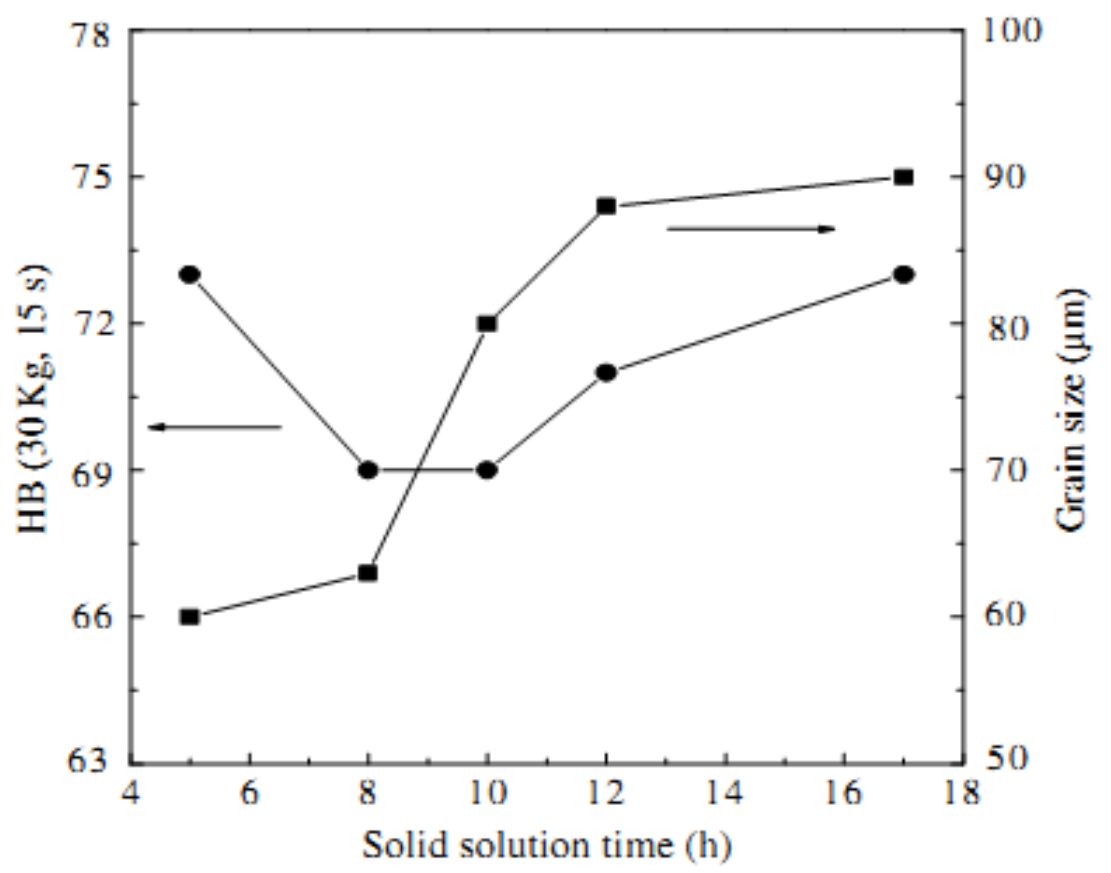

Figure 2.2: The solid solution time effect on grain size and hardness at $525^{\circ} \mathrm{C}$ [89].

Shaoxiang Zhang et al. (2010) [90] manufactured Mg-Zn alloys by melting and casting, and the observed that $\alpha$-matrix and $\gamma-\operatorname{MgZn}$ phases precipitated along the grain boundary. It was also reported that after solid solution treatment, the $\gamma$ phase disappeared and a refined microstructure was achieved to which the improved mechanical properties were attributed (Table 1.2). The alloying element, $\mathrm{Zn}$ increased the corrosion potential of the alloy. In-vivo test with the alloys (femoral shaft) in rabbits had a degradation rate of $2.32 \mathrm{~mm} /$ year. It was further reported that degradation products of these alloys exhibited no adverse effect on the heart, kidney, liver and spleen.

Fe and $\mathrm{Mg}$ are almost insoluble in each other due to the disparity in their atomic radii [91]. According to Haitani et al., the maximum solubility of $\mathrm{Fe}$ in $\mathrm{Mg}$ is approximately $0.00041 \mathrm{at} \% \mathrm{Fe}$ and the Fe concentration at the eutectic point is estimated to be less than 0.008 at $\%$ [92]. The manufacture of alloys with different compositions of 
Fe and $\mathrm{Mg}$ were attempted. However, by using a high temperature and a relatively moderate pressure (20 GPa), it was possible to synthesize a homogeneous Fe-Mg alloy with up to 4 at $\% \mathrm{Mg}$. It was assumed that an increase in the percentage of $\mathrm{Fe}$ in $\mathrm{Mg}$ would enhance the biodegrade ability of the alloy with no or minimal toxicity.

Hort et al. (2010) used Gd to enhance the mechanical properties of Mg alloys. In their investigation, alloys of different compositions in wt\% (Mg-2Gd, Mg-5Gd, Mg$10 \mathrm{Gd}, \mathrm{Mg}-15 \mathrm{Gd})$ were manufactured by casting [93]. It was reported that about $10 \%$ of the rare earth elements were lost during melting and casting, which is referred to as "melting loss" [93,94,95]. Gd has a higher affinity to form oxides such as $\mathrm{Gd}_{2} \mathrm{O}_{3}$ and or the spinel, $\mathrm{MgGd}_{2} \mathrm{O}_{4}$ as compared with $\mathrm{Mg}[96,97]$. The formation of this layer can further prevent oxidation, because as previously discussed, $\mathrm{Mg}$ with a lower affinity for oxide formation as compared with most rare earth elements is restricted from oxidation [93]. The mechanical properties (tensile and yield strength) and corrosion resistance increase with Gd content up to $10 \mathrm{wt} \%$, in the $\alpha$-matrix of the solid solution (Table 2.1). As shown in Figure 2.3, an increase in Gd of upto $10 \mathrm{wt} \%$ results in a decrease in corrosion rate as well as hydrogen evolution. However, at $15 \mathrm{wt} \% \mathrm{Gd}$, both corrosion rate and hydrogen evolution increased substantially. Gd leads to potential fatal conditions to the patients with kidney disease called nephrogenic systemic fibrosis (NSF), which can lead to Gd renal failure. 


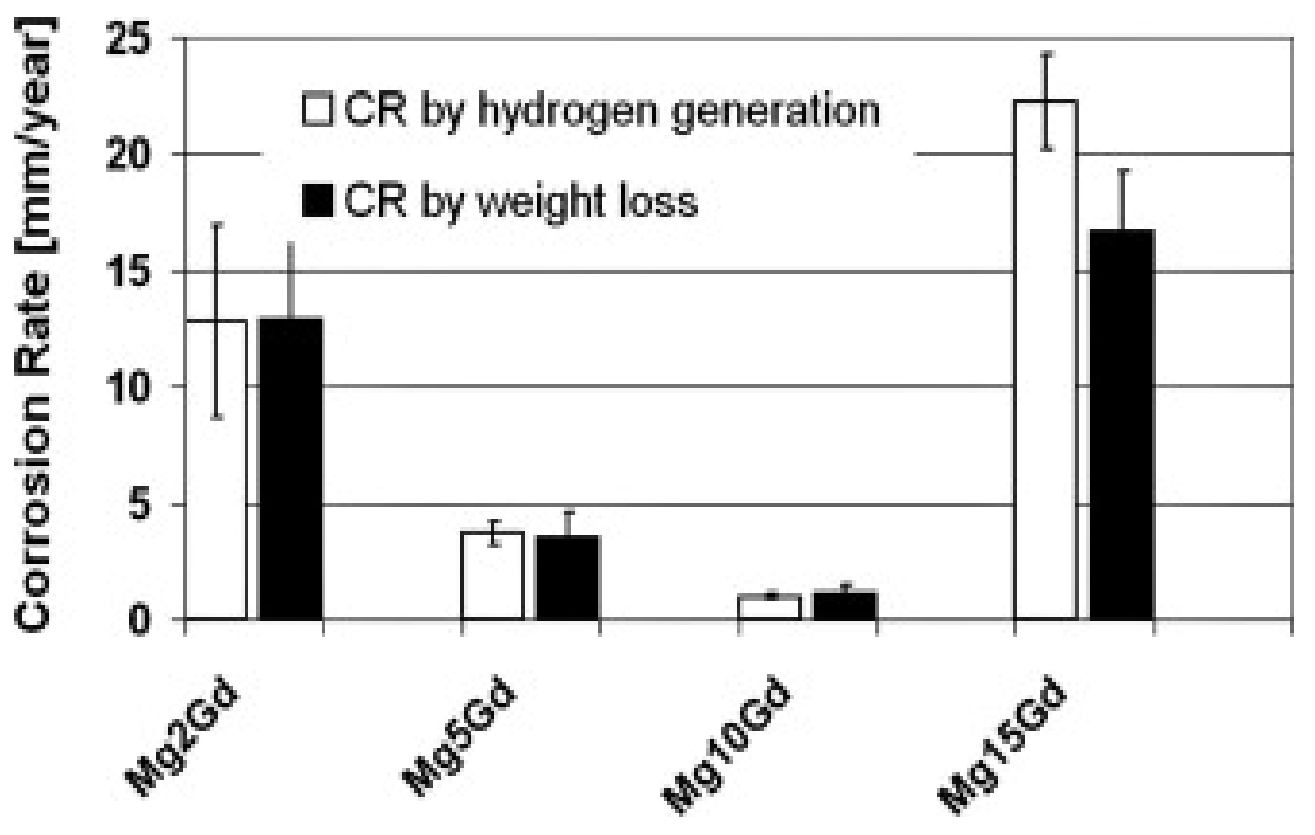

Figure 2.3: Corrosion rates variation with concentration of Gd in Mg [93].

Witte et al. (2005) implanted four alloys (AZ31, AZ91, WE43 and LAE442) manufactured by gravity casting in 40 female Dunkin Hartley guinea pigs and observed non-uniform corrosion in all magnesium alloys as compared with SR-PLA96 polymer [98]. During in-vivo testing, it was observed that a layer of calcium ions replaced the corroded mass of the alloys. This was accompanied by an increase in bone growth as compared to SR-PLA96 [98]. Figure 2.4 shows the new bone formation with Mg alloys primarily in the periosteal and endosteal areas of bones [98]. Overall response from biodegradable materials is with time when the tissue/bone heals and mechanical properties of the material decreases. 

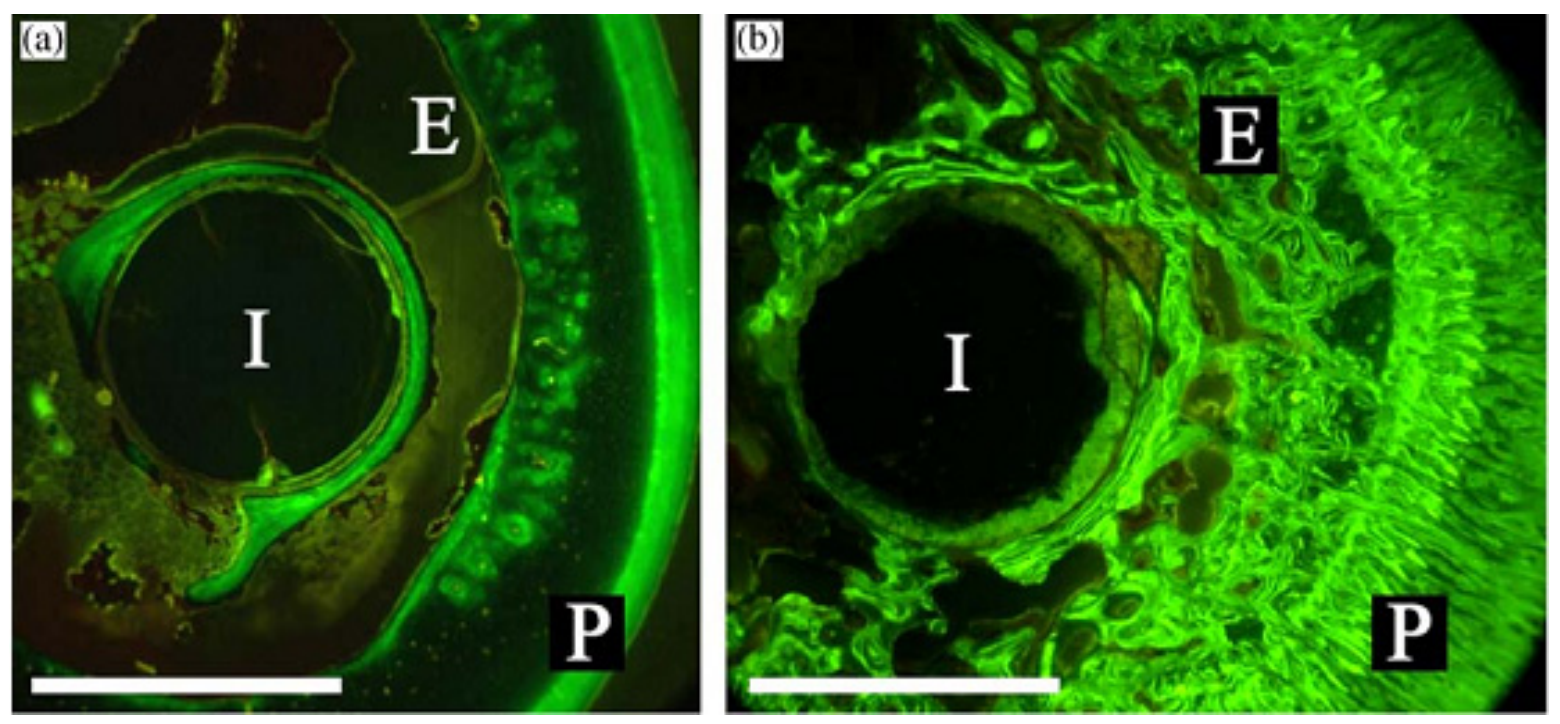

Figure 2.4: Flouroscopic images of cross-sections of: (a) degradable polymer and (b) magnesium rod in a guinea pig femura, performed $10 \mathrm{~mm}$ below trochanter. The specimens were harvested 18 weeks postoperatively and images were taken in-vivo by staining the new bone with calcein green . Bar $=1.5 \mathrm{~mm}$; I=implant residual; $P=$ periosteal bone formation; E=endosteal bone formation [98].

Zhang et al. (2008) [99] manufactured $\mathrm{Mg}-1 \mathrm{Zn}-0.8 \mathrm{Mn}$ (wt\%) by extrusion process and implanted in the femora of the rat. A non-uniform degradation of an implant was reported with no gas bubbles where $55 \%$ of the implant was degraded after 26 weeks. It was observed that with the increase in implantation time, more bone tissues were grown and no fibrous capsules nor macrophage were found around the implant [99]. 
Table 2.1: Summary of (approximate) properties of some of the potential Mg based alloys for bone and stent applications. $[64,65,79,83,86,88,90,93,115]$

\begin{tabular}{|c|c|c|c|c|}
\hline Material & $\begin{array}{c}\text { Young's Modulus } \\
\text { (GPa) }\end{array}$ & $\begin{array}{c}\text { Elongation } \\
(\%)\end{array}$ & $\begin{array}{l}\text { Tensile } \\
\text { (MPa) }\end{array}$ & $\begin{array}{c}\text { Corrosion Rate } \\
\text { (mm/year) }\end{array}$ \\
\hline Cortical Bone & & $1.07-2.10$ & $35-283$ & \\
\hline Titanium (TiAl6V4, cast) & & 12 & $830-1025$ & \\
\hline Stainless Steel 316L & & $30-40$ & $480-620$ & \\
\hline $\mathrm{Mg}-0.8 \mathrm{Ca}$ & & & 428 & \\
\hline Mg2Gd (as Casted) & & 6.362 & 103.73 & 13.5 \\
\hline Mg-5Gd (as Casted) & & 6.620 & 128.468 & 5 \\
\hline Mg-10Gd (as Casted) & & 2.500 & 131.152 & 1 \\
\hline Mg-15Gd (as Casted) & & 0.950 & 175.220 & 17 \\
\hline $\mathrm{Mg}-28 \mathrm{Zn}-5 \mathrm{Ca}$ & 48 & & $675-894$ & \\
\hline WE43 (crystalline) & 44 & & 270 & \\
\hline ZQCa3 (crystalline) & 44 & & 250 & \\
\hline ZK31 (crystalline) & 44 & & 300 & \\
\hline AZ31/gravity-cast & & 15 & 260 & - \\
\hline AZ91D/gravity-cast & & 3 & 230 & 2.8 \\
\hline WE43/gravity cast & & 2 & 220 & - \\
\hline LAE442/gravity cast & & & - & 6.9 \\
\hline MMC-HA/as extruded & & 3.5 & 325 & 1.25 \\
\hline
\end{tabular}




\begin{tabular}{|c|c|c|c|c|}
\hline Material & $\begin{array}{c}\text { Young's Modulus } \\
\text { (GPa) }\end{array}$ & $\begin{array}{c}\text { Elongation } \\
(\%)\end{array}$ & $\begin{array}{l}\text { Tensile } \\
\text { (MPa) }\end{array}$ & $\begin{array}{c}\text { Corrosion Rate } \\
\text { (mm/year) }\end{array}$ \\
\hline Mg-2Ca/rapidly solidification & & 7.3 & 380 & - \\
\hline $\mathrm{Mg}-1 \mathrm{Ca} /$ as extruded & & 10.63 & 239.63 & 1.74 \\
\hline $\mathrm{Mg}-1 \mathrm{Ca} /$ as rolled & & 3 & 166.7 & 1.63 \\
\hline $\mathrm{Mg}-1 \mathrm{Ca} /$ as cast & & 1.87 & 71.38 & 12.56 \\
\hline $\mathrm{Mg}$ as rolled & & 12 & 172 & 0.84 \\
\hline $\mathrm{Mg}-1 \mathrm{Mn}$ as rolled & & 3.9 & 170 & 0.45 \\
\hline $\mathrm{Mg}-1 \mathrm{Y}$ as rolled & & 9.2 & 200 & 1.65 \\
\hline $\mathrm{Mg}-1 \mathrm{Zn}$ as rolled & & 7 & 240 & 0.92 \\
\hline $\mathrm{Mg}-1 \mathrm{Zr}$ as rolled & & 17.5 & 185 & 0.91 \\
\hline $\mathrm{Mg}-7 \mathrm{Gd}$ & & 5.2 & 145 & \\
\hline Mg-7Gd-3Y & & 8.4 & 253 & \\
\hline Mg-7Gd-5Y & & 5.4 & 258 & \\
\hline $\mathrm{Mg}-\mathrm{Zn}-\mathrm{Zr} / \mathrm{nHA}$ & & & & 0.75 \\
\hline $\mathrm{Mg}-6 \mathrm{Zn}$ & $42.3 \pm 0.1$ & $18.8 \pm 0.8$ & $279.5 \pm 2.3$ & 0.16 \\
\hline $\mathrm{Mg}-\mathrm{Mn}-\mathrm{Zn}$ & 44 & 20 & 280 & \\
\hline Mg-Zn-Mn & & $21.8 \pm 0.6$ & $280.3 \pm 0.9$ & \\
\hline $\begin{array}{l}\mathrm{Mg}-12 \mathrm{Gd}-4 \mathrm{Y}-2 \mathrm{Nd}-0.3 \mathrm{Zn}-0.6 \mathrm{Zr} \\
\text { (RT) T6 }\end{array}$ & & 2.8 & 310 & \\
\hline
\end{tabular}




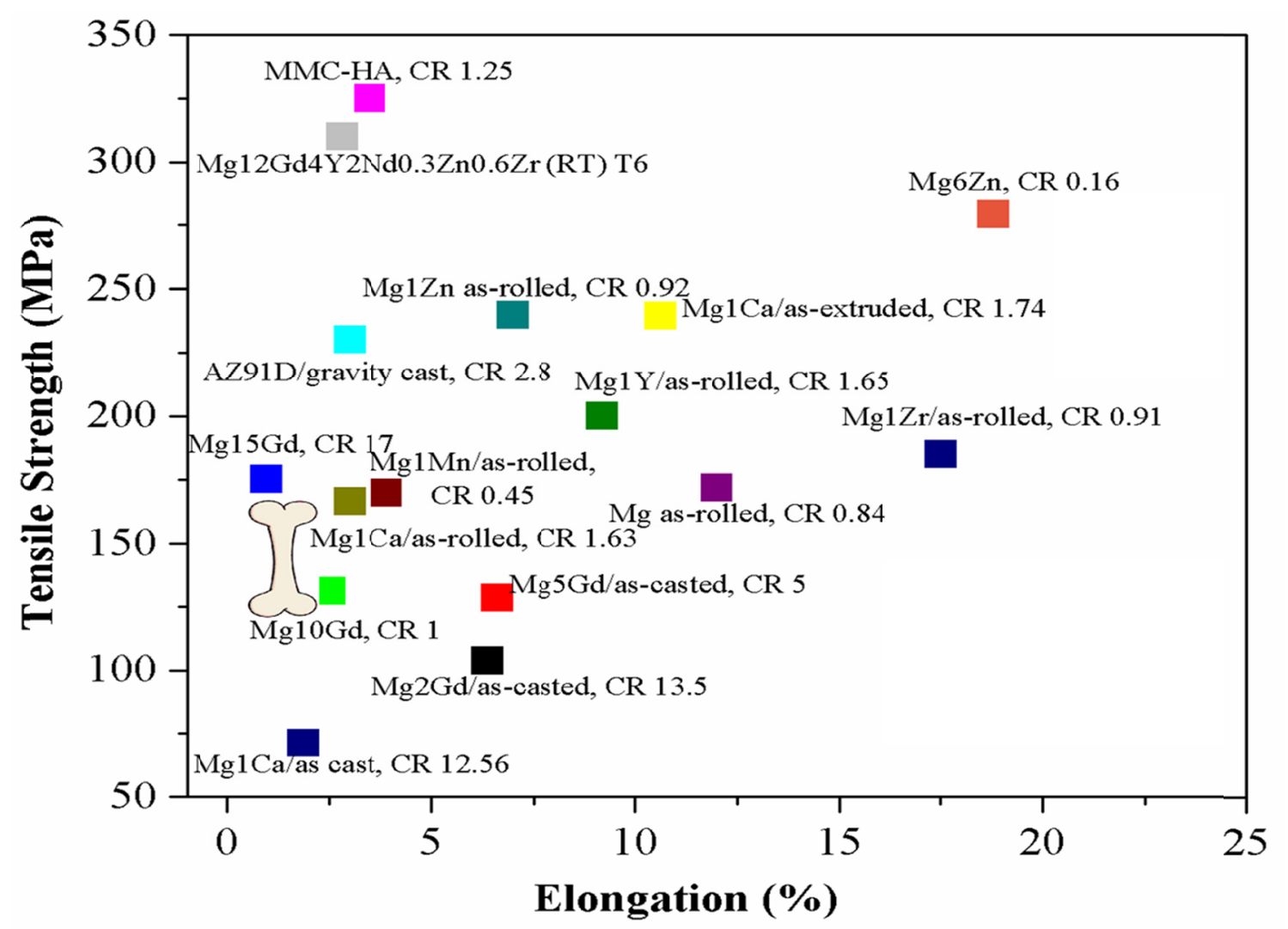

Figure 2.5: Schematic representation of (approximate) properties of potential Mg based alloys for biomedical applications (corrosion rate (CR), mm/year) $[64,65,79,83,86,88,90,93,115]$. 


\subsection{MATERIALS AND METHODS}

\subsection{Synthesis of Mg Biodegradable Materials}

This chapter provides information on the synthesis of $\mathrm{Mg}$ alloys and various experimental techniques used in this investigation. The alloys were received from two sources, ACI Alloys and Brunel Centre for Advanced Solidification Technology (BCAST) at Brunel University London. ACI alloys were manufactured by melting the elements at $1000{ }^{\circ} \mathrm{C}$ under an inert atmosphere (Argon) and casting in a water cooled copper mould. The ramp-up time from room temperature to melting temperature was 1 minute and alloys were further heat treated at $350{ }^{\circ} \mathrm{C}$ and water quenched.

The alloys received from Brunel were manufactured by heating in an electrical resistance furnace, and melted in a steel crucible under inert atmosphere $\left(99.6 \% \mathrm{~N}_{2}+\right.$ $0.4 \% \mathrm{SF}_{6}$ ). The mixing process was conducted for three times, at 20 minute intervals, with mixing for 3 to 4 minutes. The standard test procedure-1 (TP-1) $660{ }^{\circ} \mathrm{C}$ samples were produced. Figure 3.1 shows the schematic for the alloy preparation [37] and Table 3.1 shows the nominal and analyzed compositions of the materials in $w t \%$.

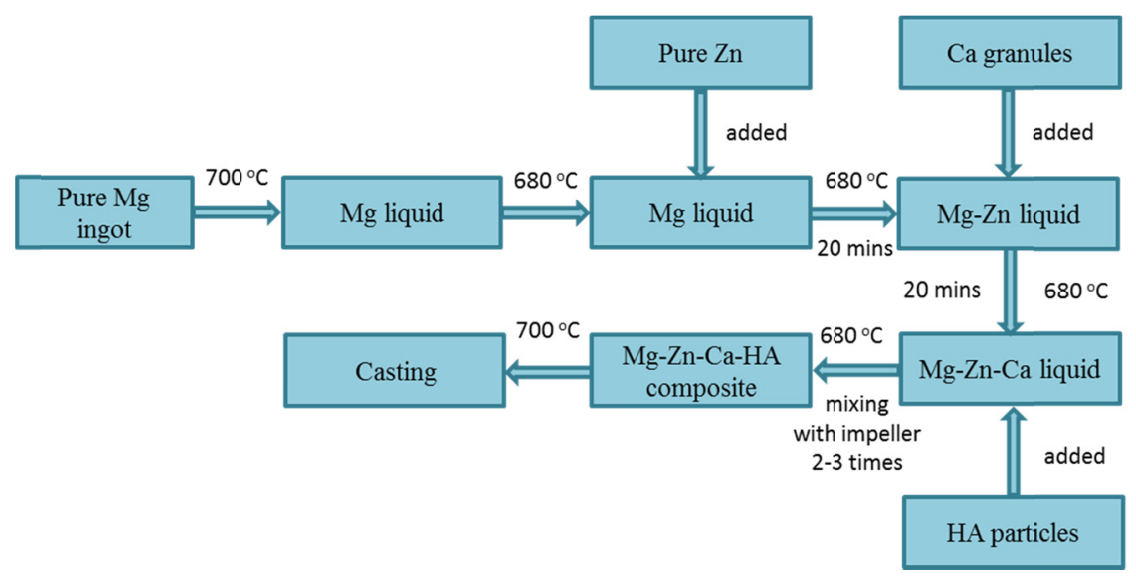

Figure 3.1: Schematic representation of Brunel alloy manufacturing process [37]. 
Table 3.1: Nominal and analyzed compositions of the materials in weight percentage (wt\%)

\begin{tabular}{|c|c|c|c|c|c|c|c|c|c|c|c|c|}
\hline Elements & Mg & $\mathbf{Z n}$ & $\mathbf{C a}$ & HA & Gd & $\mathbf{O}$ & Mg & $\mathbf{Z n}$ & $\mathrm{Ca}$ & HA & Gd & $\mathbf{O}$ \\
\hline Mg1Zn (ACI) & Balance & 1 & NA & NA & NA & NA & Balance & 0.71 & $\mathrm{NA}$ & NA & NA & 12.59 \\
\hline Mg1Zn1Ca8Gd (ACI) & Balance & 1 & 1 & NA & 8 & NA & Balance & 1.01 & 0.76 & NA & 5.08 & 0.81 \\
\hline Mg1Zn1Ca & Balance & 1 & 1 & NA & NA & NA & Balance & 1.62 & 0.37 & NA & NA & 2.28 \\
\hline Mg1Zn1Ca1HA & Balance & 1 & 1 & 1 & NA & NA & Balance & 1.80 & 1.38 & No Analysis & NA & 4.88 \\
\hline Mg5Zn1Ca & Balance & 5 & 1 & NA & NA & NA & Balance & 1.77 & 0.99 & NA & NA & 2.26 \\
\hline Mg5Zn1Ca1HA & Balance & 5 & 1 & 1 & NA & NA & Balance & 5.03 & 1.09 & No Analysis & NA & 1.81 \\
\hline Mg5Zn1Ca3HA & Balance & 5 & 1 & 3 & NA & NA & Balance & 5.17 & 1.04 & No Analysis & NA & 2.18 \\
\hline
\end{tabular}




\subsection{Sample Preparation}

The ingots were cut into cubes of dimensions $0.414 \times 0.414 \times 0.08$ (inch) using a linear precision saw (ISOMET 4000). Each cube was mounted into epoxy resin with an exposed working area of $0.414 \times 0.414$ (inch), which were then mechanically polished to achieve a roughness close to 0.05 microns using abrasives, abrasive papers (Buehler) and lubricants (Sigma-Aldrich). Samples were polished in four steps as shown in Table 3.2. The usage of water based solutions was avoided during sample preparation, in order to prevent the hydrolysis of the alloy.

Table 3.2: Lubricants and abrasives used during sample preparation

\begin{tabular}{|c|c|c|}
\hline Surface & Lubricant & Abrasive \\
\hline Carbimet $^{\circledR}$ & Ethanol & SiC, 400 grit \\
\hline Texmet $^{\circledR}$ & Ethanol-Ethylene Glycol $(3: 1)$ & Metadi $^{\circledR}$ Paste, $9 \mu \mathrm{m}$ \\
\hline Texmet $^{\circledR}$ & Ethanol-Ethylene Glycol $(3: 1)$ & Metadi $^{\circledR}$ Paste, $3 \mu \mathrm{m}^{(2)}$ \\
\hline Chemomet $^{\circledR}$ & Ethanol & Masterpolish $^{\circledR}, 0.05 \mu \mathrm{m}$ \\
\hline
\end{tabular}

Anodizing is an important surface treatment for Mg alloys, which can efficiently reduce the corrosion rate. Anodizing mainly develops a passivation oxide layer on the surface of the alloys. The firmness of the surface oxide layer directly affects the biocompatibility of the implant as it acts as a barrier between the bulk and the electrolyte, which further confines the ion exchange and increases the implant stability [111]. Furthermore, anodizing is selected as a coating process in this study because: (a) the 
anodized coating is hard compared with other conventional coatings; and (b) is porous (structure similar to cancellous microstructure of a bone), which may be favorable to bone tissue [114]. Another advantage of anodizing is that it can offer a very effective protection to $\mathrm{Mg}$ implants before the surgery region has healed after which, the coating will break down enabling the implant to be dissolved gradually.

In this study, each alloy was anodized by Electrobright ${ }^{\circledR}$ (Macungie, PA, USA). The electrolytes used during the process were organic acids and high chain alcohol. Because of its proprietary nature of the process, no further information on the electrolytes used has been disclosed by Electrobright ${ }^{\circledR}$. Figure 3.2 shows the typical anodizing setup.

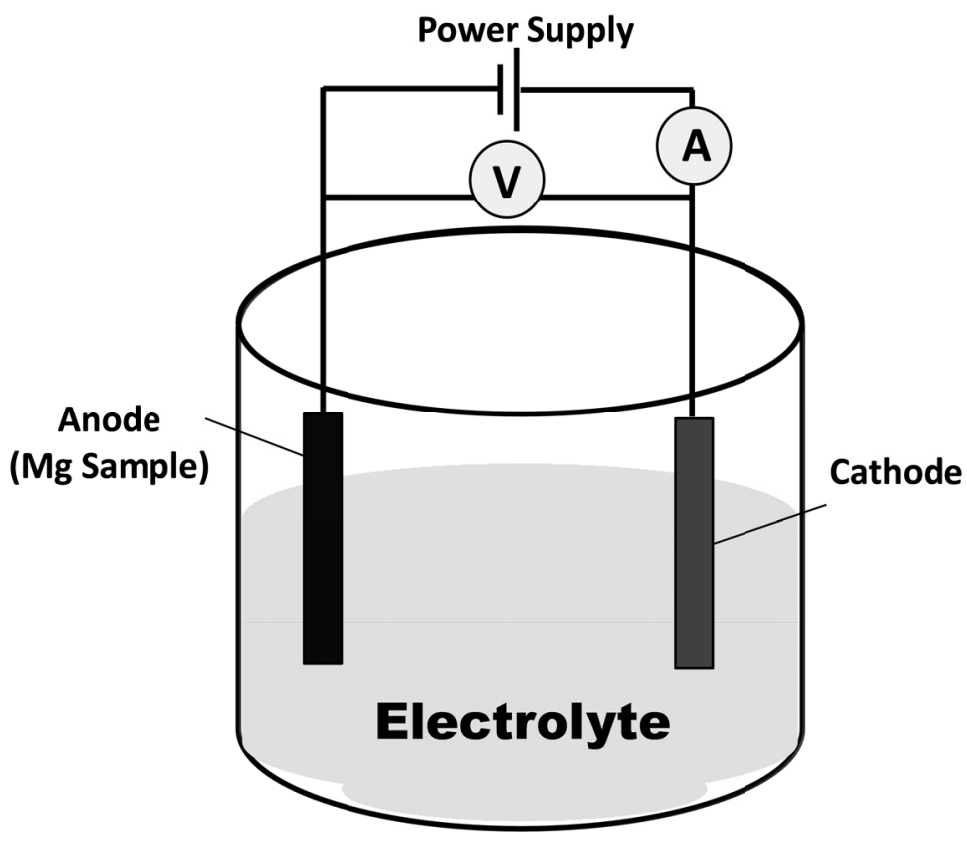

Figure 3.2: Typical anodization setup.

\subsection{Reagents}

Phosphate Buffered Saline (PBS), a reagent grade solution conforming to the specifications of the Committee on Analytical Reagents of the American Chemical 
Society was used as the standard test solution for corrosion analysis. PBS (Sigma Aldrich) and three amino acids (Acros Organics), cysteine C (0.25 mM), glutamine Q $(0.568 \mathrm{mM})$ and tryptophan $\mathrm{W}(0.042 \mathrm{mM})$ were used as electrolytes for corrosion studies, with the latter at concentrations typically found in human blood [104]. Additionally, ethyl alcohol (99.9\%) and chromic acid were purchased from Sigma Aldrich. The samples were ultrasonically cleaned in ethyl alcohol for 5 minutes, prior to conducting each test. Chromic acid was used to remove the oxides from the samples attained by immersing them in $180 \mathrm{~g} / 1$ of chromic acid for $20 \mathrm{~min}$. Table 3.3 shows the chemical composition of PBS solution used in this investigation.

Table 3.3: Chemical composition of $P B S$ solution in $g / L$.

\begin{tabular}{cccccccc}
\hline $\mathrm{NaCl}$ & $\mathrm{Na}_{2} \mathrm{HPO}_{4}$ & $\mathrm{NaHCO}_{3}$ & $\mathrm{KCl}$ & $\mathrm{KH}_{2} \mathrm{PO}_{4}$ & $\mathrm{MgSiO}_{4}$ & $7 \mathrm{H}_{2} \mathrm{O}$ & $\mathrm{CaCl}_{2}$ \\
\hline 8.0 & 0.06 & 0.35 & 0.4 & 0.06 & 0.2 & 0.14 \\
\hline
\end{tabular}




\subsection{ELECTROCHEMICAL STUDIES}

\subsection{Corrosion Behavior of Medical Implants}

Corrosion is defined as a destructive attack on the surface of a material as a result of an electrochemical reaction with its environment. Electrochemical deterioration occurs as positive ions are released from the anode as electrons flow towards the cathode $[139,155]$. Typical anodic and cathodic reactions are shown below $[68,139,156]$.

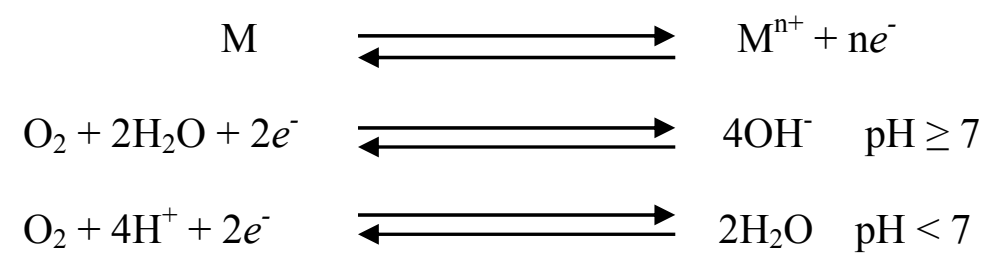

Equation (1) represents the oxidation of a metal; equation (2) is the reduction process in neutral or basic conditions; and equation (3) is also a reduction process in acidic conditions.

Pitting corrosion is one of the most common forms of corrosion in implants, where intense attack occurs at localized sites while the remainder of the surface corrodes at a much lower rate, either because of the formation of a protective oxide layer or due to some physiological conditions. Some other contributing factors to pitting are caused by the presence of reactive sites, on the surface that are more anodic or cathodic.

\subsection{Magnesium - Corrosion Mechanism}

Equilibria between metal and solution can be illustrated via the Eh-pH (Pourbaix) diagrams. The first extensive use of such diagrams was made by Marcel Pourbaix while describing the thermodynamics of metallic corrosion. The Eh-pH diagram primarily 
describes the equilibrium conditions in terms of two variables, a single electrode (reduction) potential and $\mathrm{pH}$, under which dissolved ions are in equilibrium with the metal/metallic phases. Diagrams are drawn with contour lines depicting solution composition, such as metal ion concentration at $25^{\circ} \mathrm{C}$ or some higher temperature. The lines on an Eh-pH diagram are computed from the general equilibria equation:

$$
a A+b B+m H^{+}+n e \leftrightharpoons c C+d D
$$

For which the equilibrium (reversible) single electrode potential can be written as:

$$
E_{(1)}=E_{(1)^{-}}^{o} \frac{R T}{n F} \ln \frac{a_{C}^{c} a_{D}^{d}}{a_{A}^{a} a_{B}^{b} a_{H^{+}}^{m}}
$$

In fatigue analysis, there is no endurance limit for $\mathrm{Mg}$ and its alloys. Under corrosive conditions, this phenomenon is more pronounced and the slope of the fatigue curve depends on the environment and the alloy composition [58]. Corrosion is generally unwanted in engineering and science applications, whereas in the case of biodegradable implants, this phenomenon could revolutionize the biomedical industry if the degradation rate could be controlled. $\mathrm{Mg}$ is susceptible to oxidation at room temperature, which produces a passivation oxide layer. $\mathrm{Mg}$ standard electrode potential is $-2.37 \mathrm{~V}$ as compared with the standard hydrogen electrode. In the presence of moisture, $\mathrm{Mg}$ oxide is converted to $\mathrm{Mg}$ hydroxide. The immunity region of $\mathrm{Mg}$ oxide in the Eh-pH diagram falls below the region of water stability, which is indicative of its vulnerability to corrosion [55,59]. At potentials above $-2.37 \mathrm{~V}$ and $\mathrm{pH}$ value below 11, Mg corrodes producing $\mathrm{Mg}^{+2}$ and $\mathrm{H}_{2}[55,59]$ as shown in Figure 4.1. At $\mathrm{pH}$ values between 8.5 and 12.5, a protective layer $\left(\mathrm{MgO}\right.$ and $\left.\mathrm{Mg}\left(\mathrm{OH}_{2}\right)\right)$ is formed [55]. It has been reported that these protective or passivating layers can promote osteoinductivity and osteoconductivity 
[60]. Generally, the degradation rate of $\mathrm{Mg}$ alloys depends on their composition, surface roughness, morphology, surface energy and the environment into which they are placed.

The most important requirement for biodegradable alloys is its uniform degradation, which necessitates a fine grained material. Tunold et al. (1977) reported transgranular corrosion of pure commercial $\mathrm{Mg}$, whereas $\mathrm{Mg}$ alloys have been shown to exhibit uniform corrosion [61,62].

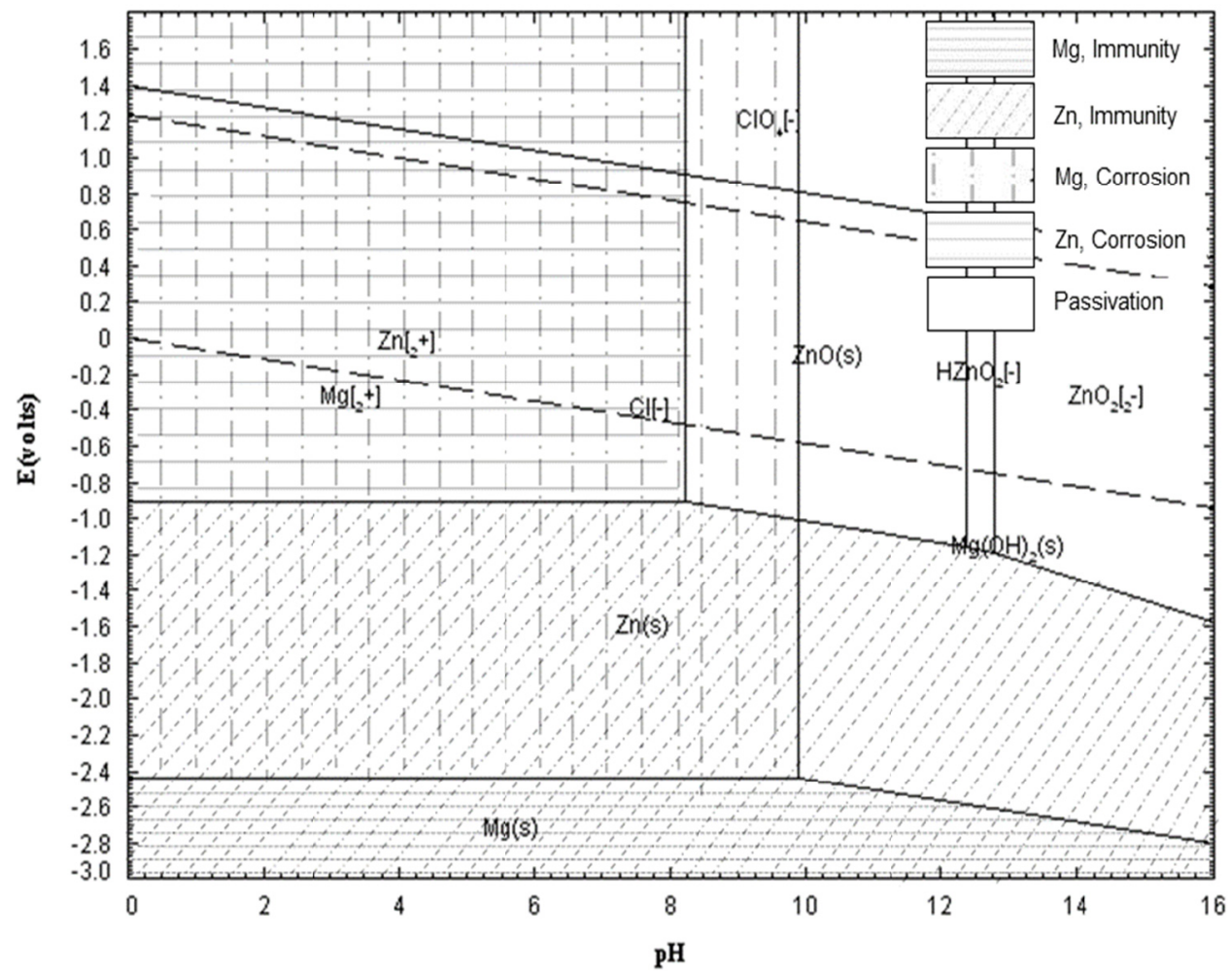

Figure 4.1: Potential-pH (Pourbaix) diagram for $\mathrm{Mg}$-zinc in water at $25^{\circ} \mathrm{C}$, showing the theoretical domains of corrosion, immunity and passivation.

Nevertheless, corrosive attack often involves micro galvanic coupling between cathodic and anodic sites. The overall corrosion reaction of $\mathrm{Mg}$ in aqueous environments is given below $[63,64]$ : 


$$
\mathrm{Mg}_{(s)}+2 \mathrm{H}_{2} \mathrm{O}_{(a q)} \rightarrow \mathrm{Mg}(\mathrm{OH})_{2(s)}+H_{2(g)}
$$

This overall reaction may include the following partial reactions:

$$
\begin{aligned}
& \left.\mathrm{Mg}_{(s)} \rightarrow \mathrm{Mg}_{(a q)}^{2+}+2 e^{-} \text {(anodic reaction, }-2.37 \mathrm{~V}\right) \\
& 2 \mathrm{H}_{2} \mathrm{O}_{(a q)}+2 e^{-} \rightarrow \mathrm{H}_{2(g)}+2 \mathrm{OH}_{(a q)}^{-}(\text {cathodic reaction, }-0.83 \mathrm{~V}) \\
& \left.\mathrm{Mg}_{(a q)}^{2+}+2 \mathrm{OH}_{(a q)} \rightarrow \mathrm{Mg}(\mathrm{OH})_{2(s)} \text { (product formation, }-2.69 \mathrm{~V}\right)
\end{aligned}
$$

The presence of chloride ions $\left(\mathrm{Cl}^{-}\right)$transforms $\mathrm{Mg}(\mathrm{OH})_{2}$ into soluble $\mathrm{MgCl}_{2}$ (see equation 5), resulting in excess $\mathrm{OH}^{-}$ions in the solution [65].

$$
\begin{aligned}
& \mathrm{Mg}(\mathrm{OH})_{2}+2 \mathrm{Cl}^{-}=\mathrm{MgCl}_{2}+2 \mathrm{OH}^{-} \\
& \mathrm{MgCl}_{2}+2 \mathrm{H}_{2} \mathrm{O}=\mathrm{Mg}(\mathrm{OH})_{2}+2 \mathrm{HCl}
\end{aligned}
$$

However, $\mathrm{MgCl}_{2}$ is water soluble and hydrolyzed in accordance with equation (6). The reaction undermines the integrity of the $\mathrm{Mg}(\mathrm{OH})_{2}$ layer. Pitting corrosion occurs when $\mathrm{Cl}^{-}$ions diffuse through a breach in the passivating layer, which accelerates the corrosion of Mg alloys. The reduction process of hydrogen overvoltage of the cathodic phase plays an important role in corrosion, whereas with Mg a low overvoltage cathode facilitates hydrogen evolution and alkalization of solution, causing a substantial corrosion rate $[63,64]$.

The $\mathrm{H}^{+}$ions from equation (6) combine with $\mathrm{Cl}^{-}$producing $\mathrm{HCl}$, which accelerate the dissolution of the metal, producing $\mathrm{MgCl}_{2}$. This process repeats itself in an autocatalytic manner, producing pits.

Alloying is one method of improving the mechanical properties and corrosion resistance of $\mathrm{Mg}$ [66]. For bioabsorbable applications, the alloying element must be non- 
toxic and biocompatible, so that the concentration of the dissolved ions once implanted, would not substantially exceed the concentration normally found in human blood. The hydrogen evolved from corroding Mg implants have been reported to form gas pockets adjacent to the implant, which delays the healing of tissues in the surgery region, leading to necrosis. The gas pockets can cause separation of tissues and tissue layers [121].

Huntsman et al. in 1960 reported the presence of magnesium $\left(\mathrm{Mg}^{2+}\right)$ and calcium ions $\left(\mathrm{Ca}^{2+}\right)$, both competing for reactive sites with clotting factors, which lead to the prolonged clotting time [67]. $\mathrm{Ca}^{2+}$ is an efficient catalyst in the clotting of blood, but the addition of $\mathrm{Mg}^{2+}$ competes with $\mathrm{Ca}^{2+}$, so that a sub-optimal amount of $\mathrm{Ca}^{2+}$ is available to bind with all reaction sites during the clotting process. Figure 4.2 [67] depicts the optimal concentration of $\mathrm{Ca}^{2+}$ and $\mathrm{Mg}^{2+}$ ions as a function of clotting time of human plasma.

$$
\mathrm{Ca}^{2+} \leftrightarrow \mathrm{Mg}^{2+} \rightarrow \text { clotting molecules } \rightarrow \text { prolongs thrombosis }
$$

The relevance of this plot in predicting clotting time will be discussed in section 4.5 , with regard to our alloys based upon the concentration of $\mathrm{Ca}^{++}$and $\mathrm{Mg}^{++}$measured by Inductively Coupled Mass Spectroscopy (ICP-MS) analyses of the electrolyte after corrosion. 


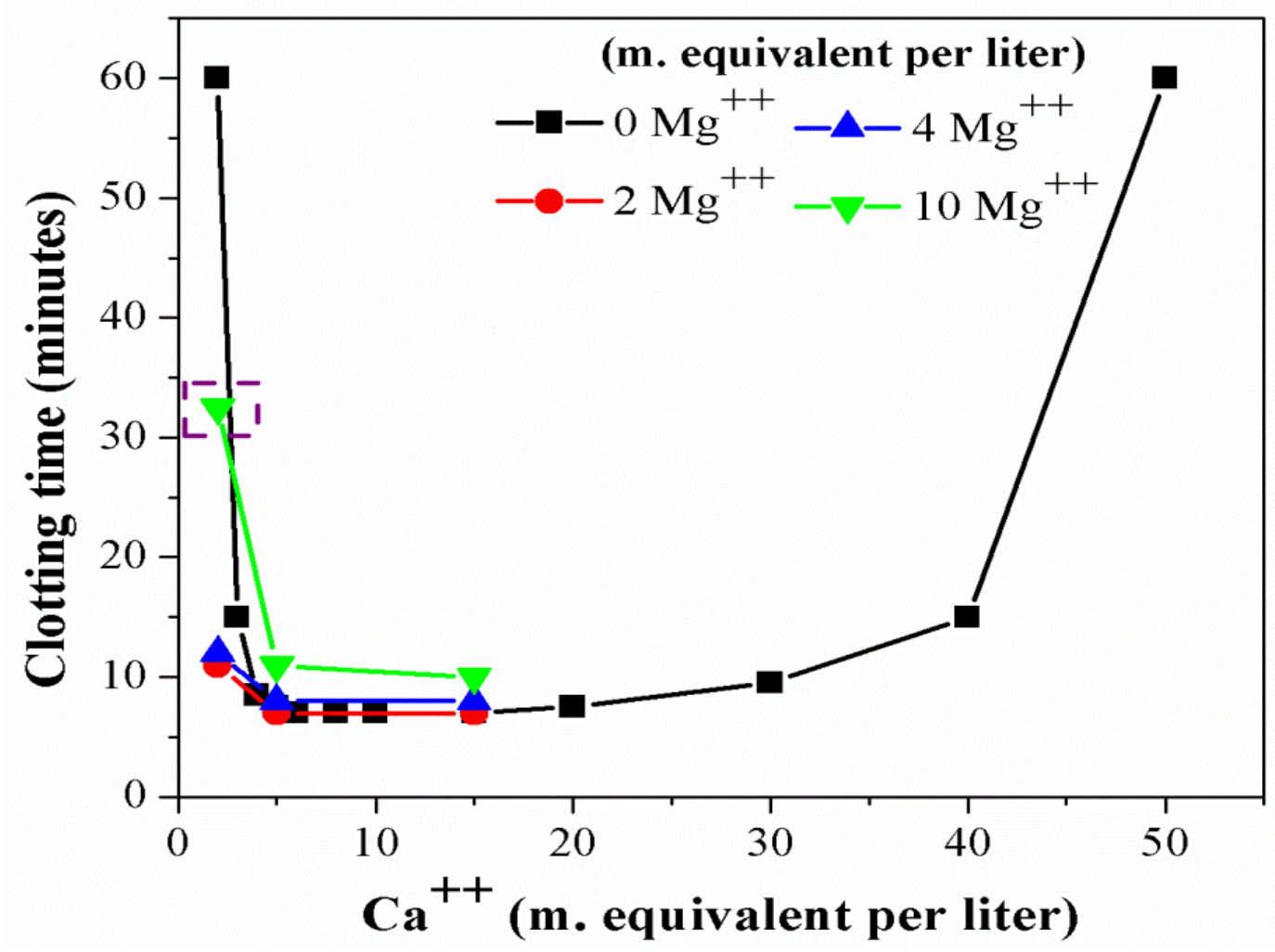

Figure 4.2: $\mathrm{Ca}^{2+}$ and $\mathrm{Mg}^{2+}$ concentration as a function of clotting time of human plasma [67].

\subsection{Factors Affecting Corrosion}

The most important requirement of a biodegradable implant is its degradation properties in a given biological environment, which are influenced by various intrinsic and extrinsic factors. Intrinsic factors include: chemical composition, microstructure, surface energy, wettability, thickness and stability of the passivating oxide film. Extrinsic factors include: temperature, $\mathrm{pH}$, dissolved oxygen content, amino acids, biomolecules and chloride ions in the surrounding environment [68]. Tissue fluids in the human body also present a very corrosive environment for implant devices. Furthermore, the regeneration of a passivating oxide film is delayed since the concentration of dissolved oxygen in body fluids is approximately one fourth of that in air. Additionally, the 
concentration of $\mathrm{Cl}^{-}$ions (the prime species in the initiation of pitting corrosion) in serum and interstitial fluid is 113 and $117 \mathrm{mEq} / \mathrm{L}$ respectively [68]. As previously mentioned, $\mathrm{Cl}^{-}$ions induce pitting corrosion at sites where the passive film is breached. This is followed by the propagation of the pit, at a rate that occasionally increases with time, because of the increasing acidity inside the pit. In addition to inorganic species in body fluid, different types of biomolecules and cells may attach to the implant surface and affect its surface chemistry.

The study of degradation of $\mathrm{Mg}$ based implants is a quite complicated subject. This is partly attributed to the inherent stochastic nature of corrosion. Figure 4.3 (not drawn to scale) is a schematic representation of the extrinsic factors that effects the degradation, biocompatibility and mechanical properties of biodegradable implants.

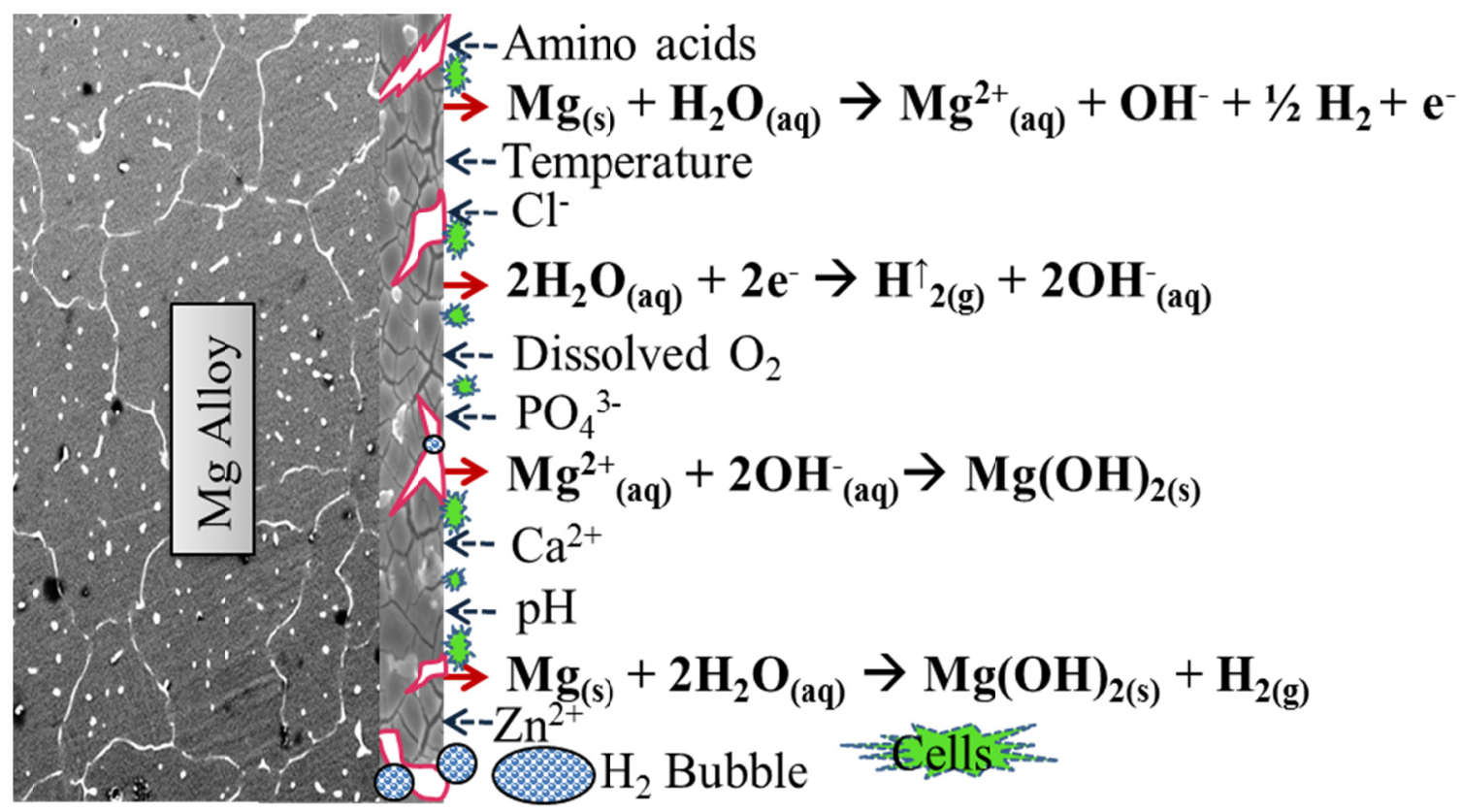

Figure 4.3: Factors affecting the corrosion behavior of implant materials. 


\subsubsection{Pilling-Bedworth Ratio}

Thermodynamics is the driving force for corrosion, where a negative change in Gibb's free energy $(-\Delta G)$ indicates the tendency of reaction to occur, in this case the formation of oxides. The Pilling-Bedworth ratio $\left(\mathrm{R}_{\mathrm{PB}}\right.$ ratio), in the corrosion of metals, is the ratio of the volume of the elementary cell of a metal oxide to the volume of the elementary cell of the corresponding metal (from which the oxide is created). It describes the type of oxide film (passivating film) that will form on the surface of metals during the process of oxidation, which can further predict the stability of the oxides.

$$
R_{P B}=\left(M_{\text {oxide }} \cdot \rho_{\text {metal }}\right) /\left(M_{\text {metal }} \cdot \rho_{\text {oxide }}\right)
$$

where: $\mathrm{R}_{\mathrm{PB}}$ is the Pilling-Bedworth ratio, $\mathrm{M}$ is the atomic or molecular mass, $\mathrm{n}$ is number of atoms of metal per one molecule of the oxide, $\rho$ is the density, and $\mathrm{V}$ is the molar volume.

$\mathrm{R}_{\mathrm{PB}}<1$ : Oxide coating layer is too thin, likely broken and provides no protective effect (tensile stresses in oxide film $\rightarrow$ brittle oxide cracks)

$\mathrm{R}_{\mathrm{PB}}>2$ : Oxide coating chips off and provides no protective effect (large compressive stresses in oxide film $\rightarrow$ oxide cracks)

$1<\mathrm{R}_{\mathrm{PB}}<2$ : Oxide coating is passivating and provides a protecting effect against further surface oxidation (compressive stresses in oxide film $\rightarrow$ uniformly cover metal surface and is protective).

Table 4.1 shows the Pilling-Bedworth ratios depicting the light metal (porous oxides) and heavy metal (non-porous oxides) oxides. The surface oxides of $\mathrm{Mg}$ and $\mathrm{Ca}$ are less stable as compared with those of $\mathrm{Zn}$ and Gd. 
Table 4.1: Calculated Pilling-Bedworth ratio for the elements used in this investigation

\begin{tabular}{cc}
\hline Oxides & $\mathbf{R}_{\mathbf{P B}}$ \\
\hline $\mathrm{MgO}$ & 0.80505 \\
$\mathrm{ZnO}$ & 1.5852 \\
$\mathrm{CaO}$ & 0.6474 \\
$\mathrm{Gd}_{2} \mathrm{O}_{3}$ & 1.2293 \\
\hline
\end{tabular}

\subsubsection{Corrosion Kinetics}

Three equations generally describe the mode by which metals oxidize: (a) linear; (b) parabolic; and (c) logarithmic equations $[157,158]$.

$$
\begin{array}{ll}
y=K_{1} t+A_{1} & \text { (Linear equation) } \\
y^{2}=K_{2} t+A_{2} & \text { (Parabolic equation) } \\
y=K_{3} \log \left(A_{3} t+c\right) & \text { (Logarithmic equation) }
\end{array}
$$

where: $\mathrm{y}$ is film thickness, $\mathrm{t}$ is time, and $\mathrm{K}, \mathrm{A}$ and $\mathrm{c}$ are constants.

The parabolic rate law may be attributed to a mechanism involving diffusion of solvent ions through a porous film (passivating) that is produced during the course of the corrosion reaction, which retards its rate. The rate-determining step is diffusion through a passivating film, thickness of film increases in proportion to the extent of corrosion. In the case of linear oxidation the formation of highly porous, poorly adherent and fractured non-protective oxide layers do not retard the rate of corrosion [158]. On the other hand, the slow leaching of ions from an implant may be due to the nature of the solute atoms (impurities) present in the alloy or on the adsorption of proteins on the surface of an 
implant. However, transportation of ions from the liquid phase occupying pores through the film or passivating layer, is parabolically rate controlled with low activation energy. The actual rate determining step may be either diffusion of a reactant species towards the metal interface or diffusion of a corrosion product through the outer passivation or protein film surfaces. The rate of oxidation or corrosion will depend on the pore volume and the "tortuosity" of the pores as well as the film thickness.

\subsection{Corrosion Testing}

The corrosion behavior of biodegradable implants is one of the major contributing factors on their failure. In order to better understand the corrosion phenomenon, three different techniques were adopted as shown in Figure 4.4.

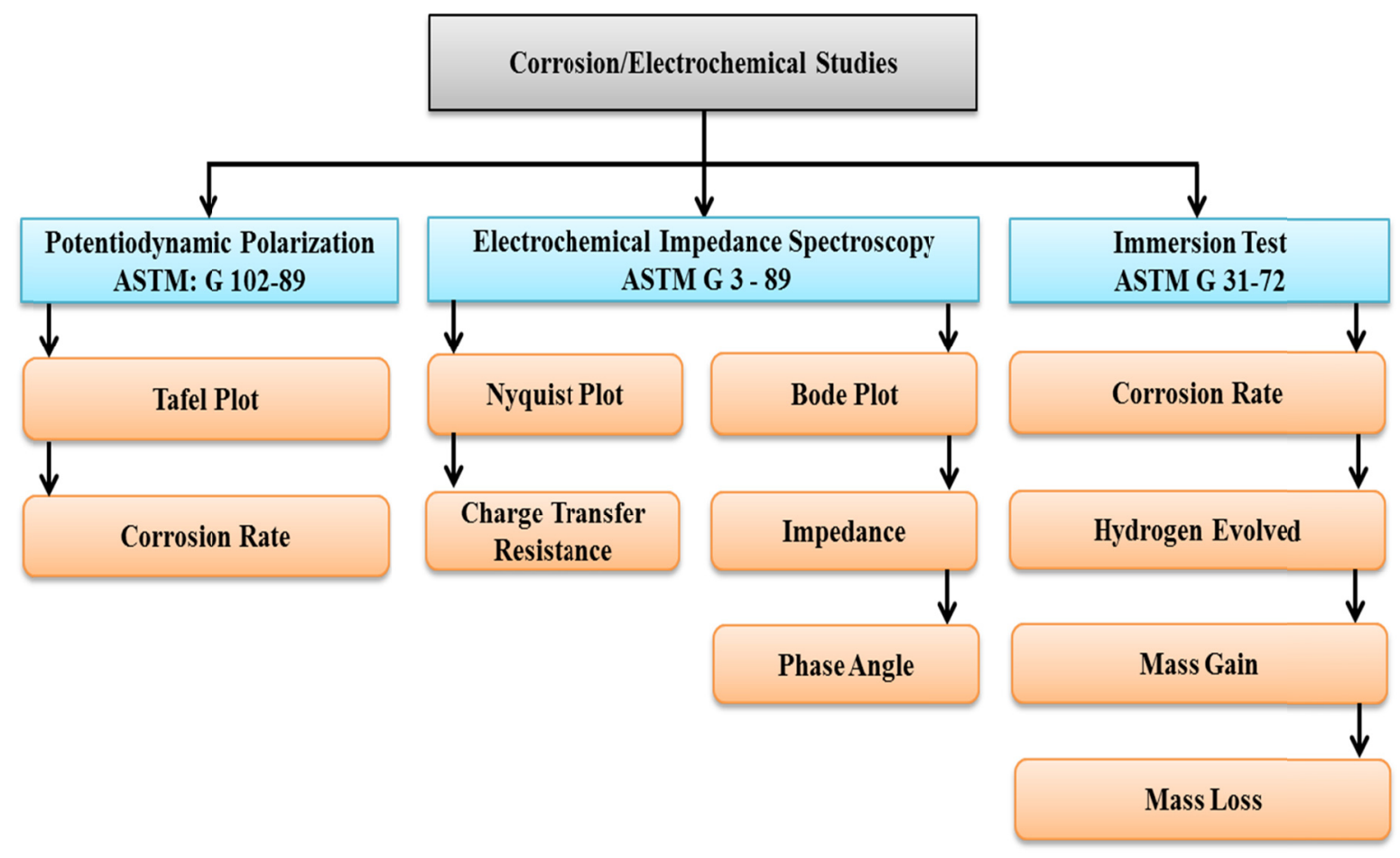

Figure 4.4: Classification of three different techniques used for corrosion studies for magnesium alloys. 


\subsubsection{Electrochemical Test}

A potentiostat is used to study the electrochemical behavior of a material. This is often used to measure the corrosion properties of a given material by maintaining it at a constant potential or by varying it as a function of time with respect to a standard reference electrode. The resulting current between the working electrode and counter electrode serves as a measure of the corrosion rate. A schematic diagram illustrating the connections made during corrosion measurement is shown in Figure 4.5.

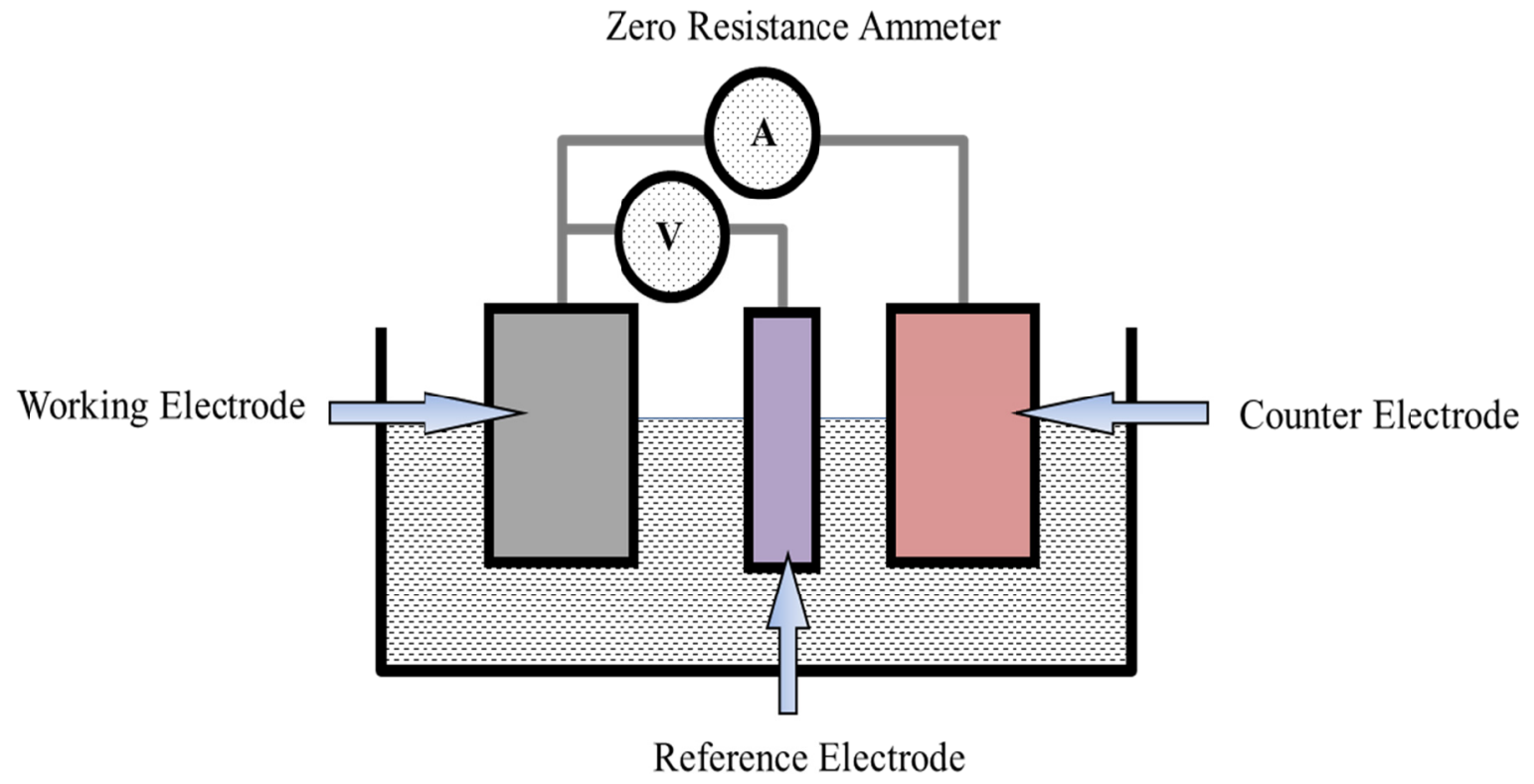

Figure 4.5: Potentiostat corrosion cell arrangement.

A typical three electrode (working, counter and reference) corrosion cell interphased with a potentiostat $\left(G A M R Y^{\circledR}\right)$ was used, in which the implant material (working electrode) is placed in deaerated simulated physiological solution (PBS) and PBS containing amino acids $(\mathrm{PBS}+\mathrm{C}, \mathrm{PBS}+\mathrm{Q}, \mathrm{PBS}+\mathrm{W})$. The potential between the working electrode and the reference electrode (saturated calomel electrode, SCE) is 
increased in the positive direction. The current flowing between the working electrode and the counter electrode (platinum) is measured on a high impedance ammeter. The data is plotted with the current density in $\mathrm{A} / \mathrm{cm}^{2}$ on the $\mathrm{x}$ axis (logarithmic axis) versus the potential in $\mathrm{V}$ on the $\mathrm{y}$ axis (linear axis).

The potentiodynamic polarization tests were performed in accordance with ASTM: G 102-89 [160] and electrochemical impedance spectroscopy (EIS) tests were performed in accordance with ASTM G 3-89 at $37{ }^{\circ} \mathrm{C}$ employing a GAMRY ${ }^{\circledR}$ potentiostat (G-750). Potentiodynamic polarization tests were conducted at a scan rate of $1.0 \mathrm{mV} / \mathrm{s}$. The electrolyte was purged with high purity nitrogen for 30 minutes prior to immersion of the sample, as well as continuously during the corrosion test.

EIS tests were conducted in PBS under high purity nitrogen to determine the effect of alloying elements on the charge transfer resistance and were conducted in the frequency range from $1.0 \mathrm{E}-02 \mathrm{~Hz}$ to $1.0 \mathrm{E}+05 \mathrm{~Hz}$ with 10 points per decade. Figure 4.6 shows schematic representation of the corrosion cell kit used in this investigation. Faraday's law was used to calculate the corrosion rate (CR), in terms of penetration rate of the alloys, determined by:

$$
C R=\frac{I_{c o r r} \cdot K \cdot E W}{\rho \cdot A}
$$

where, $\mathrm{I}_{\text {corr }}$ is the corrosion current (amps), $\mathrm{K}$ is a constant for the corrosion rate (3272 $\mathrm{mm} / \mathrm{amp} . \mathrm{cm}$.year), $\mathrm{EW}$ is the equivalent weight in grams/equivalent, $\mathrm{A}$ is the sample area $\left(0.28 \mathrm{~cm}^{2}\right)$ and $\rho$ is the density $\left(\mathrm{g} / \mathrm{cm}^{3}\right)$ of the alloys calculated by Archimedes principal (see section 5.3). 


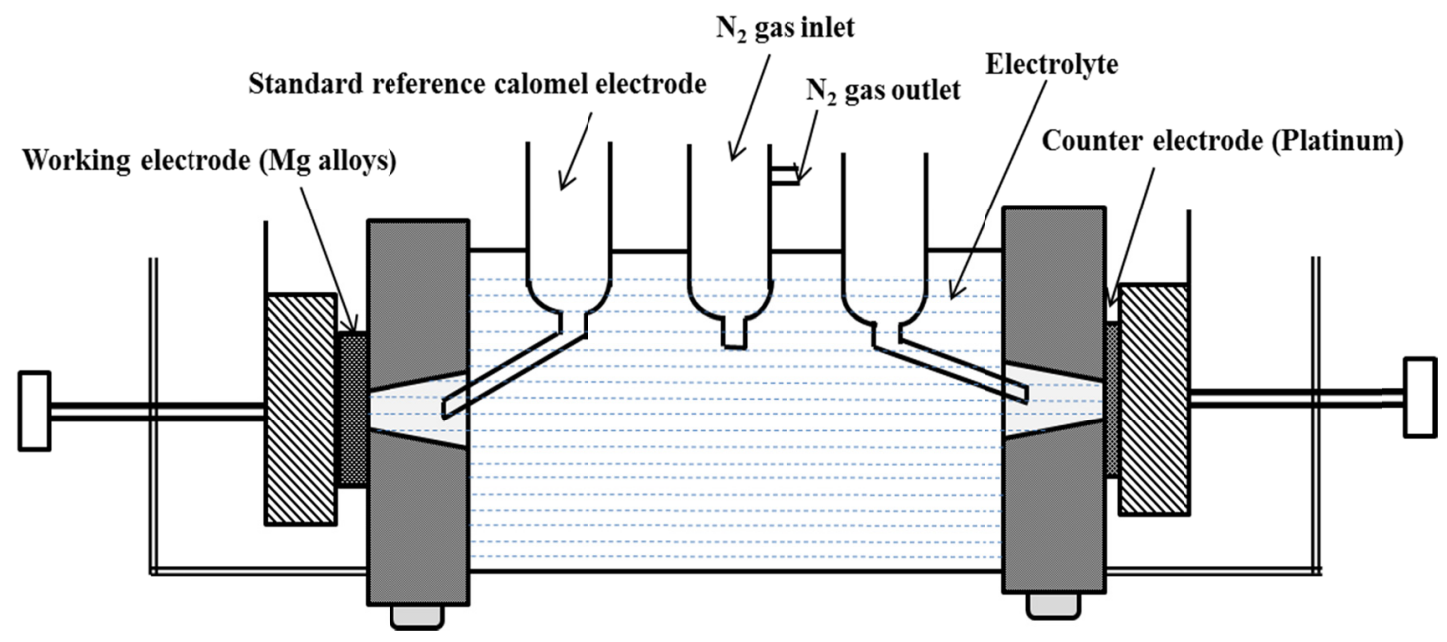

Figure 4.6: MPM custom corrosion cell kit.

\subsubsection{Immersion Test}

Immersion tests were performed in accordance with ASTM G31-72 [161]. Figure

4.7 shows a schematic representation of the immersion test setup, where samples were placed at the bottom of a beaker filled with PBS, with a funnel placed above the sample.

A solution filled measuring cylinder was placed over the funnel to collect and measure the hydrogen gas evolved as the solution was displaced. The samples were soaked in 300 $\mathrm{mL}$ of PBS for 192 hours (8 days) at $37{ }^{\circ} \mathrm{C}$. The hydrogen evolution (per square $\mathrm{cm}$ surface area), weight gain and corrosion rate were evaluated during the experiment by taking the average of three measurements. The volume of test solution was large enough to avoid any appreciable change in its corrosivity during the test, either through exhaustion of corrosive constituents or by accumulation of corrosive products that might 
affect further corrosion [161]. The samples were weighed before and after 24, 48, 72, 96, 120, 144, 168 and 192 hours. For each time interval, the sample was removed from the PBS, rinsed in distilled water, air dried and then weighed. Once the immersion test was completed, the samples were cleaned by immersing in $180 \mathrm{~g} / \mathrm{l}$ of chromic acid for $20 \mathrm{~min}$. The weight gain in grams was calculated as follows [161, 162]:

$$
\text { weight gain }=\frac{\text { weight after immersion }- \text { weight before immersion }}{\text { surface area }}
$$

$$
\text { weight loss }=\frac{\text { weight before immerison }- \text { weight after cleaning }}{\text { surface area }}
$$

The corrosion rates were also calculated from the quantity of hydrogen evolved and weight change during the immersion test. The corrosion rate (CR, mm/year) was calculated as follows:

$$
C R=\frac{t W .10}{\rho A T}
$$

where, $\mathrm{t}$ is a constant $(8760 \mathrm{~h}), \mathrm{W}$ is mass loss, $\mathrm{g}$ (mass before immersion - mass after cleaning)/surface area, $\mathrm{A}$ is the surface area before immersion $\left(\mathrm{cm}^{2}\right), \mathrm{T}$ is the immersion time $(\mathrm{h})$ and $\rho$ is the sample density $\left(\mathrm{g} / \mathrm{cm}^{3}\right)$. 


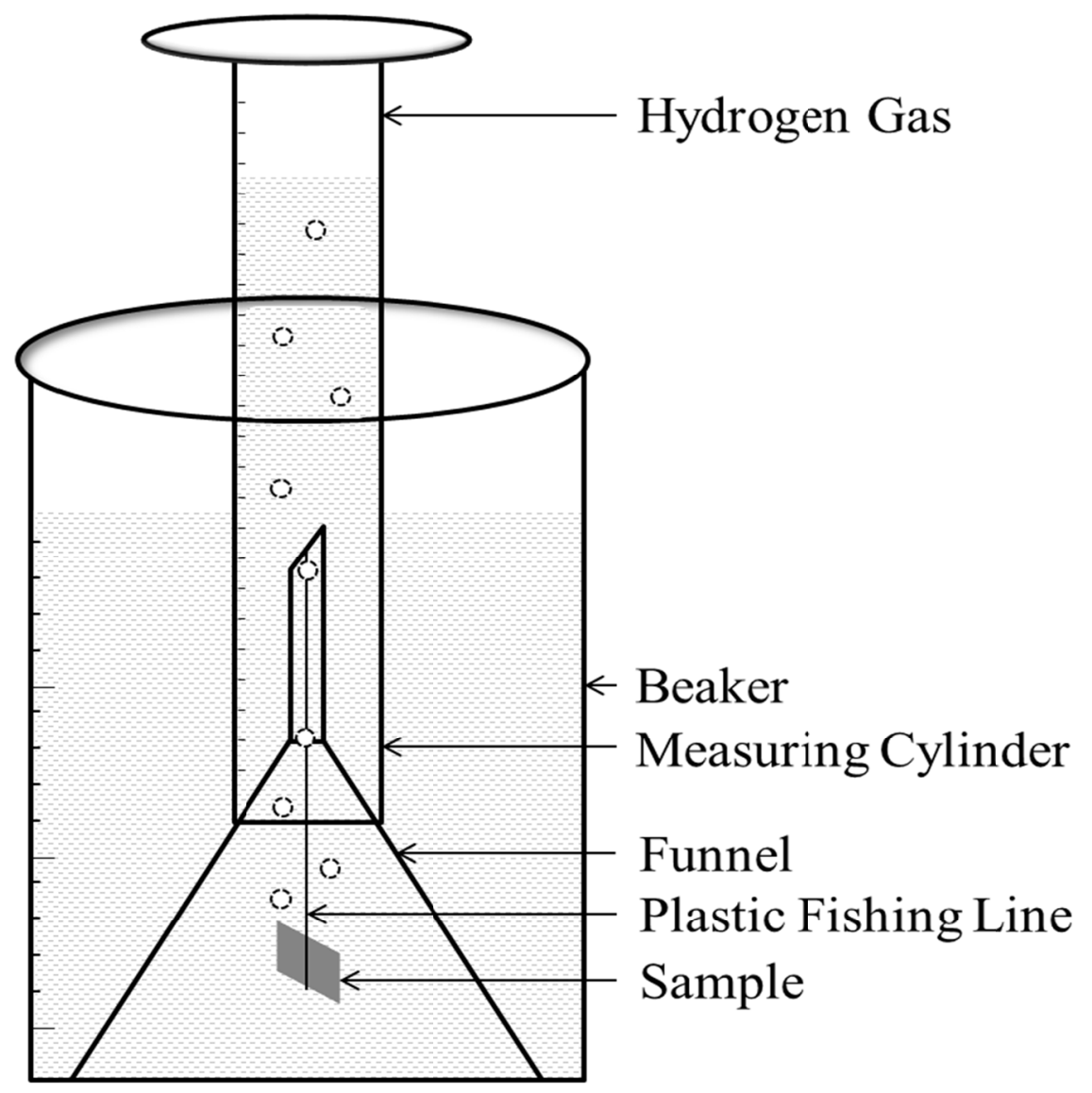

Figure 4.7: Schematic representation of immersion test setup.

\subsection{Corrosion Results and Discussion}

\subsubsection{Potentiodynamic Polarization Test}

Figure 4.8 shows typical potentiodynamic polarization curves for mechanically polished samples. A Tafel fit was employed to analyze the polarization curves, where passivation control occurred between $0.001-0.02 \mathrm{~A} / \mathrm{cm}^{2}$ and corrosion potential ranged between -1.3 to -1.6 . The jagged anodic curves were indicative of continuous breakdown (pitting corrosion) and passivation $[158,163]$. The addition of alloying elements zinc, calcium, hydroxyapatite and gadolinium exhibited improved corrosion resistance and influenced the quantity and distribution of binary and ternary phases. These phases have 
been reported to enhance the corrosion properties of the alloys. The corrosion parameters of the alloys in PBS are shown in Table 4.2.

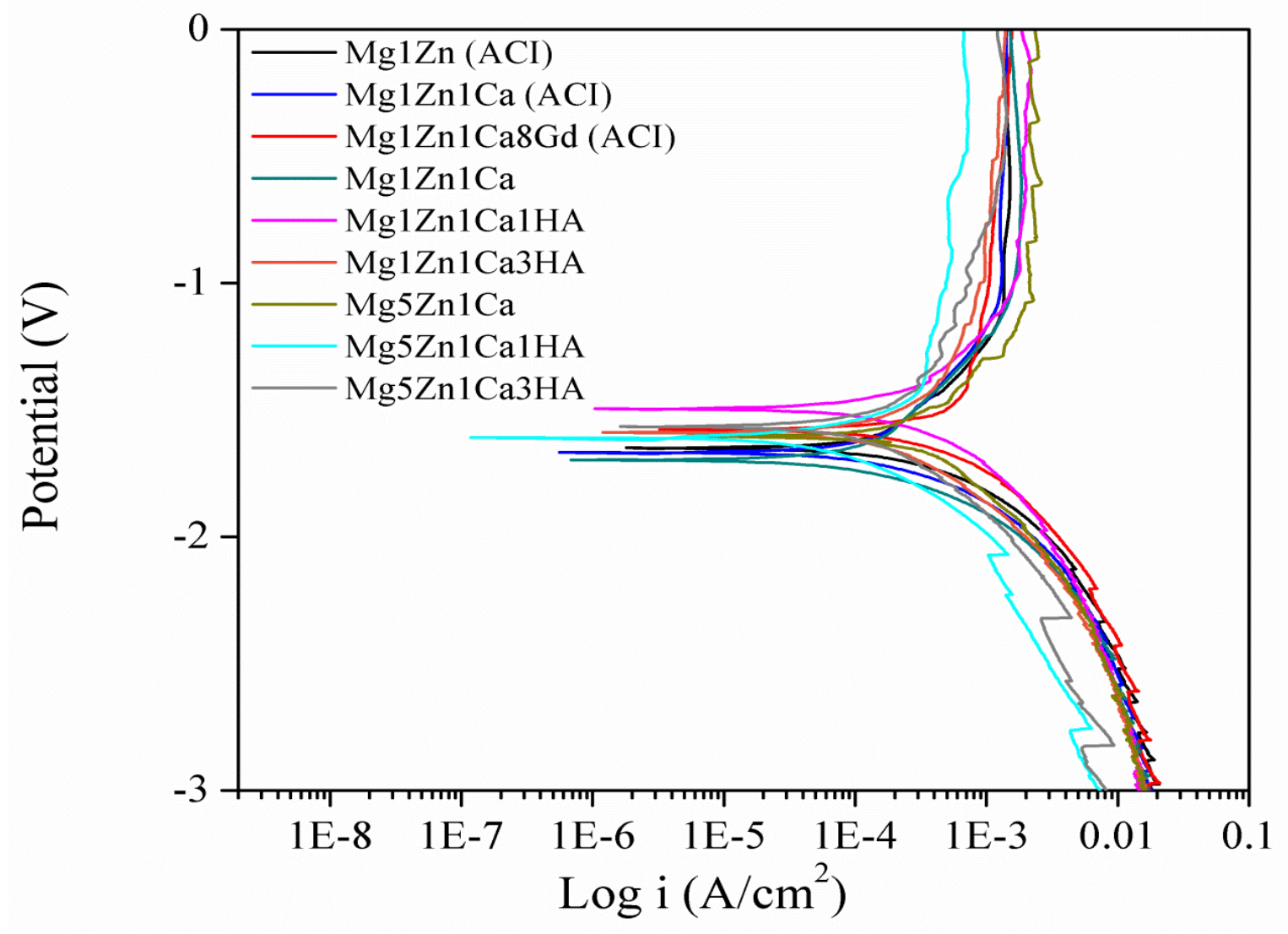

Figure 4.8: Typical potentiodynamic polarization curves of mechanically polished $\mathrm{Mg}$ samples in PBS at $37^{\circ} \mathrm{C}$. 
Table 4.2: Average potentiodynamic polarization data for mechanically polished samples in PBS at $37^{\circ} \mathrm{C}$

\begin{tabular}{|c|c|c|c|}
\hline Samples (MP) & $\mathbf{E}_{\text {corr }}(\mathbf{V})$ & $\mathbf{I}_{\text {corr }}(\boldsymbol{\mu A})$ & Corr Rate $(\mathbf{m m} /$ year) \\
\hline $\mathrm{Mg} 1 \mathrm{Zn}(\mathrm{ACI})$ & -1.43 & 72.35 & 5.90 \\
\hline $\mathrm{Mg} 1 \mathrm{Zn} 1 \mathrm{Ca}(\mathrm{ACI})$ & -1.54 & 159.33 & 12.98 \\
\hline $\mathrm{Mg} 1 \mathrm{Zn} 1 \mathrm{Ca} 8 \mathrm{Gd}(\mathrm{ACI})$ & -1.54 & 283.33 & 23.61 \\
\hline $\mathrm{Mg} 1 \mathrm{Zn} 1 \mathrm{Ca}$ & -1.40 & 26.35 & 2.51 \\
\hline $\mathrm{Mg} 1 \mathrm{Zn} 1 \mathrm{Ca} 1 \mathrm{HA}$ & -1.57 & 256 & 20.86 \\
\hline $\mathrm{Mg} 1 \mathrm{Zn} 1 \mathrm{Ca} 3 \mathrm{HA}$ & -1.38 & 213 & 17.41 \\
\hline $\mathrm{Mg} 5 \mathrm{Zn} 1 \mathrm{Ca}$ & -1.40 & 133.05 & 10.9 \\
\hline $\mathrm{Mg} 5 \mathrm{Zn} 1 \mathrm{Ca} 1 \mathrm{HA}$ & -1.55 & 27.02 & 2.2 \\
\hline $\mathrm{Mg} 5 \mathrm{Zn} 1 \mathrm{Ca} 3 \mathrm{HA}$ & -1.49 & 169.05 & 13.78 \\
\hline
\end{tabular}

The effect of amino acids on degradation behavior of Mg alloys was also studied at $37{ }^{\circ} \mathrm{C}$ by employing concentrations of amino acids typically found in the human blood $(\mathrm{C}=0.25 \mathrm{mM} ; \mathrm{Q}=0.568 \mathrm{mM}$ and $\mathrm{W}=0.042 \mathrm{mM})$. The corrosion parameters of the samples in PBS and PBS with amino acids are shown in Table 4.3 (polarization curves, Figure 4.9). Mg1Zn had the lowest corrosion rate in PBS (5.90 mm/year) and exhibited the highest corrosion rate in PBS+Q $(66.65 \mathrm{~mm} /$ year). A similar trend was observed with the remainder of the alloys, where the corrosion rate increased in PBS with amino acids. Pound (2010) reported that amino acids in PBS increased the pitting susceptibility of Nitinol alloys [164], and attributed it to the acid-base/polarity nature of amino acids. Also, with titanium alloys, it was reported that amino acids are readily adsorbed onto the surface of $\mathrm{TiO}_{2}$ via their carboxyl groups by replacing the basic hydroxyl group on a $\mathrm{Ti}$ site $[10,158,165]$.

The ions released from implant materials into the human body are influenced by their composition as well as the environment into which they are placed. Amino acids are 
essential building blocks in an immense array of macromolecules present in most organisms including blood; the general structure is $\mathrm{R}-\mathrm{CH}\left(\mathrm{NH}_{2}\right)-\mathrm{COOH}[104,158]$. Amino acids have a zwitterionic or ampholyte character, which are important for the adsorption process. The susceptibility to corrosion of Mg alloys can be influenced by the presence of amino acids. However, the change in susceptibility is dependent on the type of amino acid. Amino acids exhibit either acid-base/polar or non-polar properties. For example, cysteine, C (neutral/slightly polar), glutamine, Q (neutral/polar) and tryptophan, W (neutral/slightly polar).

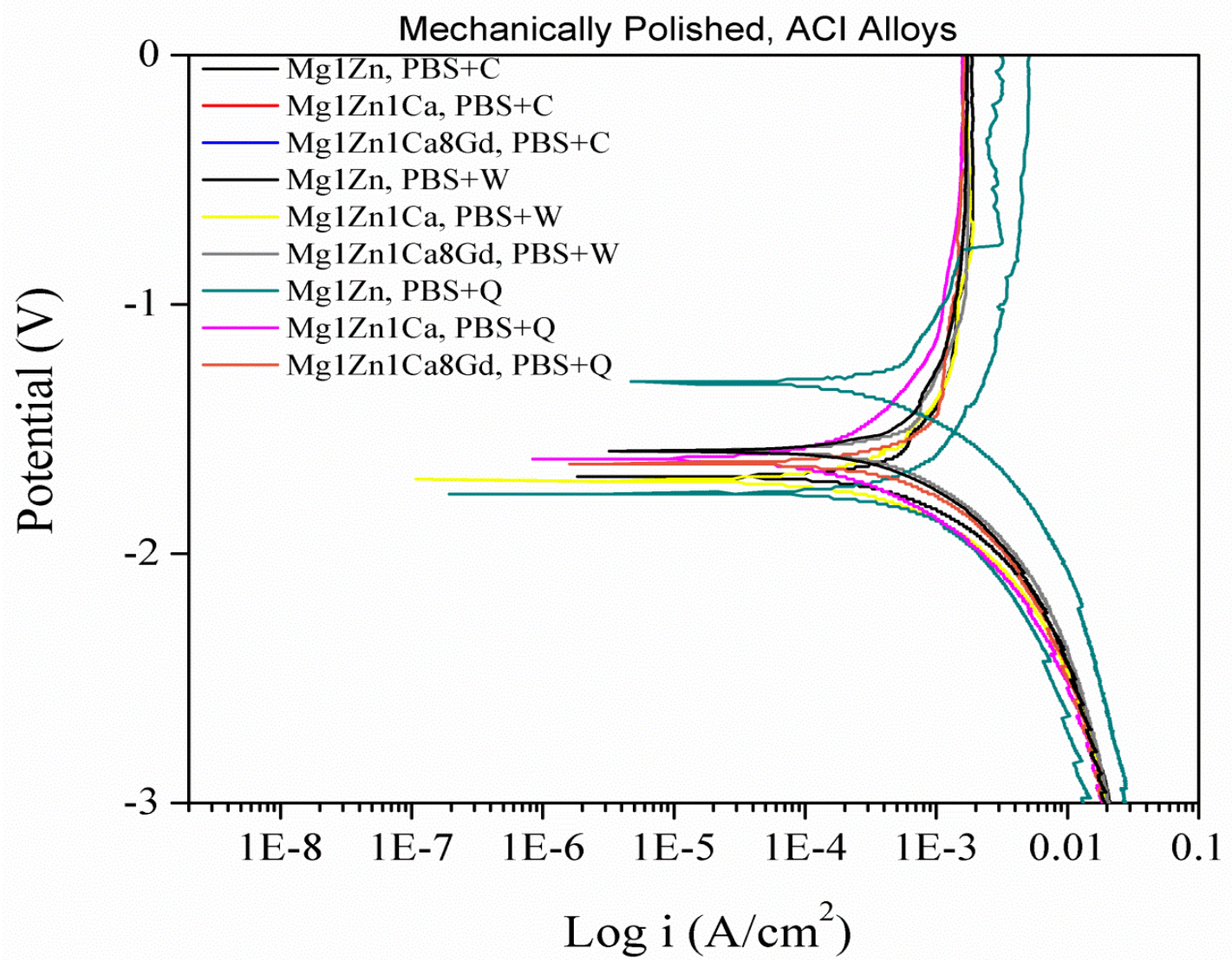

Figure 4.9: Typical potentiodynamic polarization curves of mechanically polished $\mathrm{Mg}$ alloys in PBS containing amino acids at $37^{\circ} \mathrm{C}$. 
Table 4.3: Average potentiodynamic polarization data from three test values in PBS and PBS containing amino acids

\begin{tabular}{|l|c|c|c|}
\hline Samples, MP & Ecorr (V) & Icorr $(\boldsymbol{\mu A})$ & Corr Rate (mm/year) \\
\hline Mg1Zn, PBS & -1.43 & 72.35 & 5.90 \\
\hline Mg1Zn, PBS+C & -1.68 & 648.0 & 52.91 \\
\hline Mg1Zn, PBS+Q & -1.66 & 816.0 & 66.65 \\
\hline Mg1Zn, PBS+W & -1.73 & 416.5 & 34.02 \\
\hline Mg1Zn1Ca, PBS & -1.54 & 159.3 & 12.98 \\
\hline Mg1Zn1Ca, PBS+C & -1.71 & 335.5 & 27.33 \\
\hline Mg1Zn1Ca, PBS+Q & -1.61 & 538.5 & 43.87 \\
\hline Mg1Zn1Ca, PBS+W & -1.65 & 391.5 & 31.915 \\
\hline Mg1Zn1Ca8Gd, PBS & -1.54 & 283.3 & 23.61 \\
\hline Mg1Zn1Ca8Gd, PBS+C & -1.61 & 1345.5 & 141.80 \\
\hline Mg1Zn1Ca8Gd, PBS+Q & -1.59 & 538.5 & 44.82 \\
\hline Mg1Zn1Ca8Gd, PBS+W & -1.63 & 756.5 & 62.10 \\
\hline
\end{tabular}

In order to decrease the corrosion rates and to increase the initial stability, the alloys were anodized, during which an oxide layer (magnesium oxides/hydroxides) develops on the surface of the alloy forming a passivating film of approximately 4-6 $\mu \mathrm{m}$ thick. Ling-Ling et al. (2008) investigated anodized AZ91 magnesium alloy and reported an increase in corrosion resistance due to the anodic film, which increased with an 
optimal treatment time of 40 minutes [166]. The anodized coating is relatively harder than other conversion coatings or fluoridated coatings which imparts high wear resistances. Furthermore, anodized surfaces are porous (similar to the bone microstructure) [114]. Another attractive feature of anodized coatings is that they can offer very effective protection to before the surgery region has healed. Subsequent degradation enables the implant to dissolve gradually [114]. Figure 4.10 shows the potentiodynamic polarization curves of anodized Mg alloys. The corrosion parameters obtained from Tafel interpolation are shown in Table 4.4.

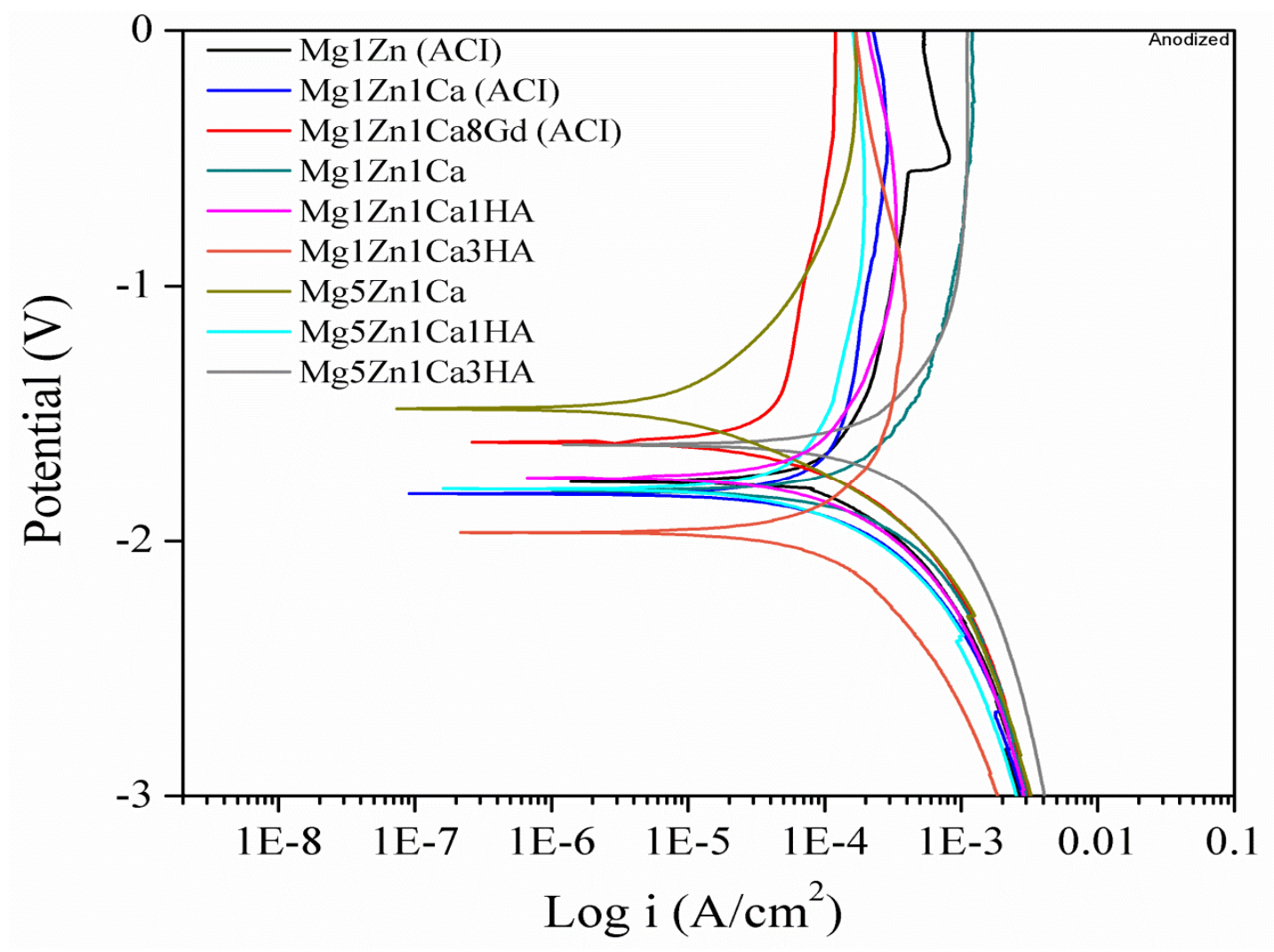

Figure 4.10: Typical potentiodynamic polarization curves of anodized Mg samples in PBS at $37^{\circ} \mathrm{C}$. 
Table 4.4: Average potentiodynamic polarization data for anodized samples in PBS at 37 ${ }^{\circ} \mathrm{C}$

\begin{tabular}{|c|c|c|c|}
\hline Anodized Samples & $\mathbf{E}_{\text {corr }}(\mathbf{V})$ & $\mathbf{I}_{\mathbf{c o r r}}(\boldsymbol{\mu A})$ & Corr Rate (mm/year) \\
\hline $\mathrm{Mg} 1 \mathrm{Zn}(\mathrm{ACI})$ & -1.770 & 84.20 & 3.85 \\
\hline $\mathrm{Mg} 1 \mathrm{Zn} 1 \mathrm{Ca}(\mathrm{ACI})$ & -1.820 & 58.60 & 2.68 \\
\hline $\mathrm{Mg} 1 \mathrm{Zn} 1 \mathrm{Ca} 8 \mathrm{Gd}(\mathrm{ACI})$ & -1.610 & 17.00 & 0.79 \\
\hline $\mathrm{Mg} 1 \mathrm{Zn} 1 \mathrm{Ca}$ & -1.800 & 167.0 & 7.61 \\
\hline $\mathrm{Mg} 1 \mathrm{Zn} 1 \mathrm{Ca} 1 \mathrm{HA}$ & -1.750 & 38.40 & 1.76 \\
\hline $\mathrm{Mg} 1 \mathrm{Zn} 1 \mathrm{Ca} 3 \mathrm{HA}$ & -1.970 & 83.60 & 3.82 \\
\hline $\mathrm{Mg} 5 \mathrm{Zn} 1 \mathrm{Ca}$ & -1.480 & 3.800 & 0.17 \\
\hline $\mathrm{Mg} 5 \mathrm{Zn} 1 \mathrm{Ca} 1 \mathrm{HA}$ & -1.800 & 30.00 & 1.65 \\
\hline $\mathrm{Mg} 5 \mathrm{Zn} 1 \mathrm{Ca3HA}$ & -1.62 & 555.0 & 24.64 \\
\hline
\end{tabular}

In order to illustrate the effect of anodizing on corrosion rates determined by potentiodynamic polarization, a histogram of the corrosion rates of both mechanically polished and anodized samples are shown in Figure 4.11. The corrosion rate of most of the alloys decreased drastically with anodization. $\mathrm{Mg} 5 \mathrm{Zn} 1 \mathrm{Ca} 3 \mathrm{HA}$ and $\mathrm{Mg} 1 \mathrm{Zn}$ displayed an increase in corrosion rate after anodizing; this can be attributed to the type of passivation layer generated. As was previously discussed in section 4.3, the addition of a lighter metal such as $\mathrm{Ca}$ produces porous oxides, which allow the electrolyte to come into contact with the metal as exhibited with $\mathrm{Mg} 1 \mathrm{Zn} 1 \mathrm{Ca}$ and $\mathrm{Mg} 5 \mathrm{Zn} 1 \mathrm{Ca} 3 \mathrm{HA}$. In the case of $\operatorname{Mg} 1 \mathrm{Zn} 1 \mathrm{Ca}$, the increase in corrosion rate with anodization was due to a different manufacturing process and heat treatment. 


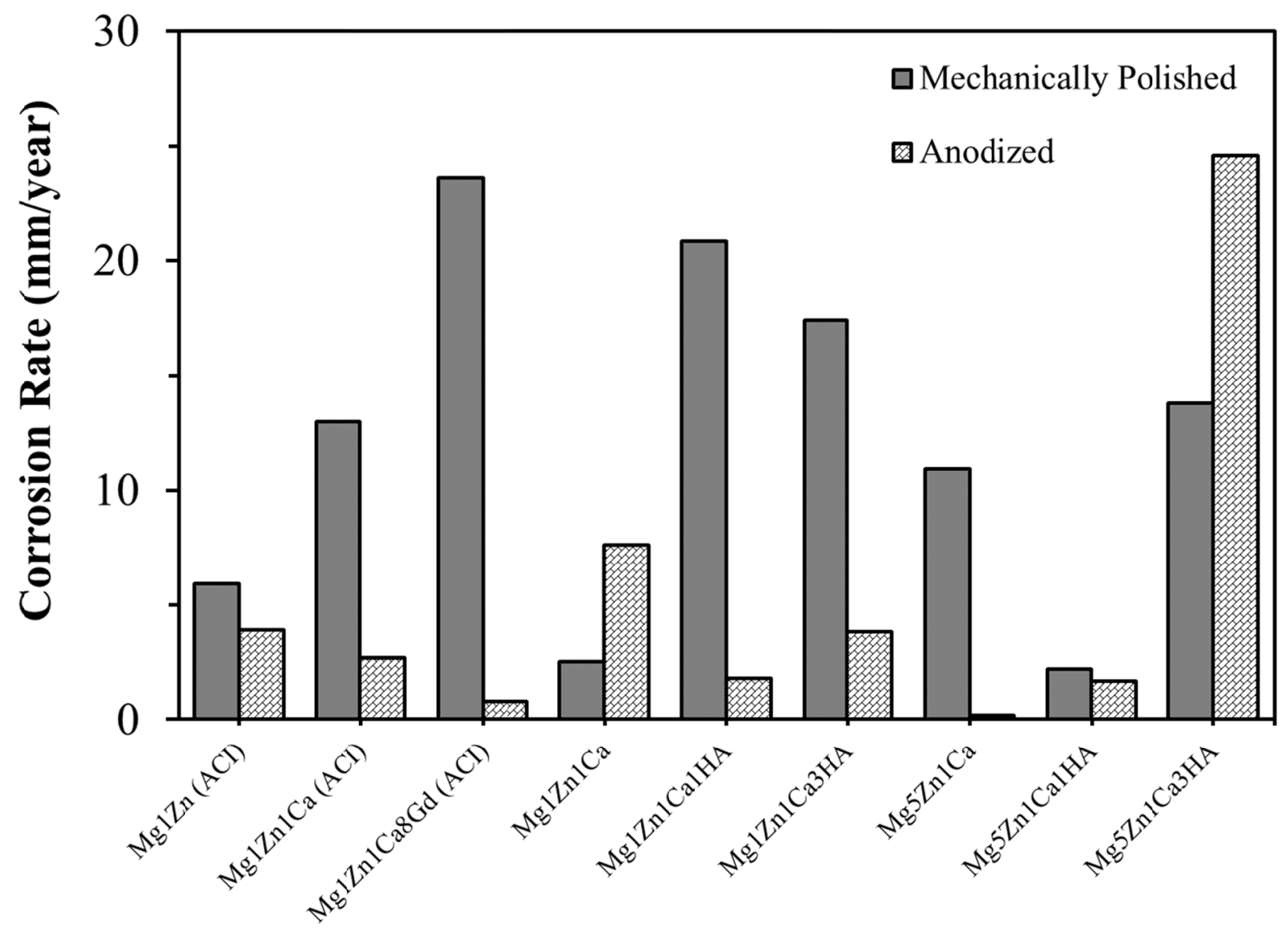

Figure 4.11: Comparison of corrosion rates between mechanically polished and anodized samples.

\subsubsection{Electrochemical Impedance Spectroscopy (EIS)}

The interphase between liquid and solid media can be described in terms of an electrical circuit with resistors and capacitors. Figure 4.12 shows the Randles equivalent circuit, where $R_{s}$ is the electrolyte resistance; $R_{c t}$ is the charge transfer resistance and $C_{d l}$ is the capacitance double layer. Figure 4.13 shows the Nyquist plots for mechanically polished alloys in PBS. The impedance of MgZn increased with the addition of $\mathrm{Ca}, \mathrm{Gd}$ and hydroxyapatite. This could be attributed to the formation of various oxides, which act as an electric barrier. In the case of biodegradable alloys, an initial slower corrosion rate followed by uniform degradation are desirable. $\mathrm{Mg} 5 \mathrm{Zn} 1 \mathrm{Ca}, \mathrm{Mg} 5 \mathrm{Zn} 1 \mathrm{Ca} 3 \mathrm{HA}$ and 
$\mathrm{Mg} 1 \mathrm{Zn} 1 \mathrm{Ca}(\mathrm{ACI})$ exhibited higher charge transfer resistance $\left(\mathrm{R}_{\mathrm{ct}}\right)$ as compared with the rest of the samples, which ranged between $2300-6500 \mathrm{ohm} . \mathrm{Mg} 1 \mathrm{Zn} 1 \mathrm{Ca} 8 \mathrm{Gd}$ exhibited a double loop of the Nyquist plot is indicative of oxide layer (the first loops are indicative of the open pore resistance of the oxide layers), which could be due to the formation of multiple oxides on the surface (mainly heavy metal oxides). The capacitive arc provides an estimate of corrosion resistance of the material, in terms of its relative diameter, which is directly proportional to the charge transfer resistance $\left(\mathrm{R}_{\mathrm{ct}}\right)$. Thus, an increase in semicircle diameter corresponds to an increase in corrosion resistance. Each mechanically polished sample displayed an inductive loop at low frequencies, which signified that the samples were susceptible to pitting corrosion. It should be noted that no second capacitive loop was observed. This occurs when $\mathrm{Cl}^{-}$ions diffuse through a breach in the passivating layer, resulting in the formation of hydrolyzed metal chlorides. Pitting corrosion can deteriorate the properties of an implant, as would the presence of various organic components in the physiological solution. Additionally, an increase in concentration of dissolved ions compresses the electrical double layer, which increases the zeta potential [194].

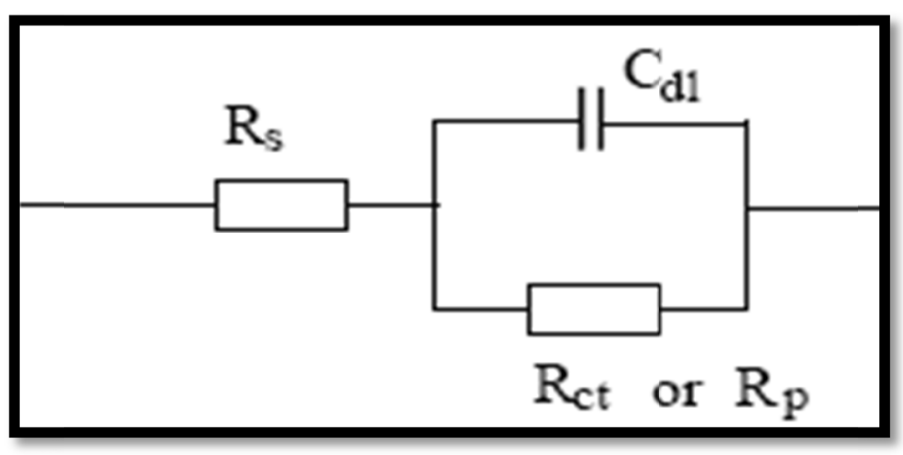

Figure 4.12: Equivalent circuit of the corrosion cell: $R_{s}=$ electrolyte resistance, $R_{c t}=$ charge transfer resistance and $C_{d l}=$ capacitance double layer [195]. 


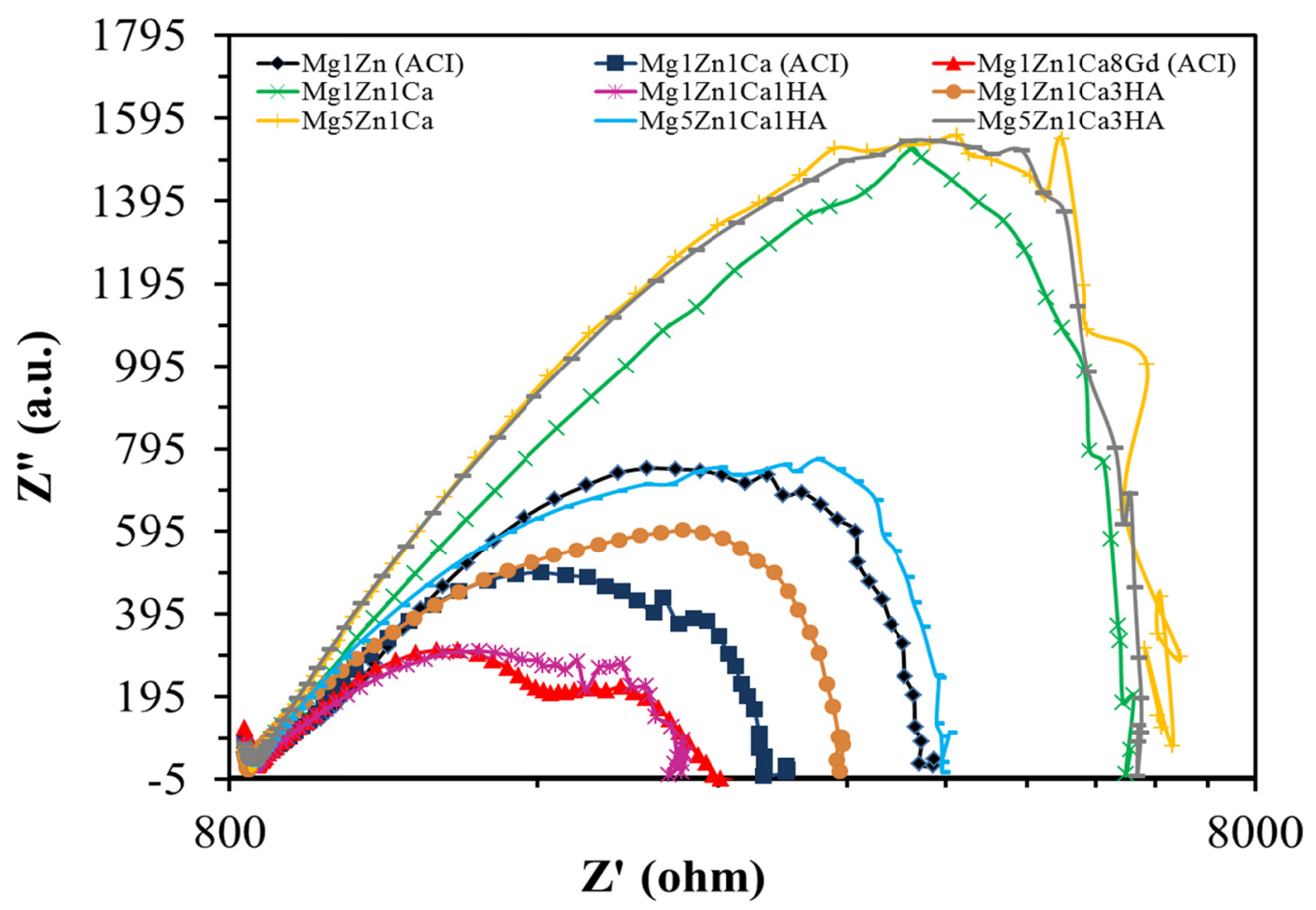

Figure 4.13: Nyquist plots (log-log representation) for mechanically polished samples in PBS at $37^{\circ} \mathrm{C}$.

The bode plots for mechanically polished $\mathrm{Mg}$ alloys in $\mathrm{PBS}$ at $37{ }^{\circ} \mathrm{C}$ are illustrated in Figure 4.14. The degree of phase shift is a function of the type and proportion of oxides produced on the surface of the alloy. The phase shift at a frequency of $\sim 80 \mathrm{~Hz}$, is most likely due to an increase in surface film capacitance, which is dependent on the oxide layers produced on the surface. The symmetry of the Bode plot is an indication of the uniformity of the surface oxide coverage. The magnitude of the phase shift is a measure of the resistance to corrosion (impedance). When the loop is depressed and shifts towards a high frequency, this is associated with adsorption and desorption phenomena occurring on the surface of the samples. Mg1Zn1Ca8Gd and Mg1Zn1Ca1HA showed a phase shift towards higher frequency of $\sim 100 \mathrm{~Hz}$, which is due to the adsorption phenomenon. For example, deposition of a layer of corrosion products and salt 
deposits from the solution could reduce the degradation rate of the alloy and impart longterm stability in a biological environment.

Impedance is defined as the ratio of the voltage phasor to the electric current phasor. Increase in concentration of ions in solution decrease impedance modulus value, which will compress the double layer as shown in Figure 4.15. Figure 4.16 shows the impedance modulus loop, where the low frequency domain represents the system resistance, which mainly depends on polarization resistance of the passivating film and double layer capacitance of the electrode and the high frequency domain represents the solution resistance $\left(\mathrm{R}_{\mathrm{s}}\right)$.

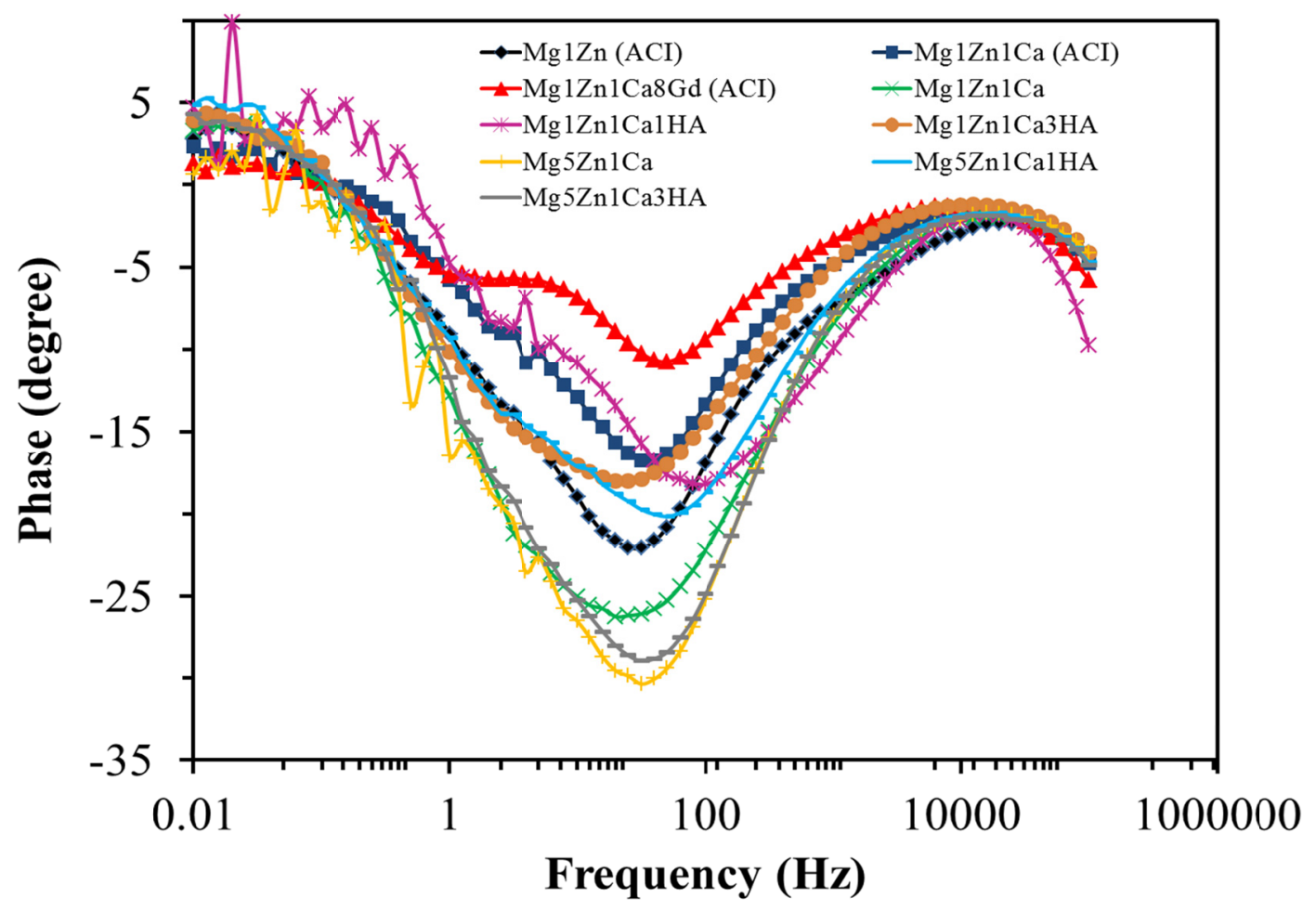

Figure 4.14: Bode plot (phase Vs frequency) for mechanically polished alloys in PBS at $37^{\circ} \mathrm{C}$. 


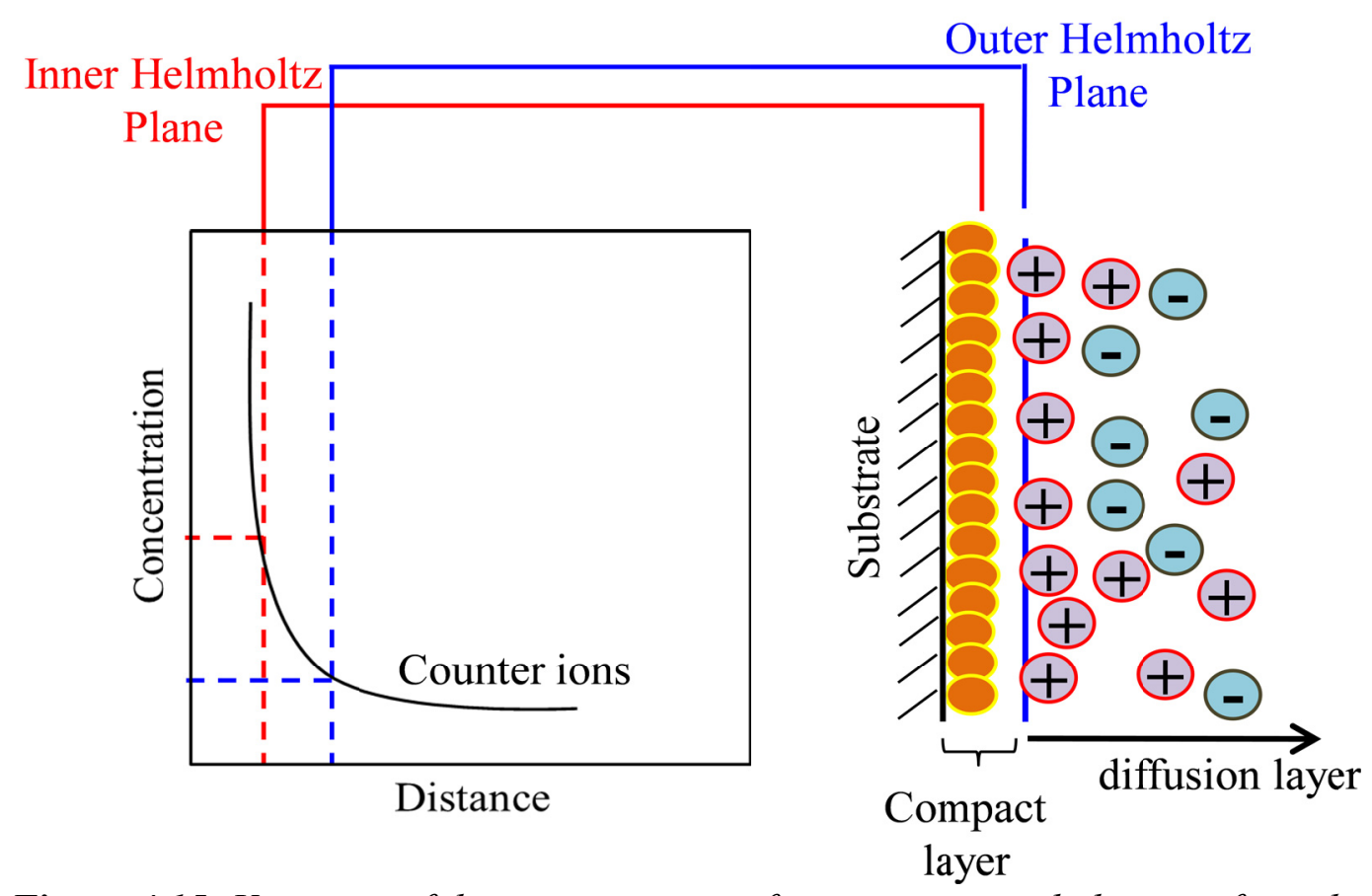

Figure 4.15: Variation of the concentration of counter ions with distance from the surface.

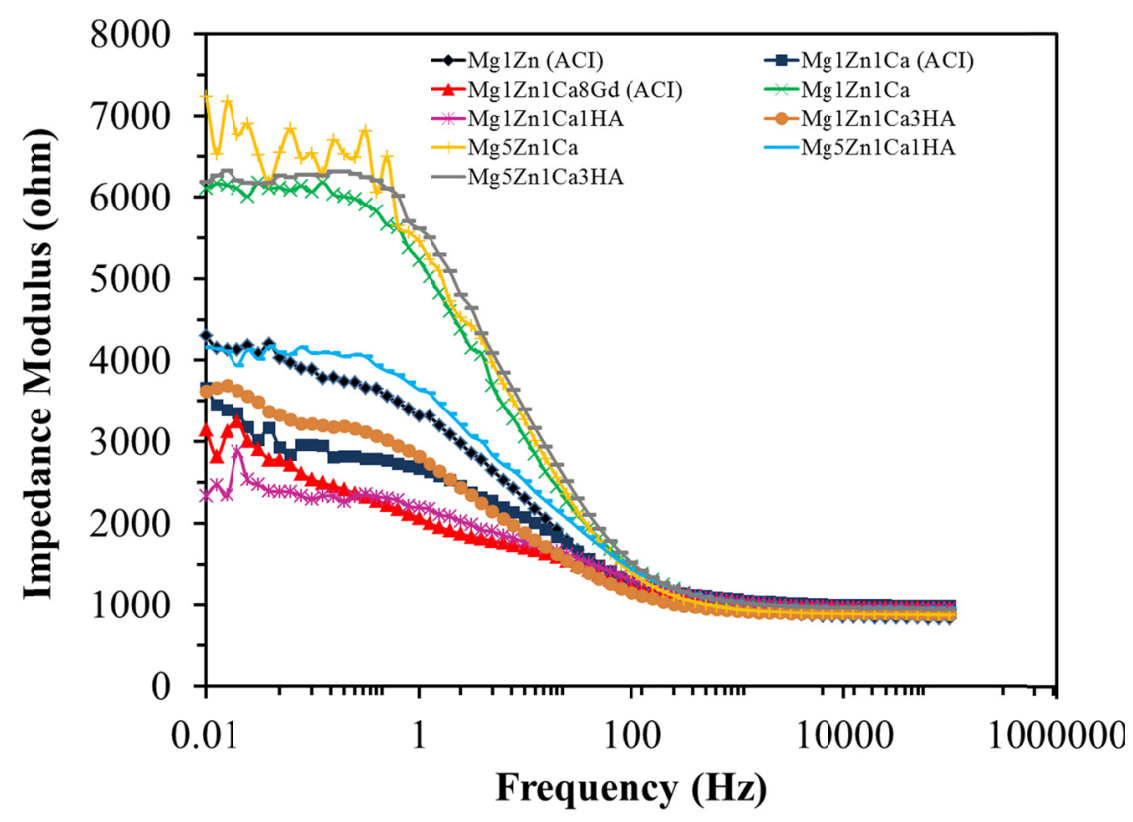

Figure 4.16: Bode plot (impedance modulus Vs frequency) for mechanically polished alloys in PBS at $37^{\circ} \mathrm{C}$.

The equivalent circuit for anodized Mg samples is shown in Figure 4.17, where $\mathrm{R}_{\mathrm{s}}$, is the electrolyte resistance; $\mathrm{R}_{\mathrm{ct}}$, is the charge transfer resistance; $\mathrm{C}_{\mathrm{dl}}$, capacitance 
double layer; $\mathrm{C}_{\mathrm{c}}$, capacitance of intact coating; and $\mathrm{R}_{\mathrm{po}}$, pore resistance (resistance of ions conducting paths developed in the coating) [195]. Figure 4.18 shows the Nyquist plots for anodized samples, where an inductive loop and capacitance double loop (non-hydrogen evolving behavior) were observed. The first capacitive loop represents the pore resistance and the second loop shows the development of new surface conditions. This may be ascribed to the formation of various oxides, which act as an electric barrier and imparts initial stability to Mg alloys. The double loop of the Nyquist plots are indicative of oxide layers (the first loop are indicative of the open pore resistance of the oxide layers). It should be noted that, in the case of anodized Mg samples, every alloy exhibited a double loop, whereas, for mechanically polished alloys only Mg1Zn1Ca8Gd exhibited a double loop.

In the case of implanted biodegradable Mg alloys, cell adherence prior to material degradation is highly desirable. Thus, anodization of the alloy implant imparts initial corrosion resistance and mechanical integrity after implantation and ensures sufficient time for the surgical region to heal. Song (2007) reported in the event of failure or breakdown of the anodized coating, the degradation products are non-toxic to the human body and that degradation mainly occurs at the damaged area [167]. Shi et al. (2006) reported the initial occurrence of pitting corrosion on anodized specimens followed by filiform corrosion or general corrosion [130]. Figure 4.19 shows the schematic representation of the factors affecting the filiform corrosion. 


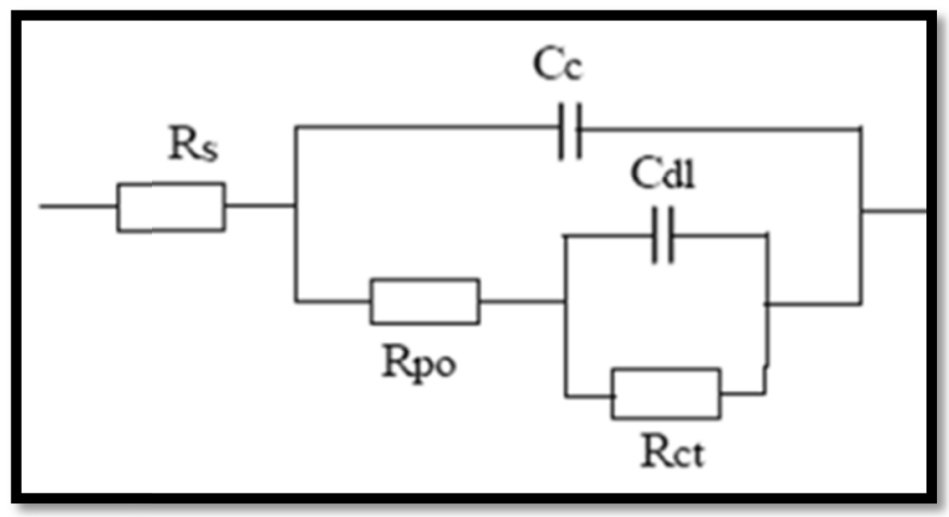

Figure 4.17: Equivalent circuit for filmed corrosion surfaces [195].

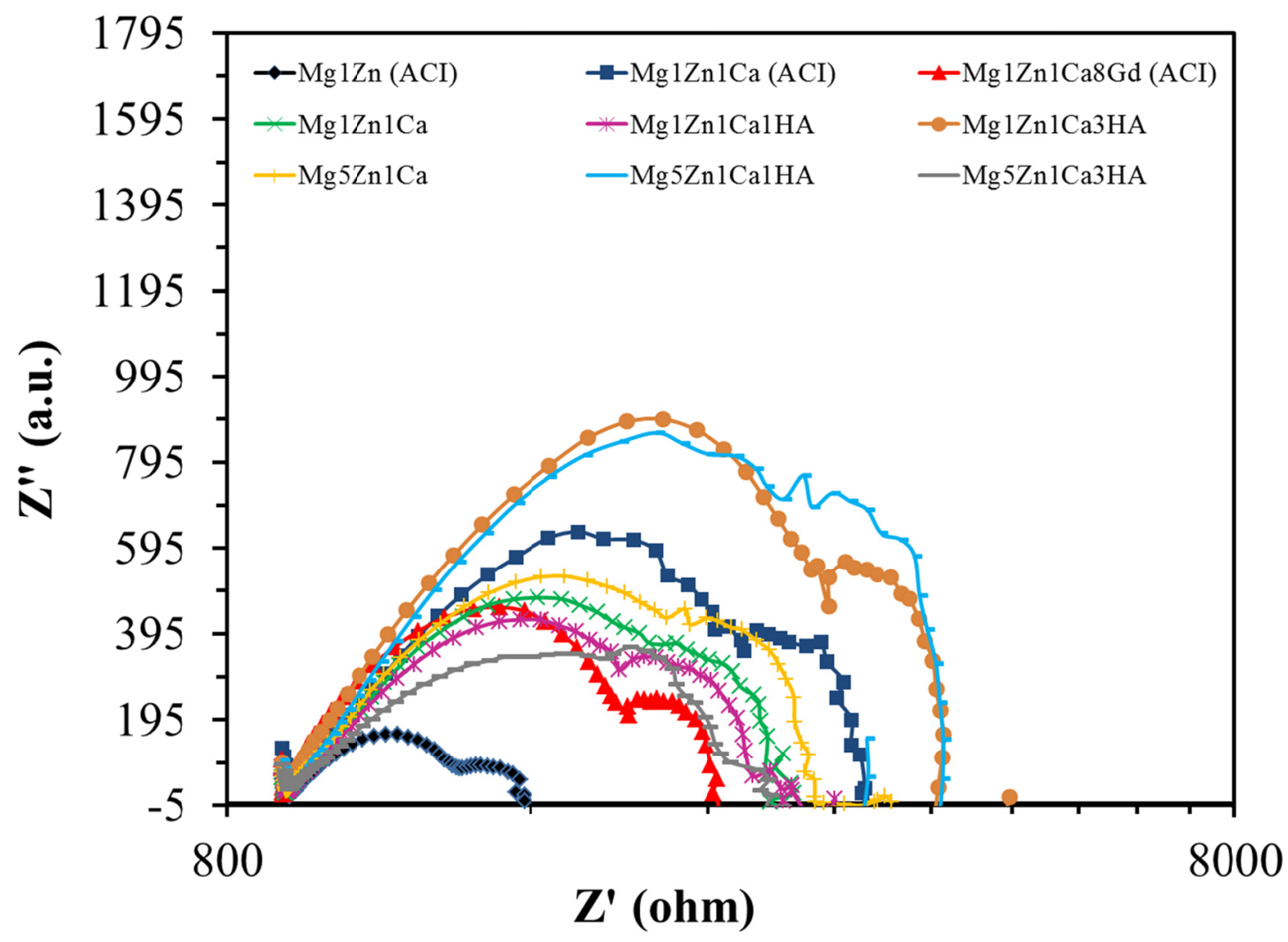

Figure 4.18: Nyquist plots (log-log representation) for anodized samples in PBS at 37 ${ }^{\circ} \mathrm{C}$. 


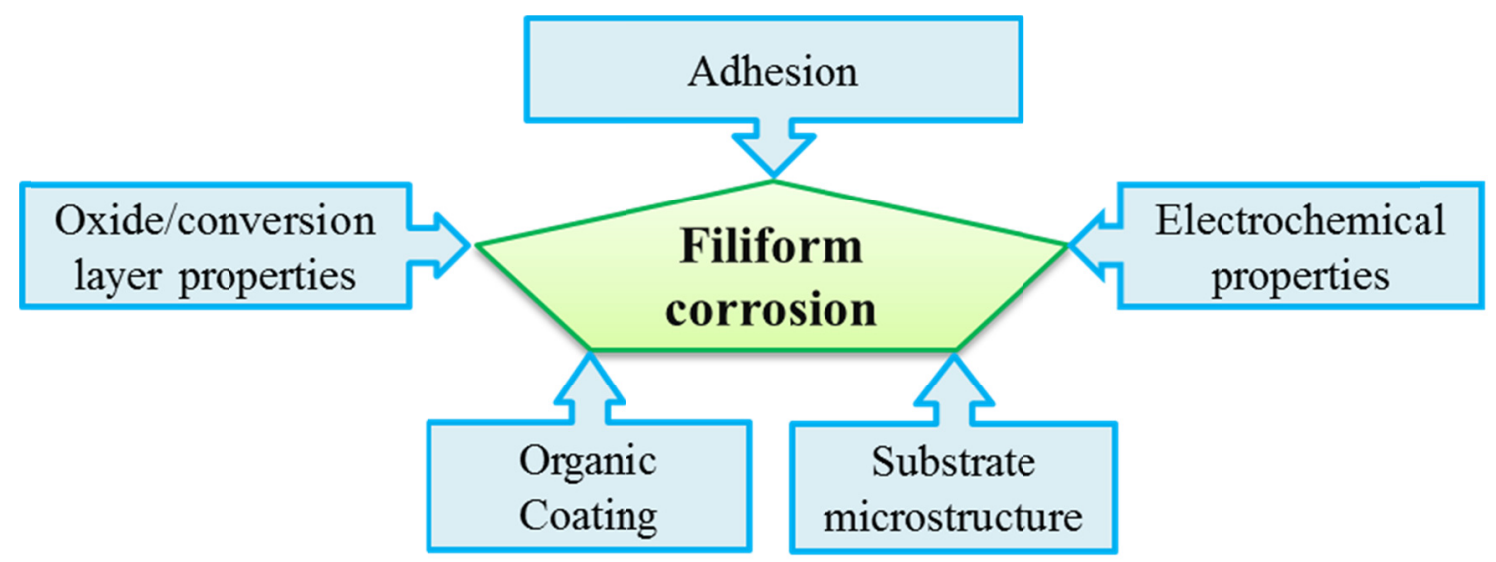

Figure 4.19: Schematic demonstrating the factors influencing the filiform corrosion [125].

Bode plots for anodized $\mathrm{Mg}$ alloys in PBS at $37{ }^{\circ} \mathrm{C}$ are illustrated in Figure 4.20 and Figure 4.21. The degree of phase shift is a function of the type and proportion of oxides produced on the surface of the alloys. The anodized alloys exhibited phase shift at a frequency of $\sim 100 \mathrm{~Hz}$, as a result of surface passivation. All the samples displayed phase shift towards higher frequency as compared with mechanically polished alloys. The samples $\mathrm{Mg} 1 \mathrm{Zn} 1 \mathrm{Ca} 3 \mathrm{HA}$ and $\mathrm{Mg} 5 \mathrm{Zn} 1 \mathrm{Ca} 1 \mathrm{HA}$ showed the highest phase shift, whereas $\operatorname{Mg} 1 \mathrm{Zn}$ displayed the lowest. In the case of the latter, the phase shift increased with the addition of $\mathrm{Ca}, \mathrm{Gd}$ and hydroxyapatite. This could be attributed to the formation of various oxides, which act as a diffusion barrier.

Figure 4.21 also shows the impedance modulus of the anodized Mg alloys, where the low frequency loop corresponds to charge transfer resistance and double layer capacitance of the electrode, whereas the high frequency region of the curve corresponds to the solution resistance. The impedance plot for anodized samples showed less scatter as compared with that of mechanically polished alloys, which is due to strong passivation 
for anodized samples. Additionally, the effect of alloying can clearly be seen, where $\mathrm{Mg} 1 \mathrm{Zn}$ had the lowest modulus as compared with MgZnCa samples.

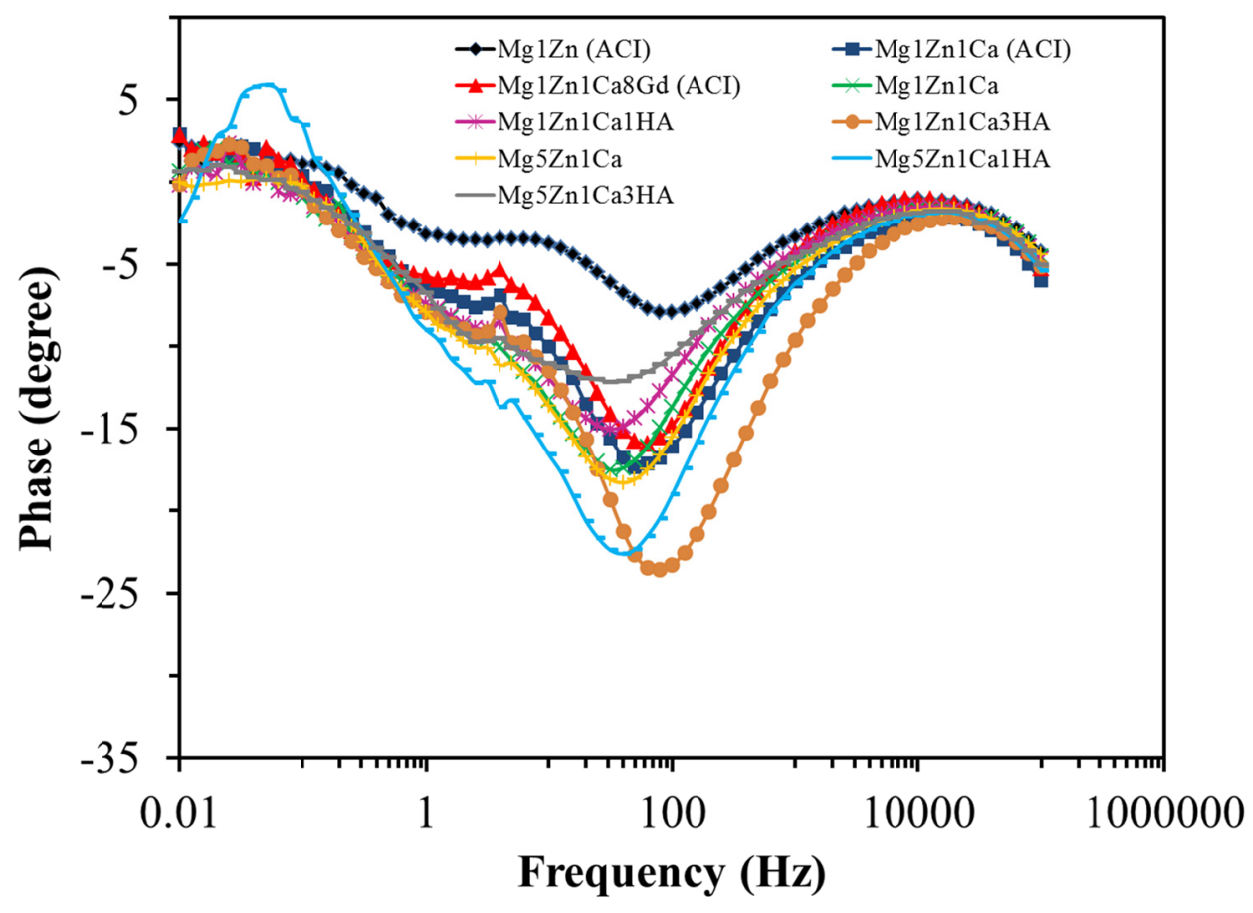

Figure 4.20: Bode plot (phase Vs frequency) for anodized samples in $P B S$ at $37^{\circ} \mathrm{C}$. 


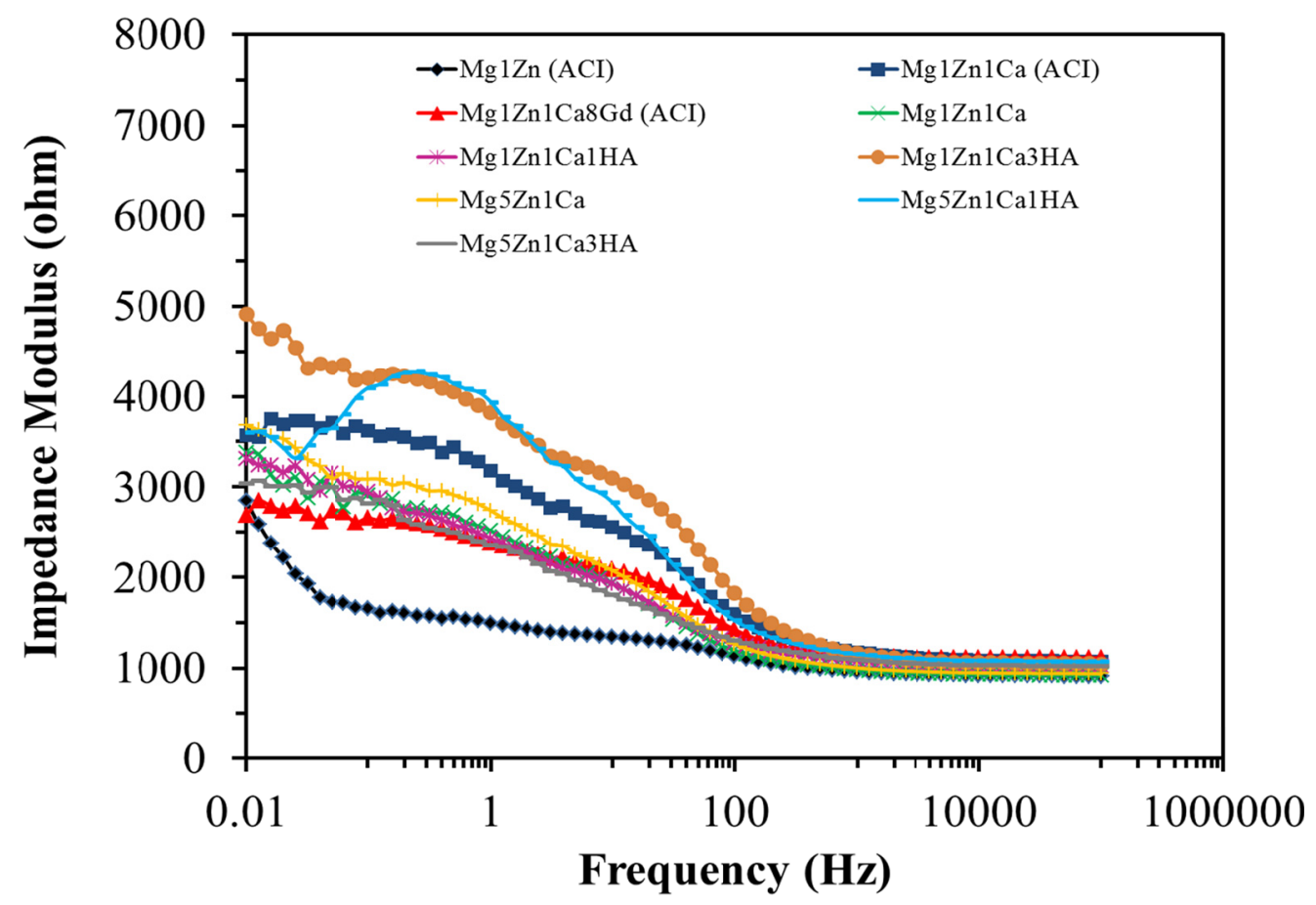

Figure 4.21: Bode plots (impedance modulus Vs frequency) for anodized alloys in PBS at $37^{\circ} \mathrm{C}$.

\subsubsection{Static Immersion Test}

Zberg et al. reported that hydrogen evolution from $\mathrm{Mg}$ based cardiovascular stents during clinical studies was of minimal concern and observed good biocompatibility with reduced inflammatory response $[86,117,118,119,120,121]$. In the case of orthopedic implants, hydrogen evolution is a major concern due to poor transport mechanisms, which leads to the formation of gas pockets. In animal studies, subcutaneous gas bubbles were removed by a puncture procedure $[122,123]$.

In-vivo hydrogen evolution from bioabsorbable $\mathrm{Mg}$ alloys occurs at cathodic sites with low hydrogen overpotential. This leads to the formation of local gas cavities. However, the solubility of the hydrogen in the gas pockets is dependent on the content of lipids, proteins and salinity [64]. Nevertheless, rapid generation of hydrogen leads to 
subcutaneous bubbles, which may delay the healing of surgical regions, resulting in necrosis of tissue, prolonged healing and discomfort to the patient [114]. Table 4.5 shows the solubility coefficient for hydrogen in biological media $[64,116]$.

Table 4.5: Ostwald solubility coefficient $L$ ( $\mathrm{ml}$ gas per $\mathrm{ml}$ medium) for hydrogen in biological media at various temperatures $\left({ }^{\circ} C\right)[64,116]$

\begin{tabular}{lcc}
\hline Medium/tissue & ${ }^{\circ} \mathrm{C}$ & $\mathrm{L}$ \\
\hline Water & 37 & 0.0185 \\
Saline $0.15 \mathrm{M}$ & 38 & 0.0178 \\
Plasma, ox & 38 & 0.0175 \\
Red cells, ox & 38 & 0.0166 \\
Whole blood, ox & 38 & 0.0170 \\
Whole blood, man & 37 & 0.018 \\
Skeletal muscle, rat & 37 & 0.0218 \\
Olive oil & 25.3 & 0.036 \\
Lard & 25 & 0.039 \\
\hline
\end{tabular}

The adsorption of chloride ions on the surface oxides of the alloy lead to the formation of $\mathrm{Mg}(\mathrm{OH})_{2}$ via the hydrolysis of $\mathrm{MgCl}_{2}$ [167]. Dissolution of $\mathrm{Mg}(\mathrm{OH})_{2}$ subsequently exposes the underlying metal, which leads to further dissolution of Mg. At anodic sites, $\mathrm{Mg}^{++}$ions are produced; $\mathrm{Cl}^{-}$ions diffuse to such sites in order to establish electrical neutrality. $\mathrm{MgCl}_{2}$ is formed in the pits and hydrolyze according to equation (1) producing hydrochloric acid, which further dissolves the Mg.

$$
\mathrm{MgCl}_{2}+2 \mathrm{H}_{2} \mathrm{O} \rightarrow \mathrm{Mg}(\mathrm{OH})_{2}+2 \mathrm{HCl}
$$

At cathodic sites, water is reduced and hydrogen is evolved in accordance with equation (2). 


$$
\begin{aligned}
& 2 \mathrm{H}_{2} \mathrm{O}+2 e \rightarrow \mathrm{H}_{2}^{\uparrow}+2 \mathrm{OH}^{-} \\
& \mathrm{Mg}+2 \mathrm{H}_{2} \mathrm{O} \rightarrow \mathrm{Mg}(\mathrm{OH})_{2}+\mathrm{H}_{2} \text { (overall reaction) }
\end{aligned}
$$

The overall reaction of equation (3) summarizes $[63,167]$ the formation of hydrogen gas pockets adjacent to the implant, which delays the healing of tissues.

Song 2007 reported both unanodized and anodized Mg alloys usually suffer from localized corrosion at which hydrogen is primarily evolved [167]. Hence, hydrogen evolution can be employed as an important parameter for comparing degradation rates of Mg and its alloys [167].

Figure 4.22 and 4.23, show the volume of hydrogen evolved per unit surface area of mechanically polished and anodized samples as a function of time. A similar volume of hydrogen was released from each sample during the initial 24 hours. However, a greater volume after 150 hours, of hydrogen evolved from the mechanically polished alloys. The decrease in hydrogen evolution from the anodized alloys was attributed to the presence of various oxides, which will be described in section 5.1. Additionally, the higher the content of $\mathrm{Zn}$ in MMC, the lower was the volume of hydrogen evolved. This was attributed to the formation of two type of oxides; those of light metals $\mathrm{Mg}$ and $\mathrm{Ca}$ (porous oxides of smaller volume); and those of heavy metals, $\mathrm{Zn}$ and $\mathrm{Gd}$ (non-porous oxides of greater volume) [158]. $\mathrm{Mg}$ and $\mathrm{Ca}$ oxidize at a rate that is nearly constant with time (linear equation) whereas, Gd and $\mathrm{Zn}$ oxidize proportionally to the logarithm of the time (parabolic equation) $[157,158]$. The high hydrogen evolution is attributed to the 
porosity of the surface oxide as described in SEM, section 5.1. In the case of mechanically polished samples, the highest volume of hydrogen was evolved (190 hours) from $\mathrm{Mg} 1 \mathrm{Zn} 1 \mathrm{Ca}$ and $\mathrm{Mg} 1 \mathrm{Zn} 1 \mathrm{Ca} 8 \mathrm{Gd}$. Higher hydrogen evolution in the latter was attributed to the inhomogeneous distribution of $\mathrm{Gd}$ in the matrix and for $\mathrm{Mg} 1 \mathrm{Zn} 1 \mathrm{Ca}$, it was mainly due to the formation of less stable and porous oxides. No significant variation in hydrogen evolution $\left(\sim 1-2 \mathrm{~mL} / \mathrm{cm}^{2}\right)$ was observed after 50 hours for anodized samples, except for Mg1Zn1Ca1HA.

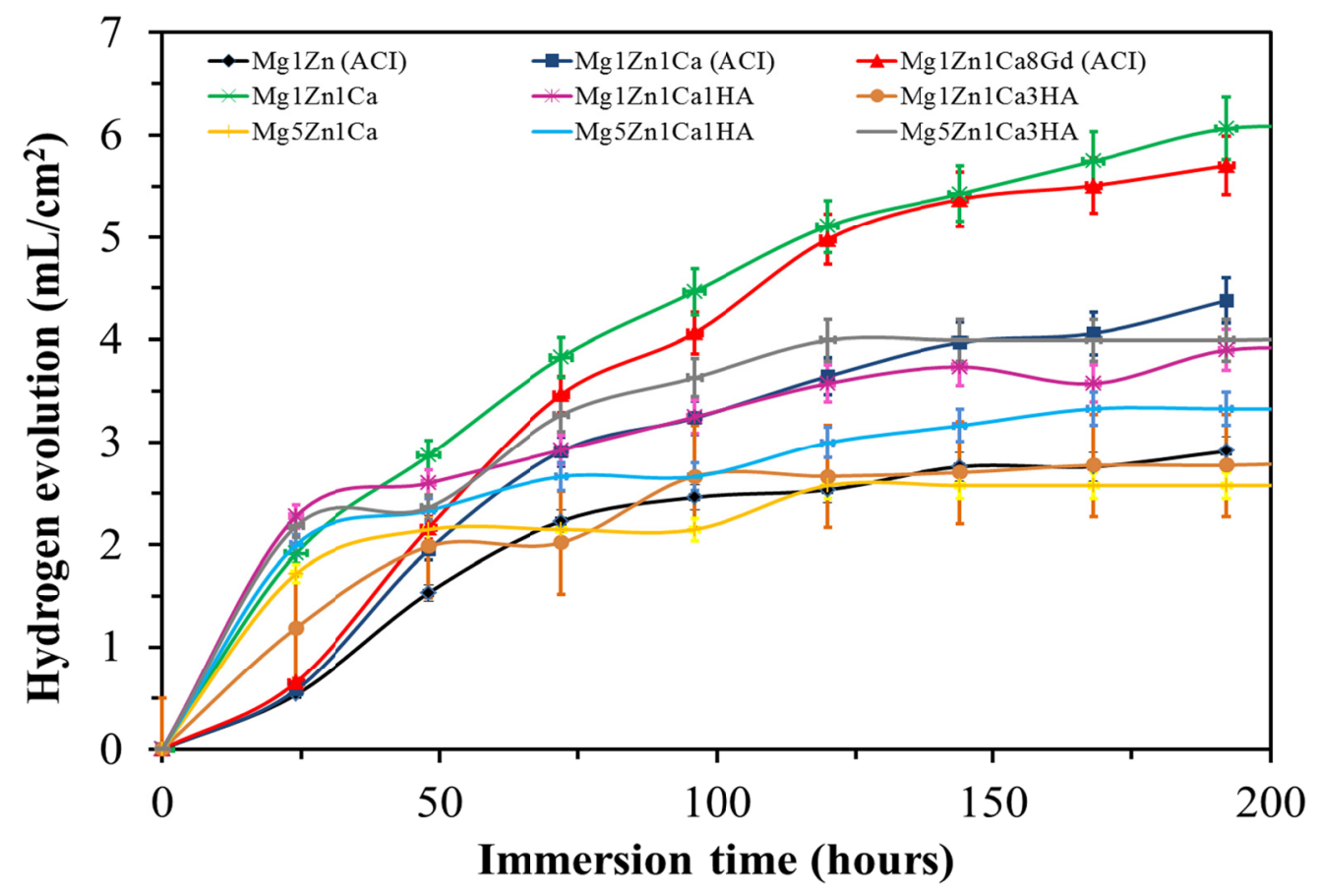

Figure 4.22: Hydrogen evolutions from mechanically polished samples immersed in PBS for 192 hours at $37^{\circ} \mathrm{C}$ (mean $\left.\pm S D, n=3\right)$. 


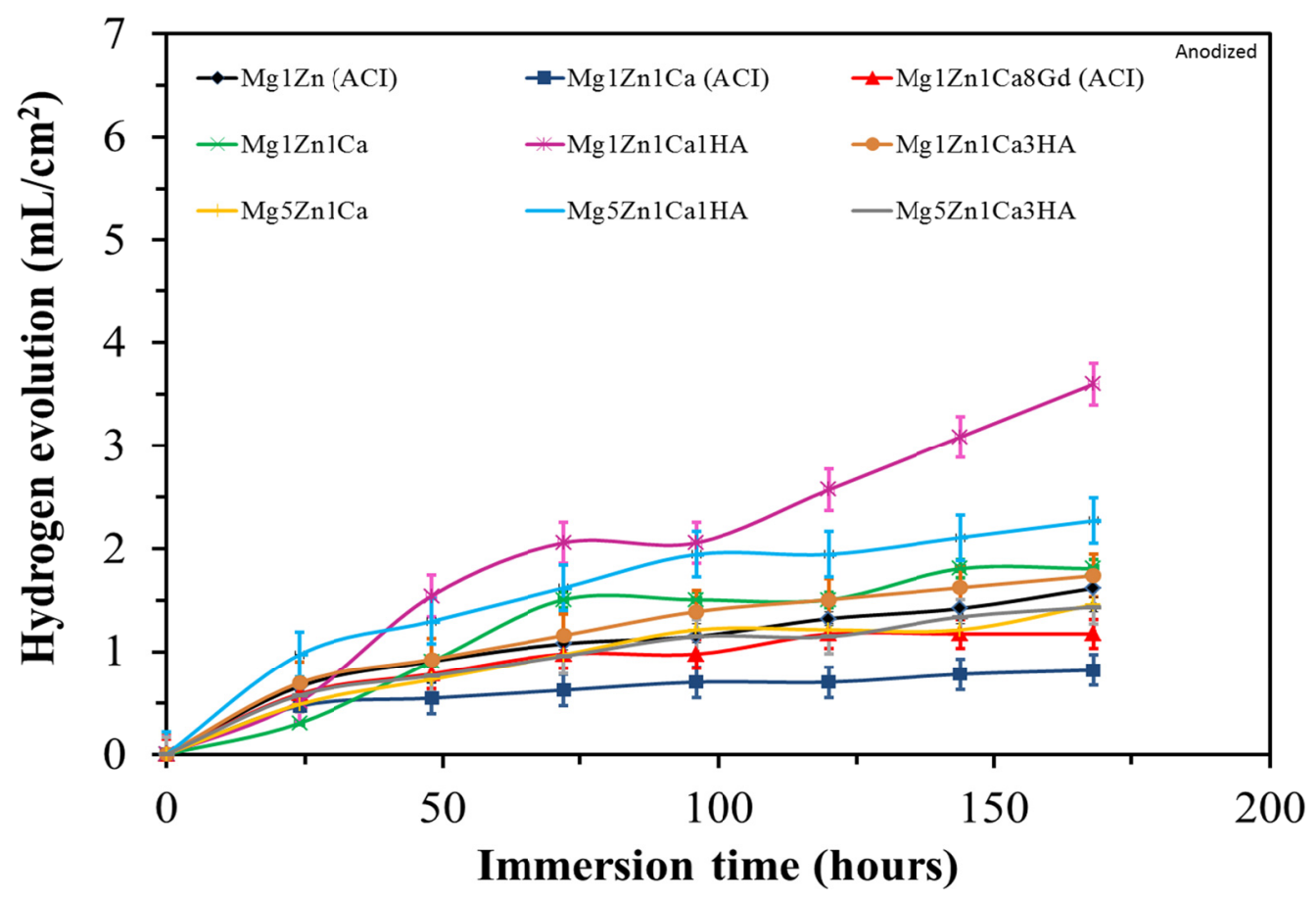

Figure 4.23: Hydrogen evolution from anodized samples immersed in PBS for 192 hours at $37^{\circ} \mathrm{C}$ (mean $\left.\pm S D, n=3\right)$.

The $\mathrm{pH}$ of the PBS was monitored during the emersion test using a Thermo Orion model\# $420 \mathrm{~A}+\mathrm{pH}$ meter. The $\mathrm{pH}$ ranged between $\sim 7.2-8.4$ and $\sim 7.2-7.5$ for mechanically polished and anodized samples, respectively, due to greater passivation with the latter. Anodization limits the concentration of $\mathrm{Mg}(\mathrm{OH})_{2}$ ions in the electrolyte and restricts further increase in $\mathrm{pH}$. Figures 4.24 and 4.25 show the $\mathrm{pH}$ of $\mathrm{PBS}$ at $37{ }^{\circ} \mathrm{C}$ into which mechanically polished and anodized samples were respectively immersed. The highest $\mathrm{pH}$ was observed with $\mathrm{Mg} 1 \mathrm{Zn}$ irrespective of surface treatment. It should be noted however, that the $\mathrm{pH}$ of PBS into which anodized samples were immersed remained relatively constant during the first 24 hours (Figure 4.25), Subsequent increase in $\mathrm{pH}$ is attributed to the degradation of the passivating oxides. As previously discussed, the oxides of light metals $\mathrm{Mg}$ and $\mathrm{Ca}$ (porous oxides of smaller volume) and those of 
heavy metals, $\mathrm{Zn}$ and $\mathrm{Gd}$ (non-porous oxides of greater volume) [158,163]. Thus the different oxidation rates of the four oxides induce stresses, which result in the formation of surface cracks and delamination of the passivation layer. An increase in $\mathrm{pH}$ could affect not only the corrosion behavior of the implant but also cell viability or hemolysis $[115,124]$. Wang et al. reported the precipitation of less soluble products, such as magnesium phosphate, $\mathrm{Mg}_{3}\left(\mathrm{PO}_{4}\right)_{2}$; magnesium apatite; zinc phosphate, $\mathrm{Zn}_{3}\left(\mathrm{PO}_{4}\right)_{2}$; and calcium phosphate, $\mathrm{Ca}_{3}\left(\mathrm{PO}_{4}\right)_{2}$ due to a local increase in $\mathrm{pH}$ [127].

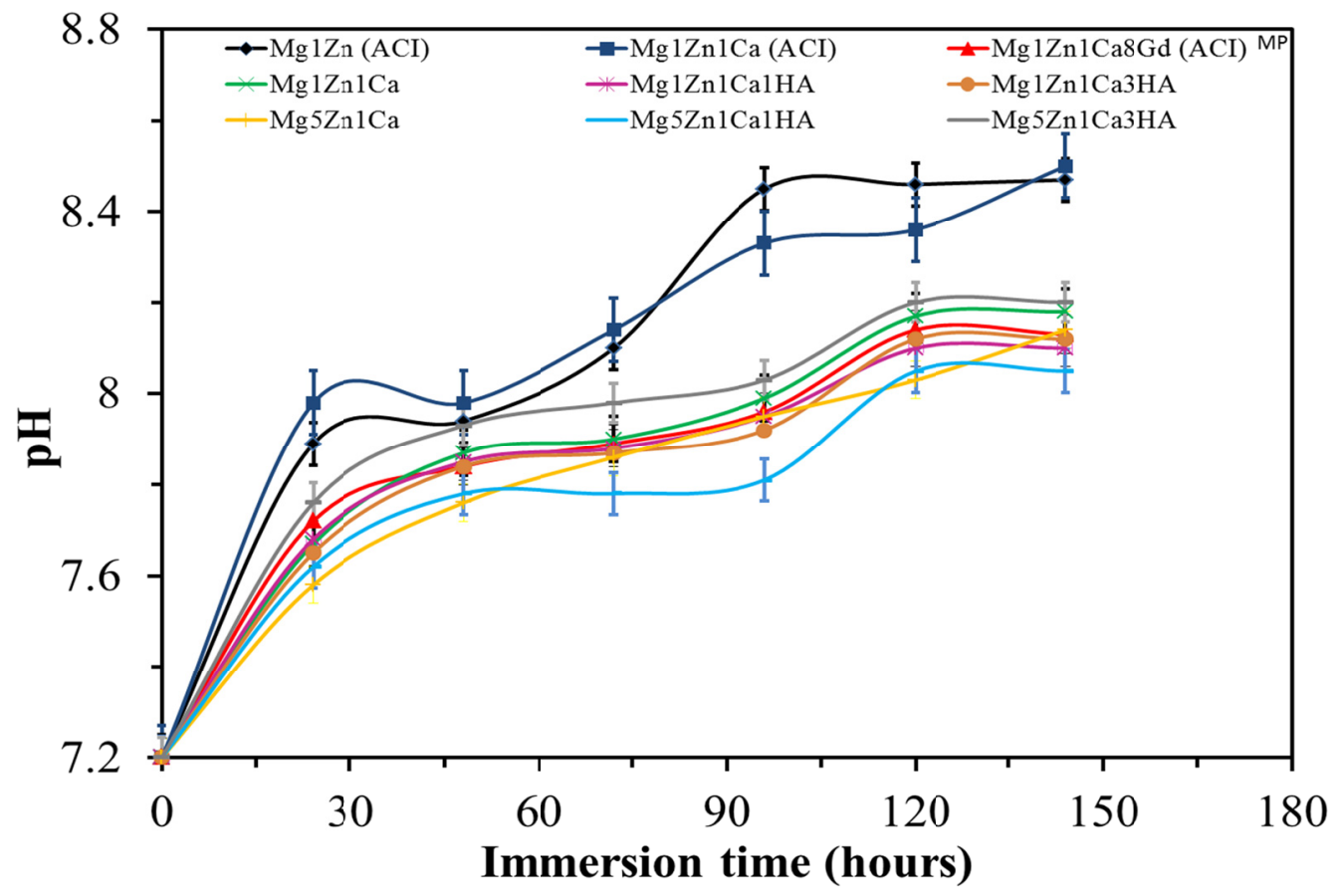

Figure 4.24: The pH for mechanically polished samples immersed in PBS at $37^{\circ} \mathrm{C}$ (mean $\pm S D, n=3)$. 


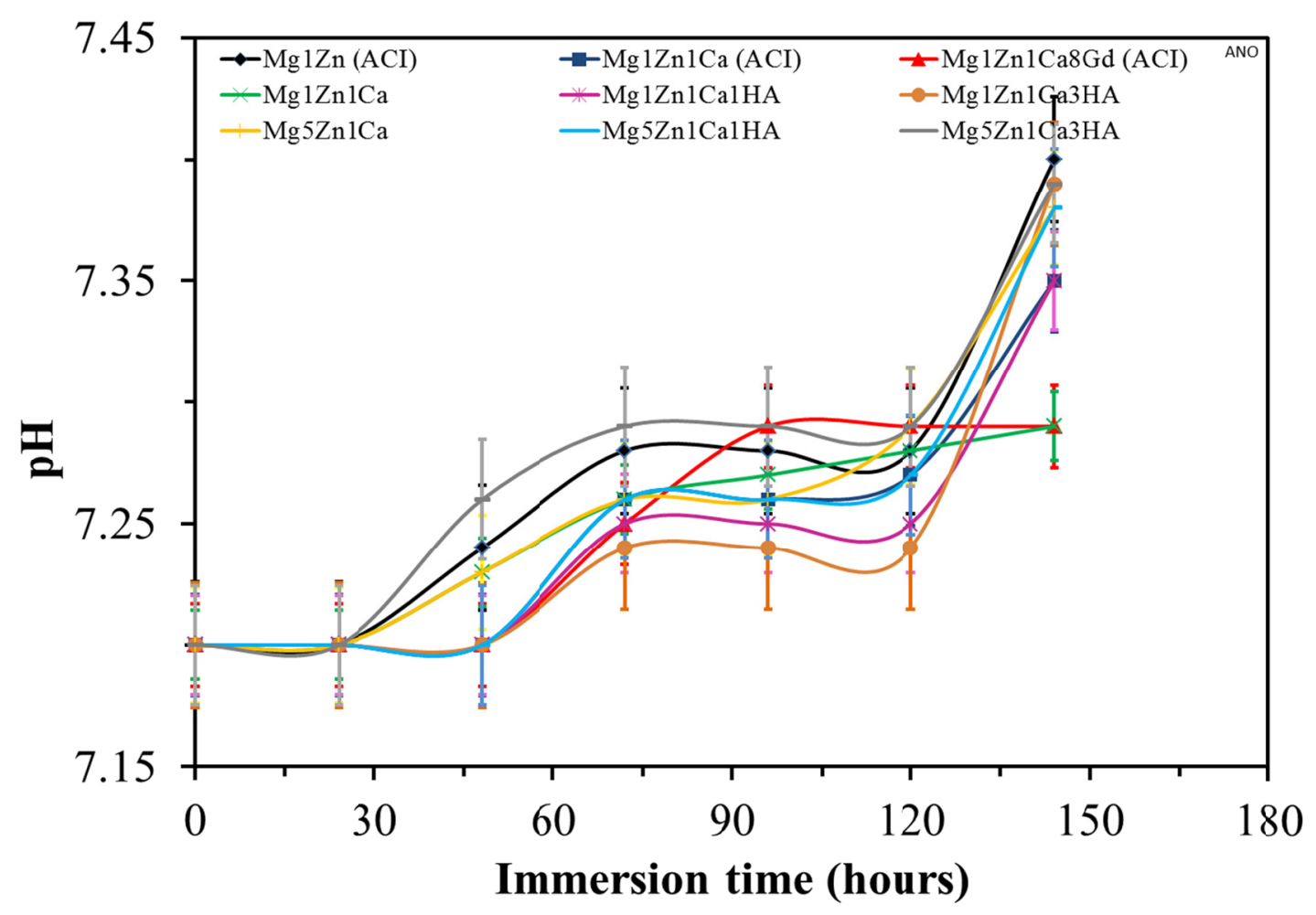

Figure 4.25: The $p H$ for anodized samples immersed in $P B S$ at $37^{\circ} C$ (mean $\pm S D, n=$ 3).

The corrosion resistance of biodegradable $\mathrm{Mg}$ alloys is influenced by several factors, such as temperature, $\mathrm{pH}$, type of media, etc. Two factors considered during invitro tests involved the usage of simulated body fluids and human body temperature of 37 ${ }^{\circ} \mathrm{C}$. Table 4.7 shows the corrosion rates of mechanically polished and anodized $\mathrm{Mg}$ samples after immersion in PBS at $37{ }^{\circ} \mathrm{C}$ for 192 hours. The mechanically polished samples exhibited a higher susceptibility to corrosion as compared with those anodized. Similar corrosion behavior was also observed with potentiodynamic polarization experiments as shown in section 4.5.1. Furthermore, the addition of $\mathrm{HA}$ to $\mathrm{MgZnCa}$ increased the rate of corrosion due to the porosity, cracking and delamination of the surface oxides. A significant decrease in corrosion rate was observed after anodization for $\mathrm{Mg} 5 \mathrm{Zn} 1 \mathrm{Ca} 1 \mathrm{HA}$ and $\mathrm{Mg} 5 \mathrm{Zn} 1 \mathrm{Ca} 3 \mathrm{HA}$, due to the formation of more stable and 
uniform oxides on the surface. $\mathrm{Mg} 1 \mathrm{Zn}(\mathrm{ACI})$ showed an increase in corrosion rate after anodization, which could be due to the formation of porous oxides on the surface. Furthermore, the rates of corrosion can be inferred from the morphology of the $\mathrm{Mg}$ samples shown in section 5.1 .

Table 4.6: Comparison between the corrosion rates depicted for mechanically polished and anodized samples via immersion test

\begin{tabular}{lcc}
\hline \multirow{2}{*}{ Alloys } & \multicolumn{2}{c}{ Immersion, $\mathrm{mm} /$ year } \\
\cline { 2 - 3 } & Mechanically Polished & Anodized \\
\hline Mg1Zn (ACI) & 0.3 & 0.8 \\
Mg1Zn1Ca (ACI) & 0.5 & 0.2 \\
Mg1Zn1Ca8Gd (ACI) & 0.6 & 0.1 \\
Mg1Zn1Ca & 2.4 & 0.6 \\
Mg1Zn1Ca1HA & 3.4 & 1.2 \\
Mg1Zn1Ca3HA & 2.6 & 1.4 \\
Mg5Zn1Ca & 2.5 & 0.9 \\
Mg5Zn1Ca1HA & 2.3 & 1.1 \\
Mg5Zn1Ca3HA & 3.1 & 1.8 \\
\hline
\end{tabular}

\subsubsection{Dynamic Immersion Test}

In order to better understand the degradation behavior of alloys/MMCs under dynamic conditions, immersion tests were performed in PBS at $37{ }^{\circ} \mathrm{C}$ using a vortex shaker with a constant speed of $\sim 500 \mathrm{rpm}$ for 144 hours. Due to the nature of the test setup, it was not feasible to determine hydrogen evolution. However, the $\mathrm{pH}$ monitored during dynamic immersion test ranged between $~ 7.2-9.3$ (Figure 4.26) and 7.2-8.4 (Figure 4.27) for mechanically polished and anodized samples respectively, which were relatively higher than the $\mathrm{pH}$ obtained under static conditions $(\sim 7.2-8.4$ and $\sim 7.2-7.5$ for mechanically polished and anodized samples respectively). Furthermore, it should be noted that there was no significant increase in $\mathrm{pH}$ in the case of anodized samples after 50 hours of immersion. 


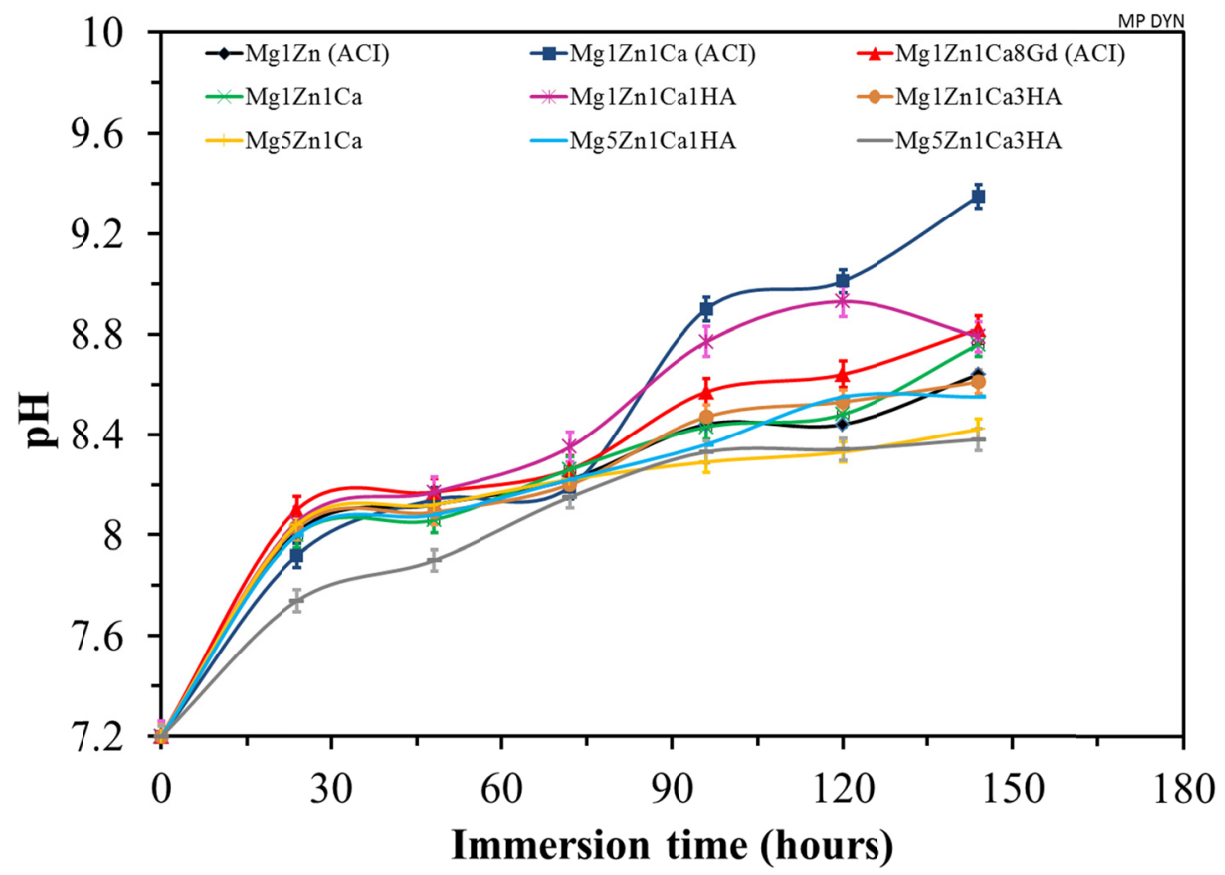

Figure 4.26: The pH of mechanically polished samples immersed in PBS at $37^{\circ} \mathrm{C}$ under dynamic conditions (mean $\pm S D, n=3$ ).

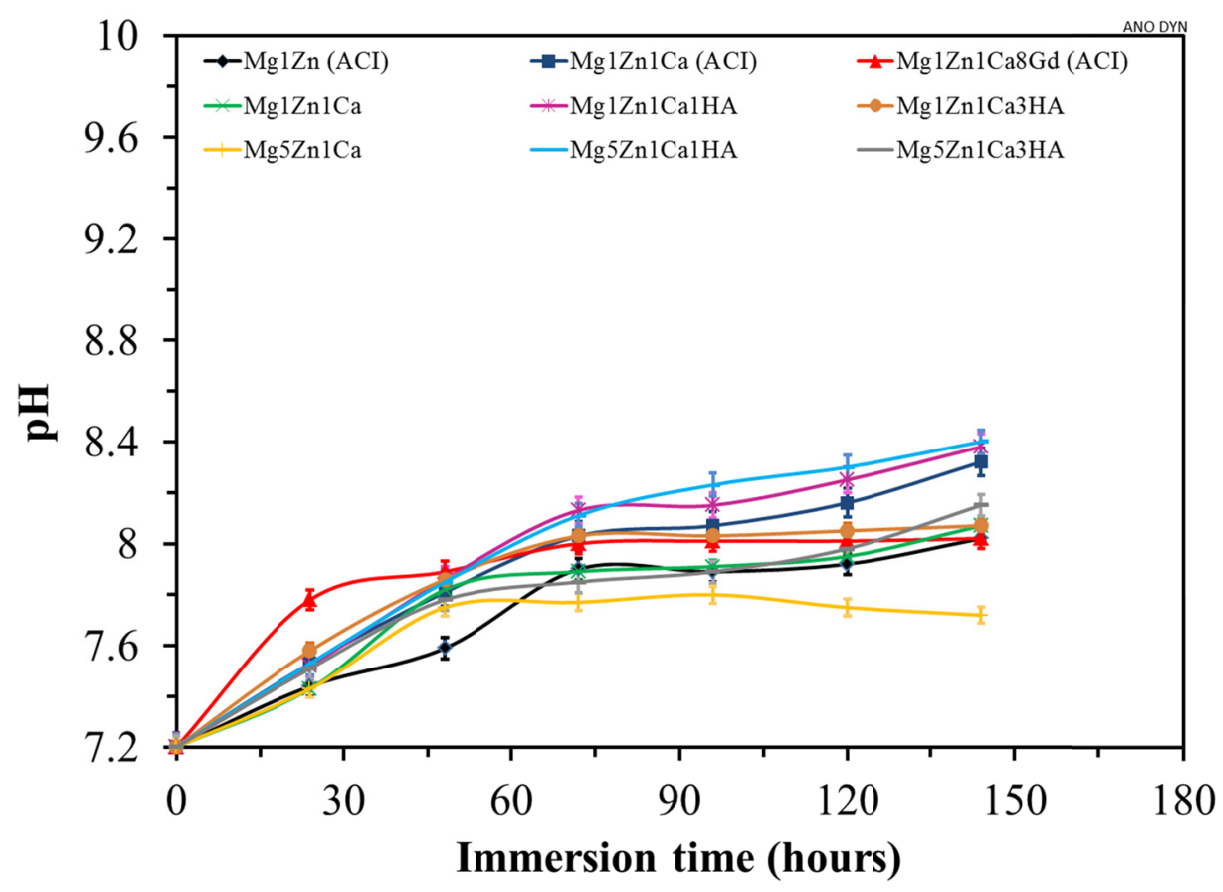

Figure 4.27: The pH of anodized samples immersed in PBS at $37^{\circ} \mathrm{C}$ under dynamic conditions (mean $\pm S D, n=3$ ). 
Table 4.7 shows the corrosion rates of mechanically polished and anodized Mg samples in PBS at $37^{\circ} \mathrm{C}$ under dynamic conditions. The mechanically polished samples exhibited higher susceptibility to corrosion as compared with anodized samples. This is attributed to the composition and thickness of the passivating oxides on the respective surfaces $(\sim 10-15 \mathrm{~nm}$ for mechanically polished and $\sim 5-10 \mu \mathrm{m}$ for anodized samples as previously discussed in section 5.1.1).

The effect of the relative velocity between the electrolyte and Mg alloys/MMCs was not apparent for anodized samples as shown in Tables 4.7. This is attributed to the difference in the relative thickness of the passivating layers. The thin oxide layer of mechanically polished alloys/MMCs was less protective than that on the anodized samples, therefore, the former was more susceptible to pitting corrosion and chloride ion attack. Thus, anodization significantly increases the corrosion resistance and can serve to regulate the degradation rate of $\mathrm{Mg}$ alloys/MMCs.

Table 4.7: Corrosion rates of mechanically polished and anodized samples under dynamic conditions.

\begin{tabular}{lcc}
\hline Samples & $\begin{array}{c}\text { Mechanically Polished } \\
\text { (mm/year) }\end{array}$ & $\begin{array}{c}\text { Anodized } \\
\text { (mm/year) }\end{array}$ \\
\hline Mg1Zn (ACI) & 1.08 & 0.86 \\
Mg1Zn1Ca (ACI) & 0.58 & 0.21 \\
Mg1Zn1Ca8Gd (ACI) & 0.98 & 0.66 \\
Mg1Zn1Ca & 1.22 & 1.33 \\
Mg1Zn1Ca1HA & 3.18 & 0.47 \\
Mg1Zn1Ca3HA & 3.81 & 0.97 \\
$M g 5 Z n 1 C a$ & 3.27 & 0.39 \\
$M g 5 Z n 1 C a 1 H A$ & 2.99 & 0.88 \\
Mg5Zn1Ca3HA & 2.26 & 0.22 \\
\hline
\end{tabular}


It should be noted that the effect of oxide composition on corrosion rate of mechanically polished samples was not as significant as compared with that on anodized samples. The phenomenon of corrosion kinetics of mixed oxides and their ensuing porosity is responsible for the aforementioned behavior and is discussed in section 4.2. However, the rate of degradation increased under dynamic conditions for mechanically polished samples. This is explained in terms of an increase in the critical limiting current, which increases with agitation as the diffusion layer thickness decreases in accordance with the Butler-Volmer equation (Mass-transfer control) [156].

$$
i_{\text {limiting }}=\frac{n F D}{\delta} C^{*}
$$

where:

$\mathrm{D}$ is the diffusion coefficient; $\delta$ is the diffusion layer thickness and $\mathrm{C}^{*}$ is the concentration of the electroactive (limiting) species in the bulk of the electrolyte. The effect of agitation on the rate of degradation of a metal under diffusion-controlled cathodic process is depicted in Figure 4.28 [198]. 


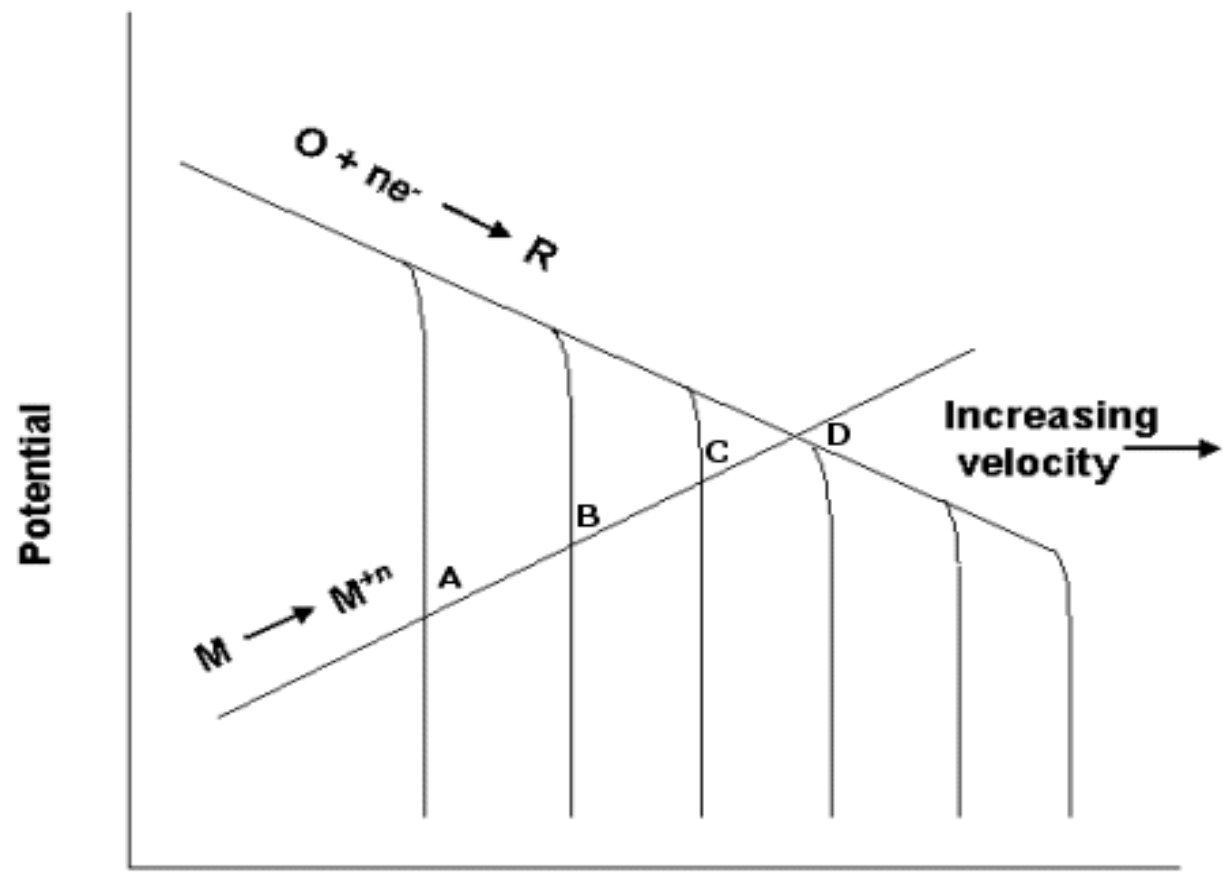

Log(current density)

Figure 4.28: Effect of velocity on the rate of degradation of a metal under diffusioncontrolled cathodic process [156]. 


\subsubsection{Dissolved Ions Released During Immersion Test}

ICP-MS (Perkin Elmer Sciex, model ELAN DRC-II) was used to determine the ions released during the immersion test. Atoms present in a solution are excited by an inductively coupled plasma and are then indentified and quantified by a mass spectrometer. The acquisition parameters of the ICP-MS used in the analysis are listed in Table 4.8 .

Table 4.8: ICP-MS acquisition parameters for the analysis of the samples

\section{ICP-MS Parameters}

\begin{tabular}{ll} 
IC RF Power & 1300 \\
Nebulizer Gas Flow & $0.92 \mathrm{~L} / \mathrm{min}$ \\
Plasma Gas Flow & $16 \mathrm{~L} / \mathrm{min}$ \\
Lens Voltage & $10.5 \mathrm{~V}$ \\
\hline
\end{tabular}

ICP-MS was performed by collecting $5 \mathrm{ml}$ of PBS after each immersion test. The PBS was filtered to remove particulate matter and each sample was analyzed in 3 replicates. Optimal grade nitric acid was used to prepare the calibration curve at the following concentrations: $0,10,25,50,60,80$ and $100 \mathrm{ppb}$. Good linearity was obtained for all elements and isotopes $\left(\mathrm{R}^{2}\right.$ better than 0.991$)$.

The concentration of $\mathrm{Mg}$ and $\mathrm{Ca}$ in the samples was higher than the concentration of $\mathrm{Zn}$ and $\mathrm{Gd}$ and therefore, two separate dilution sets were prepared and measured with two separate calibration curves. A 1:2 dilution factor was applied to each sample prior measurement of $\mathrm{Zn}$ and $\mathrm{Gd}$. A 1:500 dilution factor was applied to each sample prior to the measurement of $\mathrm{Ca}$ and $\mathrm{Mg}$. Yttrium was used as an internal standard for the analysis 
of $\mathrm{Zn}$ and $\mathrm{Gd}$, while scandium was used as an internal standard for the measurement of $\mathrm{Ca}$ and Mg. Table A.11 (see Appendix - I) shows the mean concentration of elements obtained for the 3 replicates of each sample. Uncertainty was reported as the relative standard deviation. The uncertainty represents variability of 3 replicate measurements on the same sample (instrumental variation). Instrument blanks were analyzed and the concentration for the samples were then reported after their respective background subtraction (acid blanks).

Figure $4.28-4.31$ displays the average concentrations of the dissolved metal ions in the electrolyte under static and dynamic immersion conditions. $\sim 0.6-21 \mu \mathrm{g} / \mathrm{mL}$ of $\mathrm{Mg}$ and $\sim 48-69 \mu \mathrm{g} / \mathrm{mL}$ of Ca leached from mechanically polished samples as compared with anodized $\sim 12-44 \mu \mathrm{g} / \mathrm{mL}$ of $\mathrm{Mg}$ and $\sim 63-72 \mu \mathrm{g} / \mathrm{mL}$ of $\mathrm{Ca}$ under static conditions. $\sim 20-33$ $\mu \mathrm{g} / \mathrm{mL}$ of $\mathrm{Mg}$ and $65-87 \mu \mathrm{g} / \mathrm{mL}$ of $\mathrm{Ca}$ leached from anodized samples under dynamic immersion. These results appear to contradict the corrosion rates reported and further studies need to be conducted to elucidate this phenomenon. Nevertheless, it can be concluded that the concentration of $\mathrm{Mg}$ and $\mathrm{Ca}$ ions leached from anodized samples do not vary significantly under static nor dynamic conditions. Additionally, the metal ion release is not necessarily related to the elemental composition of the alloy (in the case of mechanically polished $\mathrm{Mg}$ based alloys/MMCs) but is more dependent on compactness, stability, thickness and regeneration potential of the oxide film (in the case of anodized samples) [68]. 


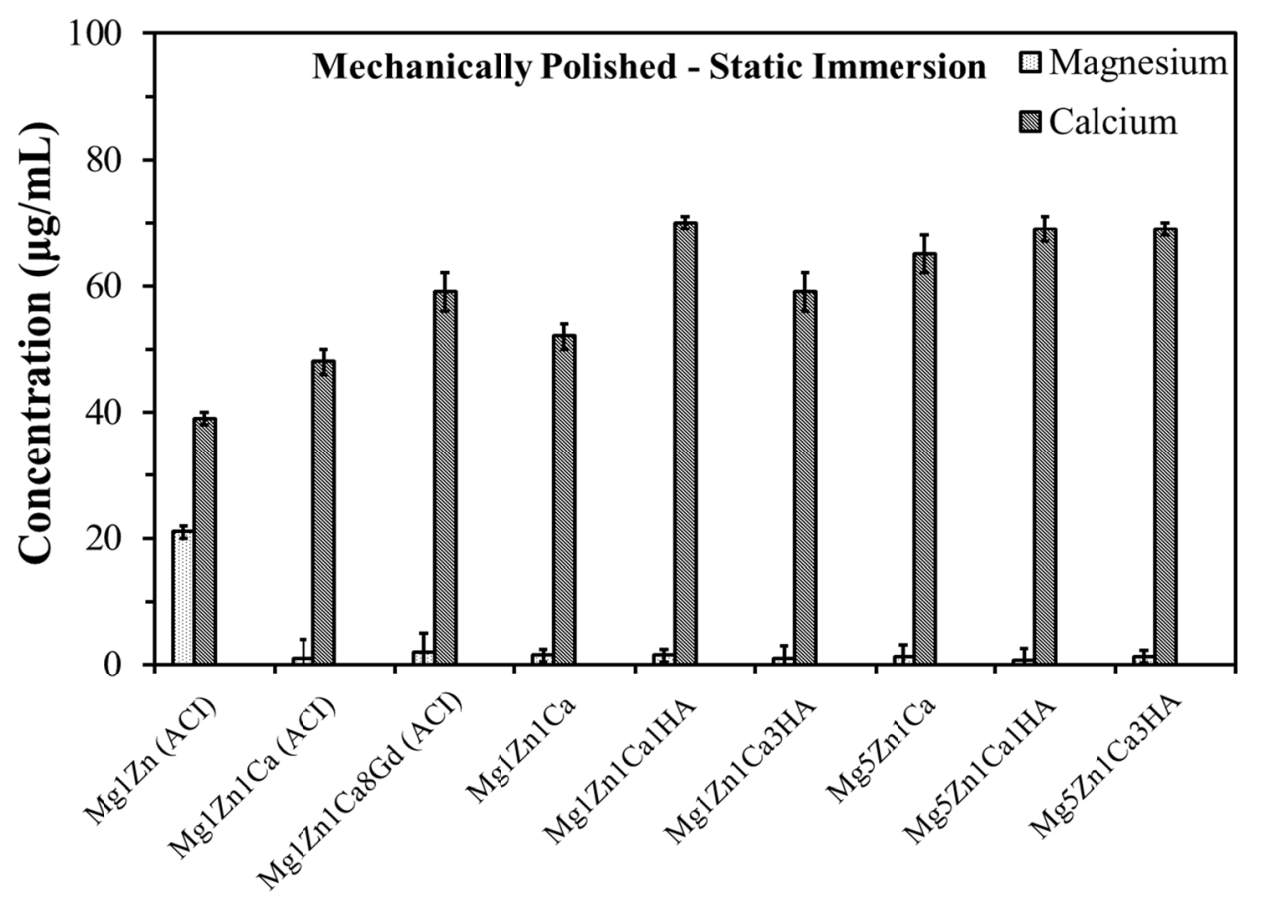

Figure 4.29: ICP-MS analysis showing the concentration of $M g$ and $C a$ ions in corrosion extract obtained from mechanically polished samples during static immersion (mean \pm $S D, n=3)$.

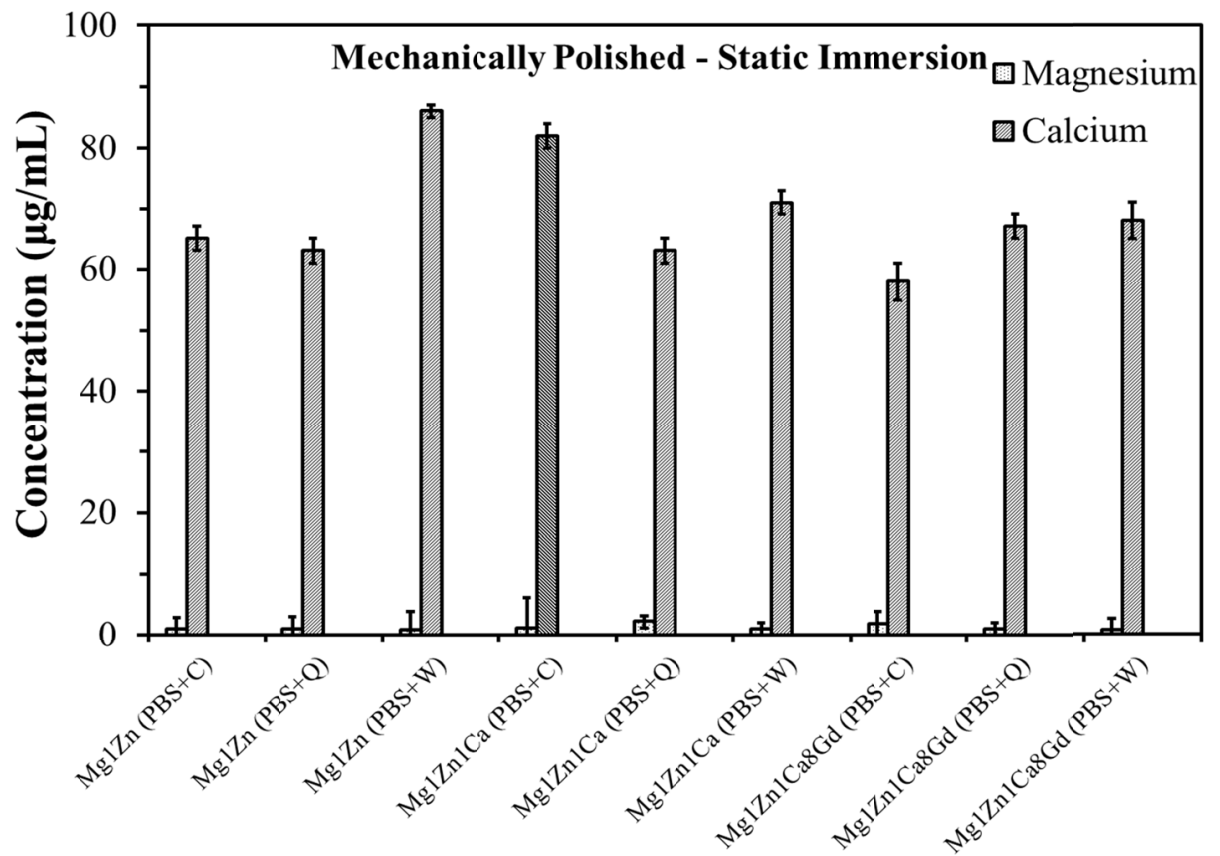

Figure 4.30: ICP-MS analysis showing the concentration of $\mathrm{Mg}$ and $\mathrm{Ca}$ ions in corrosion extract (PBS + amino acids) obtained from mechanically polished samples during static immersion (mean $\pm S D, n=3$ ). 


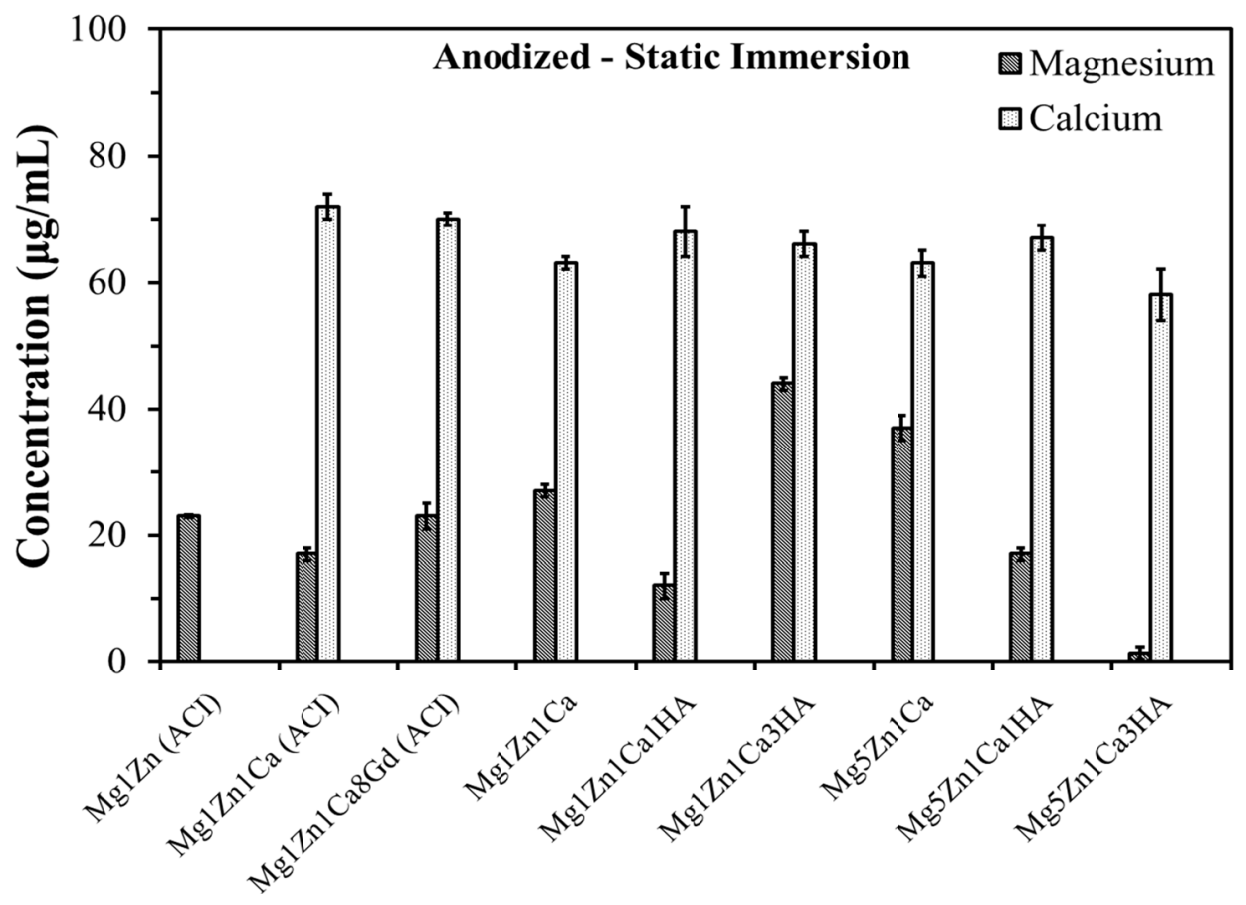

Figure 4.31: ICP-MS analysis showing the concentration of $M g$ and Ca ions in corrosion extract obtained from anodized samples during static immersion (mean $\pm S D, n=3$ ).

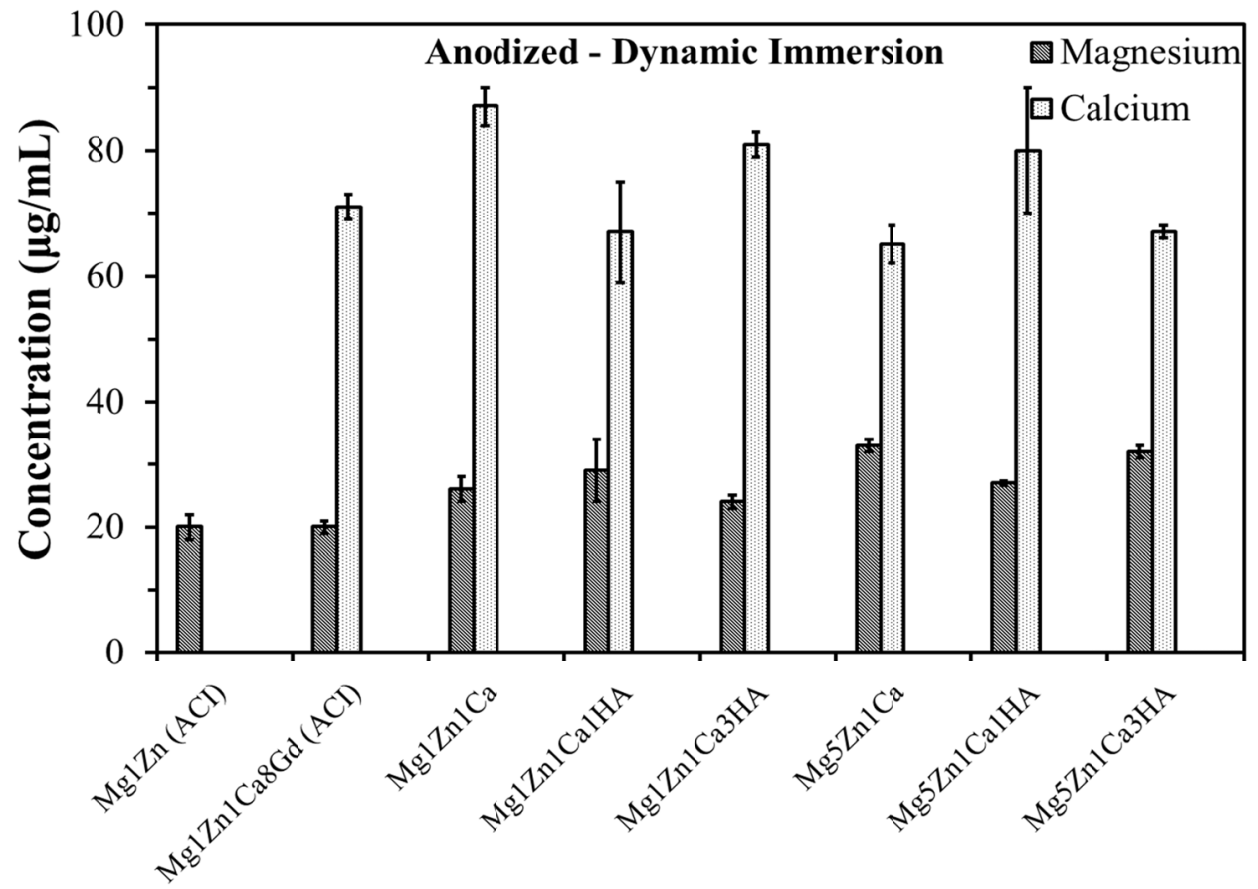

Figure 4.32: ICP-MS analysis showing the concentration of $\mathrm{Mg}$ and $\mathrm{Ca}$ ions in corrosion extract obtained from anodized samples during dynamic immersion (mean $\pm S D, n=3$ ). 


\subsection{SURFACE CHARACTERIZATION}

\subsection{Material Characterization}

Microstructure, surface morphology and qualitative chemical composition of the samples were assessed using scanning electron microscopy/energy dispersive spectroscopy (SEM/EDS), JEOL JSM 6330F. A Siemens 5000 D, XRD with Cu-K $\alpha$ radiation (wavelength, $\lambda=1.54 \mathrm{~A}^{\circ}$ ) operating at $35 \mathrm{~mA}$ and $40 \mathrm{kV}$ with a scan rate of $0.01 \%$ sec over a 2 theta from $20-90^{\circ}$, was used to determine the microstructure phases. A DIFFRAC ${ }^{\text {plus }}$ EVA software (Bruker, Madison, WI, USA) was utilized to analyze the XRD spectra. The surface roughness of the samples was determined by optical profilometer and the data was analyzed by Scanning Probe Image Processor (SPIP).

\subsubsection{SEM/EDS: Mechanically Polished and Anodized Samples}

Figure 5.1 illustrates the SEM and EDS analysis of mechanically polished as-cast samples. A number of uniformly dispersed spherical particles $(\sim 5 \mu \mathrm{m})$ were observed on the surface of polished samples. EDS analysis at these spots depicted a higher concentration of oxygen and alloying elements. Zhang et al. (2010) reported two major phases in cast $\operatorname{MgZn}$ alloys, namely $\alpha$-phase (matrix) and $\gamma-\operatorname{MgZn}$ [90]. SEM photomicrographs clearly display precipitates and grain boundaries on the surface of polished alloys as shown in Figure 5.1. EDS analysis suggests the occurrence of grain boundary segregation with relatively higher concentrations of alloying elements at the grain boundaries. Li et al. (2008) showed that $\alpha$-phase (matrix) and $\mathrm{Mg}_{2} \mathrm{Ca}$ phase precipitated along the grain boundaries [65]. The formation of these binary phases was further confirmed by XRD analysis. 
Figure 5.1 (c) Mg1Zn1Ca8Gd illustrates the formation of dendrites, which are mainly rich in $\mathrm{Zn}, \mathrm{Ca}$ and $\mathrm{Gd}$. Furthermore, Mg1Zn1Ca8Gd alloy displayed continuous rosette-shaped dendrites and partially eutectic interdendrites, which were reported by other researchers [89]. The dendrites with estimated spacing of 5-10 $\mu \mathrm{m}$ between each dendrite were distributed along the eutectic area and grain boundaries, whereas the precipitates mainly aggregate at or near the grain boundaries, especially at the triple junction. EDS analysis revealed that the primary grains were composed of $\alpha$-phase but the binary phases precipitated at the grain boundaries and further confirmed the occurrence of grain boundary segregation with relatively higher concentrations of $\mathrm{Ca}, \mathrm{Zn}$ and HA. Uniform dispersion of HA is reported to increase the corrosion resistance and mechanical properties of the samples, due to the increase in interfacial area between $\mathrm{Mg}$ $\alpha$-phase and HA particles [113]. Li et al. (2008) confirmed the presence of $\mathrm{Mg} \alpha$-phase (matrix) in the grain and $\mathrm{Mg}_{2} \mathrm{Ca}$ precipitates along the grain boundaries [65], both of which were detected by XRD in this investigation (section 5.1.2).
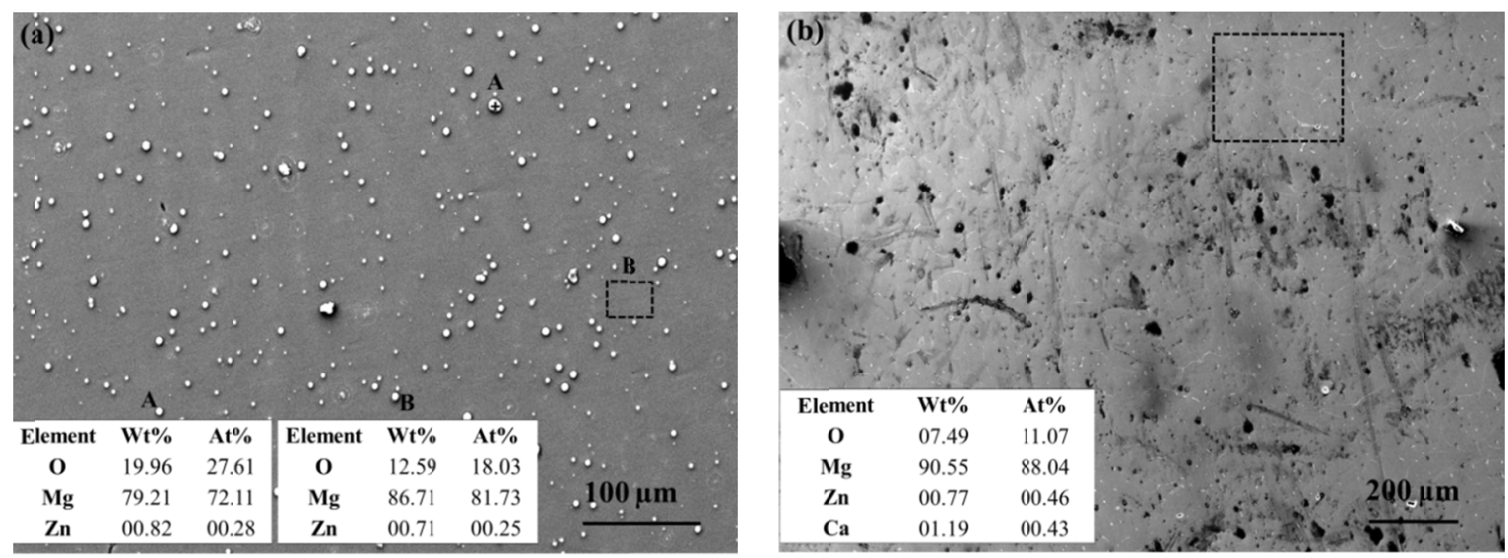

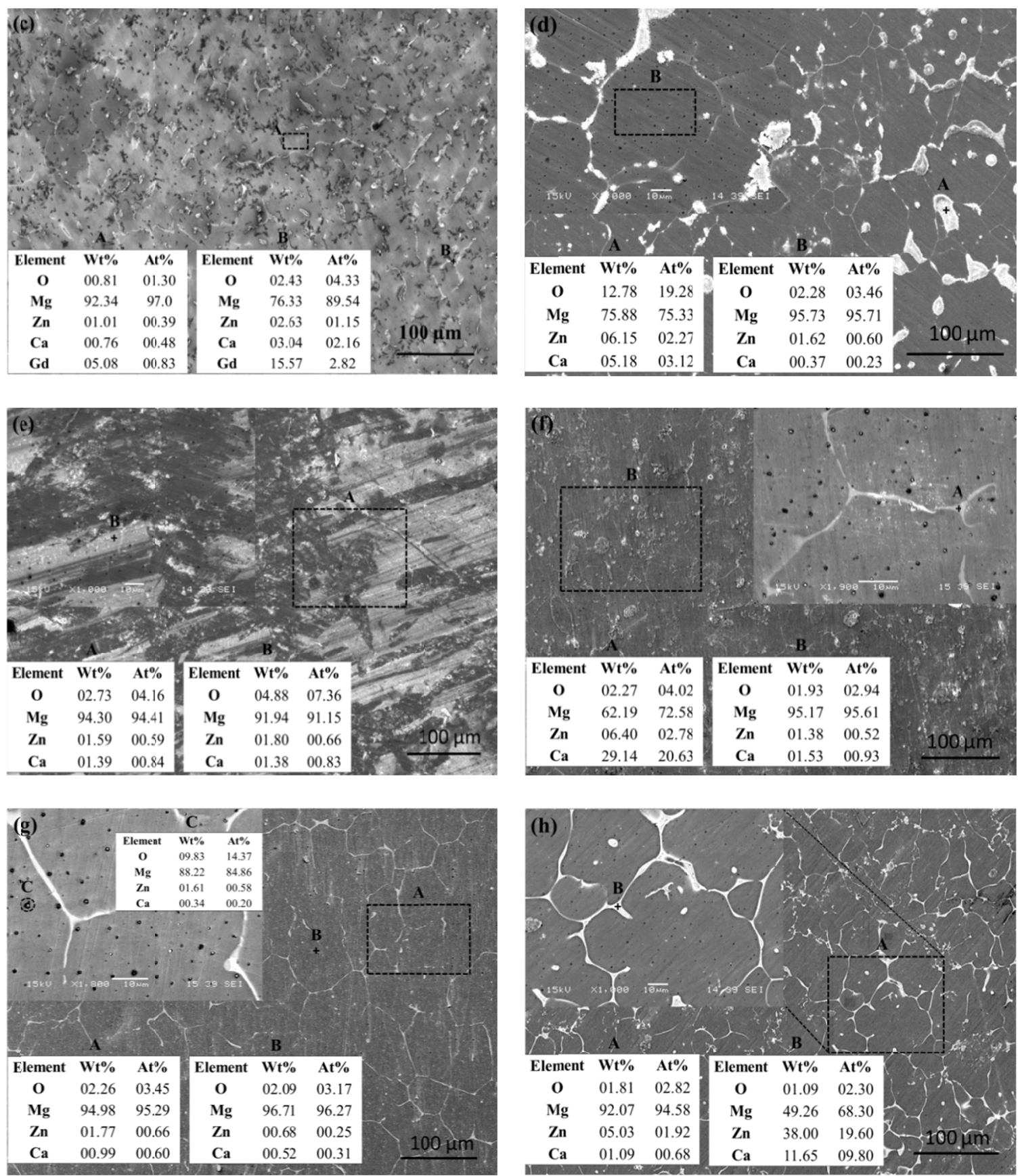


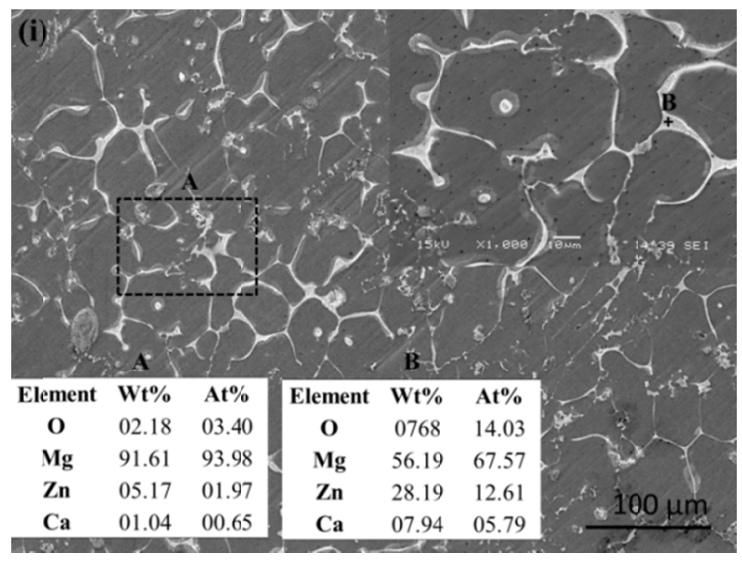

Figure 5.1: SEM photomicrographs and EDS analysis (inset): (a) $M g 1 Z n$ (ACI); (b) Mg1Zn1Ca (ACI); (c) Mg1Zn1Ca8Gd (ACI); (d) Mg1Zn1Ca; (e) Mg1Zn1Ca1HA; (f) MglZnICa3HA; (g) Mg5Zn1Ca; (h) Mg5Zn1CalHA; and (i) Mg5Zn1Ca3HA.

The $\mathrm{Mg}$ samples were anodized to improve the initial corrosion resistance and mechanical integrity. Figure 5.2 shows the SEM photomicrographs and EDS analysis of anodized samples that were mechanically polished to a roughness of $0.05 \mu \mathrm{m}$. As compared to mechanically polished samples, anodization resulted in a higher concentration of oxygen on the surface and oxides at the grain boundaries (Figure $5.2 \mathrm{~h}, \mathrm{i}$ and $\mathrm{j}$ ). The degradation products of anodize $\mathrm{Mg}$ alloy has been reported to be non-toxic [130]. Furthermore, grain boundaries are expected to be more corrosion resistant, thereby increasing implant stability. It is a well-known fact that in most of the alloys, preferential corrosion occurs at or along the grain boundaries, also known as intergranular corrosion. After anodization, the grain boundaries become more resistant to corrosion and further prolong the grain boundary attack and increase the implant stability.

The oxide layer on anodized $\mathrm{Mg} 1 \mathrm{Zn} 1 \mathrm{Ca}$ was approximately 5-10 $\mu \mathrm{m}$ as depicted in Figure 5.2 (j). However, anodize coatings of $\mathrm{Mg}$ alloys have been reported to consist of two layers, ranging in thickness from $5-50 \mu \mathrm{m}[6,131,132] . \mathrm{Mg}$ alloys/MMCs are 
anodized in an attempt to improve the corrosion resistance and initial implant stability due to the formation of metal oxides, which varies with processing parameters, such as exposure time, type of electrolyte and temperature [6]. Anodization of a $\mathrm{Mg}$ based biodegradable implant therefore, imparts initial corrosion resistance and mechanical integrity after implantation and ensures sufficient time for the surgical region to heal. Shi et al. (2006) reported the initial occurrence of pitting corrosion on anodized specimens followed by filiform or general corrosion [130]. The anodize coating is hard (high wear resistant) and porous (similar to the bone microstructure) as compared with other conversion coating or fluoridated coatings [114].
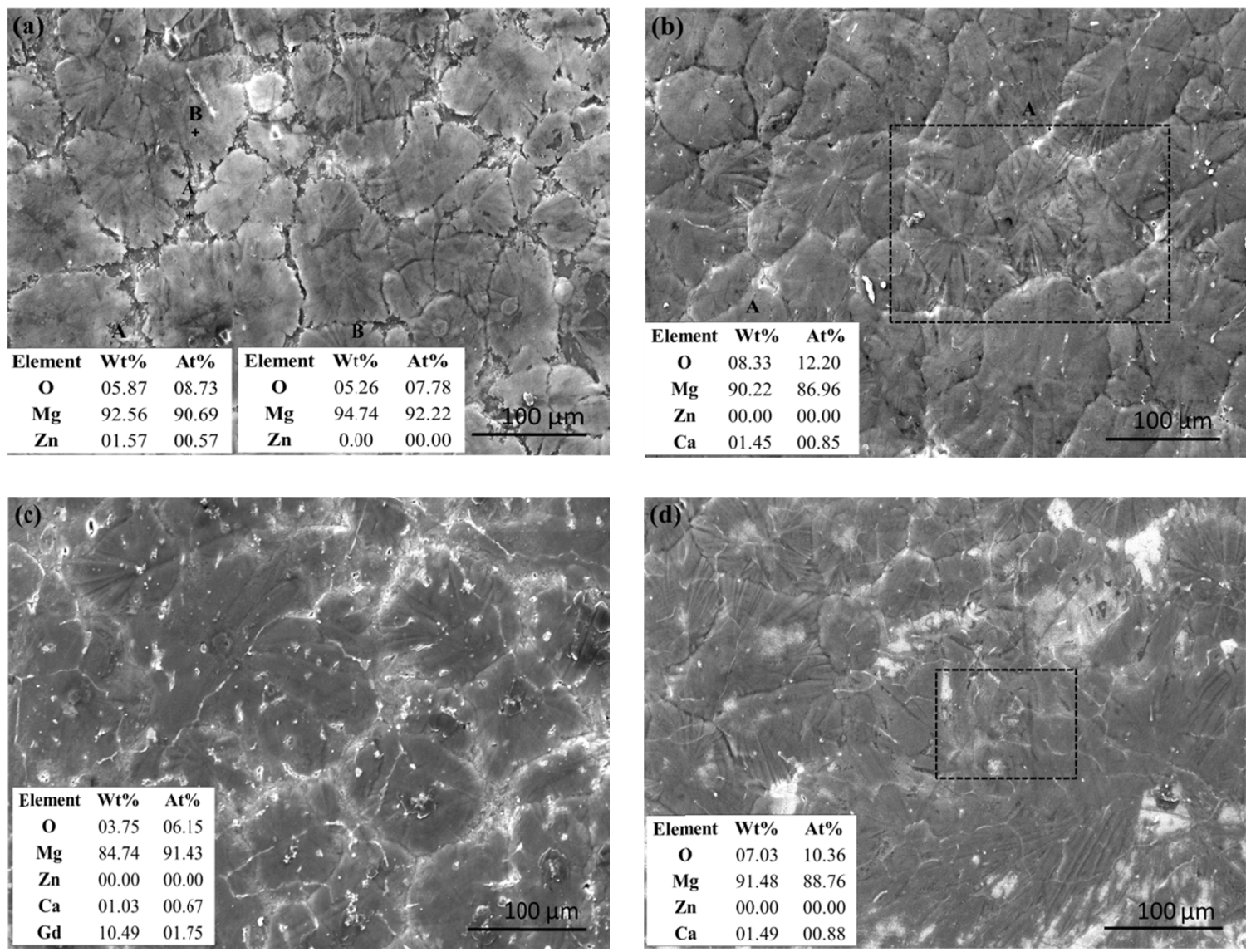

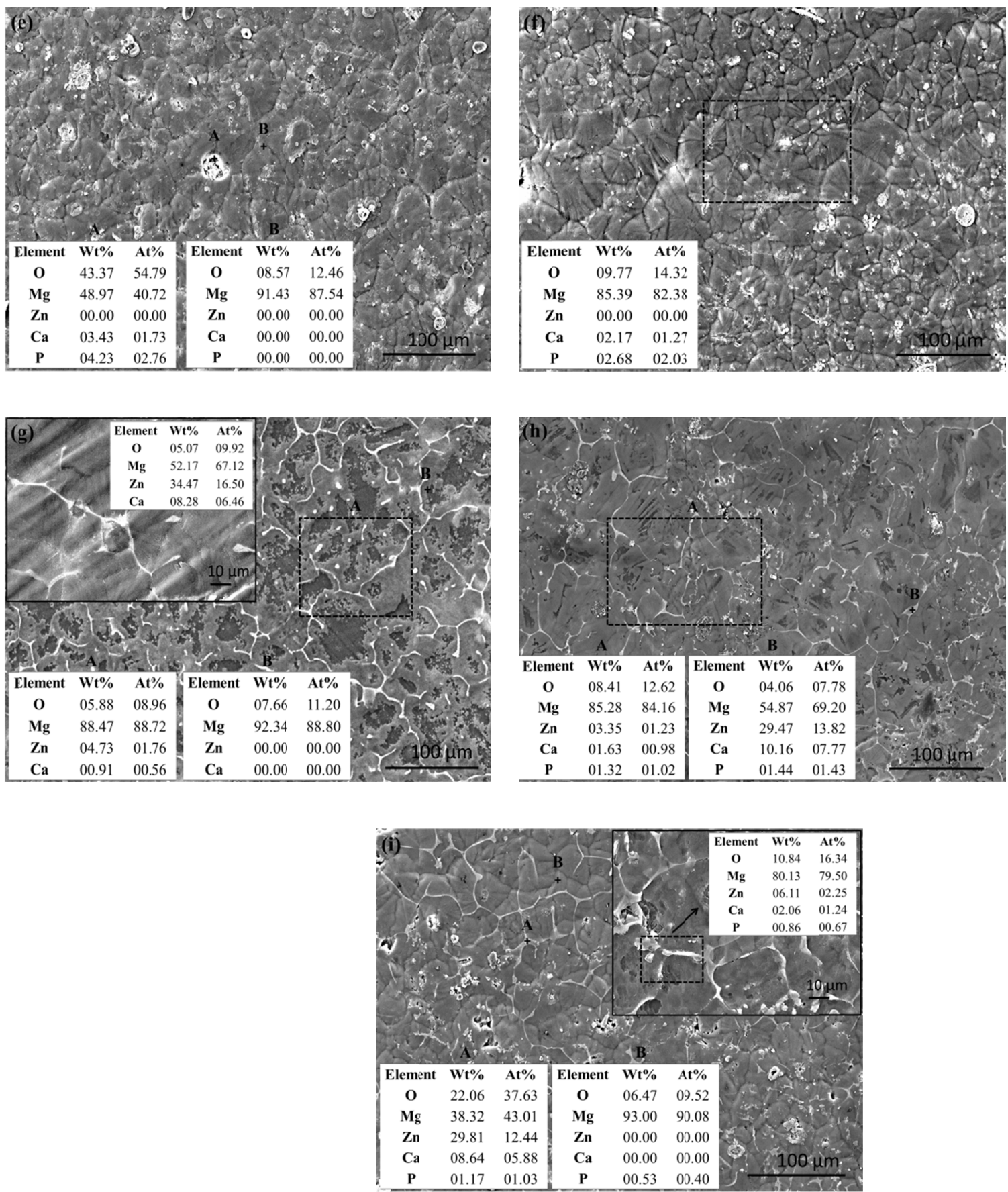


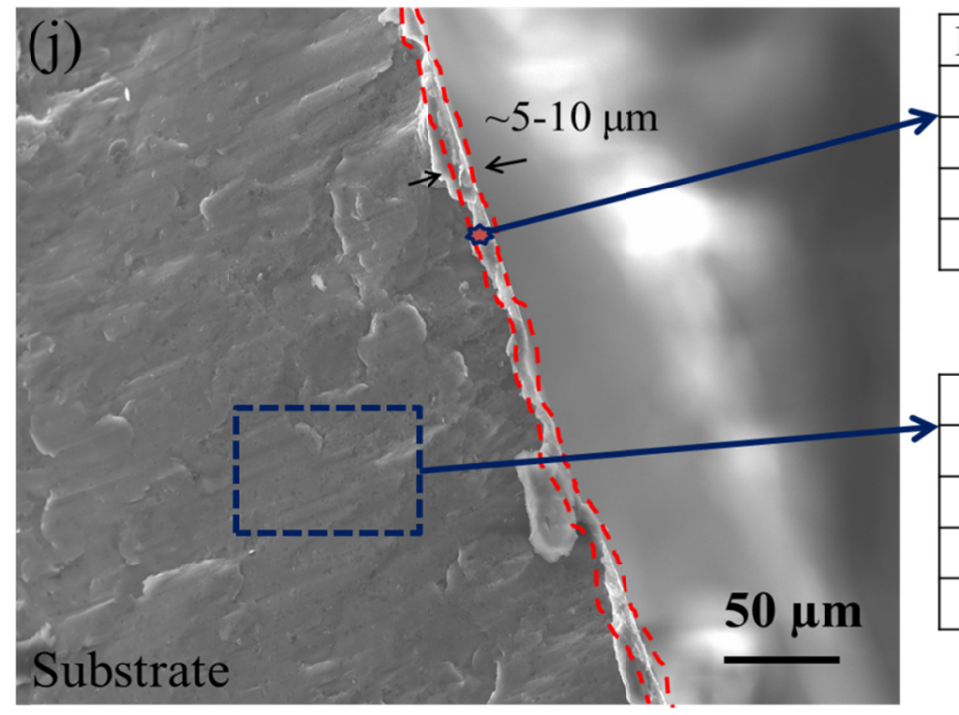

\begin{tabular}{|c|c|c|}
\hline Element $^{*}$ & $\mathbf{W t} \%$ & $\mathbf{A t} \%$ \\
\hline $\mathbf{O}$ & 15.08 & 21.49 \\
\hline $\mathbf{M g}$ & 82.33 & 77.21 \\
\hline $\mathbf{C a}$ & 1.27 & 0.72 \\
\hline $\mathbf{Z n}$ & 1.07 & 0.37 \\
\hline
\end{tabular}

*Si (0.02) and $P(0.06)$ was detected in small amount (wt\%)

Figure 5.2: SEM photomicrographs and EDS analysis (inset) for anodized samples: (a) MglZn (ACI); (b) MglZnlCa (ACI); (c) MglZn1Ca8Gd (ACI); (d) MglZnlCa; (e) Mg1Zn1Ca1HA; (f) Mg1Zn1Ca3HA; (g) Mg5Zn1Ca; (h) Mg5Zn1Ca1HA; (i) Mg5Zn1Ca3HA; and (j) cross-section of the anodized Mg1Zn1Ca (ACI) alloy.

\subsubsection{SEM/EDS of Mechanically Polished Alloys/MMCs after Potentiodynamic Corrosion in PBS and PBS with Amino Acids}

Alloying and surface treatments not only enhance the mechanical properties of $\mathrm{Mg}$, but also have a significant effect on its degradation behavior and biocompatibility. Figure 5.3-5.5 shows the surface morphology and EDS analysis of mechanically polished samples after potentiodynamic corrosion tests in PBS and PBS with amino acids (cysteine, C $0.25 \mathrm{mM}$, glutamine $\mathrm{Q}, 0.568 \mathrm{mM}$ and tryptophan $\mathrm{W}, 0.042 \mathrm{mM}$ ) at $37{ }^{\circ} \mathrm{C}$. Stress induced cracks were observed on the surface of all alloys subjected to potentiodynamic polarization tests in PBS and PBS with amino acids except for MgZn in PBS. MgZnCaGd developed a significant amount of oxides in PBS with cysteine (Figure 
$5.5 \mathrm{~b}$ and $\mathrm{c})$. Similar cracked corrosion products were reported by various researchers with various Mg alloys $[127,169]$. The adsorption of chloride ions on the surface oxides of the alloy lead to the formation of $\mathrm{Mg}(\mathrm{OH})_{2}$ via the hydrolysis of $\mathrm{MgCl}_{2}[158,167]$. Dissolution of $\mathrm{MgCl}_{2}$ subsequently exposes the underlying metal surface, which leads to further dissolution of $\mathrm{Mg}$. At anodic sites, $\mathrm{Mg}^{++}$ions are produced; $\mathrm{Cl}^{-}$ions diffuse to such sites in order to establish electrical neutrality. $\mathrm{MgCl}_{2}$ is formed in the pits and hydrolyzed as previously discussed in Chapter 4. Figure 5.5 (b and c) clearly shows partially delaminated stress induced fractured surfaces, which can lead to localized corrosion underneath the corrosion products.

EDS analysis revealed the relative concentrations of $\mathrm{Mg}, \mathrm{O}, \mathrm{P}, \mathrm{K}, \mathrm{Zn}, \mathrm{Ca}$ and $\mathrm{Gd}$ on the surface of the alloys, which corresponded to the formation of a mixture of apatite, zinc phosphate and calcium phosphate as shown in Figure 5.3-5.5 (e).
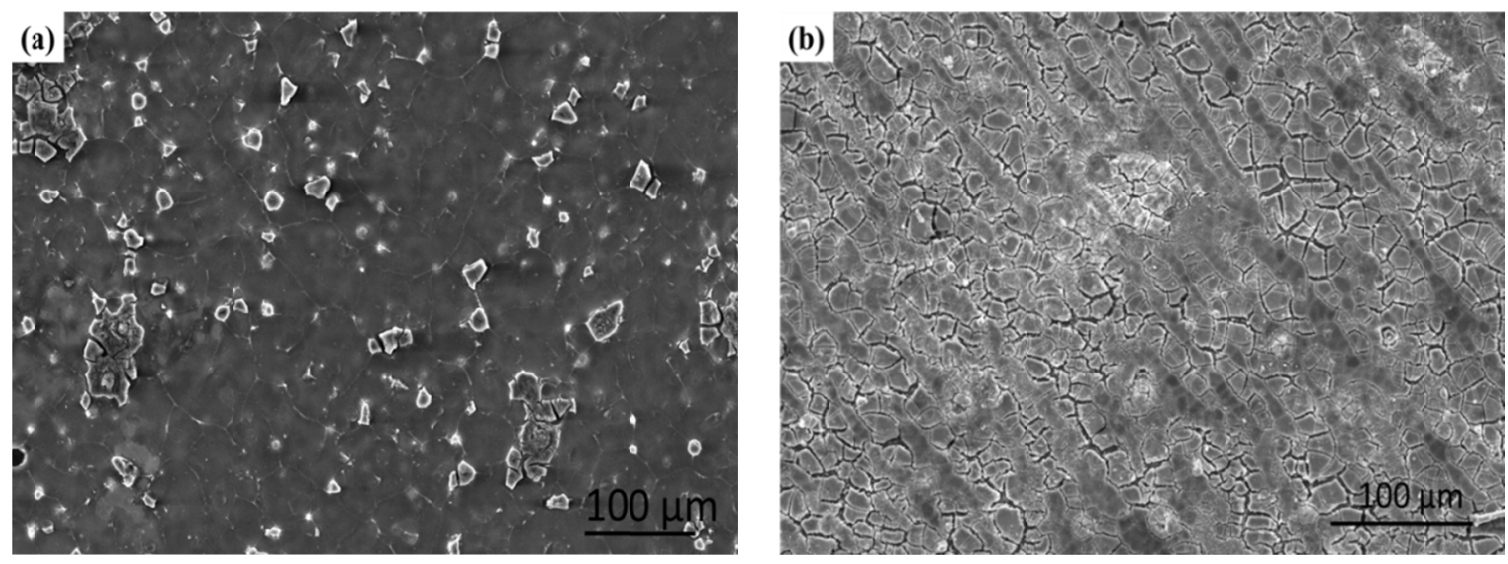

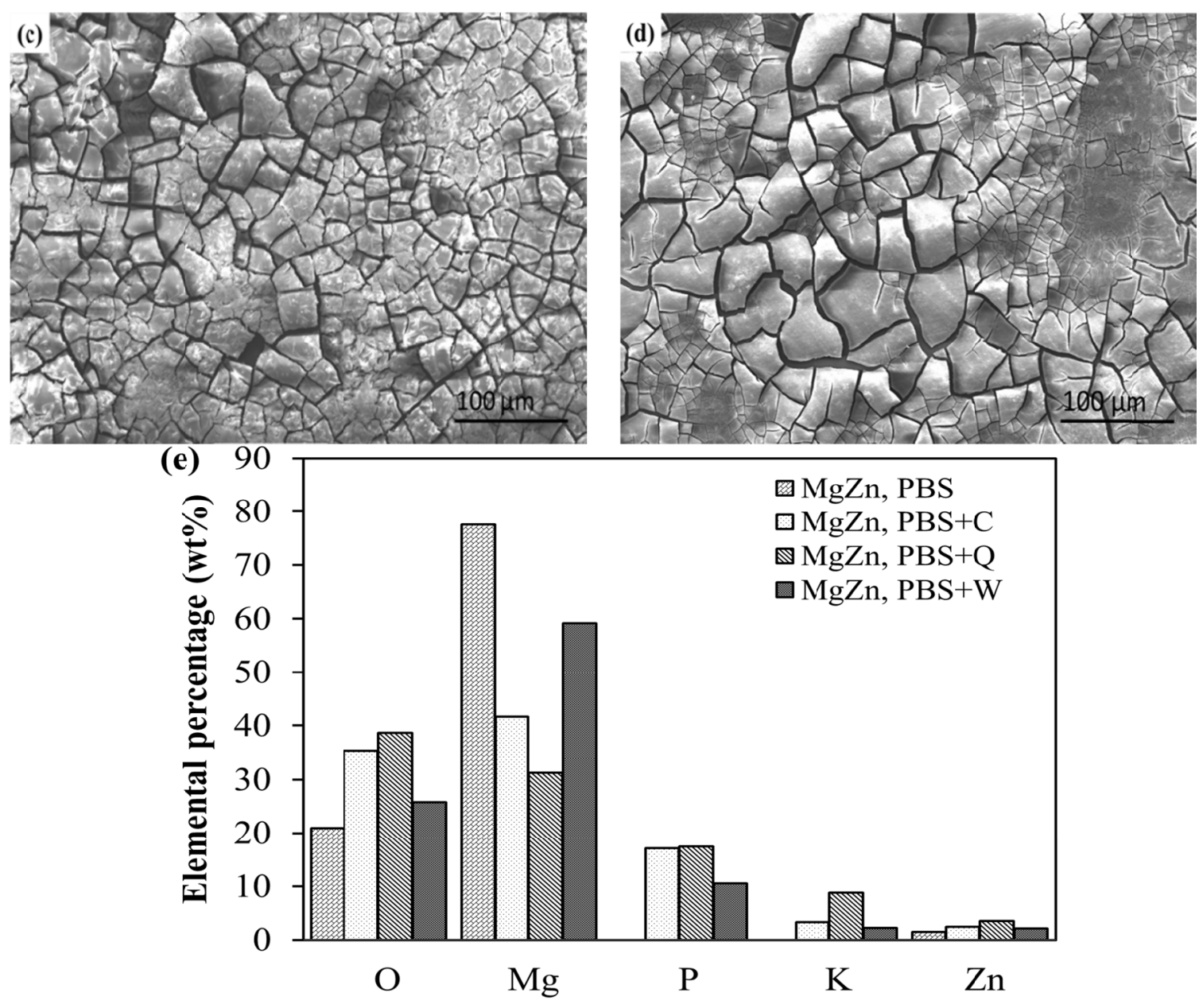

Figure 5.3: Scanning electron microscopy image of alloys after potentiodynamic corrosion: (a) $M g Z n, P B S$; (b) $M g Z n, P B S+C$; (c) $M g Z n, P B S+Q$; (d) $M g Z n, P B S+W$ and (e) composition of the surface layers formed on $\mathrm{Mg}$ alloys during accelerated corrosion tests in PBS and PBS with amino acids.
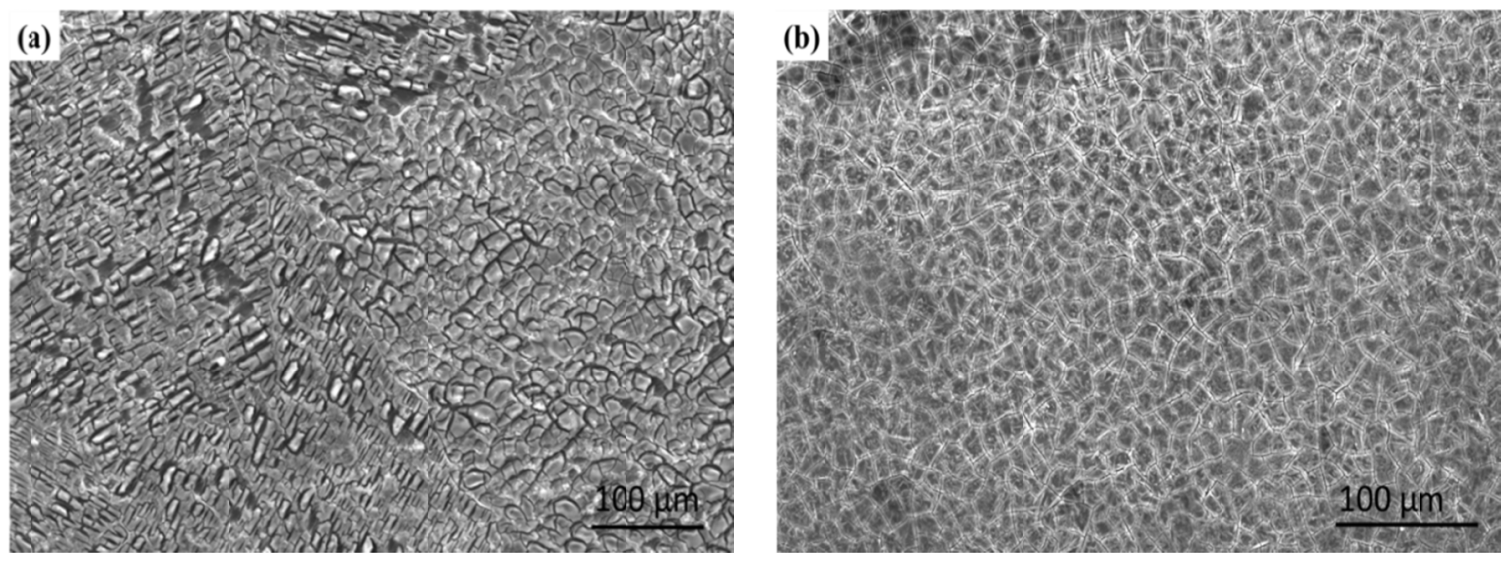

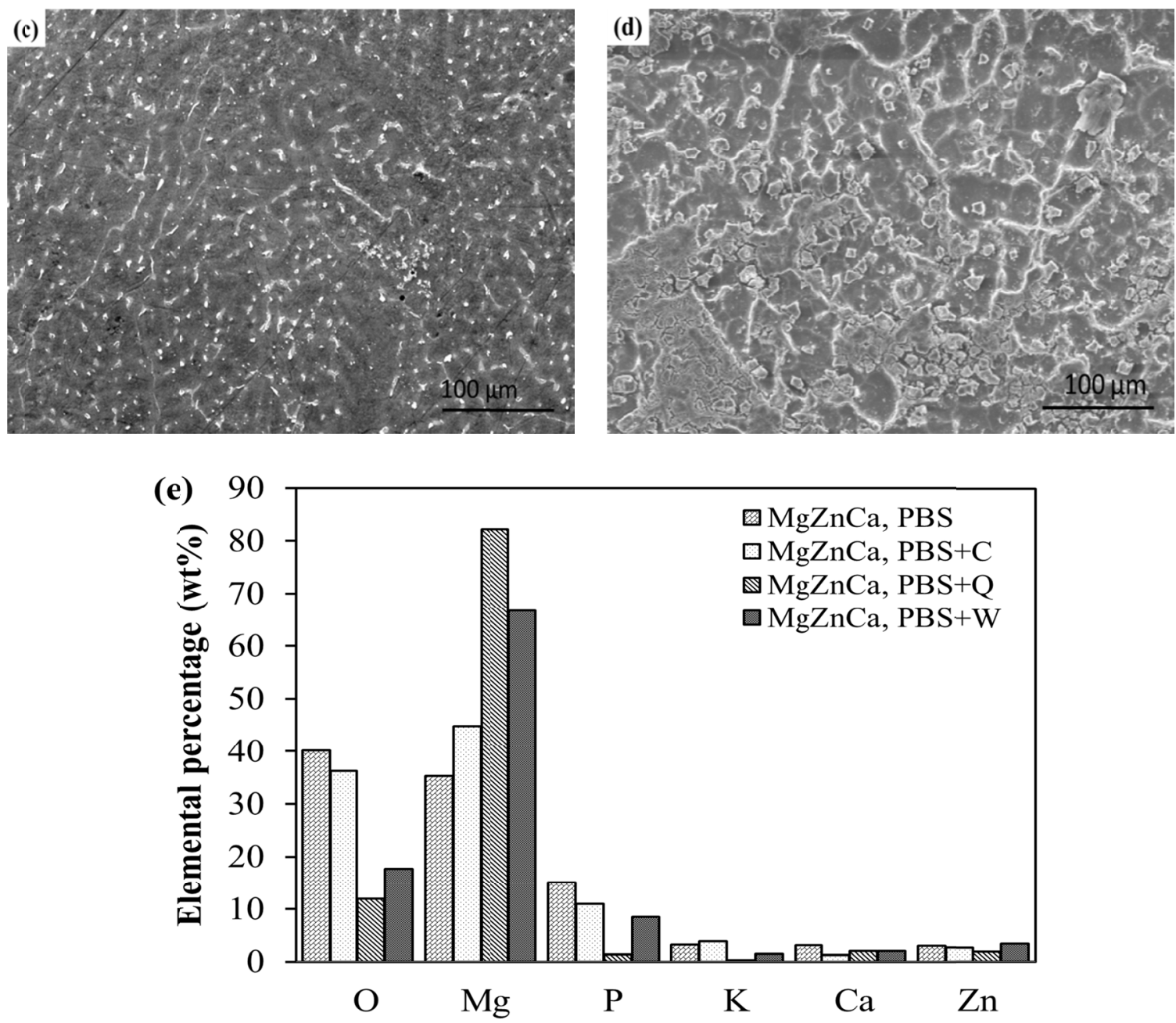

Figure 5.4: Scanning electron microscopy image of alloys after potentiodynamic corrosion: (a) $\mathrm{MgZnCa}, \mathrm{PBS}$; (b) $\mathrm{MgZnCa}, \mathrm{PBS}+\mathrm{C}$; (c) $\mathrm{MgZnCa}, \mathrm{PBS}+\mathrm{Q}$; (d) $\mathrm{MgZnCa}$, $P B S+W$ and (e) composition of the surface layers formed on Mg alloys during accelerated corrosion tests in PBS and PBS with amino acids.
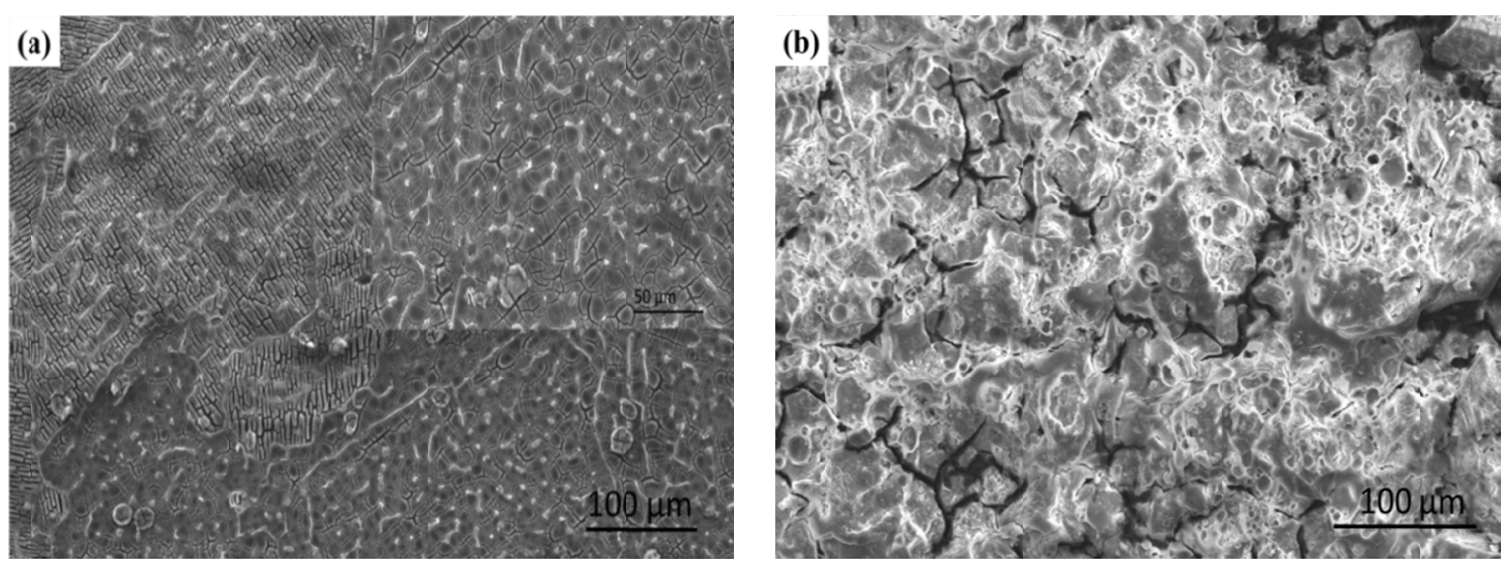

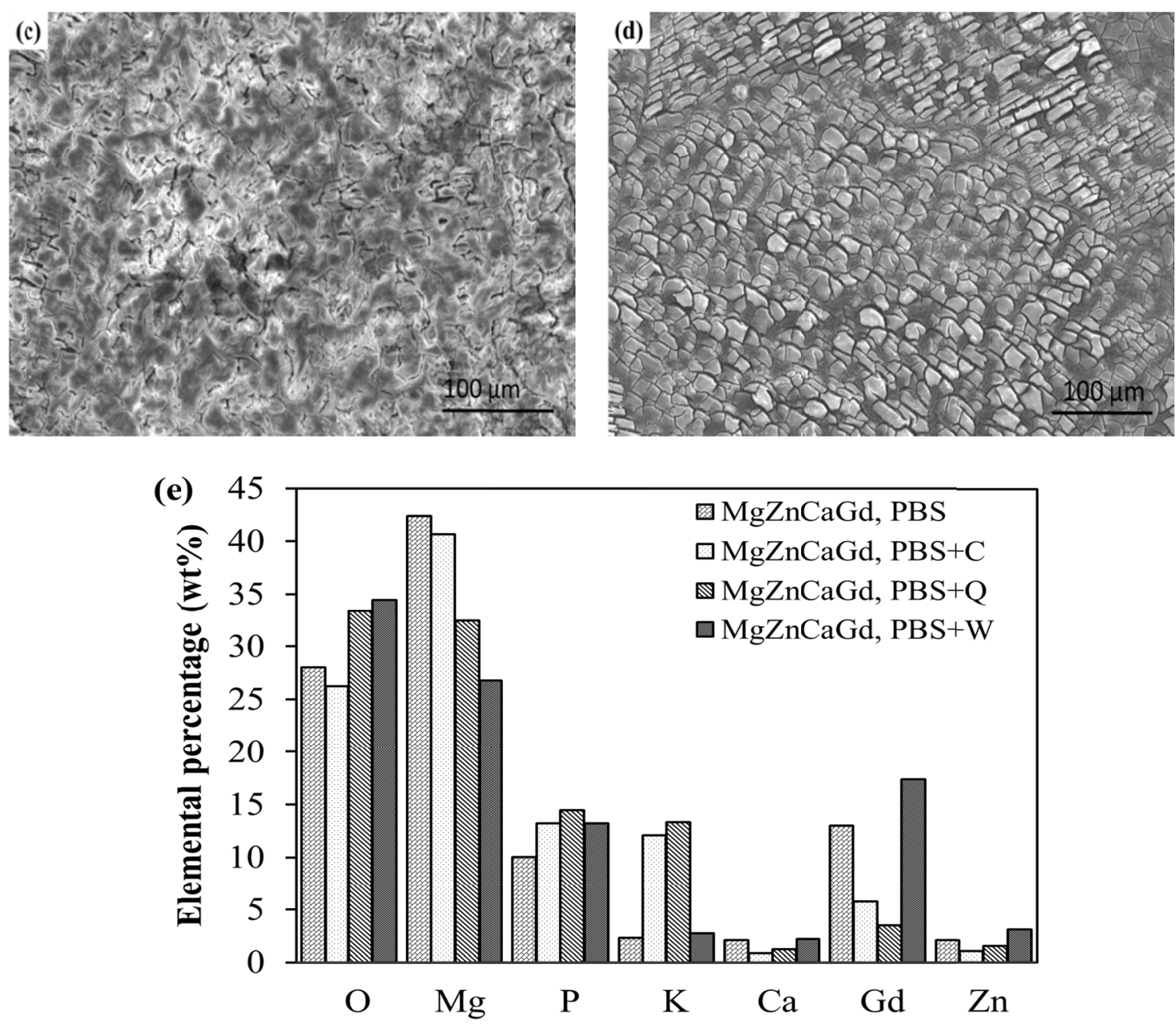

Figure 5.5: Scanning electron microscopy image of alloys after potentiodynamic corrosion: (a) $M g Z n C a G d, P B S$; (b) $M g Z n C a G d, P B S+C$; (c) $M g Z n C a G d, P B S+Q$; (d)

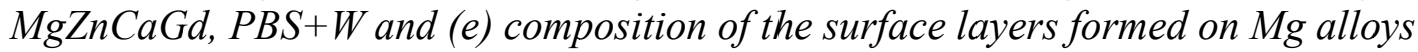
during accelerated corrosion tests in PBS and PBS with amino acids.

\subsubsection{SEM/EDS of Mechanically Polished Alloys/MMCs in PBS after Static Immersion Tests}

Surface corrosion of Mg alloys/MMCs commences immediately upon immersion in PBS due to the presence of chloride, phosphate, carbonate and sulphate ions [127]. Morphological changes also occur due to localized corrosion primarily at the grain 
boundary sites, which then propagate along the grain boundaries. EDS analysis of the surface revealed the possible formation of a mixture of apatite, zinc phosphate and calcium phosphate. Figure 5.6 shows the SEM photomicrographs after static immersion test for 192 hours in PBS at $37{ }^{\circ} \mathrm{C}$. In the case of samples with higher Zn concentration (Mg5Zn1CaxHA), SEM photomicrograph revealed localized corrosion attack preferentially on the $\alpha$-matrix and to a lesser extent on the $\beta$-phases. During corrosion $\mathrm{H}_{2} \mathrm{O}$ is reduced according to equation (1) producing $\mathrm{H}_{2}$ and $\mathrm{Mg}(\mathrm{OH})_{2}$, with an increase in $\mathrm{pH}$. Wang et al. reported localized $\mathrm{pH}$ increase, which is believed to cause the precipitation of less soluble products such as: magnesium phosphate, magnesium apatite, zinc phosphate and calcium phosphate [127]. EDS analysis of samples after immersion in PBS for 192 hours are shown in Figure 5.7 (a). Higher concentrations of alloying elements were observed on the surface of samples, which revealed preferential degradation of Mg. Figure 5.7 (b) shows the SEM photomicrograph of mechanically polished Mg5Zn1Ca alloy after 192 hours of immersion and the inset shows the SEM of human bone. Both photomicrographs display similar morphology, which may be advantageous for cellular activity. Such surface morphology can be conducive to cell viability since the filopodia can grow into the micro-pores and accelerate adherence and spreading. Furthermore, these micro-pores can serve as supply routes or reservoirs for 
nutrients that are essential for good cellular viability. Marinucci et al. reported that surface roughness, cellular attachment and osteoblast activity can be directly correlated [133].
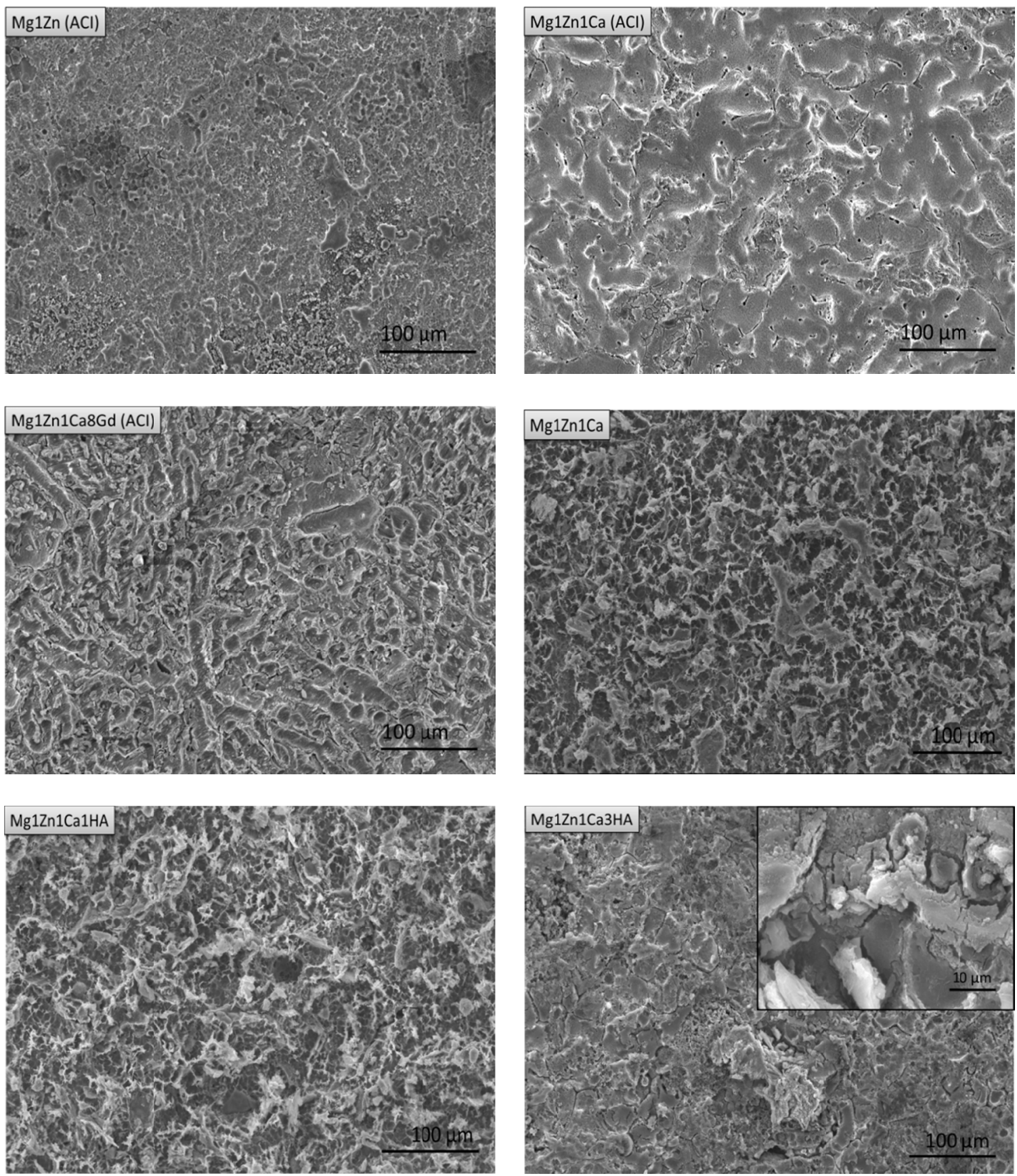

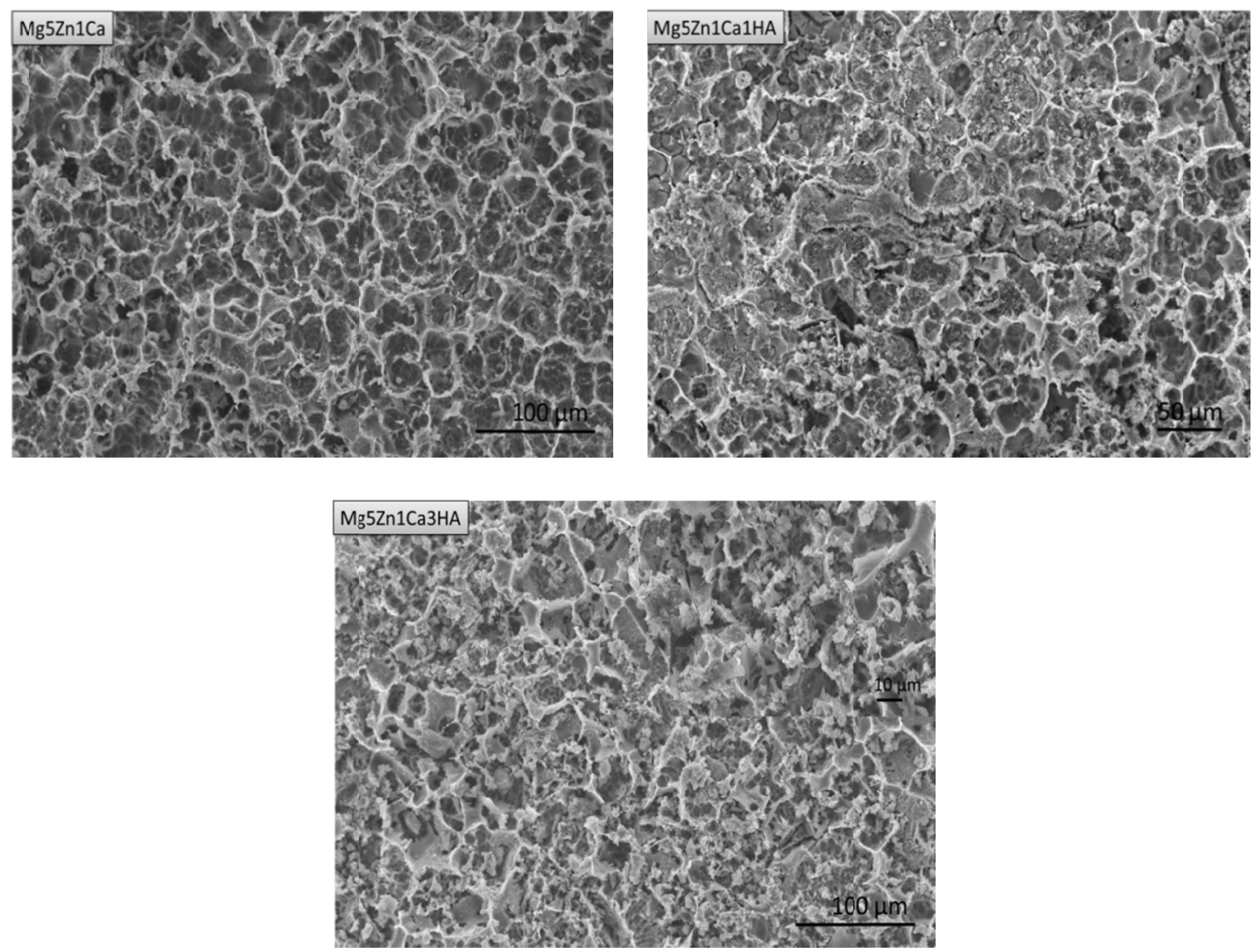

Figure 5.6: SEM photomicrographs of mechanically polished samples after 192 hours of immersion in PBS at $37^{\circ} \mathrm{C}$. 

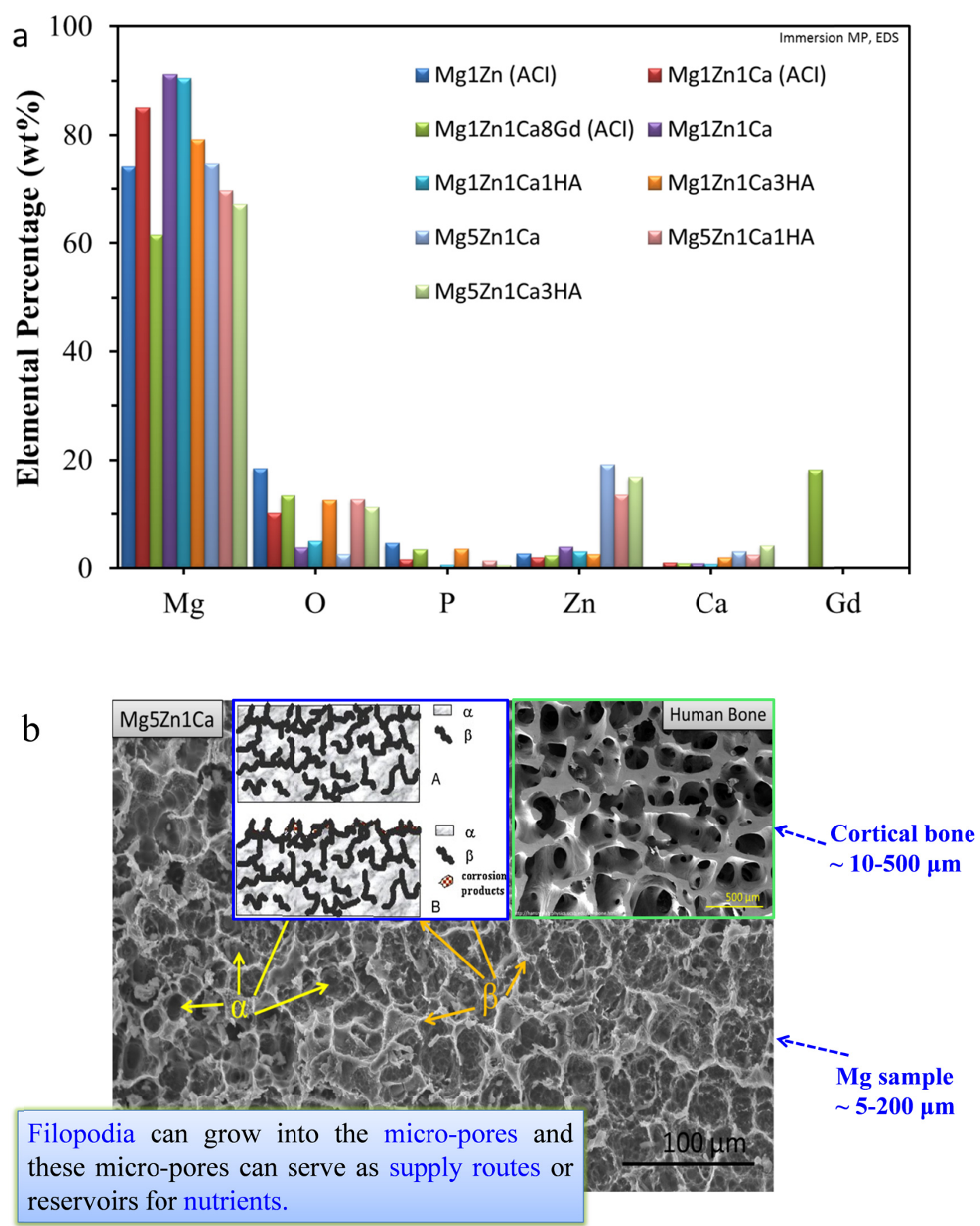

Figure 5.7: (a) Plot showing composition of the surface layers formed on mechanically polished Mg samples after immersion and (b) microstructure of Mg5Zn1Ca corroded in $P B S$, showing $\alpha$ and $\beta$ phases (Right inset SEM of human bone of 22 year old male [126] and left inset change of surface composition during corrosion, where (A) is the initial surface and (B) is the surface after corrosion [63]) . 


\subsubsection{SEM/EDS of Mechanically Polished Alloys/MMCs in PBS after Dynamic Immersion Test}

Dynamic immersion tests were performed to access the effect of velocity on degradation behavior of $\mathrm{Mg}$ alloys/MMCs in PBS at $37{ }^{\circ} \mathrm{C}$ using a vortex shaker with a constant speed of $\sim 500 \mathrm{rpm}$ for 144 hours. Figure 5.8 shows the SEM photomicrographs of mechanically polished samples after dynamic immersion. All samples exhibited evidence of severe pitting as compared with those under static conditions (see Figure 5.6). Crack were observed on the surfaces of $\mathrm{Mg} 1 \mathrm{Zn} 1 \mathrm{Ca}(\mathrm{ACI})$ and $\mathrm{Mg} 1 \mathrm{Zn} 1 \mathrm{Ca} 8 \mathrm{Gd}$ (ACI), (inset) Figure 5.8, which are known to cause premature failure. During dynamic immersion, relative motion between the electrolyte and the samples dislodges the corrosion products from the surface, which leads to higher degradation rate as compared with static conditions. This is explained in terms of an increase in the critical limiting current, which increases with agitation as the diffusion layer thickness decreases in accordance with the Butler-Volmer equation (Mass-transfer control), see section 4.5.4.
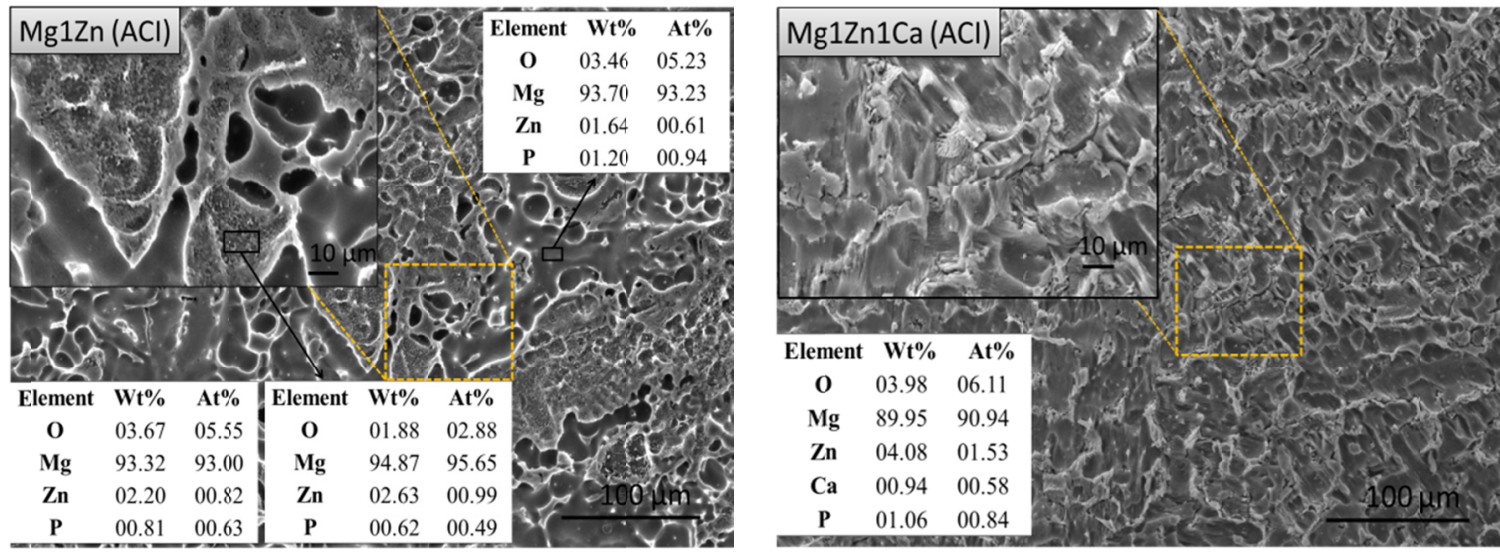

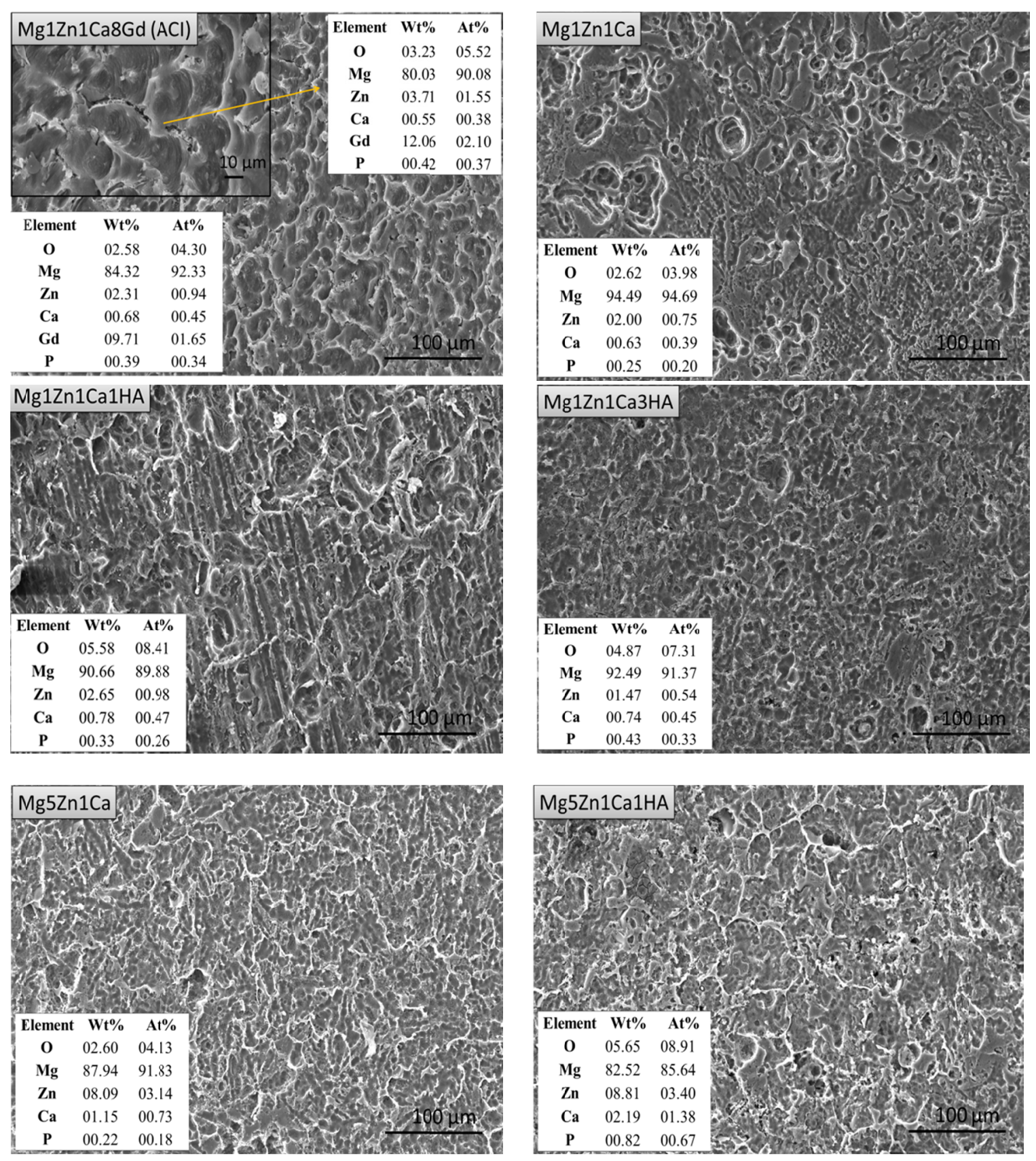


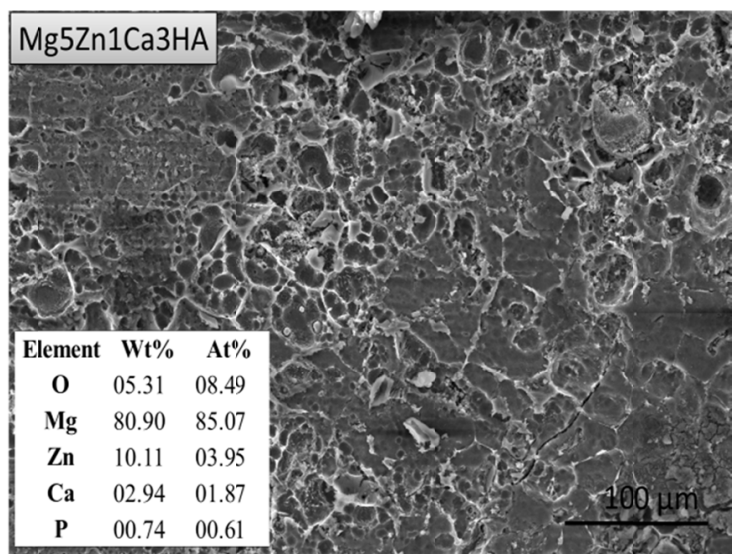

Figure 5.8: SEM photomicrographs of mechanically polished alloys after dynamic immersion test in PBS.

\subsubsection{SEM/EDS of Anodized Mg Alloys/MMCs after Potentiodynamic Corrosion in PBS}

The surface of anodized $\mathrm{Mg}$ alloys/MMCs generally consists of two layers; oxides composed of heavy metals that are dense and non-porous and the other composed of light metals that are less dense and porous (see section 4.3.2 on corrosion kinetics). The thickness of surface oxides on $\mathrm{Mg}$ based alloys/MMCs has been reported to range between $5-50 \mu \mathrm{m}[6,131,132]$, but is dependent on processing parameters such as: exposure time, type of electrolyte and temperature. The aforementioned conditions significantly affect the morphology, tribological properties and oxide adhesion [6]. The resulting material properties affect its corrosion resistance, mechanical integrity and initial stability in physiological solutions. Thus, an anodized implant device can provide adequate corrosion resistance to allow healing after surgery, such that once implanted, 
corrosion is delayed as healing takes place in the area of the surgery. SEM/EDS analyses of anodized samples after potentiodynamic corrosion are shown in Figure 5.9, where although the anodized samples appeared to be smoother than mechanically polished samples, there was no significant variation in composition (see EDS analysis in Figure 5.9). Anodization develops a uniform passivation layer on the surface, which prevents direct contact of electrolyte with the substrate. Evidence of the occurrence of pitting corrosion during anodization, and in some cases, stress-induced cracks were observed. Pits generally develop due to aggressive attack by chloride ions at defects in the oxide film [6].
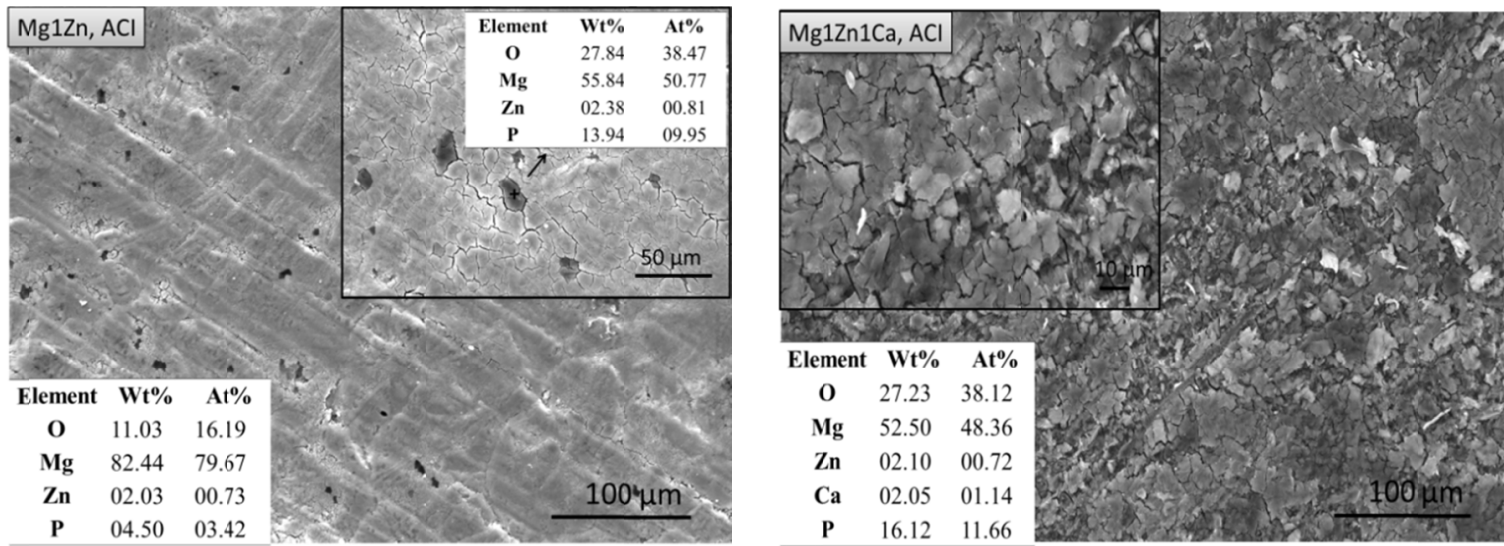

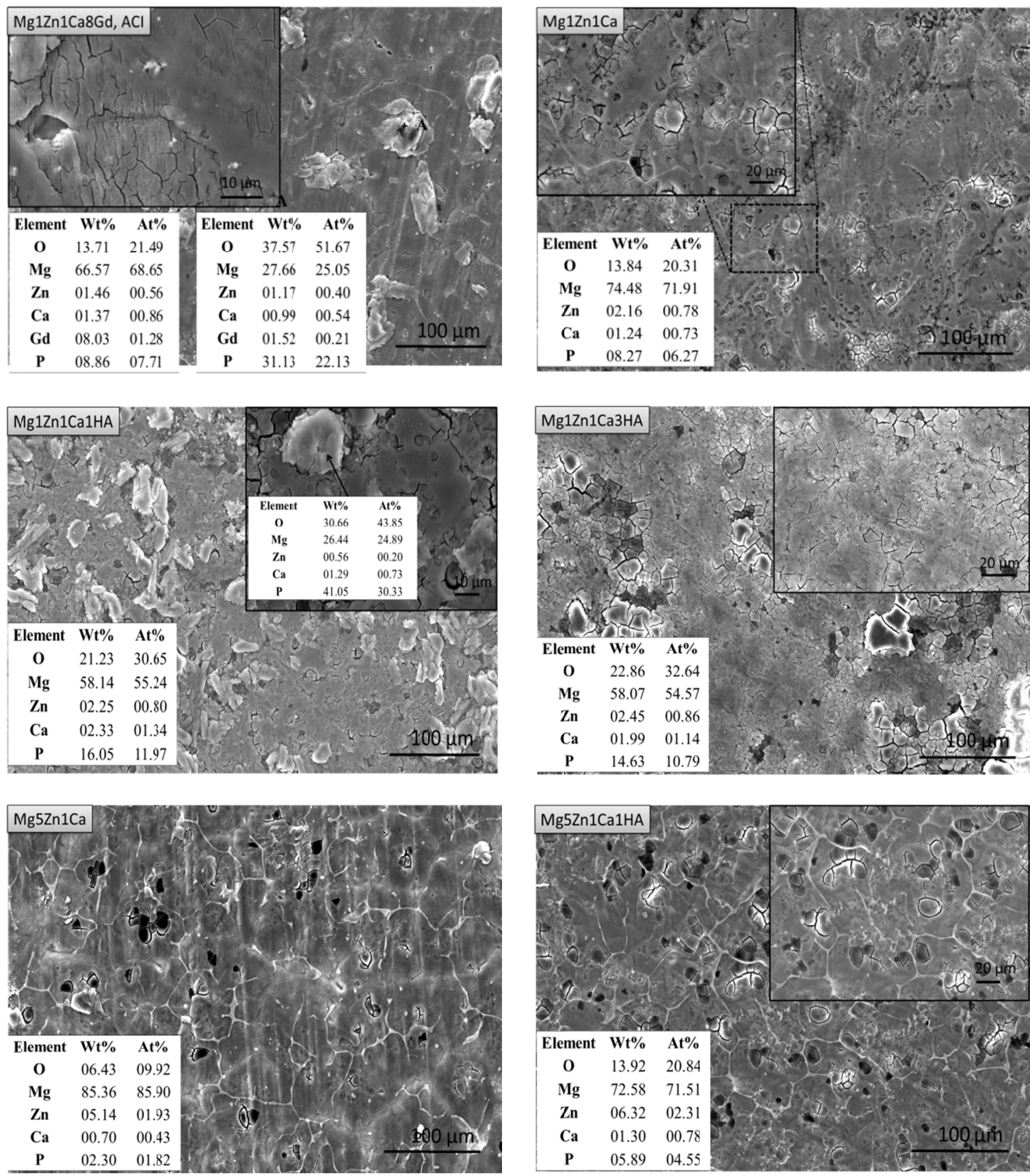


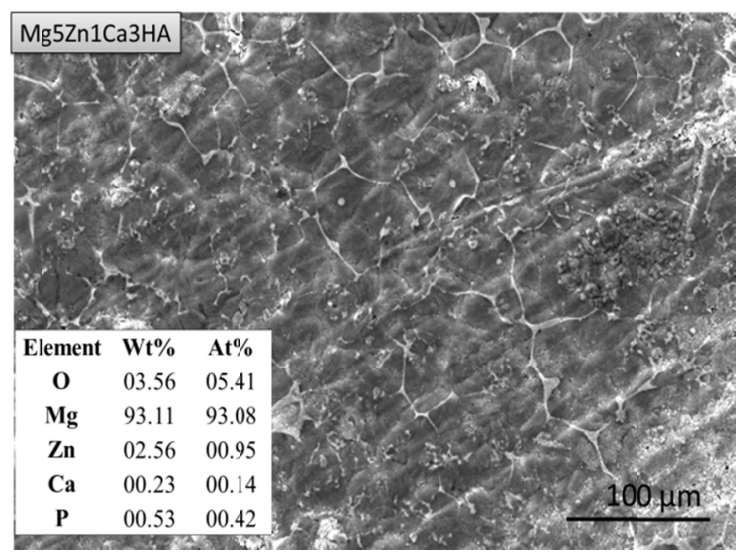

Figure 5.9: Photomicrographs of anodized samples after potentiodynamic polarization test in PBS at $37^{\circ} \mathrm{C}$.

\subsubsection{SEM/EDS of Anodized Mg Alloys/MMCs in PBS after Static Immersion Test}

As previously discussed, anodization of a biodegradable implant imparts initial corrosion resistance and mechanical integrity after implantation and ensures sufficient time for the surgical region to heal. A thicker and uniform oxide layer is produced on $\mathrm{Mg}$ samples by anodization as compared with that on mechanically polished samples under ambient conditions. Figure 5.10 shows the SEM photomicrographs of anodized samples after static immersion tests in PBS at $37{ }^{\circ} \mathrm{C}$ for 192 hours. Surface corrosion commences immediately upon immersion in PBS due to the presence of chlorides, phosphates, carbonates and sulphates. Morphological changes because of localized corrosion are observed to occur at the grain boundary sites (particularly the $\alpha$-matrix), which then propagated along the grain boundaries. EDS analysis of the surface revealed possible formation of a mixture of apatite, zinc phosphate and calcium phosphate as shown in Figure 5.10 (inset). After 192 hours of immersion in PBS, the size of pores and cavities on anodized samples were approximately $\sim 1-10 \mu \mathrm{m}$ and $\sim 10-40 \mu \mathrm{m}$ respectively, which were $1 / 4$ of the size of those observed on mechanically polished samples (pore size $\sim 10-30$ 
$\mu \mathrm{m}$ and cavities $\sim 40-100 \mu \mathrm{m}$ ). This type of surface composed of pores and cavities have been reported to be conducive to osteoblast and endothelial cell proliferation since the filopodia can grow into the micro-pores and accelerate adherence and spreading. Additionally, micro-pores serve as supply routes or reservoirs for nutrients that are essential for good cellular viability.
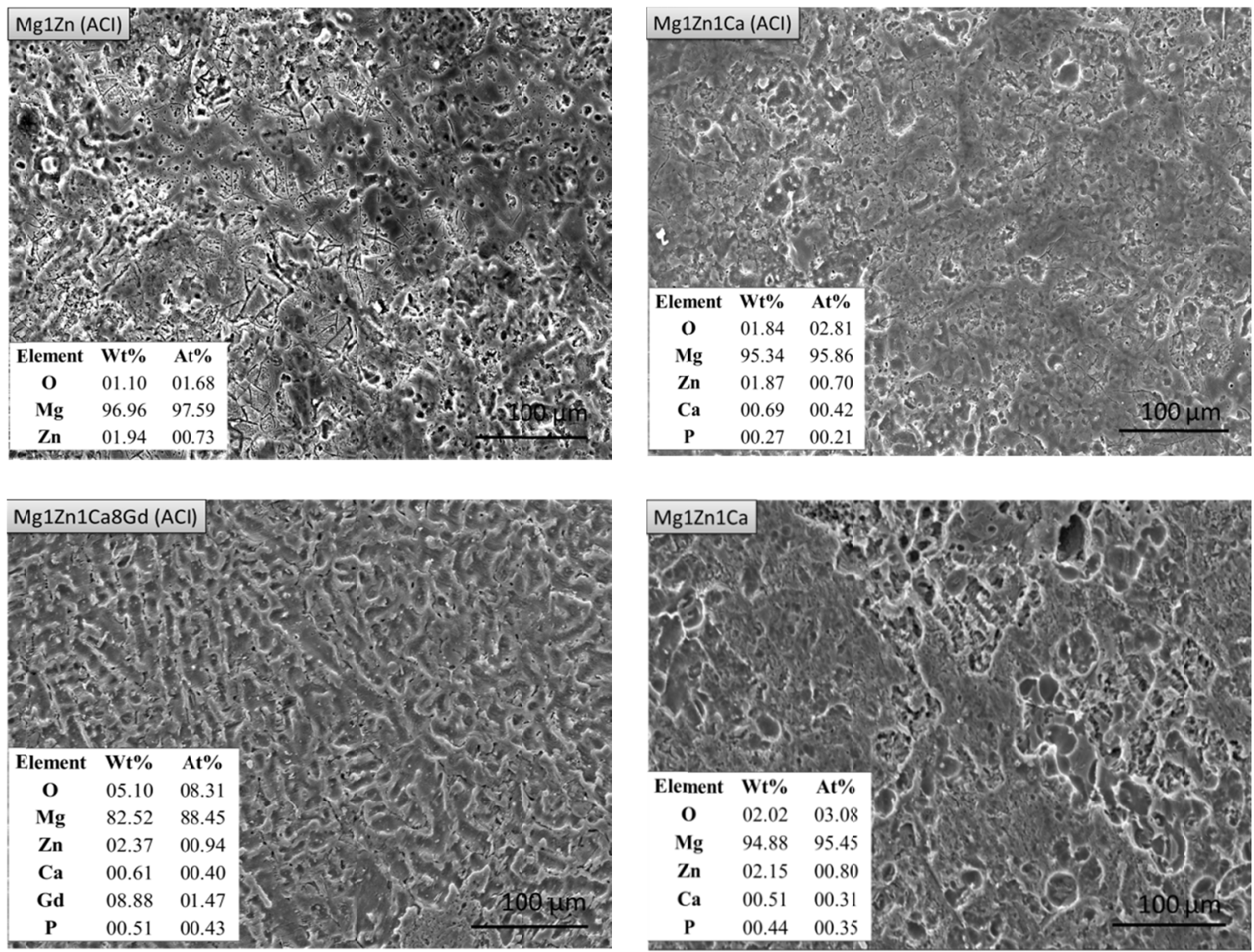

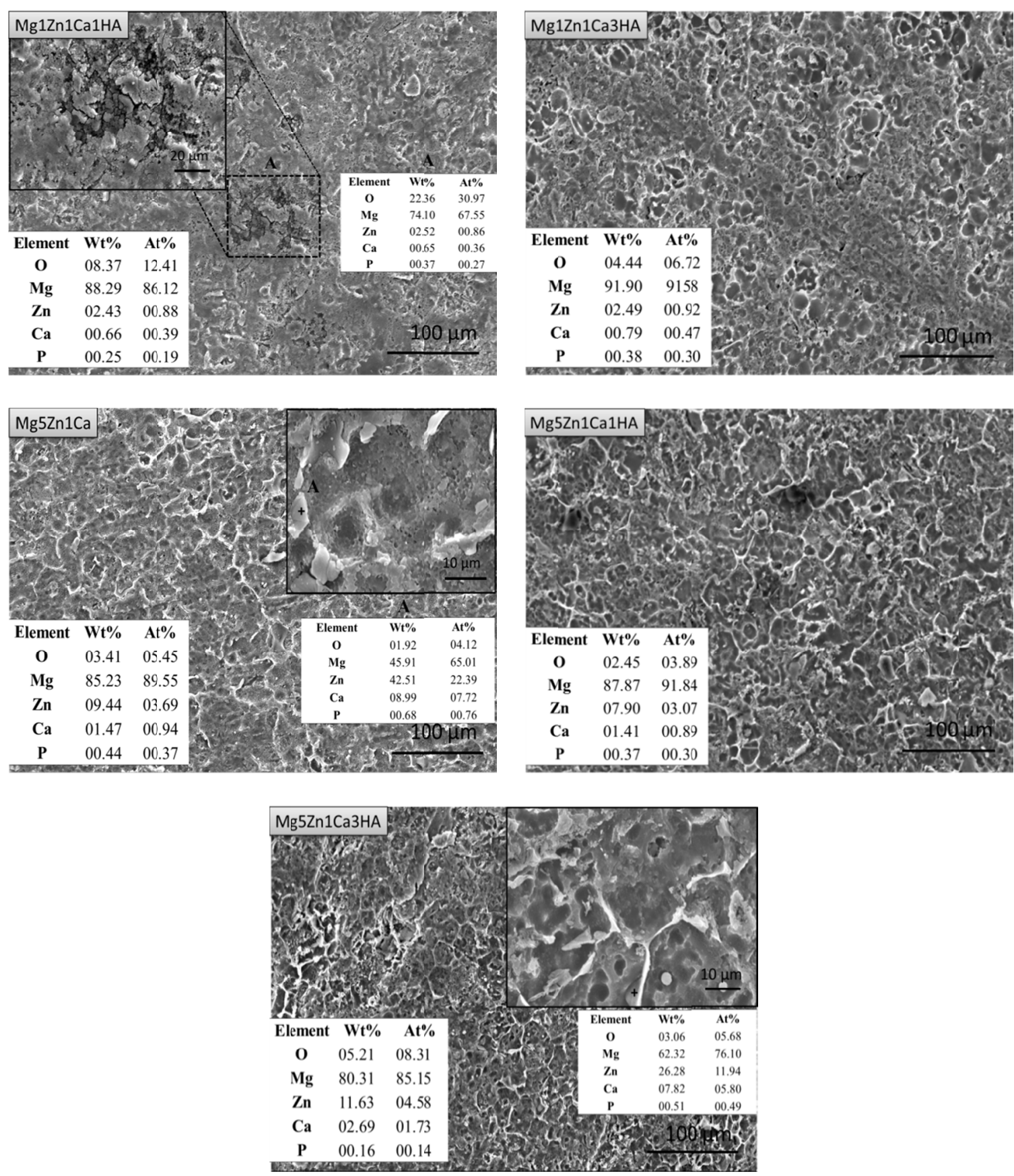

Figure 5.10: SEM photomicrographs of anodized sample after 192 hours of immersion in PBS at $37^{\circ} \mathrm{C}$. 


\subsubsection{SEM/EDS of Anodized Mg Alloys/MMCs in PBS after Dynamic Immersion}

\section{Test}

In order to better understand the degradation behavior of the $\mathrm{Mg}$ samples, dynamic immersion tests were conducted using a vortex shaker at a constant speed of $\sim 500 \mathrm{rpm}$ for 144 hours in PBS at $37{ }^{\circ} \mathrm{C}$. As discussed in section 4.5, corrosion rates increased under dynamic conditions and so did the $\mathrm{pH}$ of the electrolyte. This was in contrast to what was observed for anodized samples under static conditions as shown in Figure 2.7 and 2.5 respectively.

Figure 5.11 shows the SEM photomicrograph of Mg alloys/MMCs after dynamic immersion, where the size of the pits and cavities are larger than those created under static conditions. Pitting corrosion appears to have initiated at defects in the matrix before extending towards the grain boundaries forming a honeycomb structure of pore and cavity sizes ranging between $\sim 1-10 \mu \mathrm{m}$ and $\sim 10-80 \mu \mathrm{m}$ respectively. The aforementioned dimensions are within the acceptable range for cellular activity. Generally, grain boundaries corroded to a greater extent under dynamic conditions as compared with that under static conditions. 

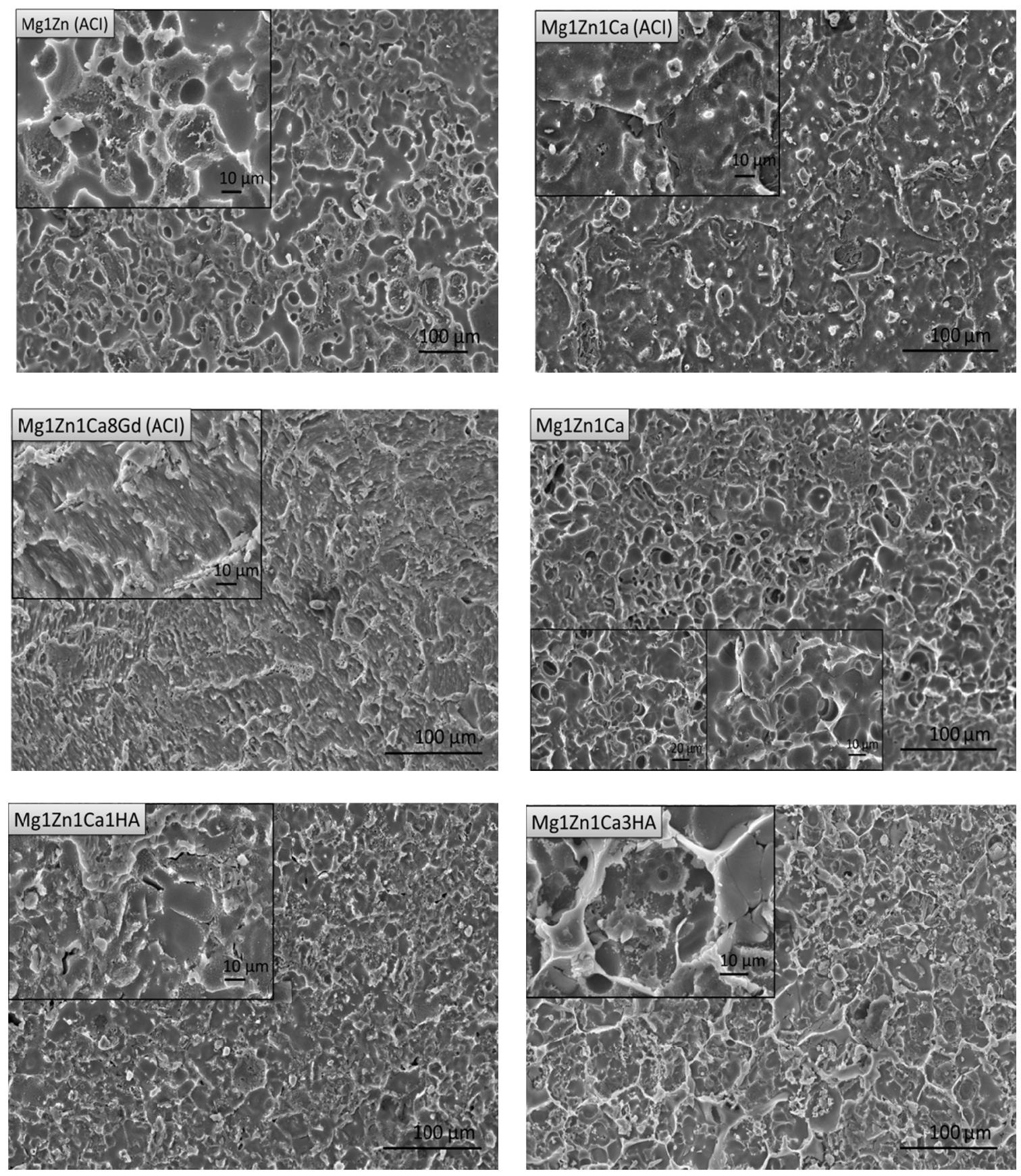

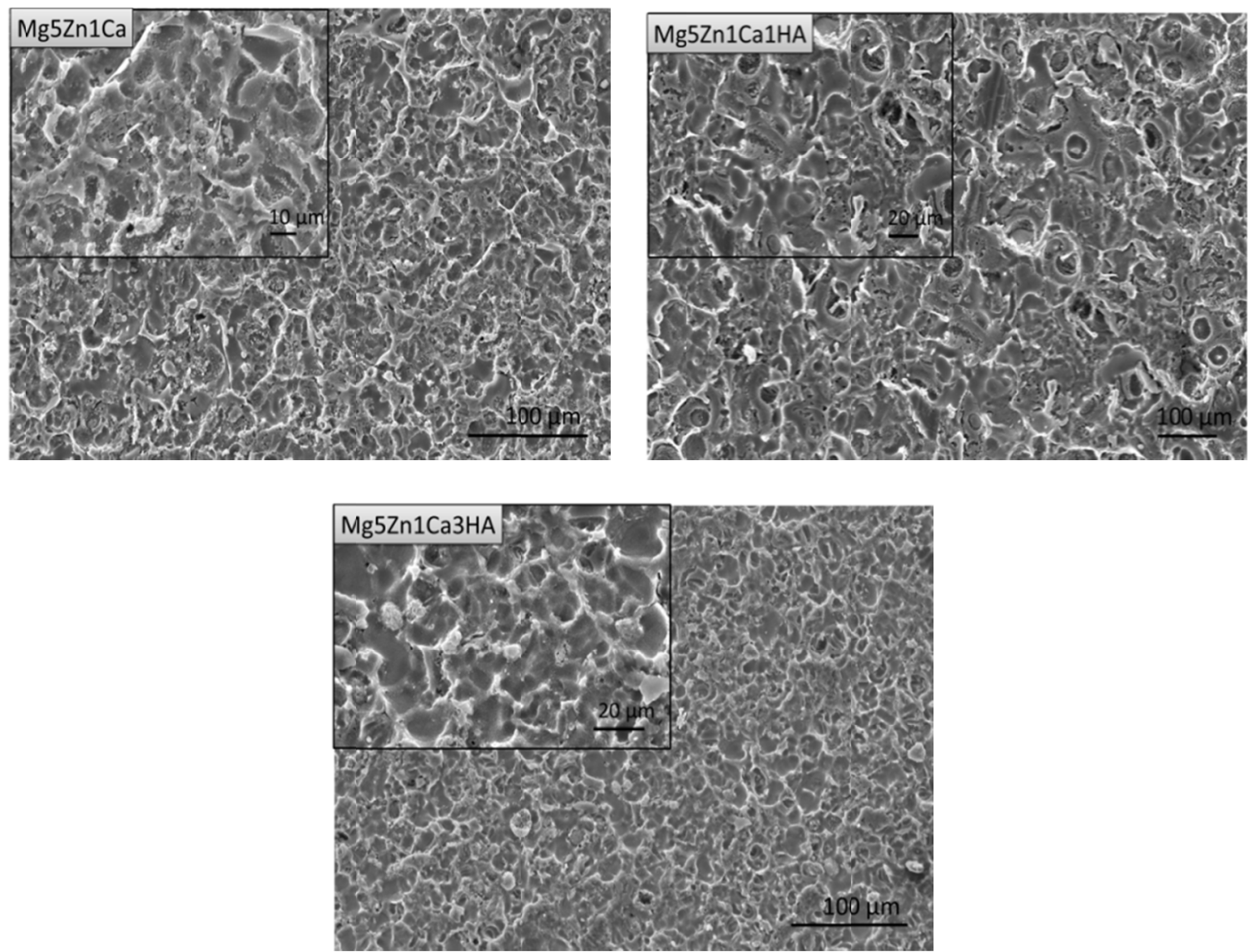

Figure 5.11: Photomicrographs of anodized samples after dynamic immersion for 192 hours in PBS at $37^{\circ}$ C.in PBS at $37^{\circ} \mathrm{C}$.

Figure 5.12 shows the plots for EDS analysis for anodized samples subjected to static and dynamic immersion, where for static immersion overall higher concentration of $\mathrm{Mg}$ was observed. In the case of dynamic immersion, lower concentration of $\mathrm{Mg}$ was observed, which is an indicative of higher degradation. Moreover, during dynamic immersion higher concentration of $\mathrm{Zn}$ was observed on the surface, which is comparable with SEM photomicrographs confirming that the grain boundaries remained intact. The 
corrosion attack preferentially occurred at $\alpha$-matrix and to some extent at $\beta$-phases, which slows the propagation of corrosion over $\alpha$-matrix. Similar concentrations of oxides were observed on the surface of anodized samples, which could be undamaged oxide layer.

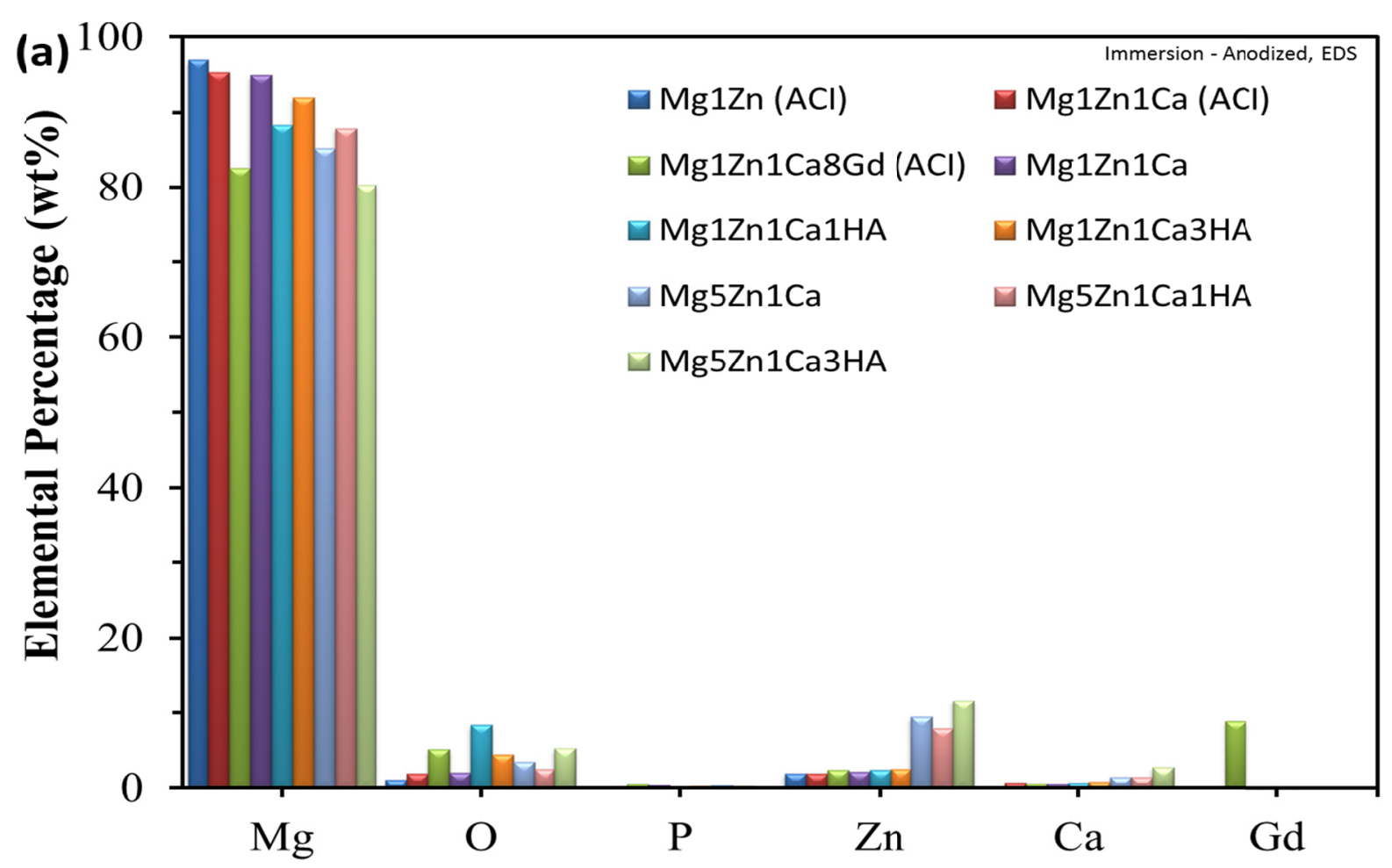




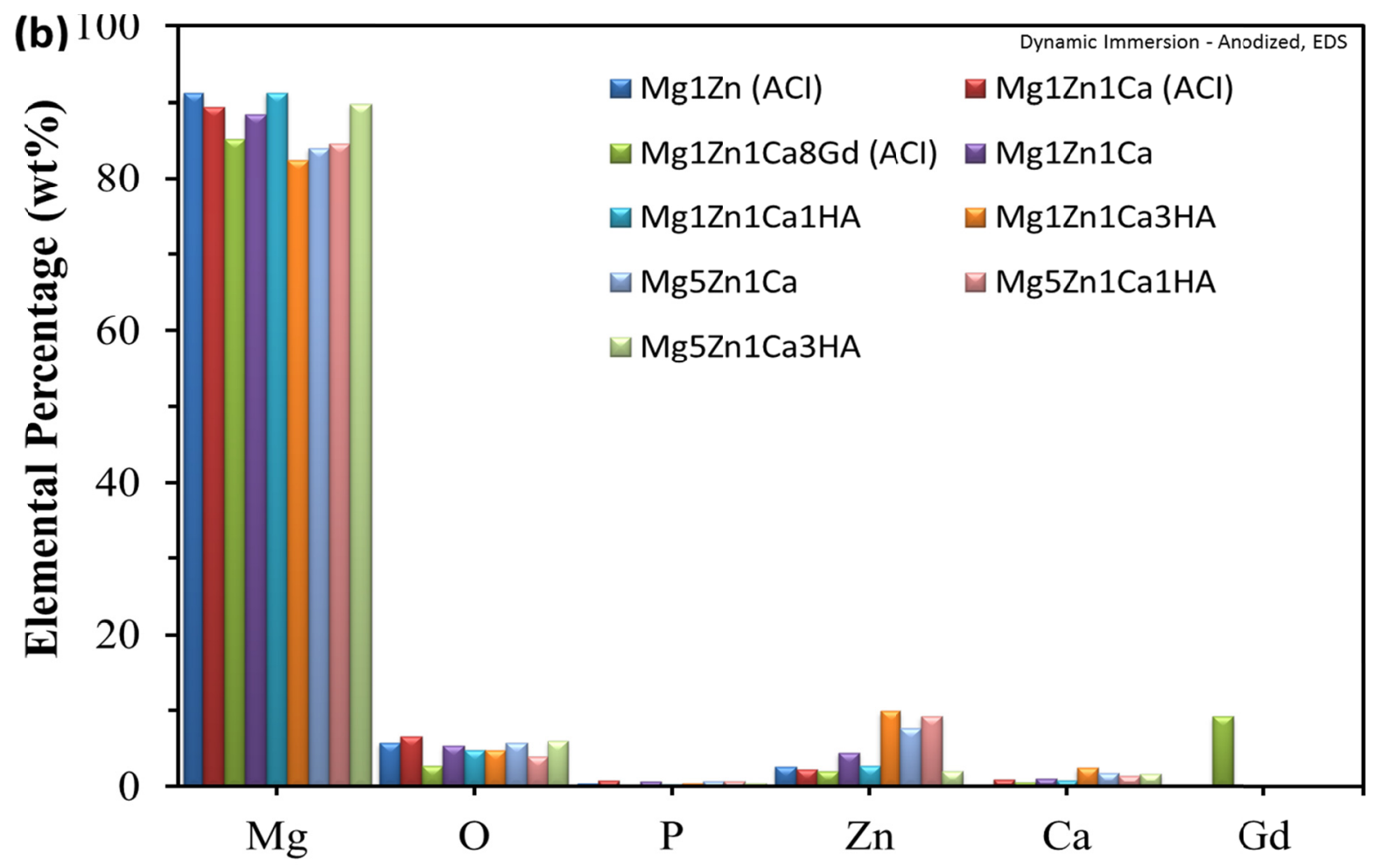

Figure 5.12: Plot showing composition of the surface layers formed on anodized $M g$ samples: (a) static immersion and (b) dynamic immersion.

\subsubsection{X-Ray Diffraction of Mg Alloy/MMCs Before and After Corrosion}

XRD analysis was conducted in an effort to determine the presence of intermetallic phases, which are known to affect the mechanical and corrosion properties of Mg based alloys/MMCs. Various phases were depicted in the spectra as shown in Figure 5.13. The samples were mainly composed of $\alpha$-Mg solid solution with stable intermetallic compounds such as, $\mathrm{Mg}_{2} \mathrm{Ca}, \mathrm{MgZn}_{2}, \mathrm{CaZn}_{2}$ and $\mathrm{Mg}_{5} \mathrm{Gd}$. Zhou et al. reported that $\mathrm{MgZnCa}$ alloys synthesized by twin-roll rapid solidification technique produced a large number of precipitates, which contribute to precipitation hardening [105]. Peng et al. manufactured Mg-Gd based alloys and reported superior mechanical properties due to a microstructure composed of fine metastable precipitates dispersed in the matrix $[79,89]$. 
The relative amount of each phase present in the samples was evaluated from the respective areas under the XRD spectra. The relative proportion $(w t \%)$ of each intermetallic phase occurred in the following order: $\mathrm{MgZn}_{2}(0.04-0.34)>\mathrm{Mg}_{2} \mathrm{Ca}(0.009$ $0.018)>\mathrm{Ca}_{5}\left(\mathrm{PO}_{4}\right)_{3}(\mathrm{OH})(0.005-0.013)>\mathrm{Ca}_{2} \mathrm{Mg}_{6} \mathrm{Zn}_{3}(0.002-0.008)>\mathrm{Mg}_{5} \mathrm{Gd}(0.010)$. The binary phases, referred to as Laves phase [171], are known to improved creep resistance due to solid solution strengthening, precipitation strengthening and grain boundary pinning, which increase hardness and wear resistance. Additionally, these phases serve as grain refining agents and contribute to grain boundary strengthening. Tao et al. (2008) reported the formation of fine precipitates of $\mathrm{Mg}_{2} \mathrm{Ca}$ dispersed within the grains [87], as was observed in our work.

Figure 5.13 (b) shows the XRD spectra of the Mg samples received from Brunel University. The samples were mainly composed of $\alpha-\mathrm{Mg}$ matrix and various binary and ternary intermetallic compounds $\mathrm{Mg}_{2} \mathrm{Ca}, \mathrm{CaZn}, \mathrm{MgZn}_{2}, \mathrm{CaZn}_{5}, \mathrm{Ca}_{2} \mathrm{Mg}_{6} \mathrm{Zn}_{3}$ and $\mathrm{Ca}_{5}\left(\mathrm{PO}_{4}\right)_{3}(\mathrm{OH})$. Zibiao Li (2010) matched MgZnCaHA with HA phase and the latter remained chemically unaffected during manufacturing [113]. Figure 5.14 shows the XRD spectra for anodized samples. It should be noted that both mechanical and anodized samples exhibited similar XRD peaks. This was attributed to the fact that the depth of penetration of the X-ray beam was greater than the thickness of the anodized oxide layer so that, the effect of anodization could not be detected as the beam interacted with the substrate in each case. 

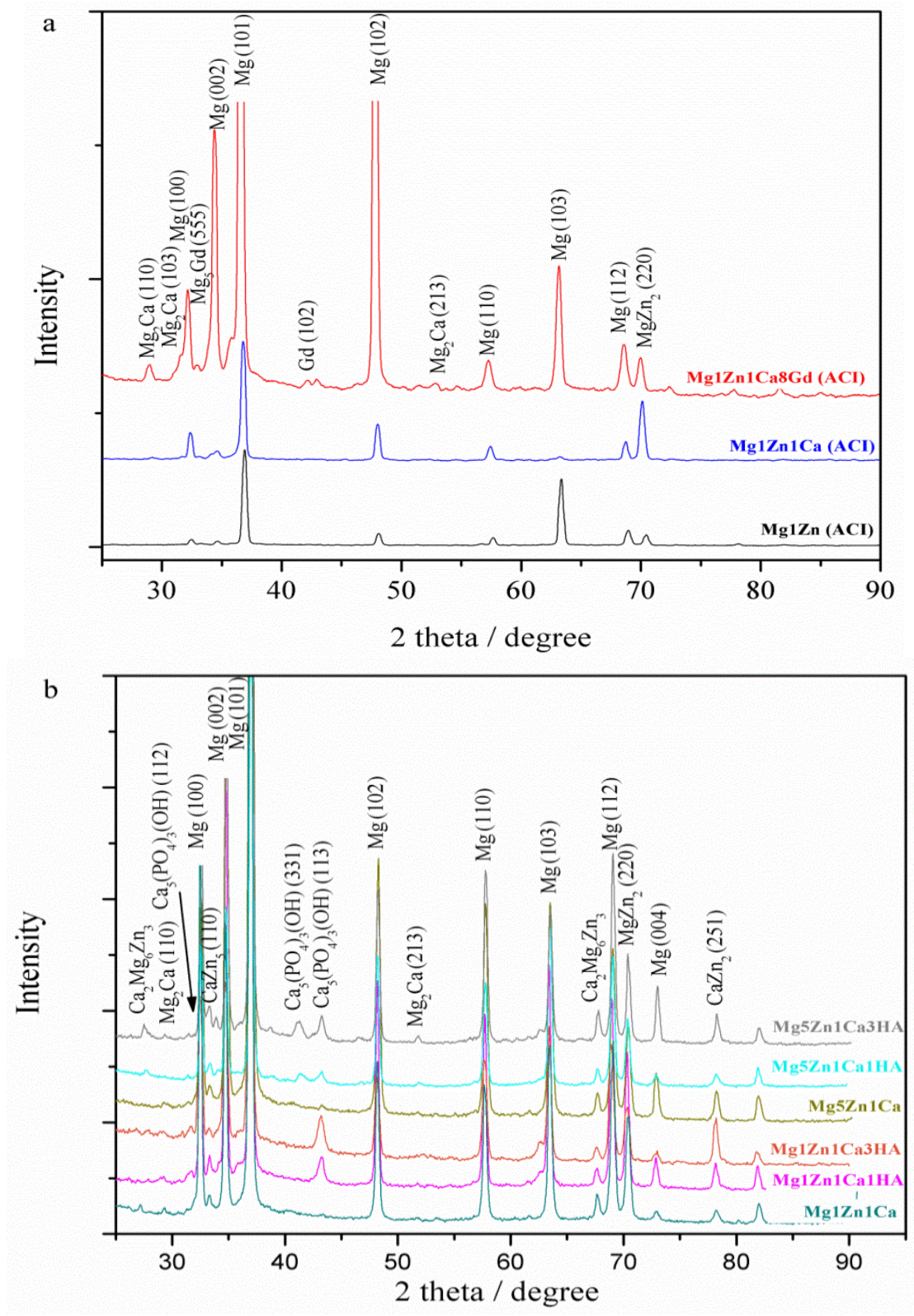

Figure 5.13: XRD spectra of mechanically polished samples: (a) MglZn (ACI); MglZn1Ca (ACI); Mg1Zn1Ca8Gd (ACI) and (b) Mg1Zn1Ca; Mg1Zn1CalHA; MglZn1Ca3HA; Mg5Zn1Ca; Mg5Zn1CalHA; and Mg5Zn1Ca3HA. 


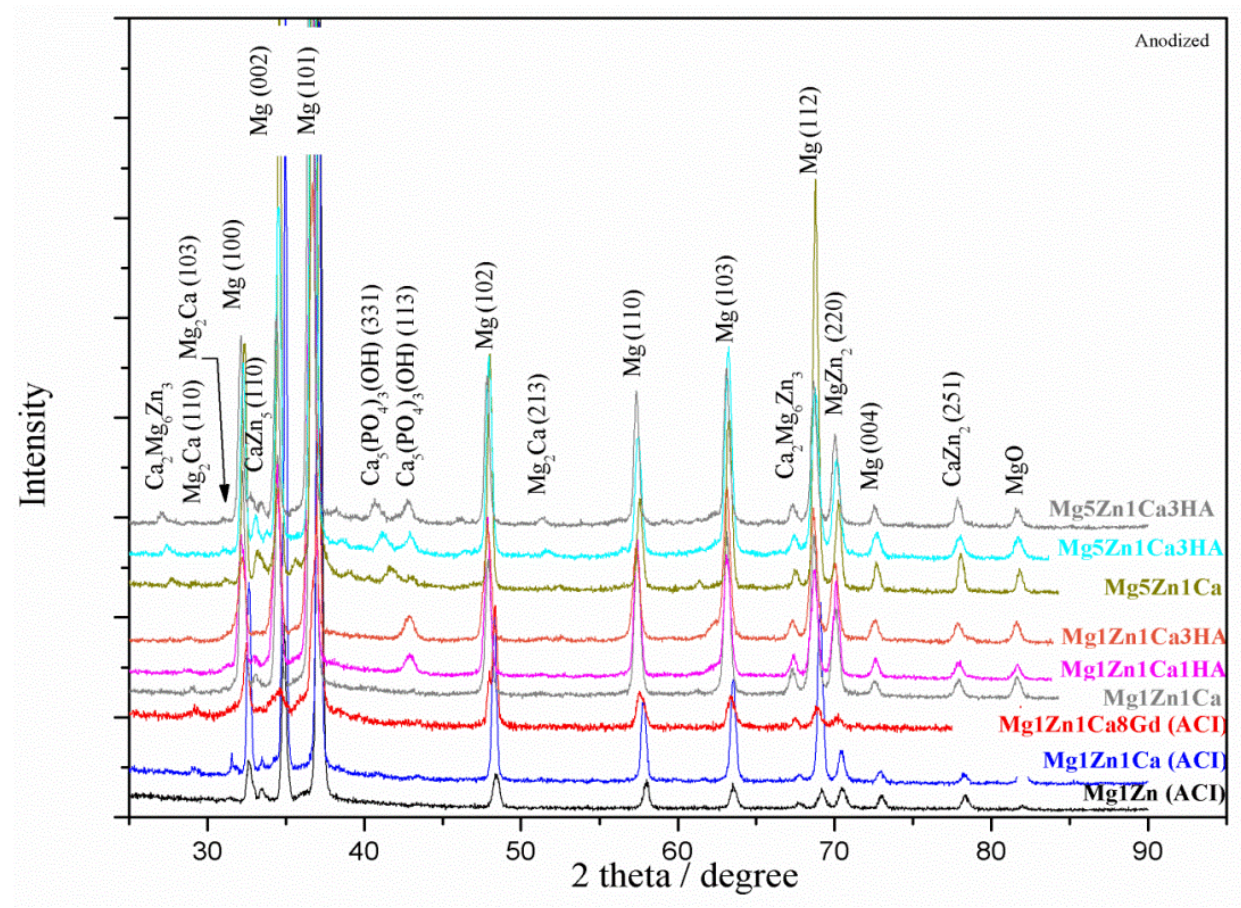

Figure 5.14: XRD spectra of anodized samples.

Figure 5.15 and 5.16 show the XRD analyses of the samples after corrosion, where it can be observed that the intensity of Mg peaks is low for mechanically polished samples as compared with those for anodized samples. These results correlated with the composition of the alloys/MMCs (EDS analysis), where a lower concentration of Mg was observed for the former samples (see section 5.1.1.2). A higher Mg peak intensity for confirmed a higher corrosion resistance of anodized samples. Furthermore, the peak intensity results also correlated with corrosion rates discussed in section 4.5 , where lower corrosion rates were observed for anodized samples as compared with those obtained for mechanically polished samples. 


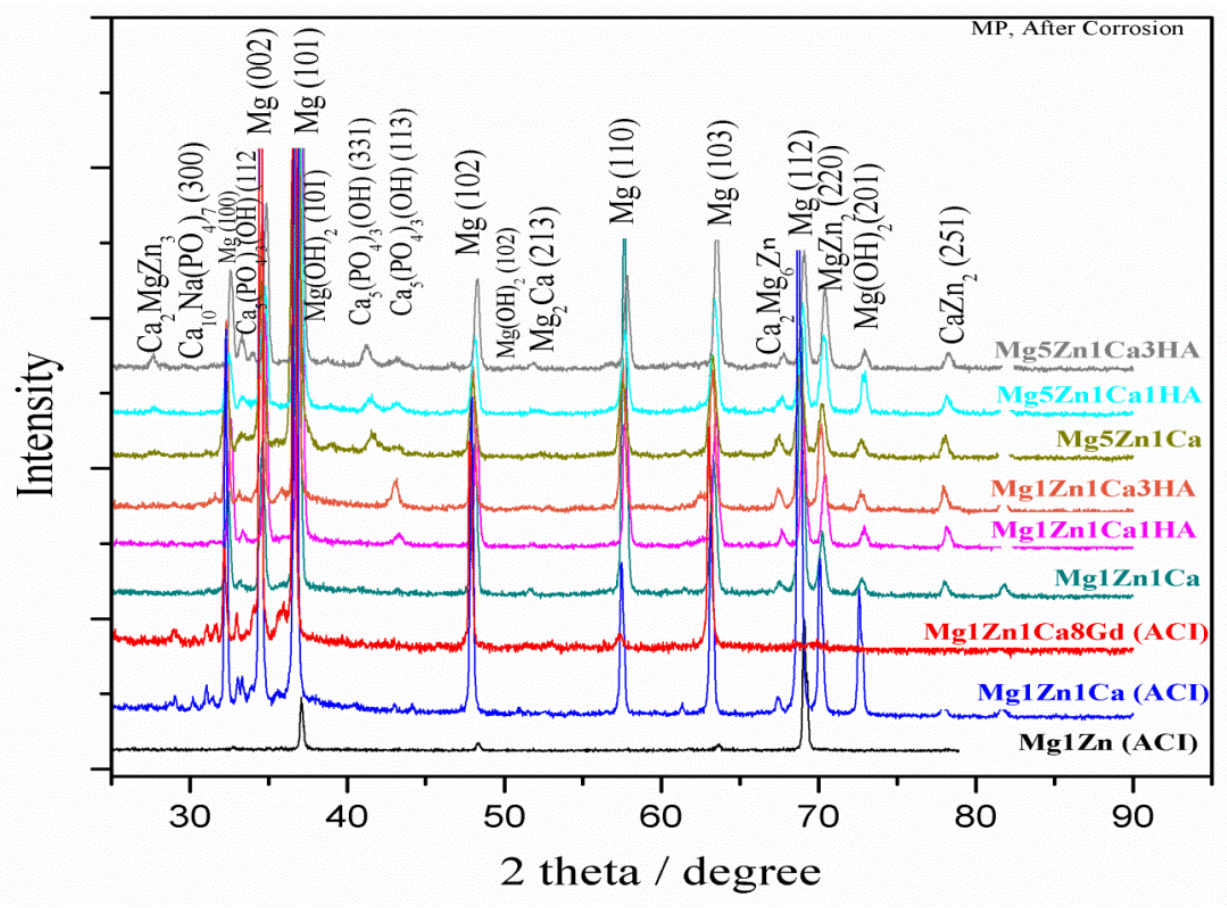

Figure 5.15: XRD spectra of mechanically polished samples after corrosion in PBS.

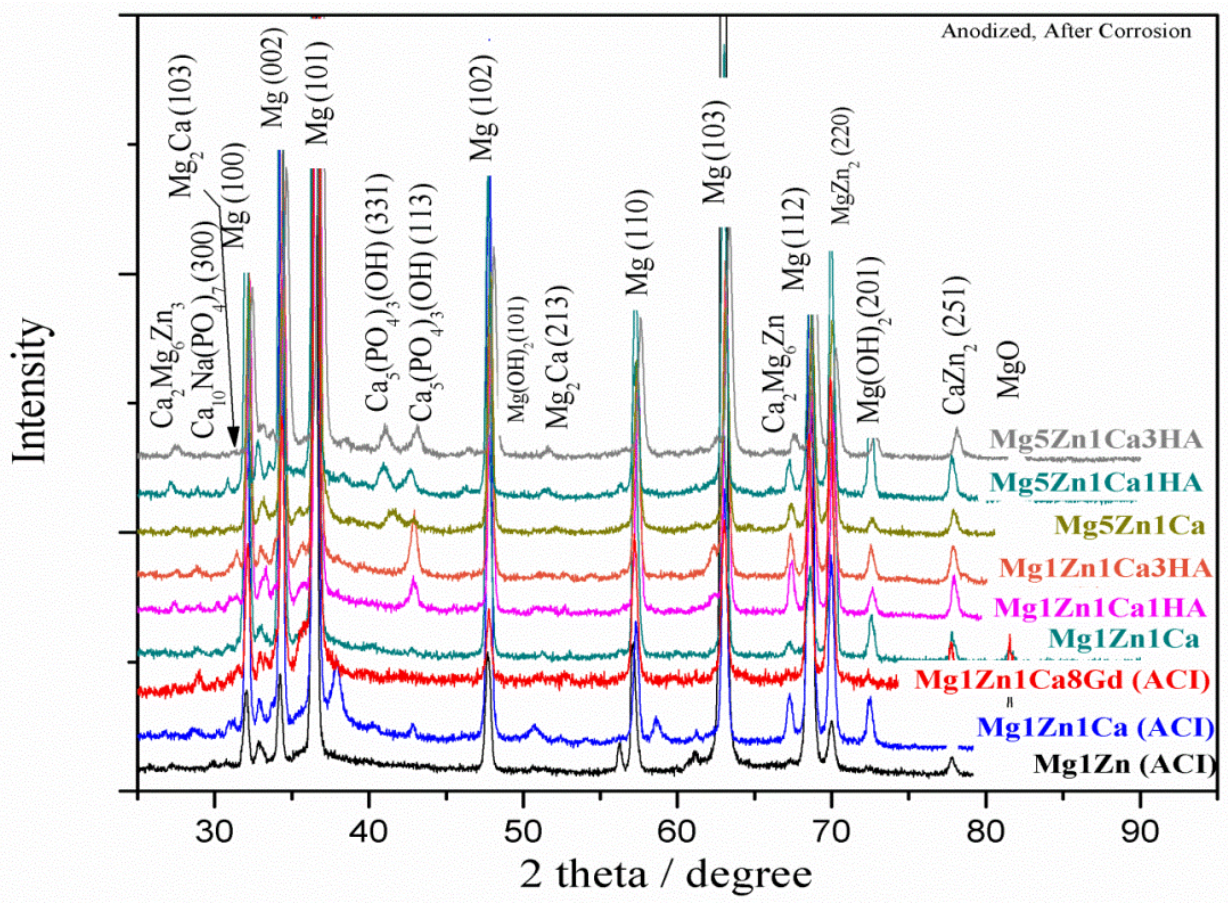

Figure 5.16: XRD spectra of anodized samples after corrosion in PBS. 
Figure 5.17 shows the XRD spectra of the anodized samples subjected to dynamic immersion in PBS for 9 days at $37{ }^{\circ} \mathrm{C}$. Comparatively lower intensity of $\mathrm{Mg}$ and $\mathrm{Mg}(\mathrm{OH})_{2}$ was observed for latter, which reveals faster degradation during dynamic immersion. A similar behavior was also noted in the case of binary and ternary phases.

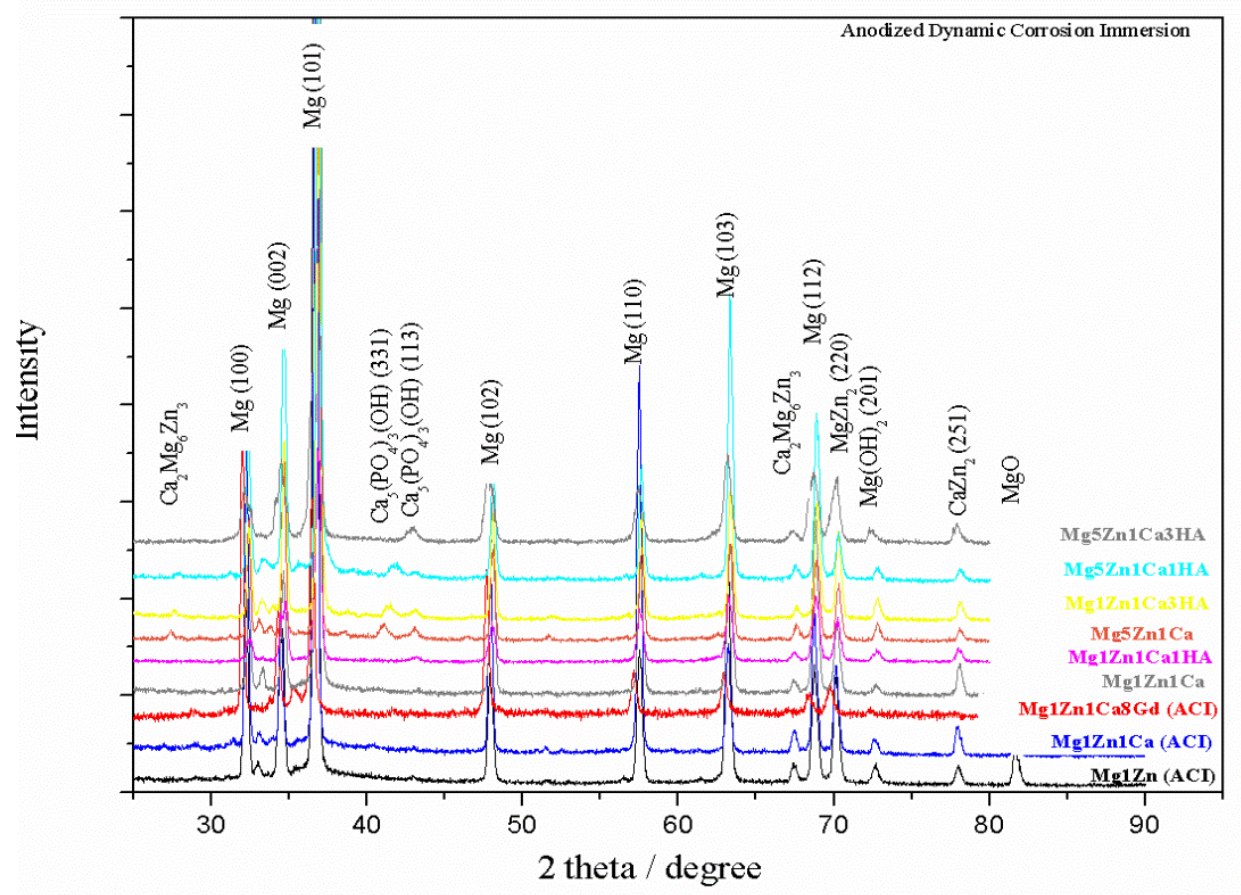

Figure 5.17: XRD spectra of anodized samples after dynamic corrosion in $P B S$ at $37^{\circ} \mathrm{C}$.

\subsection{Grain Size Determination}

Factors that affect the degradation behavior of $\mathrm{Mg}$ alloys/MMCs include: grain size, composition, microstructure and distribution of intermetallic phases. The grain size of the Mg alloys/MMCs were determined by swabbing the surfaces with acetic glycol etchant of composition: water $19 \mathrm{~mL}$, ethylene glycol $60 \mathrm{~mL}$, acetic acid $20 \mathrm{~mL}$ and $\mathrm{HNO}_{3} 1 \mathrm{~mL}$ for a duration of $1-5$ seconds. An optical microscope was then used to observe and measure the grains [128]. 
Figure 5.18 shows the overall grain size of the $\mathrm{Mg}$ samples, which ranged between $\sim 60-110 \mu \mathrm{m}$. The smallest grains $(\sim 60 \mu \mathrm{m})$ were observed in $\mathrm{Mg}$ samples with 3 wt.\% HA. Alvarez-Lopez et al. (2010) reported that fine grained AZ31 possessed good corrosion resistance [60]. Li et al. showed that the addition of HA reduced the solid/liquid interfacial energy in Mg alloys. Since the lattice parameter for HA (9.41 $\AA)$ is three times greater than that of $\mathrm{Mg}(3.21 \AA)$, it results in heterogeneous nucleation and good wettability [113]. Furthermore, the large variation in lattice parameters can lead to grain boundary segregation and grain growth restriction. During solidification, alloying elements can be rejected by the $\alpha-M g$, which restricts grain growth. However, according to Hall-Path formula, an increase in $\mathrm{Zn}$ concentration decreases the grain size of the alloy and increases the yield strength [113]. Becerra and Pekguleryuz achieved an effective grain refinement with $\mathrm{Zn}$, which was explained by its segregation and minimization of surface energy [129]. As shown in Figure 5.18, the grain size decreased when Ca, HA and $\mathrm{Zn}$ were added to Mg. This may be attributed to the precipitation of intermetallic phases $\left(\mathrm{Ca}_{2} \mathrm{Mg}_{6} \mathrm{Zn}_{3}, \mathrm{MgCa}_{2}, \mathrm{CaZn}_{2}, \mathrm{Ca}_{5}\left(\mathrm{PO}_{4}\right)_{3}(\mathrm{OH})\right.$ and $\left.\mathrm{MgZn}_{2}\right)$ previously shown in Figure 5.14. 


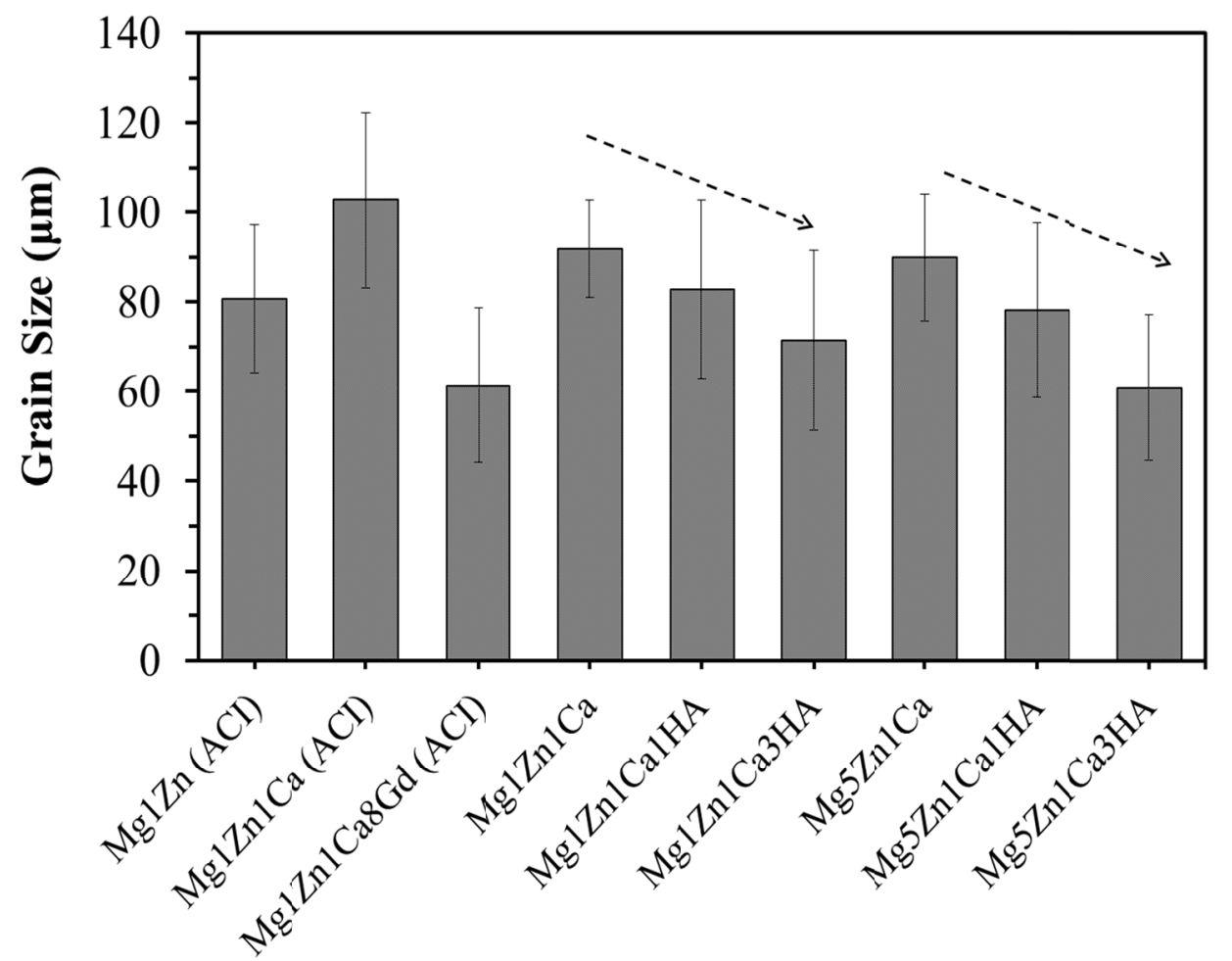

Figure 5.18: Average grain size of $M g$ samples.

\subsection{Density Measurement}

Density depends on the weight of the individual atoms and molecules making up matter, and how much space exists between them. It also depends on whether the matter is solid, porous, or composed of other elements. Densities is expressed using the term specific gravity, which is expressed mathematically as:

Density $\left(\rho_{1}\right)=$ mass $/$ volume

In our work, Archimedes Principal was used to calculate the density $\left(\rho_{1}\right)$ in accordance with the following equation:

$$
\rho_{1}=\frac{W_{1}}{\mathrm{~W}_{1}-W_{3}} \times \text { S.G.of.water }{ }_{1}
$$


Where: $\mathrm{W}_{1}$ is weight of the thoroughly dried sample, $\mathrm{W}_{3}$ is the weight of the sample when immersed in water and S.G. is the specific gravity of the water.

Mg alloys have a density that is $\sim 1 / 3$ that of titanium alloys [106]. Due to their light weight and load bearing capacity, $\mathrm{Mg}$ alloys/MMCs are attractive materials for the manufacture of orthopedic implant devices, because they reduce the risk of stress shielding that exists with other metallic implants. Figure 5.19 shows the calculated density (Archimedes principle method) and theoretical density of $\mathrm{Mg}$ samples. The density ranged between $\sim 1.69-1.87 \mathrm{~g} / \mathrm{cm}^{3}$, which is similar to that of human bone (1.8$2.1 \mathrm{~g} / \mathrm{cm}^{3}$ ) [6]. All alloys containing $1 \mathrm{wt} . \% \mathrm{Zn}$ displayed a density of $\sim 1.75 \mathrm{~g} / \mathrm{cm}^{3}$, except for Mg1Zn1Ca8Gd $\left(\sim 1.85 \mathrm{~g} / \mathrm{cm}^{3}\right)$. Alloys with $5 \mathrm{wt} . \% \mathrm{Zn}$ displayed densities of $\sim 1.83 \mathrm{~g} / \mathrm{cm}^{3}$.

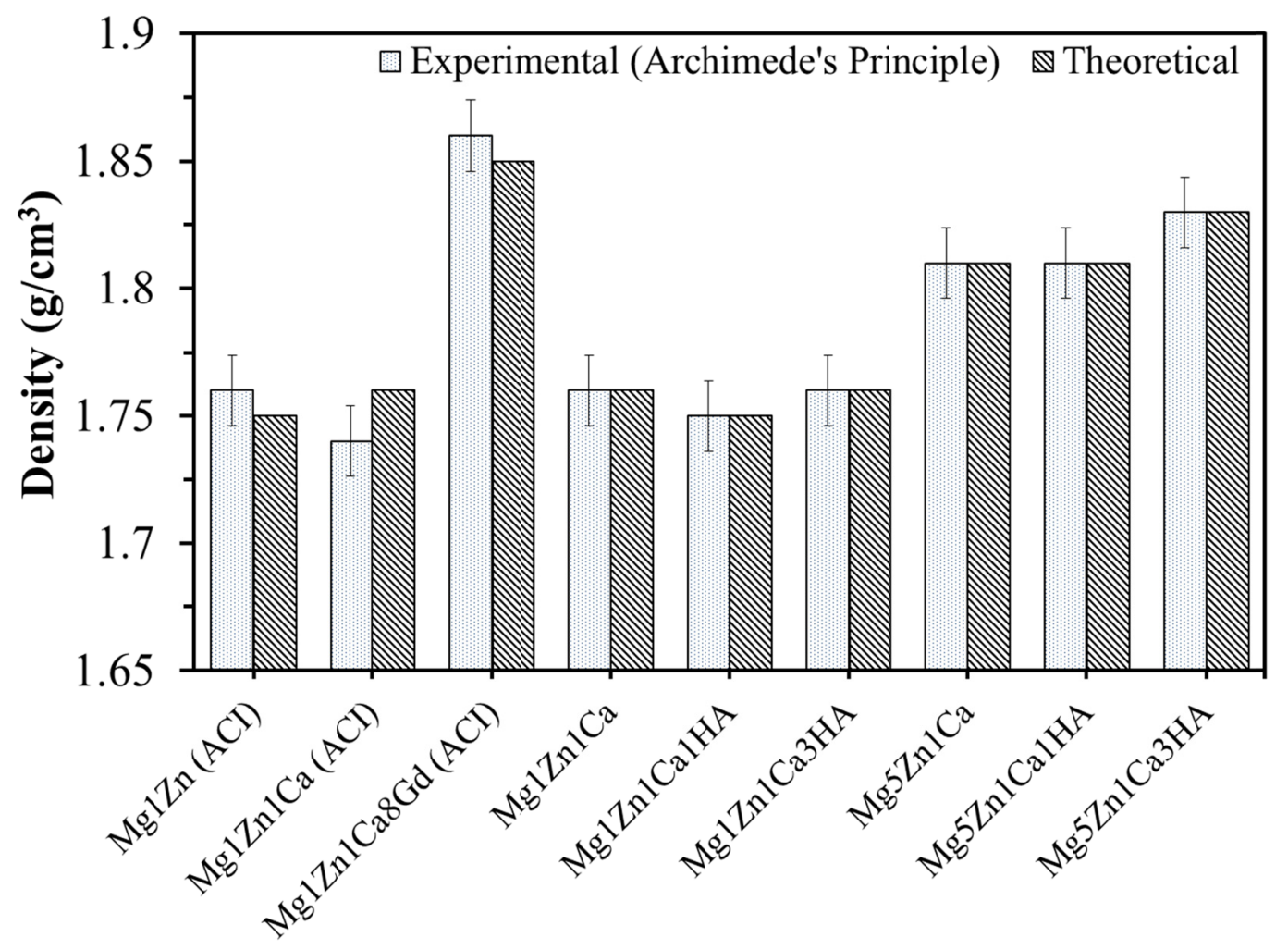

Figure 5.19: Experimental and theoretical densities of mechanically polished samples. 


\subsection{Wettability}

Subbiahdoss et al. (2010) reported wettability as an important property influencing cellular interactions with biomaterials [108]. In this investigation, the wettability of samples were determined by measuring contact angles on the samples using a Kyowa contact angle meter model DM-CE1 (Figure 5.20a). The sessile drop method was adopted by employing three different solvents: mildly polar (distilled water); neutral (ethylene glycol) and highly polar (diiodomethane). Ten tests were performed per solvent on each specimen at locations separated by sufficient spacing $(\sim 0.5 \mathrm{~mm})$ to prevent the potential influence of previous tests. Figure 5.20 (b) shows the contact angle formed by a liquid droplet resting on a solid substrate. According to the Young-Dupre equation, the contact angle $\theta$ can be expressed as [113]:

$$
\gamma_{l v} \cos \theta=\gamma_{s v}-\gamma_{s l}
$$

where, $\gamma_{s v}$ is the surface energy of the solid, $\gamma_{s l}$ is the solid liquid interfacial energy, $\gamma_{l v}$ is the surface energy of the liquid and $\theta$ is the contact angle.
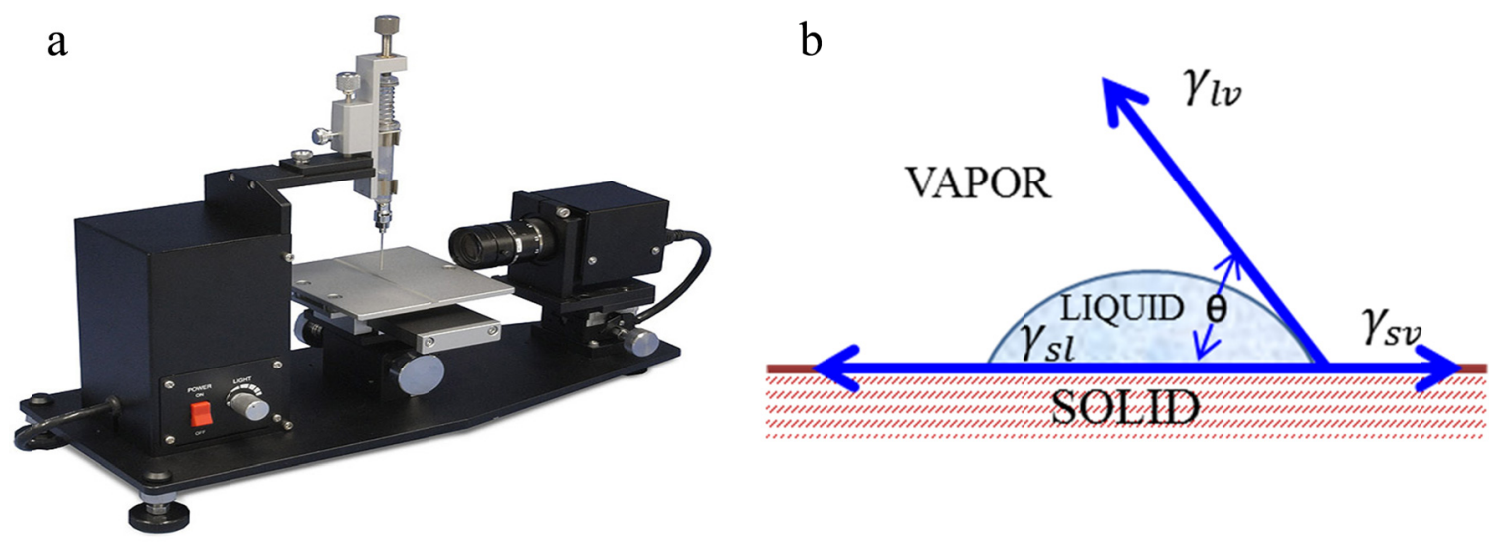

Figure 5.20: (a) Kyowa contact angle meter, DM-CE1 and (b) Schematic representing interfacial forces and contact angle of a liquid drop on a solid surface. 
FAMAS analysis software was used to evaluate the surface free energy (SFE) parameters of samples by adopting the Lifshitz-van der Waals (LW) acid-base interaction and Kitazaki-Hata theory. The SFE was calculated using:

$$
\gamma^{\text {total }}=\gamma^{d}+\gamma^{p}+\gamma^{h}
$$

where, $\gamma^{\text {total }}$ is the total SFE; $\gamma^{\mathrm{d}}$ is SFE dispersion component; $\gamma^{\mathrm{p}}$ is SFE polar component; and $\gamma^{\mathrm{h}}$ is SFE hydrogen bond component.

According to the energy interchange model of the acid and base, liquids of different surface tensions, two of which are polar (water and diiodomethane) are employed. The following energy balanced equation is established [172]:

$$
\gamma_{i}\left(1+\cos \theta_{i}\right)=2\left(\sqrt{\gamma_{i}^{d} \gamma_{s}^{d}}+\sqrt{\gamma_{i}^{+} \gamma_{s}^{-}}+\sqrt{\gamma_{i}^{+} \gamma_{s}^{-}}\right)
$$

where,

$$
\gamma_{i}=\gamma_{i}^{d}+2 \sqrt{\gamma_{i}^{+} \gamma_{i}^{-}}
$$

and,

$$
\begin{aligned}
& \gamma_{S}=\gamma_{S}^{d}+2 \sqrt{\gamma_{S}^{+} \gamma_{S}^{-}} \\
& \gamma_{s}=\gamma_{s}^{d}+2 \sqrt{\gamma_{s}^{+} \gamma_{s}^{-}}
\end{aligned}
$$

Where,

$\gamma_{i}$ surface tension of testing drop

$\gamma_{i}^{d}$ dispersion portion of surface tension (testing drop, i)

$\gamma_{i}^{+}$surface tension contribution by acid (testing drop, i)

$\theta_{\mathrm{i}}$ contact angle between solid and liquid $\gamma_{s}$ surface tension of solid sample

$\gamma_{s}^{d}$ dispersion portion of surface tension (testing surface, $\mathrm{s}$ )

$\gamma_{s}^{+}$surface tension contribution by acid (testing surface, $\mathrm{s}$ )

$\gamma_{i}^{-}$surface tension contributed by base $\gamma_{s}^{-}$surface tension contributed by base (testing drop, i) (testing surface, $\mathrm{s}$ ) 


\subsubsection{Wettability Measurements of Mg Alloys/MMCs}

The contact angle, wettability and surface free energy are inherently interdependent parameters that are known to have significant influence on biocompatibility of implants [68]. In this investigation, the water contact angle of mechanically polished and anodized samples ranged between $70^{\circ}-110^{\circ}$. A decrease in water contact angle was observed with alloying. However, anodization caused a slight increase in the water contact angle, as illustrated in Figures 5.22 and 5.24. It should be noted that there was no significant difference between the surface free energy of mechanically polished and anodized samples as shown in Figures 5.23 and 5.25.

The surface layer of metal could be oxides or sulphides, followed by strong polar bonds, water strongly interact with the $-\mathrm{OH}$ group and final layer with low surface energy, Figure 5.21 [152]. Detailed parameters can be found in Appendix I. The surface of bare metals is normally electropositive, the magnitude of which is dependent on the type of surface treatment. Coating a metal surface takes advantage of a materials surface free energy and in some cases, can lead to reduced risk of thrombosis [68]. The coating of Nitinol and stainless steel implants with polymers was adopted to improve corrosion resistance and reduce nickel leaching. But the advent of drug eluting polymer coated stents witnessed an increase in thrombosis. This led to the introduction of thromboresistant hydrophobic polymers. 


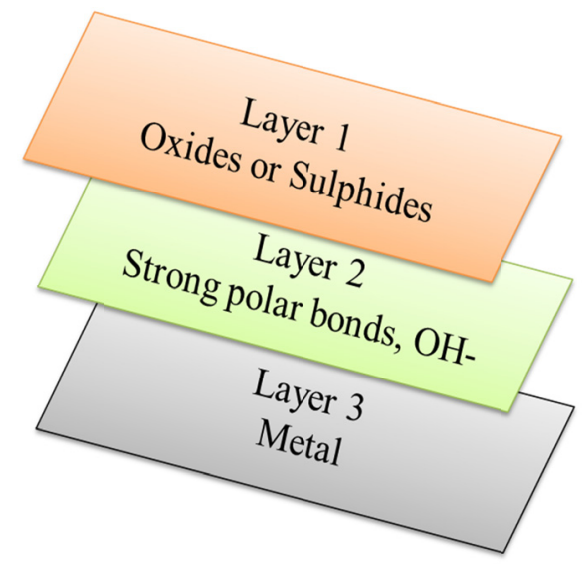

Figure 5.21: Schematic illustrating various layers in metals effecting interfacial free energy and polarity.

In this investigation, the surfaces of $\mathrm{Mg}$ alloys/MMCs exhibited high electron donor (basic) and low electron acceptor (acidic) characters, which are conducive for cell viability as shown in Table 5.1 and 5.2. Ponsonnet et al. (2003) observed similar acidic and basic characteristics for titanium and titanium alloys and reported good cell health [152]. The surficial layers of the alloys consist of oxides that are conducive to providing strong polar bonds with water or amino acids. Studies have also shown that materials with low surface free energy corresponds to favorable cellular adhesion and cell activity $[109,110]$. Ponsonnet et al. reported that lower surface free energy corresponds to higher fibroblast proliferation and indicated an inflection point in the range of $30-50 \mathrm{~mJ} / \mathrm{m}^{2}$ [152]. Mani et al. (2006) reported that high surface energy increases the risk of thrombogenicity [111]. Figure 5.23 and 5.25, shows the polar (p), dispersion (d) and hydrogen bonding (h) components of surface free energy of mechanically polished and anodized samples, respectively. Fractional polarity $(\mathrm{FP}=$ polar/dispersion + polar $)$ ranged from $\sim 0-0.9$, where FP less than 0.3 is a favorable parameter for good cellular adhesion [152]. 
Studies have shown that in case of Ti and Ti alloys low interfacial free energy $(\sim 5$ $\mathrm{mJ} / \mathrm{m}^{2}$ ) with water can be associate with optimum biocompatibility [158]. In this investigation, the interfacial free energy (Acid-Base) of mechanically polished samples decreased with alloying and ranged between $10-42 \mathrm{~mJ} / \mathrm{m}^{2}$, whereas for anodized samples it ranged between $23-52 \mathrm{~mJ} / \mathrm{m}^{2}$. Anodized $\mathrm{Mg} 1 \mathrm{Zn} 1 \mathrm{Ca} 1 \mathrm{HA}$ showed the lowest interfacial free energy, which can be favorable for cellular activity.

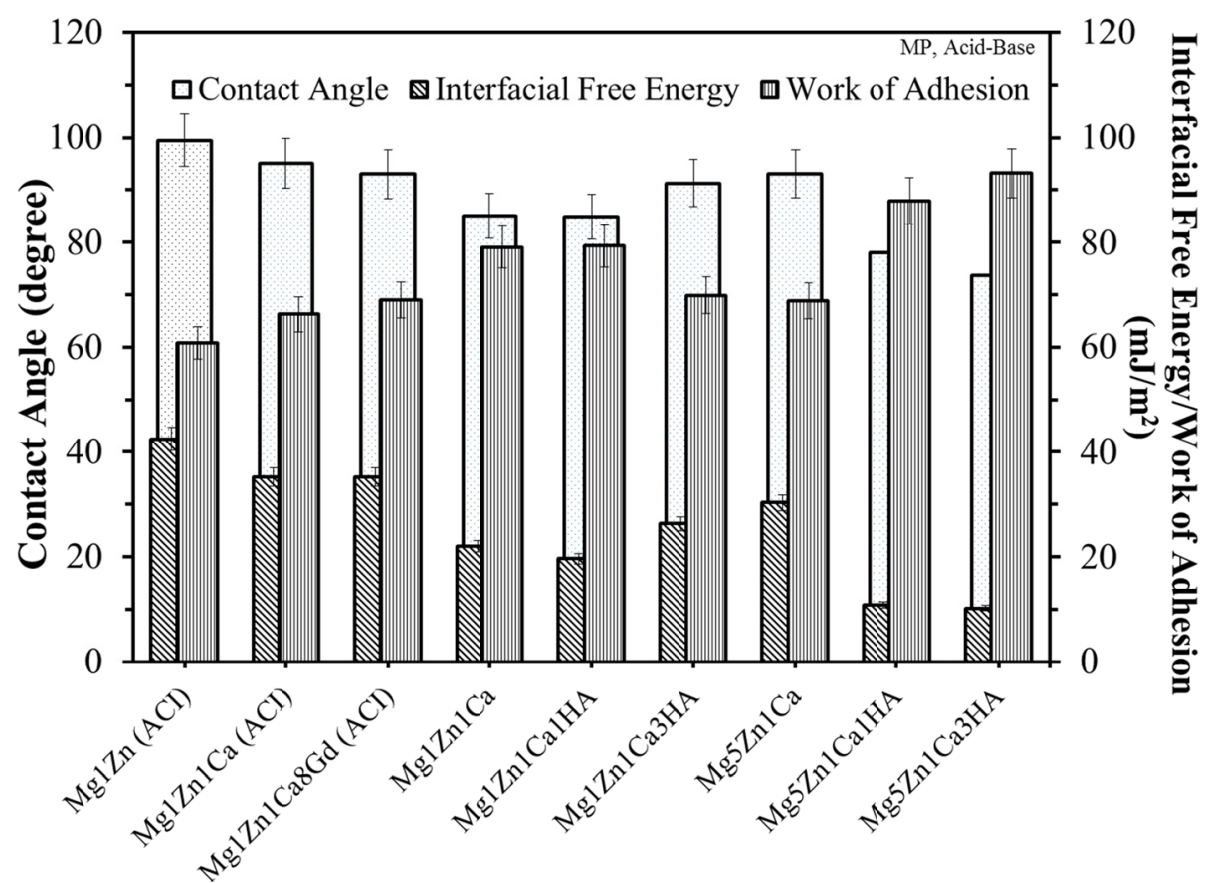

Figure 5.22: Acid-Base theory contact angle, interfacial free energy and work of adhesion components for mechanically polished samples (mean $\pm S D, n=10$ ).

Table 5.1: Acid-Base, average values of surface free energy components $\left(\mathrm{mJ} / \mathrm{m}^{2}\right)$ for mechanically polished samples

\begin{tabular}{|c|c|c|c|c|}
\hline \multirow{2}{*}{ Samples } & Lifshitz-van der & Acidic (Electron & Basic (Electron \\
& Waals & Acceptor) & + & Tonor) \\
& $\mathrm{LW}$ & - & - & \\
\hline $\mathrm{Mg} 1 \mathrm{Zn}(\mathrm{ACI})$ & 30.1 & 0.4 & 0.1 & 30.5 \\
\hline $\mathrm{Mg} 1 \mathrm{Zn} 1 \mathrm{Ca}(\mathrm{ACI})$ & 28.7 & 0.0 & 2.6 & 28.7 \\
\hline $\mathrm{Mg} 1 \mathrm{Zn} 1 \mathrm{Ca} 8 \mathrm{Gd}(\mathrm{ACI})$ & 30.5 & 0.1 & 2.0 & 31.4 \\
\hline
\end{tabular}




\begin{tabular}{|c|c|c|c|c|}
\hline $\mathrm{Mg} 1 \mathrm{Zn} 1 \mathrm{Ca}$ & 28.3 & 0.0 & 8.5 & 28.3 \\
\hline $\mathrm{Mg} 1 \mathrm{Zn} 1 \mathrm{Ca} 1 \mathrm{HA}$ & 26.1 & 0.0 & 9.8 & 26.1 \\
\hline $\mathrm{Mg} 1 \mathrm{Zn} 1 \mathrm{Ca} 3 \mathrm{HA}$ & 23.4 & 0.0 & 6.0 & 23.4 \\
\hline $\mathrm{Mg} 5 \mathrm{Zn} 1 \mathrm{Ca}$ & 26.4 & 0.0 & 4.3 & 26.4 \\
\hline $\mathrm{Mg} 5 \mathrm{Zn} 1 \mathrm{Ca} 1 \mathrm{HA}$ & 25.9 & 0.0 & 16.0 & 25.9 \\
\hline $\mathrm{Mg} 5 \mathrm{Zn} 1 \mathrm{Ca} 3 \mathrm{HA}$ & 30.6 & 0.0 & 16.9 & 30.6 \\
\hline
\end{tabular}




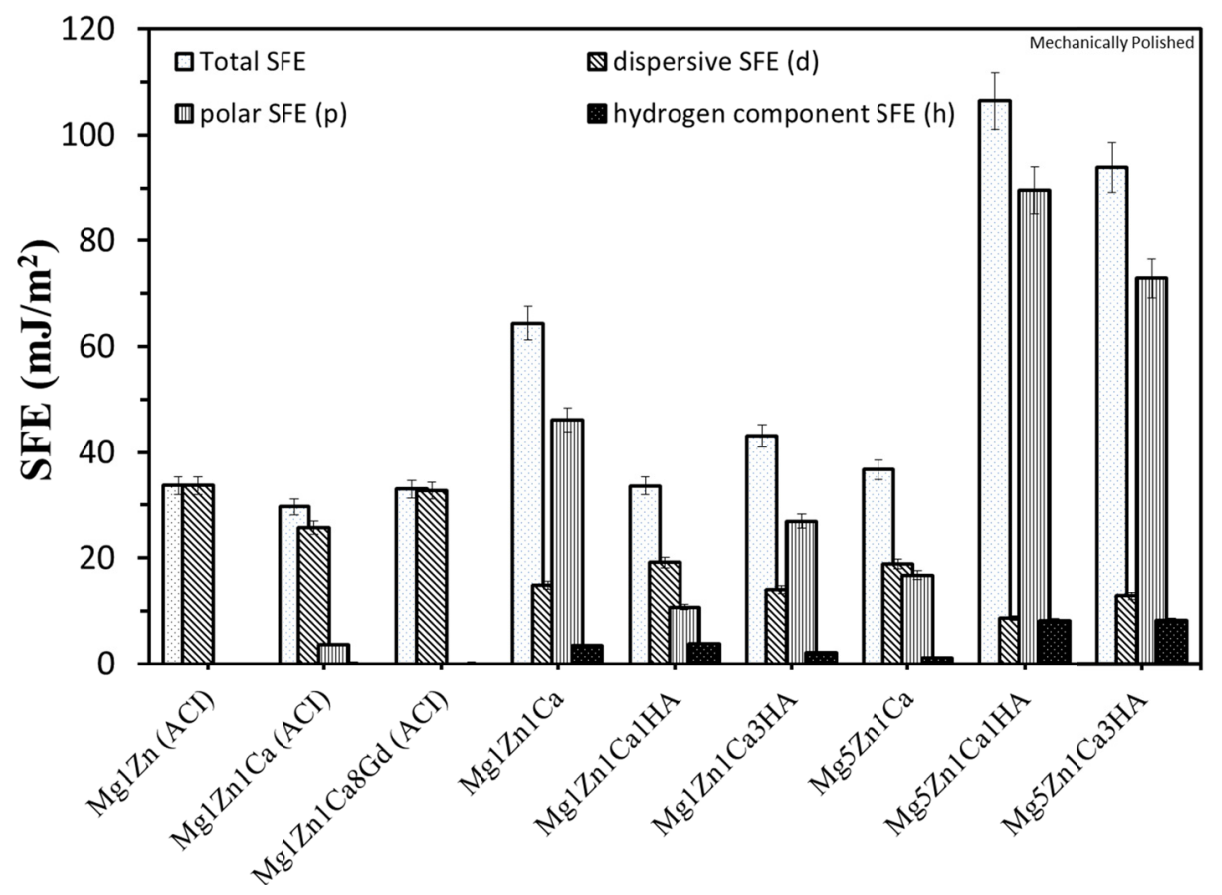

Figure 5.23: Kitazaki-Hata surface free energy components of mechanically polished samples (mean $\pm S D, n=10$ ).

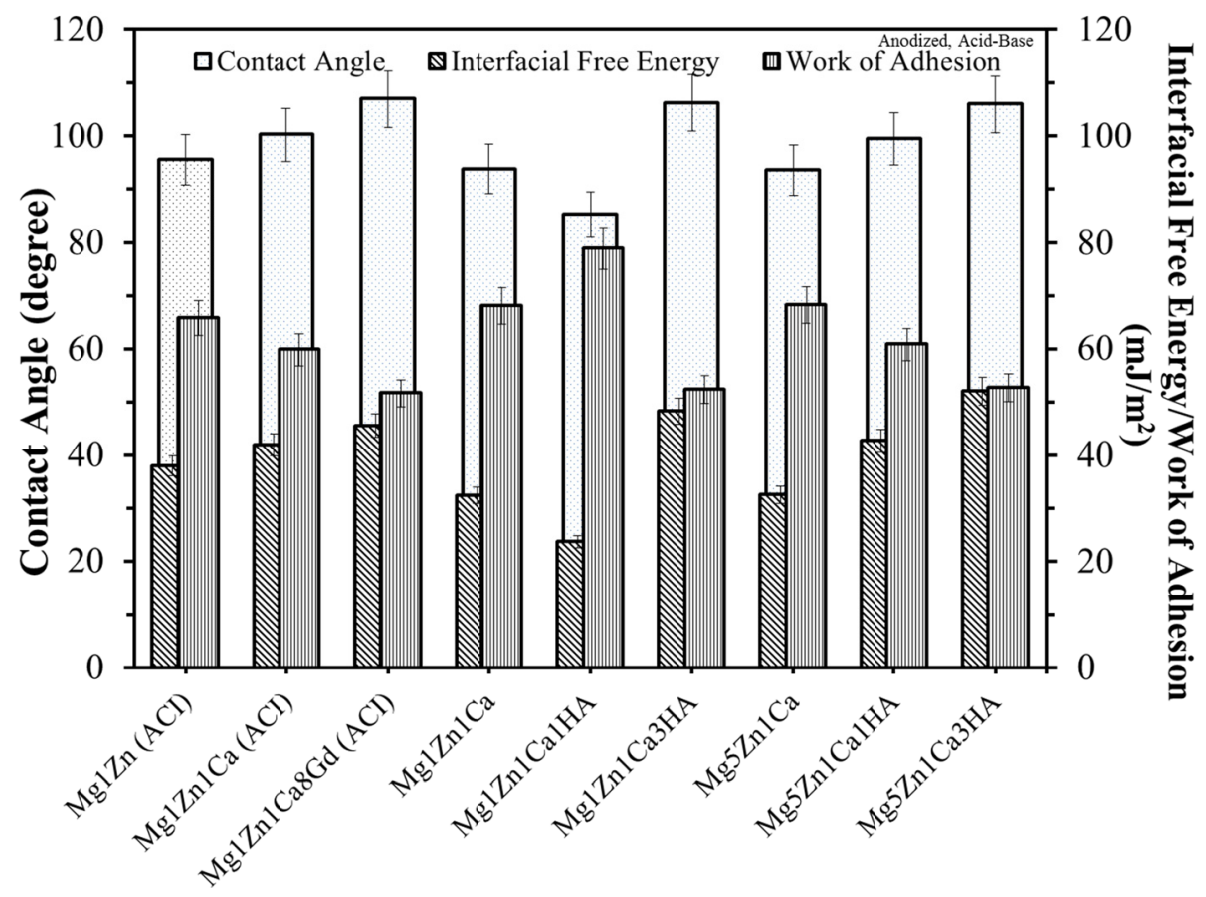

Figure 5.24: Acid-Base theory contact angle, interfacial free energy and work of adhesion components for anodized samples (mean $\pm S D, n=10$ ). 
Table 5.2: Acid-Base, average values of surface free energy components $\left(\mathrm{mJ} / \mathrm{m}^{2}\right)$ for anodized samples

\begin{tabular}{|c|c|c|c|c|}
\hline \multirow{3}{*}{ Anodized Samples } & $\begin{array}{c}\text { Lifshitz-van der } \\
\text { Waals } \\
\text { LW }\end{array}$ & $\begin{array}{c}\text { Acidic (Electron } \\
\text { Acceptor) } \\
+\end{array}$ & $\begin{array}{c}\text { Basic (Electron } \\
\text { Donor) } \\
-\end{array}$ & Total \\
\hline Mg1Zn (ACI) & 30.8 & 0.0 & 1.9 & 30.8 \\
\hline $\mathrm{Mg} 1 \mathrm{Zn1Ca}(\mathrm{ACI})$ & 28.9 & 0.0 & 0.9 & 28.9 \\
\hline $\mathrm{Mg} 1 \mathrm{Zn1Ca} 8 \mathrm{Gd}(\mathrm{ACI})$ & 24.3 & 0.0 & 0.3 & 24.3 \\
\hline $\mathrm{Mg} 1 \mathrm{Zn1Ca}$ & 27.6 & 0.0 & 3.5 & 27.6 \\
\hline $\mathrm{Mg} 1 \mathrm{Zn1Ca1HA}$ & 29.6 & 0.0 & 7.7 & 29.6 \\
\hline $\mathrm{Mg} 1 \mathrm{Zn1Ca3HA}$ & 27.7 & 0.0 & 0.1 & 27.7 \\
\hline $\mathrm{Mg} 5 \mathrm{Zn} 1 \mathrm{Ca}$ & 27.9 & 0.0 & 3.5 & 27.9 \\
\hline $\mathrm{Mg} 5 \mathrm{Zn} 1 \mathrm{Ca} 1 \mathrm{HA}$ & 30.7 & 0.0 & 0.8 & 30.7 \\
\hline $\mathrm{Mg} 5 \mathrm{Zn1Ca3HA}$ & 31.9 & 0.0 & 0.0 & 31.9 \\
\hline
\end{tabular}

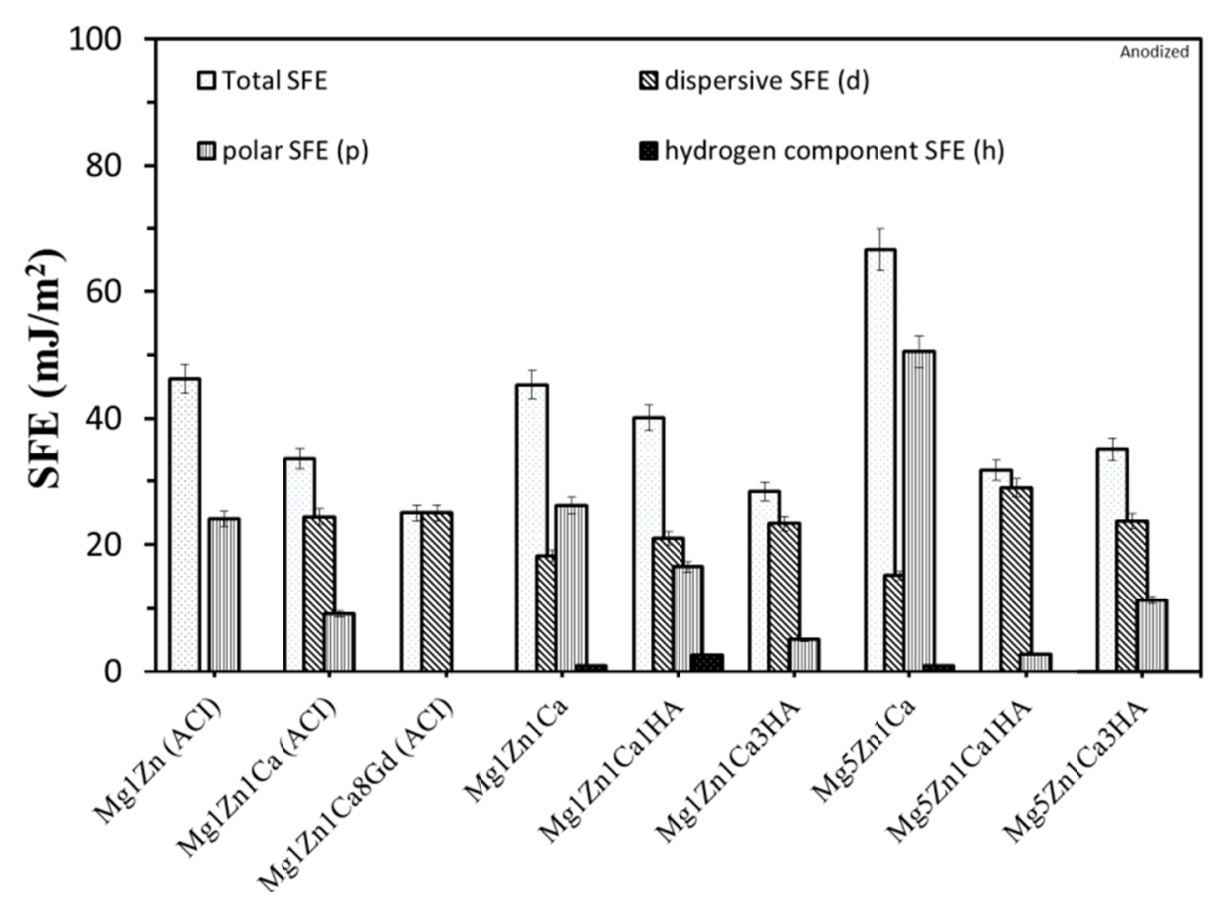

Figure 5.25: Kitazaki-Hata surface free energy components of anodized surfaces (mean $\pm S D, n=10)$. 


\subsection{DETERMINATION OF MECHANICAL PROPERTIES}

\subsection{Elastic Modulus and Hardness Via Nanoindentation}

The bulk hardness and Young's modulus of elasticity were determined using a MTS Nanoindenter XP with a diamond Berkovich indenter. Due to the large grain size of the specimens, high peak loads $(\sim 500 \mathrm{mN})$ were used, which leads to deeper indentations that provide more accurate bulk properties. At least 10 indentations (spaced 100 microns apart) were used to estimate the modulus and hardness of the specimen. The OliverPharr [173] approach was adopted, where the load displacement is defined as:

$$
P=\propto h^{m}
$$

where, $\mathrm{P}$ is the indenter load, $\mathrm{h}$ is the elastic displacement of the indenter and $\alpha$ and $\mathrm{m}$ are constants.

The elastic modulus was calculated by the load displacement behavior described in the following equation:

$$
\frac{1}{E_{r}}=\left(\frac{1-v^{2}}{E}\right)_{\text {sample }}+\left(\frac{1-v_{i}^{2}}{E_{i}}\right)_{\text {indenter }}
$$

where, E is Young's modulus, $v$ is Poisson's ratio and $E_{i}$ and $v_{i}$ are the indenter parameters.

The experimental method was designed to minimize errors due to thermal drift, machine compliance, etc. The stiffness (Young's modulus) was evaluated from the unloading curve by taking the derivative at the inception of the best-fitted polynomial function with respect to the displacement, i.e. $\mathrm{dP} / \mathrm{dh}$. The contact area was defined by a polynomial function obtained by using reference data from a fused silica specimen with a 
known modulus (72.1 GPa by ultrasonic measurements) and hardness. The area function was calculated for a depth greater than the maximum depth penetrated in the specimens, where the tip radius was calibrated using a tungsten specimen.

\subsection{Vicker's Hardness}

Vicker's hardness test was performed in accordance with ASTM E 384-07 [174] using a Zhongguo HXD-100 TMC Shanghai Taiming Optical Instruments microhardness tester applying loads of 10,25 and 50 grams with a dwell time of 10 seconds. The force applied to the indenter (a square-based pyramidal shaped diamond indenter with face angle $136^{\circ}$, Figure 6.1) was divided by the surface area of the permanent impression made by the indenter. Vicker's hardness was calculated using the average of the two diagonals in the following formula:

$$
\mathrm{HV}=(\text { constant }) \mathrm{x} \text { (test force) } / \text { indent diagonal squared }
$$

The constant is a function of the indenter geometry and the units used for quantifying force and diagonal dimensions. It was assumed that no elastic recovery occurred after the loading cycle once the indenter was removed. Special precautions were taken during the measurements to minimize vibration and to ensure that the specimen was flat and level during indentation. 


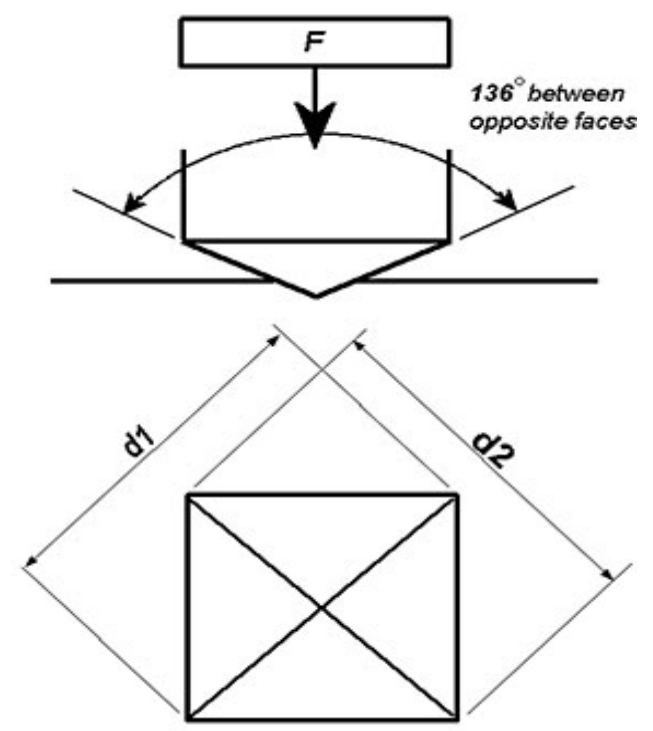

Figure 6.1: Schematic of indentation dimensions during Vicker's hardness test [175].

\subsection{Results and Discussions of Mechanical Properties}

Reliable results are obtained by the Oliver-Pharr method when the ratio of $h_{f} / h_{\max }$ is less than 0.7 , where $h_{f}$ is the final displacement at complete unloading and $h_{\max }$ is the maximum depth of penetration during a nanoindentation test [176]. This approach does not account for possible pile-up behavior. The Mg alloys/MMCs exhibited mainly plastic behavior, where indentation measurements at depths greater than $1000 \mathrm{~nm}$ and peak loads greater than $25 \mathrm{mN}$ produced mechanical properties that are relatively constant with indentation and are representative of the bulk material. However, an increase in the modulus was observed with the addition of alloying elements. Due to the possibility of the formation of oxides on the surface of the Mg alloys/MMCs, shallow depths less than $1000 \mathrm{~nm}$ were not utilized in the determination of mechanical properties. Additionally, since grain-sizes of the samples were greater than 60 microns (section 5.2), mechanical 
properties based on indentation at depths greater than $1000 \mathrm{~nm}$ were considered comparable to those of the bulk.

Tao et al. (2008) reported that micro hardness of $\mathrm{MgZnCa}$ increased from 59.3 GPa to $120.8 \mathrm{GPa}$ with age hardening and that addition of $\mathrm{Ca}$ lead to the formation of hardening phases such as: $\mathrm{Mg}_{2} \mathrm{Ca}$ and $\mathrm{Ca}_{2} \mathrm{Mg}_{6} \mathrm{Zn}_{3}$ [104]. Witte et al. (2007) determined the Vicker's hardness Mg alloys by applying a $1000 \mu \mathrm{N}$ load and obtained a hardness of $73 \mathrm{GPa}-111 \mathrm{GPa}$, although lower hardness was observed with large and inhomogeneous conglomerates [177]. The Young's modulus of AZ91D and Mg MMC/HA was reported to be $40 \mathrm{GPa}$ [177], which is comparable with that obtained in the present investigation.

In this investigation, the hardness and the modulus of the specimens remained almost constant at depths greater than $1000 \mathrm{~nm}$ at various peak loads as shown in Figure 6.2 (a), (b) and (c). MgZnCaGd exhibited the highest modulus ( $52 \mathrm{GPa})$ and hardness ( 1.2 $\mathrm{GPa})$ followed by $\mathrm{MgZnCa} / \mathrm{nHA}$ modulus $(\sim 45-50 \mathrm{GPa})$ and hardness $(\sim 0.8-1.1$ GPa). This was attributed to grain boundary segregation of $\mathrm{Zn}, \mathrm{Ca}$ and $\mathrm{HA}$ in the case of $\mathrm{MgZnCa} / \mathrm{nHA}$ and $\mathrm{Zn}, \mathrm{Ca}$ and $\mathrm{Gd}$ for $\mathrm{MgZnCaGd}$. It was reported that $\mathrm{Zn}, \mathrm{Ca}$ and $\mathrm{HA}$ act as grain-refining agents and contribute to solid solution formation, precipitation and grain boundary strengthening as previously discussed in Chapter 5. Gd improved the strength and creep resistance of $\mathrm{Mg}$ alloys, and $\mathrm{Zn}$ along with other alloying elements, improved the strength and corrosion resistance of $\mathrm{Mg}$ [38]. With the addition of $\mathrm{Ca}$ and Gd in MgZn, the average displacement curves of $\mathrm{MgZnCa}$ and $\mathrm{MgZnCaGd}$ show an increase in the work of indentation or the hysteresis loop energy.

The hardness of Mg alloys/MMCs was determined by Nanoindentation (Figure 6.3) and by Vicker's hardness (Figure 6.4). The results by each method were comparable 
and ranged between 0.7-1.4 GPa. $\mathrm{Mg} 1 \mathrm{Zn}$ and $\mathrm{Mg} 1 \mathrm{Zn} 1 \mathrm{Ca}$ exhibitted the lowest hardness $\sim 0.8 \mathrm{GPa}$, which increased with the addition of $\mathrm{Gd}$ and $\mathrm{Zn}$ to $\mathrm{MgZnCa}(\sim 1.2 \mathrm{GPa})$.

(a)

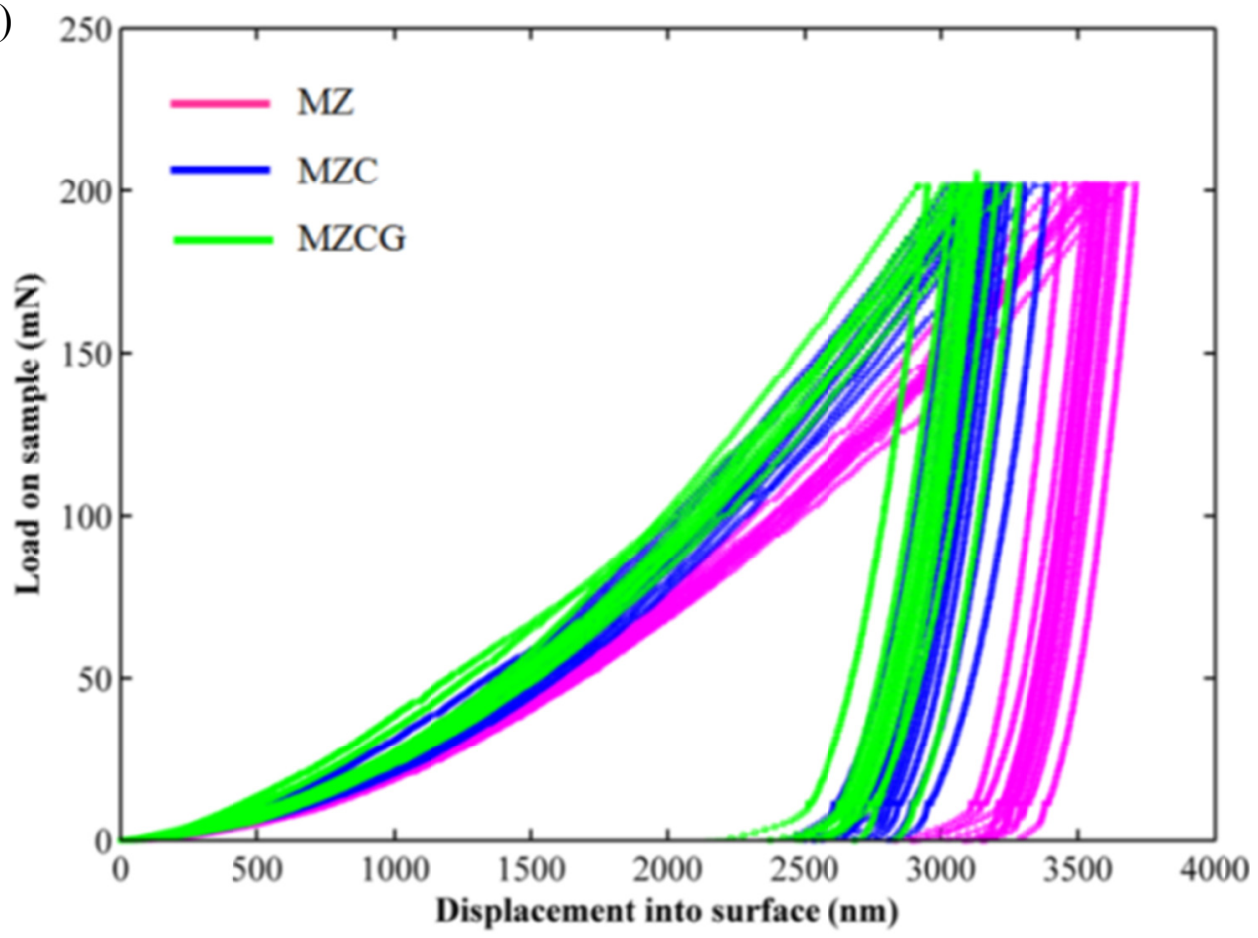

(b)

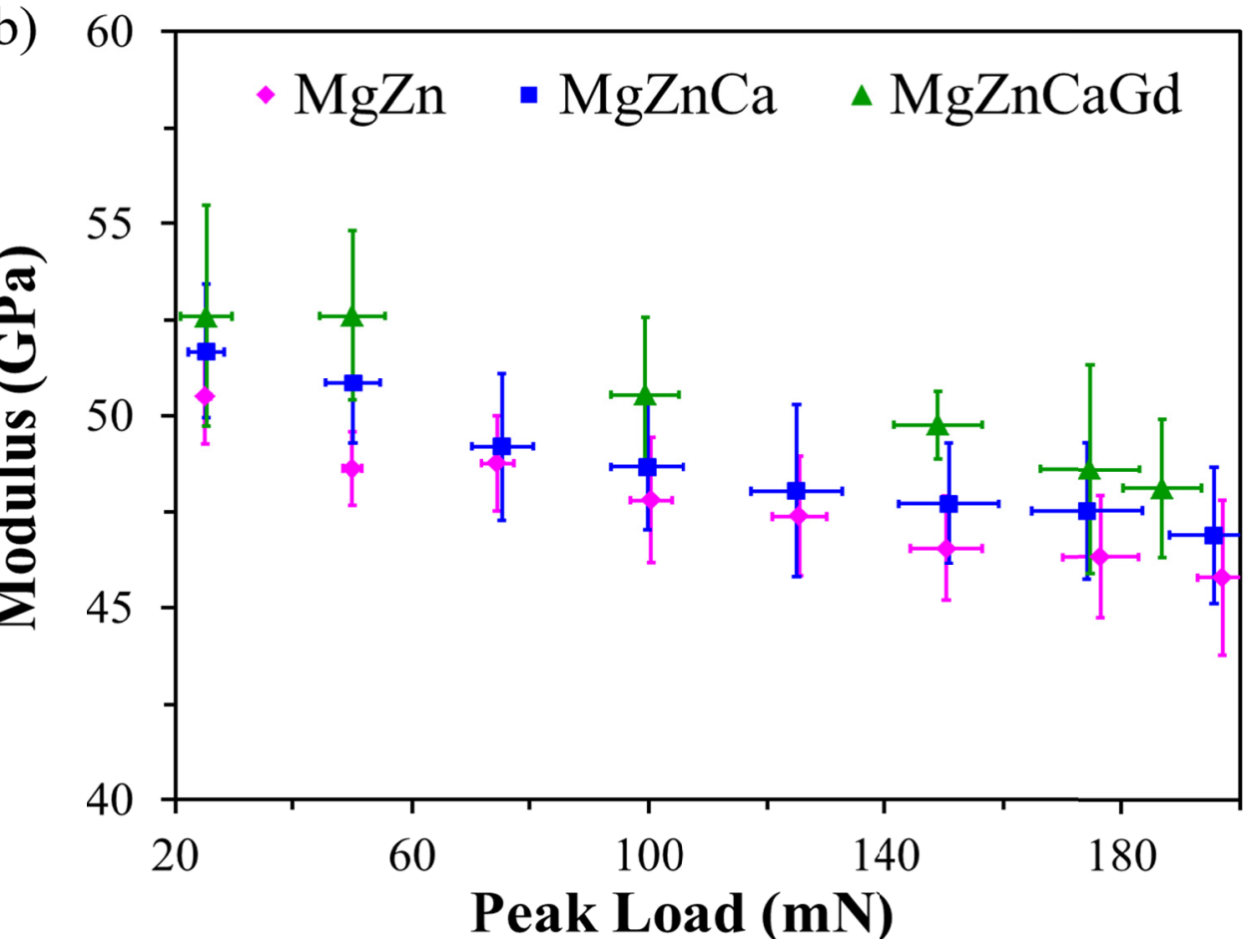




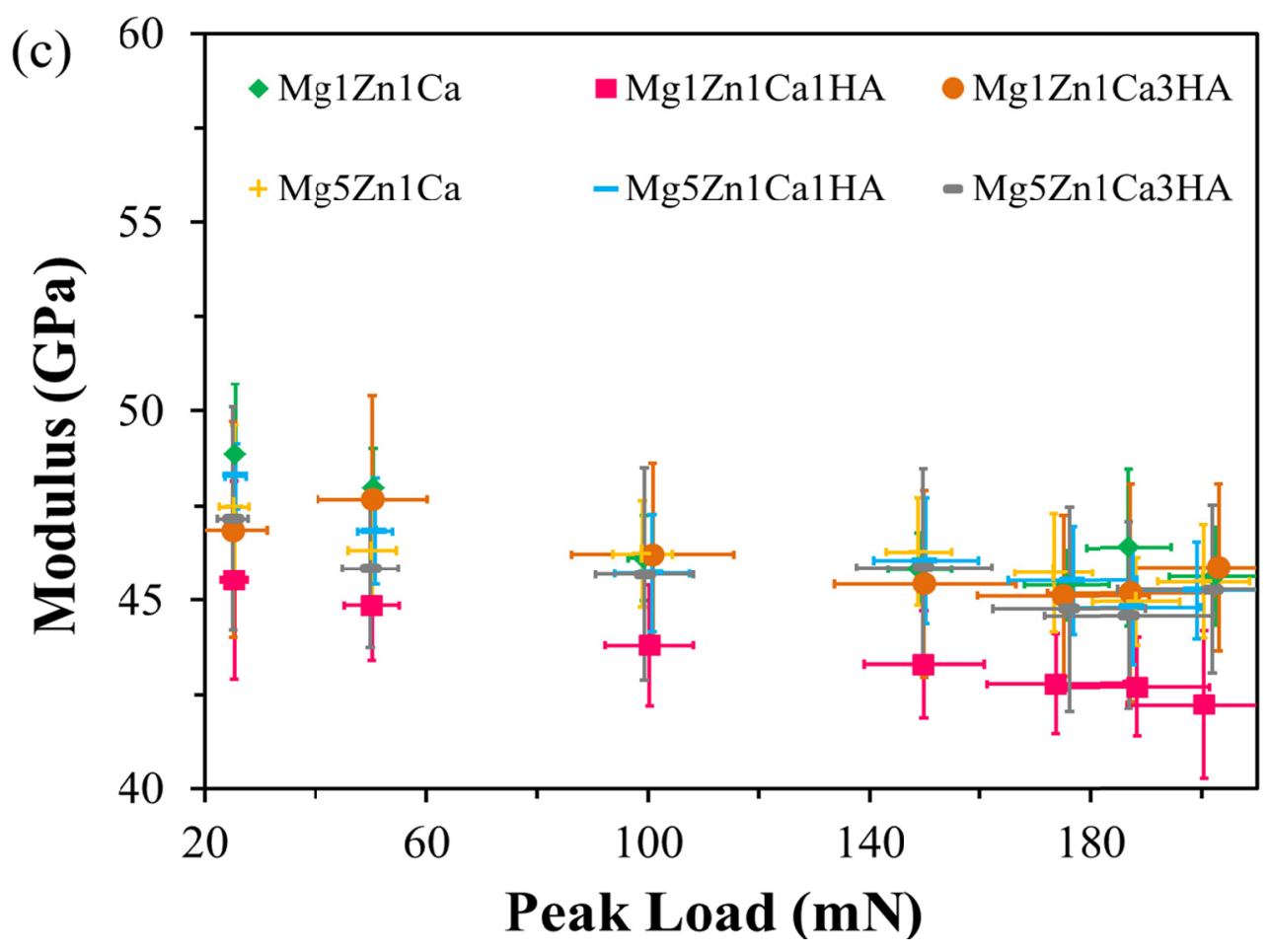

Figure 6.2: Nanoindentation: (a) Typical load Vs displacement curves for $200 \mathrm{mN}$ peak load, (b) Peak load Vs modulus; Mg1Zn, Mg1Zn1Ca and Mg1Zn1Ca8Gd and (c) Peak load Vs modulus; Mg1Zn1Ca, Mg1Zn1Ca1HA, Mg1Zn1Ca3HA, Mg5Zn1Ca, Mg5Zn1CalHA and Mg5Zn1Ca3HA (mean $\pm S D, n=10)$.

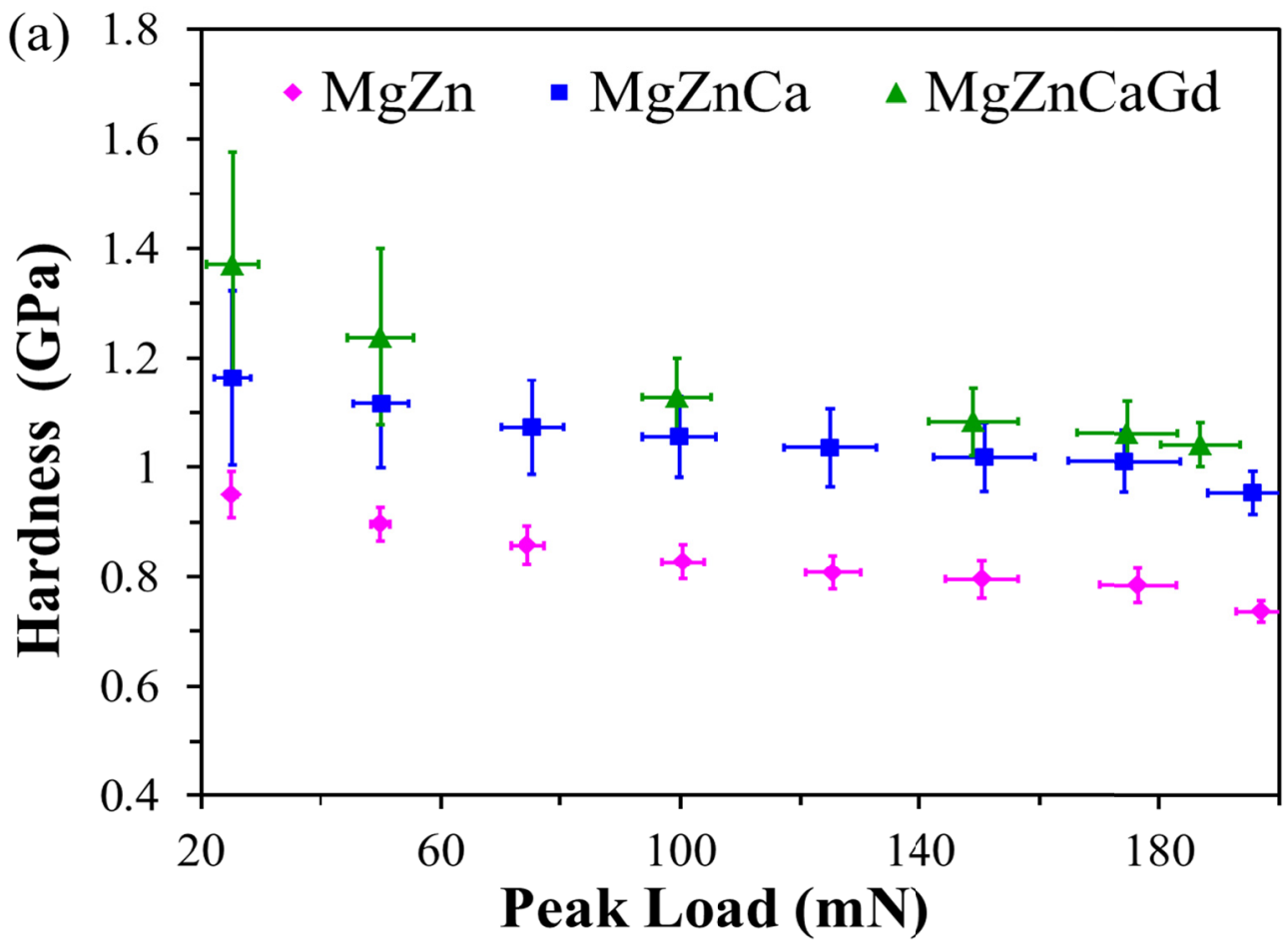




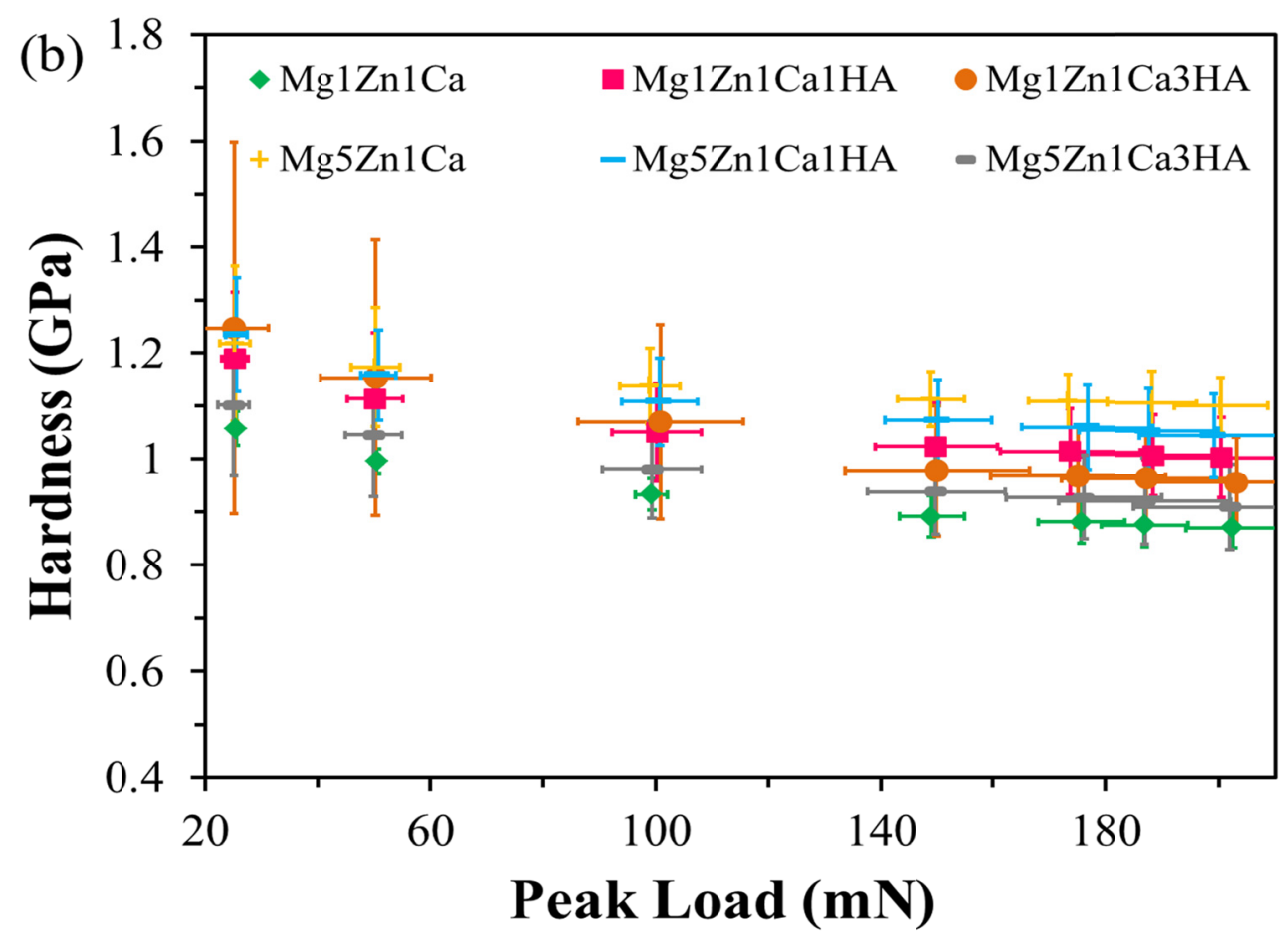

Figure 6.3: Hardness calculated by Oliver Pharr approach: (a) Mg1Zn, Mg1Zn1Ca and Mg1Zn1Ca8Gd and (b) Mg1Zn1Ca, Mg1Zn1Ca1HA, Mg1Zn1Ca3HA, Mg5Zn1Ca, Mg5Zn1CalHA and Mg5Zn1Ca3HA (mean $\pm S D, n=10)$.

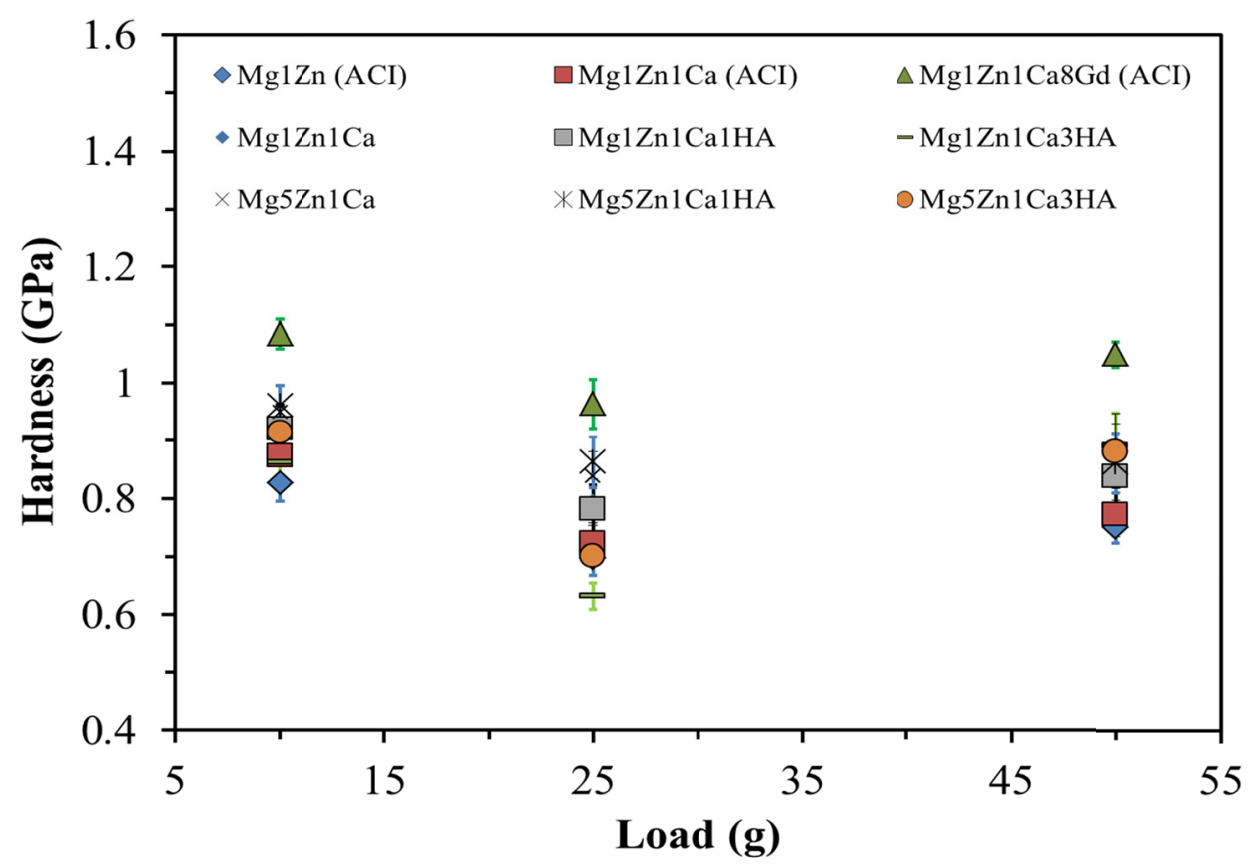

Figure 6.4: Load Vs hardness calculated from Vicker's hardness (mean $\pm S D, n=5$ ). 


\subsection{Ultimate Tensile Strength}

Ultimate tensile strength measurements were conducted at Brunel University [113]. As compared with biodegradable $\mathrm{Mg}$ alloys, polymers possess low mechanical properties $[88,135]$. The mechanical properties of $\mathrm{Mg}$ alloys are similar to that of human bone, which can reduces stress shielding [113]. Zibiao Li (2010) reported mechanical properties of selected $\mathrm{Mg}$ alloys/MMCs as shown in Figure 6.5[113], where the tensile strength of $\mathrm{MgZnCaHA}$ increased with $\mathrm{Zn}$ and $\mathrm{HA}$ content. As already discussed in Section 5.2, the addition of $\mathrm{Zn}$ and HA restricts grain growth, which leads to improved mechanical properties. According to the Hall-Petch equation, there is an inverse relationship between grain size and yield strength. In this case, yield strength increased with reduced grain size [113]. Thus, with the addition of HA increased the tensile and yield strength by serving as load transfer sites in metal matrices [113]. However, it was reported that the scatter in the elongation data was due to microstructural defects [113].

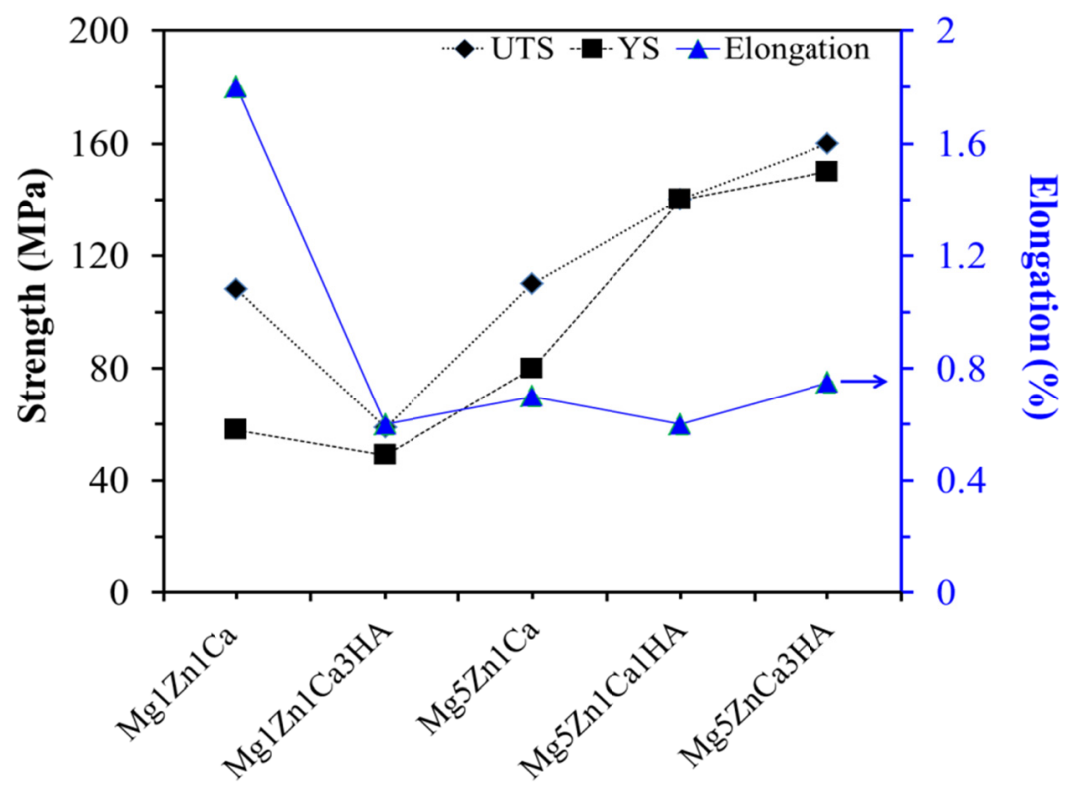

Figure 6.5: Approximate tensile properties of Mg alloys/MMCs adopted from Zibiao Li, M. Phil thesis at Brunel University, Brunel Center for Advanced Solidification Technology (BCAST), August 2010 [113]. 


\subsection{BIOCOMPATIBILITY STUDIES}

The biocompatibility of implant materials is mainly dependent on basic characteristics such as material composition, nature and thickness of the passivating layer, surface morphology, surface charge and wettability. Alloying and surface treatments change the aforementioned surface properties, which in turn affect their biocompatibility. In this research, alloying of $\mathrm{Mg}$ with $\mathrm{Zn}, \mathrm{Ca}, \mathrm{Gd}$ and $\mathrm{HA}$ improved the mechanical properties and corrosion resistance as discussed in Chapters 4 and 6 . Biocompatibility assessment of a material usually comprises of in-vitro corrosion tests, cell proliferation and cytotoxicity of ions released on cells. The following schematic diagram shown in Figure 7.1 illustrates the approach that was adopted in this research to elucidate the biocompatibility of Mg alloys/MMCs.

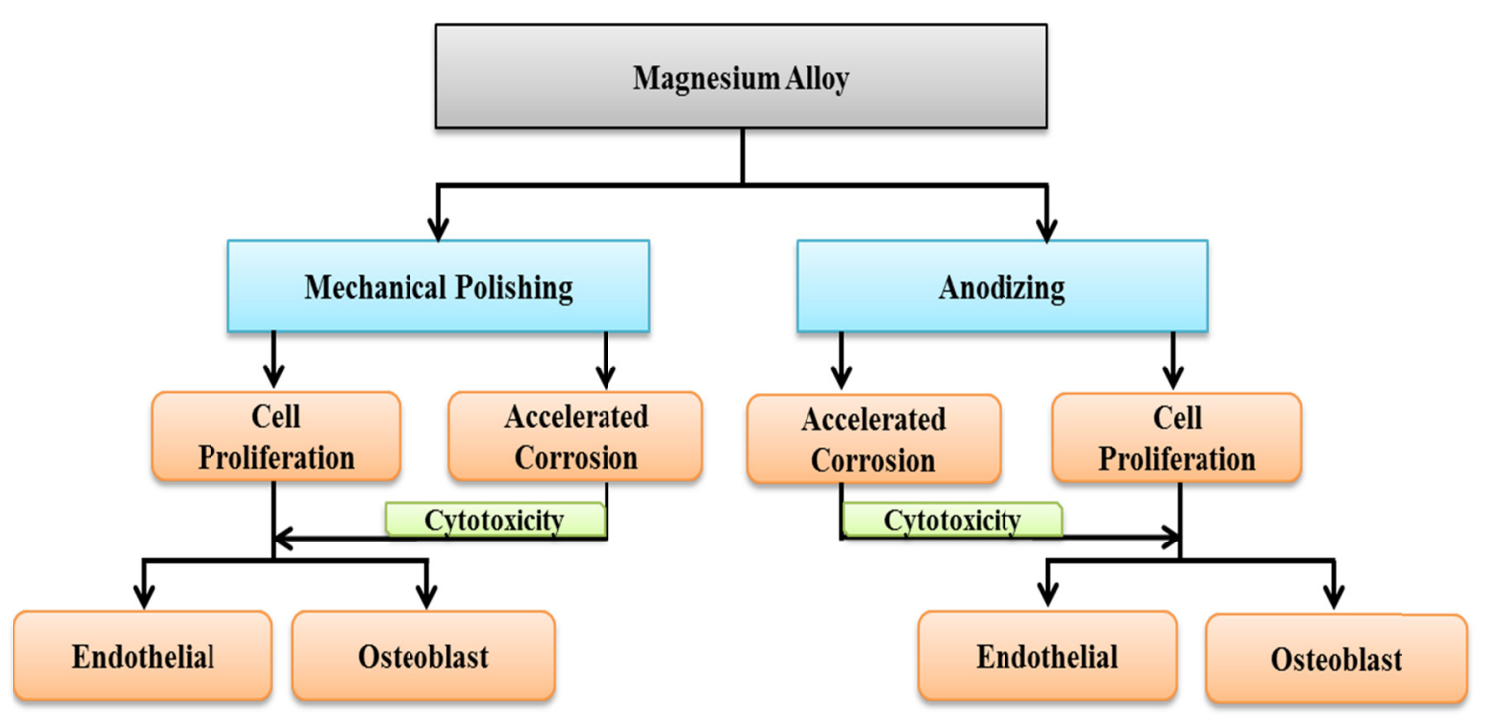

Figure 7.1: Schematic representation of procedure adopted for biocompatibility studies.

Bioabsorbable $\mathrm{Mg}$ alloys/MMCs are composed of alloying elements that are essential in human metabolic and healing processes. For example, $\mathrm{Ca}$ and $\mathrm{Mg}$ ions released from the aforementioned materials could prolong blood clotting time as reported 
by R.G. Huntsman et al., 1960 [67]. It is envisaged that the usage of biodegradable Mg alloys/MMCs for the manufacture of stents and orthopedic implants will obviate the need for repeat surgical procedures, which increase healthcare costs and possibility of patient morbidity.

\subsection{Endothelial Cell Proliferation on Mg Alloys/MMCs}

Damage to the endothelium layer and exposure of the subendothelial matrix at the site of arterial injury may result in intimal hyperplasia (a physiological healing response after damage to blood vessels that causes thickening of the walls), which leads to in-stent restenosis (narrowing of blood vessels with $>50 \%$ luminal closure) [137]. Restenosis remains a significant problem, with $15 \%-20 \%$ of patients affected after primary stenting. Restenosis occurs typically 3 to 6 months after installation of stents. Drug eluting stents (DES) evolved in an effort to prevent in-stent restenosis. On the other hand, surfaceinduced thrombosis also causes failure of cardiovascular stents, which may be reduced if the stent surface is rendered suitable for endothelialization. Biodegradable $\mathrm{Mg}$ alloys/MMCs have been used to minimize the effects of thrombosis and in-stent restenosis [195]. Maier et al. (2004) reported Mg deficiency promotes atherosclerosis, thrombosis and hypertension [138].

The growth of human pulmonary artery endothelial cells (HPAEC, Fischer Scientific, catalog\# PH30205AK) on the surface of magnesium samples was assessed using the ISO 10993 protocols for biological evaluation of medical devices. Endothelial cells were maintained in accordance with the instructions provided by the commercial source (Fischer Scientific, catalog\# PH30205AK). The cells were first cultured in a T-75 
cell culture flask using F-12K as the medium, the composition of which is listed in Table 7.1. When cells were $90 \%$ confluent, they were trypsinized, centrifuged and then resuspended in culture media for cell counting and cell seeding as further discussed elsewhere [68].

In order to assess endothelial cell proliferation, $\mathrm{Mg}$ samples of dimensions 0.414 ” x 0.414 " x 0.08 " were placed into a 24 -well plate and seeded with $50 \times 10^{3}$ cells per well. Cell culture plates with samples in cell culture media were incubated for 48 hours at 37 ${ }^{\circ} \mathrm{C}$ under $5 \% \mathrm{CO}_{2}$. Later, the cell culture media was removed and the samples were gently washed with Dulbecco's phosphate buffered saline (DPBS). $2 \mathrm{ml}$ of Hoechst dye $(5 \mu \mathrm{M})$ and Mitotracker Red dye (100nM) were added into the wells. Hoechst dye was used to highlight the nuclei of the cells, while Mitotracker Red dye was used to highlight the mitochondria of the cells. The plates were again incubated for 20 minutes, after which the samples were washed 3 times with DPBS. Finally, the cells were fixed on the surface of the samples with $10 \%$ formaldehyde and covered by glass slides. Due to fast degradation and hydrogen gas evolution from the samples, no clear evidence of cellular activity was observed. In addition, the metal oxide that is continuously produced on the surface may have engulfed cells. Thus, cellular proliferation may have been obscured and/or inhibited by simultaneous degradation, hydrogen evolution, localized $\mathrm{pH}$ increase and oxide formation. Further investigation is needed to elucidate this phenomenon. 
Table 7.1: Composition of F-12K medium used for endothelial cells [68]

\begin{tabular}{|c|c|c|c|c|c|c|c|c|c|}
\hline Inorganic Salts & $\mathrm{g} / \mathrm{L}$ & Amino Acids & $\mathrm{g} / \mathrm{L}$ & Amino Acids & $\mathrm{g} / \mathrm{L}$ & Vitamins & $\mathrm{g} / \mathrm{L}$ & Other & $\mathrm{g} / \mathrm{L}$ \\
\hline $\mathrm{CaCl}_{2} \cdot 2 \mathrm{H}_{2} \mathrm{O}$ & 0.13524 & $\begin{array}{l}\text { L-Arginine (free } \\
\text { base) }\end{array}$ & 0.42140 & $\begin{array}{c}\text { L- } \\
\text { Phenylalanine } \\
\end{array}$ & 0.00991 & D-Biotin & 0.0000733 & D-Glucose & 1.26000 \\
\hline $\mathrm{CuSO}_{4} \cdot 5 \mathrm{H}_{2} \mathrm{O}$ & 0.000002 & L-Alanine & 0.01782 & L-Proline & 0.06906 & Choline Chloride & 0.01396 & $\begin{array}{l}\text { Phenol Red, } \\
\text { Sodium Salt }\end{array}$ & 0.00332 \\
\hline $\mathrm{FeSO}_{4} \cdot 7 \mathrm{H} 2 \mathrm{O}$ & 0.000834 & L-Asparagine $\cdot \mathrm{H}_{2} \mathrm{O}$ & 0.03020 & L-Serine & 0.02102 & Folic Acid & 0.00132 & $\begin{array}{c}\text { Sodium } \\
\text { Pyruvate } \\
\end{array}$ & 0.22000 \\
\hline $\mathrm{MgCl}_{2} \cdot 6 \mathrm{H} 2 \mathrm{O}$ & 0.10572 & L-Aspartic Acid & 0.02662 & L-Threonine & 0.02382 & Hypoxanthine & 0.00408 & Lipoic Acid & 0.00021 \\
\hline $\begin{array}{c}\mathrm{MgSO}_{4} \\
\text { (anhydrous) }\end{array}$ & 0.19264 & $\mathrm{~L}-\mathrm{Cysteine} \cdot \mathrm{HCl} \cdot \mathrm{H}_{2} \mathrm{O}$ & 0.07024 & L-Tryptophan & 0.00408 & Myo-Inositol & 0.01802 & & \\
\hline $\mathrm{KCl}$ & 0.28329 & L-Glutamic Acid & 0.02942 & $\begin{array}{l}\text { L-Tyrosine } \\
\text { (free base) }\end{array}$ & 0.01087 & Nicotinamide & 0.0000366 & & \\
\hline $\begin{array}{c}\mathrm{KH}_{2} \mathrm{PO}_{4} \\
\text { (anhydrous) }\end{array}$ & 0.05852 & L-Glutamine & 0.29220 & L-Valine & 0.02342 & $\begin{array}{c}\text { D-Pantothenic } \\
\text { Acid }\end{array}$ & 0.000477 & & \\
\hline $\mathrm{NaHCO}_{3}$ & 1.50000 & Glycine & 0.01501 & & & Putrescine $\cdot 2 \mathrm{HCl}$ & 0.000322 & & \\
\hline $\mathrm{Na}_{2} \mathrm{HPO}_{4}$ & 0.11502 & $\begin{array}{c}\mathrm{L}- \\
\text { Histidine } \cdot \mathrm{HCl} \cdot \mathrm{H}_{2} \mathrm{O}\end{array}$ & 0.04192 & & & Pyridoxine $\cdot \mathrm{HCl}$ & 0.0000617 & & \\
\hline $\mathrm{NaCl}$ & 7.59720 & L-Isoleucine & 0.00782 & & & Riboflavin & 0.0000376 & & \\
\hline \multirow[t]{3}{*}{$\mathrm{ZnSO}_{4} \cdot 7 \mathrm{H}_{2} \mathrm{O}$} & 0.000144 & L-Leucine & 0.02624 & & & Thiamine $\cdot \mathrm{HCl}$ & 0.000337 & & \\
\hline & & L-Lysine $\cdot \mathrm{HCl}$ & 0.07304 & & & Thymidine & 0.000727 & & \\
\hline & & L-Methionine & 0.00895 & & & Vitamin B-12 & 0.001355 & & \\
\hline
\end{tabular}




\subsection{Cytotoxicity of Leached Ions on Endothelial Cells by SRB Assay}

The effect of dissolved ions released from Mg alloys/MMCs in PBS during invitro corrosion tests on Human Pulmonary Artery Endothelial Cells (HPAEC) was assessed by sulphorhodamine B (SRB) assay. The cells were thawed on receiving and seeded in T-75 tissue culture flasks in endothelial cell growth medium (Fischer Scientific, Catalog\# PM211500). Once the cells were 90\% confluent in the flask, the cells were trypsinized and centrifuged for 5 minutes at $1700 \mathrm{rpm}$. The supernatant was removed and the cell pellet was dissolved in media. Cells were counted using the cell counting device (Bio-Rad TC 10, automated cell counter) and the media was further added to achieve a cell concentration of $10^{5} \mathrm{cell} / \mathrm{ml}$. $200 \mu 1$ of cell solutions (approx 20,000 cells/well) were placed in three 96 well plates. Endothelial cells in the wells were exposed to three different concentrations of corrosion extract $(10 \%, 50 \%$ and $100 \%$; with the remainder being cell culture media) over periods of 2, 4 and 7 days. The corrosion extracts were prepared by dissolving $10 \%$ FBS, $1 \%$ Penstrep into the PBS collected after corrosion. The well plates were then placed in an incubator at $37{ }^{\circ} \mathrm{C}$ and $5 \% \mathrm{CO}_{2}$ in a humidified environment. The viability of the HPAEC was assessed over different time periods using SRB assay and their relative survivability were measured from the absorbance measured.

The total concentration of $\mathrm{Mg}, \mathrm{Zn}, \mathrm{Ca}, \mathrm{Gd}$ and $\mathrm{HA}$ ions in $100 \%$ corrosion extract was $\sim 114.8 \mu \mathrm{g} / \mathrm{mL}$, with individual ionic concentrations of: $\mathrm{Mg}=33.0 ; \mathrm{Zn}=0.8 ; \mathrm{Ca}=$ 81.0 and $\mathrm{Gd}=0.01 \mu \mathrm{g} / \mathrm{mL}$. Subsequently, a $50 \%$ corrosion extract contained a total dissolved ion concentration of $\sim 57.4 \mu \mathrm{g} / \mathrm{mL}$, with individual ionic concentrations of: $\mathrm{Mg}$ 
$=16.5 ; \mathrm{Zn}=0.4 ; \mathrm{Ca}=40.5$ and $\mathrm{Gd}=0.01 \mu \mathrm{g} / \mathrm{mL} ;$ and $10 \%$ corrosion extract contained $\mathrm{a}$ total dissolved ion concentration of $\sim 11.5 \mu \mathrm{g} / \mathrm{mL}$, with individual ionic concentrations of: $\mathrm{Mg}=3.3 ; \mathrm{Zn}=0.1 ; \mathrm{Ca}=8.1$ and $\mathrm{Gd}=0.001 \mu \mathrm{g} / \mathrm{mL}$.

Figure 7.2 shows the cytotoxicity assessment of corrosion extracts from mechanically polished Mg samples in PBS at $37{ }^{\circ} \mathrm{C}$. All samples exhibited an increase in cell growth in extracts of $10 \%$ and $50 \%$ over periods of 2,4 and 7 days, which was comparable with that of the control. With a $100 \%$ corrosion extract from all samples, the net growth rate of cells decreased except for the $\mathrm{Mg} 1 \mathrm{Zn} 1 \mathrm{Ca} 3 \mathrm{HA}$ extract, in which endothelial cells proliferated. These results are supported by ICP-MS analysis (Appendix I, Table A.11), where the concentration of $\mathrm{Zn}$ in the $\mathrm{Mg} 1 \mathrm{Zn} 1 \mathrm{Ca} 3 \mathrm{HA}$ extract was at least 1 order of magnitude lower than the $\mathrm{Zn}$ concentration in all other extracts. The concentration of $\mathrm{Zn}$ appeared to be some what toxic to cells of all the ions. Furthermore, the concentrations of leached ions from $\mathrm{Mg} 1 \mathrm{Zn} 1 \mathrm{Ca} 3 \mathrm{HA}$ were comparable with those in the F-12K cell culture media as shown Table 7.2, where again the $\mathrm{Zn}$ concentration was low relative to $\mathrm{Mg}$ and $\mathrm{Ca}$. It should be noted that the culture media and $100 \%$ extract from $\mathrm{Mg} 1 \mathrm{Zn} 1 \mathrm{Ca} 3 \mathrm{HA}$ had similar concentrations of dissolved ions, which corroborate with similar cell survivability measured in both solutions. 

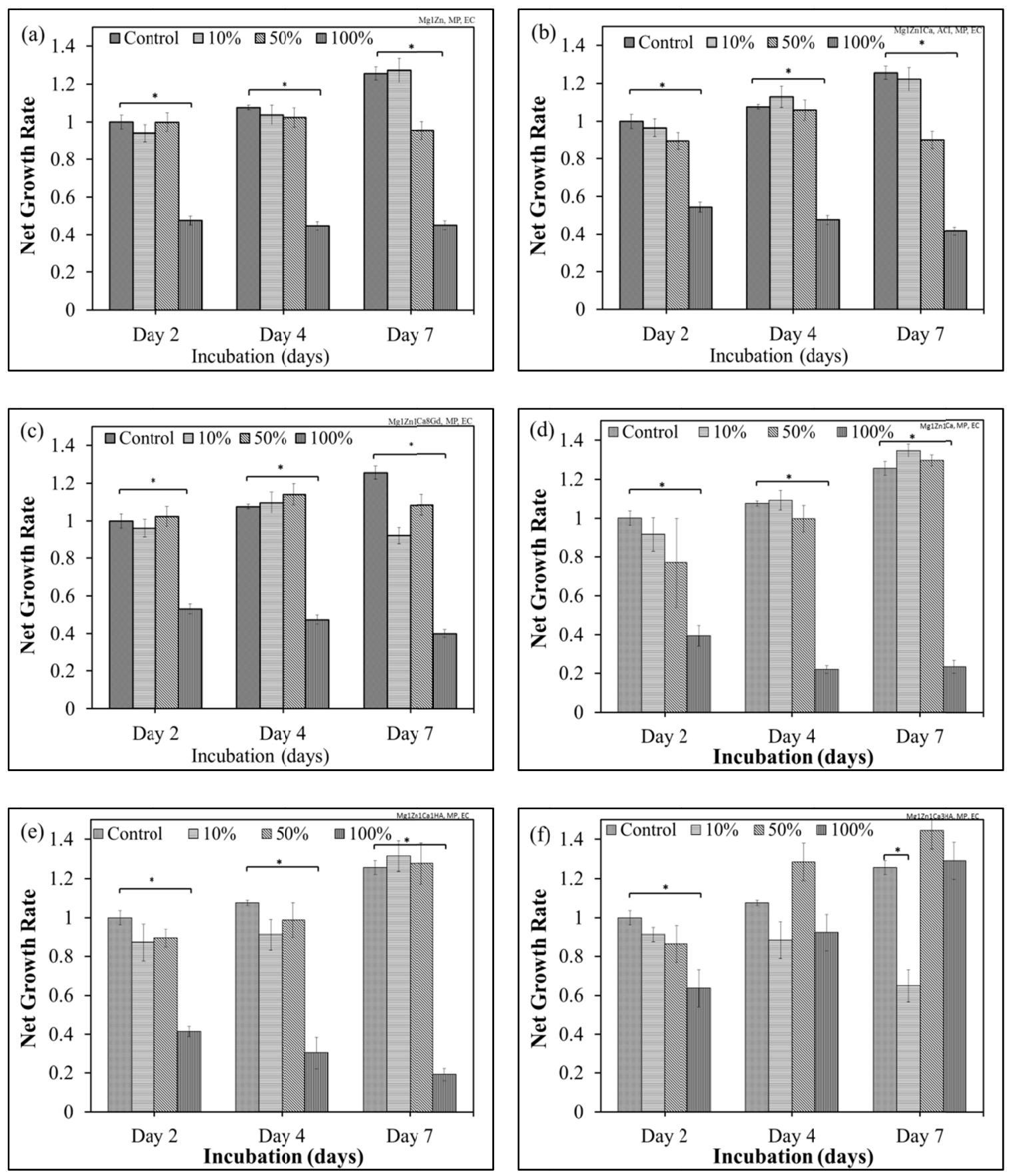

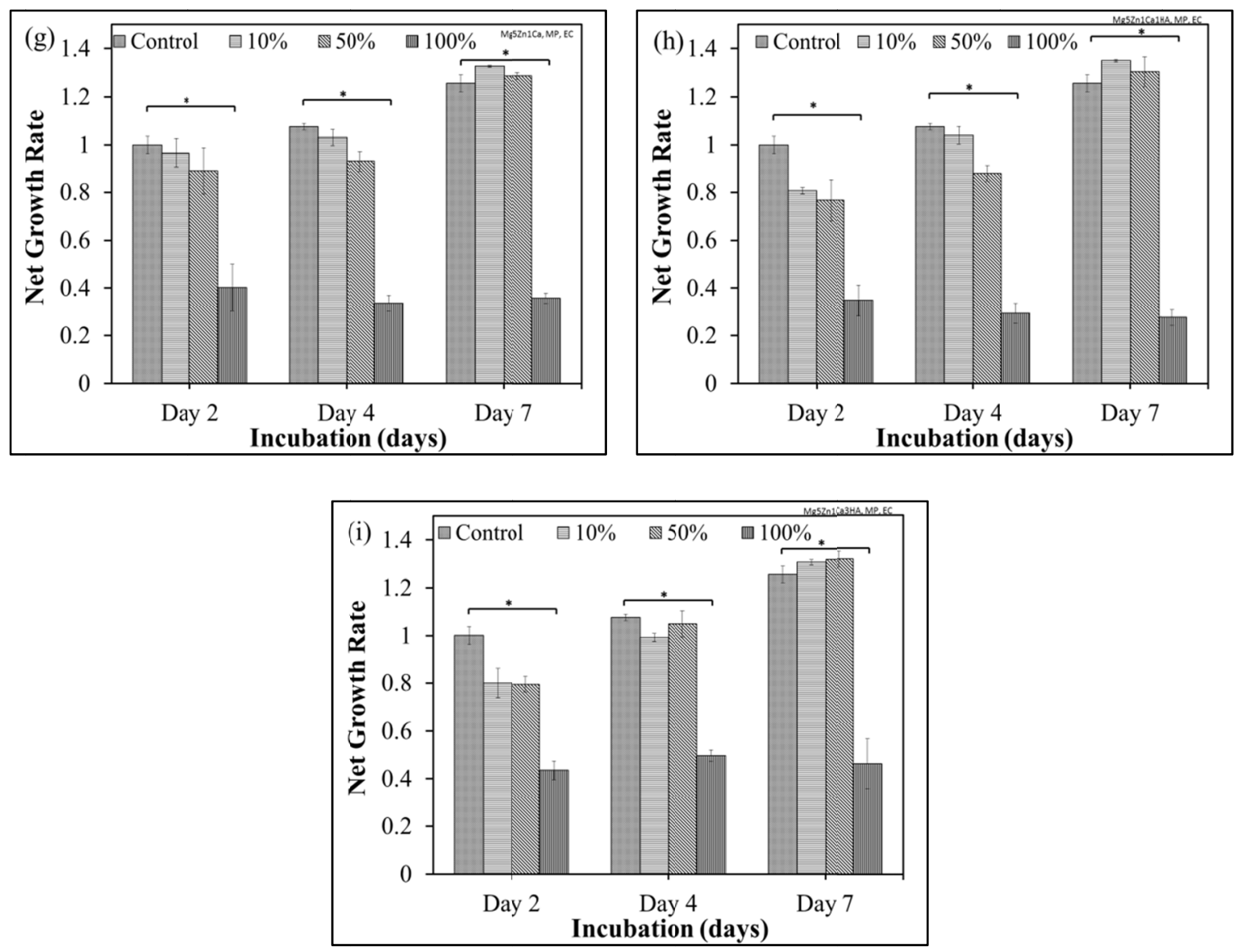

Figure 7.2: Net growth rate of endothelial cells exposed to leached ions from mechanically polished samples during static immersion test (mean $\pm S D, n=3)$ : (a) Mg1Zn (ACI); (b) Mg1Zn1Ca (ACI); (c) Mg1Zn1Ca8Gd (ACI); (d) Mg1Zn1Ca; (e) Mg1Zn1Ca1HA; (f) Mg1Zn1Ca3HA; (g) Mg5Zn1Ca; (h) Mg5Zn1Ca1HA; and (i) Mg5Zn1Ca3HA. Statistical significance $(p<0.05)$ was analyzed using the Tukey test.

\subsection{Osteoblast Cell Proliferation on Mg Alloys/MMCs}

Osteoblast cells are a cell line responsible for reconstruction and formation of bones. Cell adhesion is the initial interaction with an implant surface followed by spreading, which forms the basis for propagation. Initially after implantation, the cells do not communicate directly with the implant, but are guided to sites by biological 
interactive molecules. This process consists of two parts, namely the physicochemical bond formed between the cells and the material's surface and adhesion, which are assisted by various extra cellular matrix proteins, cytoskeleton proteins and adhesion molecules. The resulting interactions result in the formation of either a fibrous tissue or a strong bone bond [178].

The cell culture media was prepared by mixing Dulbecco's Modified Eagle Medium:Nutrient Mixture F-12 (DMEM/F-12)with $2.5 \mathrm{mM}$ L-glutamine, $0.3 \mathrm{mg} / \mathrm{ml}$ G418 and fetal bovine serum. The composition of the DMEM/F-12 medium used for osteoblast cells is shown in Table 7.2. The cell culture medium was replaced in the flask after every 36 hours to remove the dead cells and to provide additional nutrients for the existing cells, because the cell-number doubling time for the osteoblast cells has been reported to be approximately 36 hours at $34{ }^{\circ} \mathrm{C}$. Once the cells were confluent in the cell culture flask (approximately after 5 to 7 days ) they were trypsinized. The cells were then utilized in subsequent cell growth and cytotoxicity tests.

Human osteoblast cells (hFOB 1.19 cells, ATCC, Manassas, VA, USA) at a concentration of $10^{5}$ cells $/ \mathrm{ml}$, were cultivated on the pre-cleaned surface of mechanically polished samples in an incubator at $37{ }^{\circ} \mathrm{C}$ under $5 \% \mathrm{CO}_{2}$ for 48 hours. The cells were then washed with PBS and fixed with $25 \%$ formalin solution (1:3 formalin and PBS, Thermo-Shandon, 990244) for SEM analysis [10,188].

SEM analysis revealed poor cell visibility, which was attributed to localized $\mathrm{pH}$ increase, hydrogen evolution and simultaneous oxide formation on $\mathrm{Mg}$ alloys/MMCs. Similar observations have been reported by various researchers, who suggested that the cells may be present in cracks, crevices and under the oxide layers [115]. 
Table 7.2: Composition of DMEM/F-12 medium used for osteoblast cells [189,190,191,192,193]

\begin{tabular}{|c|c|c|c|c|c|c|c|c|c|}
\hline Inorganic Salts & $\mathrm{g} / \mathrm{L}$ & Amino Acids & $\mathrm{g} / \mathrm{L}$ & Amino Acids & $\mathrm{g} / \mathrm{L}$ & Vitamins & $\mathrm{g} / \mathrm{L}$ & Other & $\mathrm{g} / \mathrm{L}$ \\
\hline $\mathrm{CaCl}_{2}$ (anhydrous) & 0.1166 & Glycine & 0.01875 & L-Proline & 0.01725 & Biotin & 0.0000035 & D-Glucose & 3.151 \\
\hline $\mathrm{CuSO}_{4} \cdot 5 \mathrm{H}_{2} \mathrm{O}$ & $1.3 \mathrm{E}-06$ & L-Alanine & 0.00445 & L-Serine & 0.02625 & Choline Chloride & 0.00898 & HEPES & 3.5745 \\
\hline $\mathrm{Fe}(\mathrm{NO} 3) 3 " 9 \mathrm{H} 2 \mathrm{O}$ & 0.00005 & $\begin{array}{c}\text { L-Arginine } \\
\text { hydrochloride }\end{array}$ & 0.1475 & L-Threonine & 0.05345 & $\begin{array}{l}\text { D-Calcium } \\
\text { pantothenate }\end{array}$ & 0.00224 & $\begin{array}{c}\text { Hypoxanthine } \\
\mathrm{Na}\end{array}$ & 0.00239 \\
\hline $\mathrm{FeSO}_{4} \cdot 7 \mathrm{H} 2 \mathrm{O}$ & 0.000417 & L-Asparagine $\cdot \mathrm{H}_{2} \mathrm{O}$ & 0.0075 & L-Tryptophan & 0.00902 & Folic Acid & 0.00265 & Linoleic Acid & 0.000042 \\
\hline $\begin{array}{c}\mathrm{MgCl}_{2} \\
\text { (anhydrous) }\end{array}$ & 0.02864 & L-Aspartic Acid & 0.00665 & $\begin{array}{c}\text { L-Tyrosine } \\
\text { disodium salt } \\
\text { dihydrate }\end{array}$ & 0.05579 & Niacinamide & 0.00202 & Lipoic Acid & 0.000105 \\
\hline $\mathrm{MgSO}_{4}$ (anhydrous) & 0.04884 & $\begin{array}{c}\text { L-Cysteine- } \\
\text { hydrochloride-H2O }\end{array}$ & 0.01756 & L-Valine & 0.05285 & $\begin{array}{c}\text { Pyridoxine } \\
\text { hydrochloride }\end{array}$ & 0.002 & $\begin{array}{c}\text { Putrescine } \\
2 \mathrm{HCl}\end{array}$ & 0.000081 \\
\hline $\mathrm{KCl}$ & 0.3118 & L-Cysteine $\cdot 2 \mathrm{HCl}$ & 0.03129 & & & Riboflavin & 0.000219 & $\begin{array}{l}\text { Sodium } \\
\text { Pyruvate }\end{array}$ & 0.055 \\
\hline $\mathrm{NaHCO} 3$ & 1.2 & L-Glutamic Acid & 0.00735 & & & $\begin{array}{c}\text { Thiamine } \\
\text { hydrochloride }\end{array}$ & 0.00217 & Thymidine & 0.000365 \\
\hline $\mathrm{NaCl}$ & 6.9955 & L-Glutamine & 0.365 & & & Vitamin B12 & 0.00068 & & \\
\hline $\mathrm{Na}_{2} \mathrm{HPO}_{4}$ & 0.07102 & $\begin{array}{c}\text { L-Histidine } \\
\text { hydrochloride-H2O }\end{array}$ & 0.03148 & & & i-Inositol & 0.0126 & & \\
\hline $\mathrm{Na}_{2} \mathrm{HPO}_{4} \mathrm{H}_{2} \mathrm{O}$ & 0.0625 & L-Isoleucine & 0.05447 & & & & & & \\
\hline \multirow[t]{4}{*}{$\mathrm{ZnSO}_{4} \cdot 7 \mathrm{H}_{2} \mathrm{O}$} & 0.000432 & L-Leucine & 0.05905 & & & & & & \\
\hline & & L-Lysine hydrochloride & 0.09125 & & & & & & \\
\hline & & L-Methionine & 0.01724 & & & & & & \\
\hline & & L-Phenylalanine & 0.03548 & & & & & & \\
\hline
\end{tabular}




\subsection{Cytotoxicity of Leached Ions on Osteoblast Cells by SRB Assay}

The viability of osteoblast cells (ATCC, catalog\# CRL11372) exposed to dissolved ions in PBS after corrosion were assessed by SRB assay. The cells were thawed on receiving and seeded in T-75 tissue culture flasks in culture medium that was made from 89\% base media (Invitrogen, Catalog\# 11039-021), 10\% FBS (ATCC, Catalog\# 302020), 1\% Penstrep (ATCC, Catalog\# 30-2020) and $0.3 \mathrm{mg} / \mathrm{ml}$ of $\mathrm{G} 418$ of the base media. Once the cells were $90 \%$ confluent in the flask, the cells were trypsinzed and cell concentration was made upto 105 cells $/ \mathrm{ml}$. $200 \mu \mathrm{l}$ of that cell solution (approx 20,000 cells) were placed in three 96 well plates. Osteoblast cells in the 96 wells were exposed to three different concentrations of corrosion extract $(10 \%, 50 \%$ and $100 \%)$ over periods of 2, 4 and 7 days. The corrosion extracts were prepared by mixing FBS, penstrep and G 418 with PBS after corrosion, so that aforementioned media and prepared extracts had similar concentrations of FBS, penstrep and G 418. The well plates were then placed in an incubator at $37{ }^{\circ} \mathrm{C}$ and $5 \% \mathrm{CO}_{2}$ in a humidified environment. The viability of the osteoblast cells was assessed over different time periods using SRB assay and their relative survivability was measured from the absorbance measured.

As was discussed in section 7.2, again the total concentration of $\mathrm{Mg}, \mathrm{Zn}, \mathrm{Ca}, \mathrm{Gd}$ and HA ions in $100 \%$ corrison extract was $\sim 114.8 \mu \mathrm{g} / \mathrm{mL}$, with individual ionic concentrations of: $\mathrm{Mg}=33.0 ; \mathrm{Zn}=0.8 ; \mathrm{Ca}=81.0$ and $\mathrm{Gd}=0.01 \mu \mathrm{g} / \mathrm{mL}$. Subsequently, a $50 \%$ corrosion extract contained a total dissolved ion concentration of $\sim 57.4 \mu \mathrm{g} / \mathrm{mL}$, with individual ionic concentrations of: $\mathrm{Mg}=16.5 ; \mathrm{Zn}=0.4 ; \mathrm{Ca}=40.5$ and $\mathrm{Gd}=0.01$ 
$\mu \mathrm{g} / \mathrm{mL}$; and $10 \%$ corrosion extract contained a total dissolved ion concentration of $\sim 11.5$ $\mu \mathrm{g} / \mathrm{mL}$, with individual ionic concentrations of: $\mathrm{Mg}=3.3 ; \mathrm{Zn}=0.1 ; \mathrm{Ca}=8.1$ and $\mathrm{Gd}=$ $0.001 \mu \mathrm{g} / \mathrm{mL}$.

Figure 7.5 shows the survivability of osteoblast cells in the presence of different concentrations $(10 \%, 50 \%$ and $100 \%)$ of corrosion extracts. The growth rate increased in $10 \%$ extract from all samples. With $50 \%$ and $100 \%$ extract from all samples, there was no significant difference in the net growth after 2, 4 and 7 days. However, as compared with the control, there was a decrease in net growth of $\sim 30$ and $\sim 60 \%$ of cells exposed to $50 \%$ and $100 \%$ extracts respectively from all samples.

The cell exposed to 50\% extract from $\mathrm{Mg}$ alloys/MMCs with HA exhibited an increase in growth after 4 days. This was due to the presence of HA, which is known to induce osseointegration. The chemical composition of HA is similar to the mineral crystallites present in human bone i.e. calcium phosphate $\left(\mathrm{Ca}_{10}\left(\mathrm{PO}_{4}\right)_{6}(\mathrm{OH})_{2}\right)$, a bioceramic [56]. 

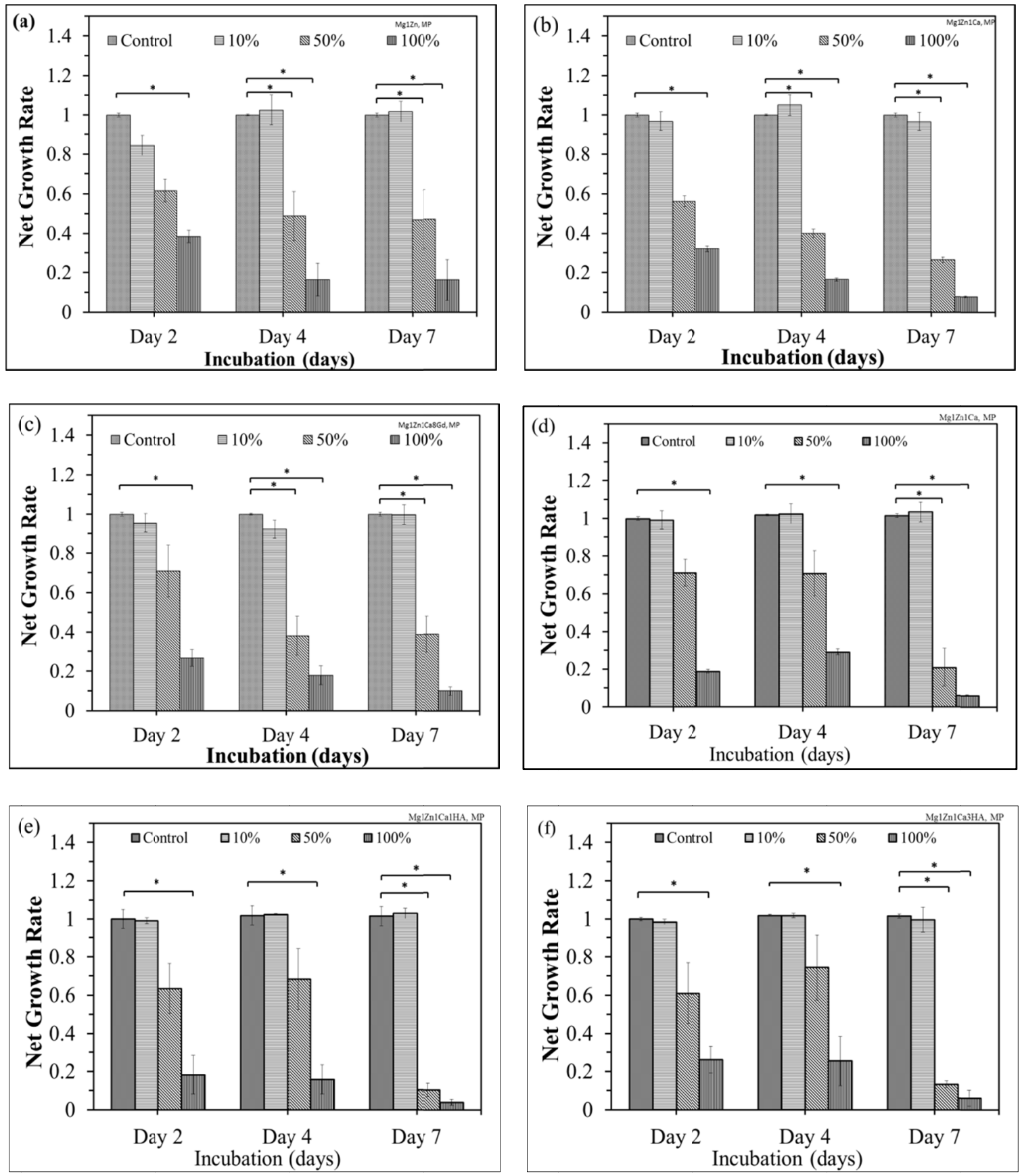

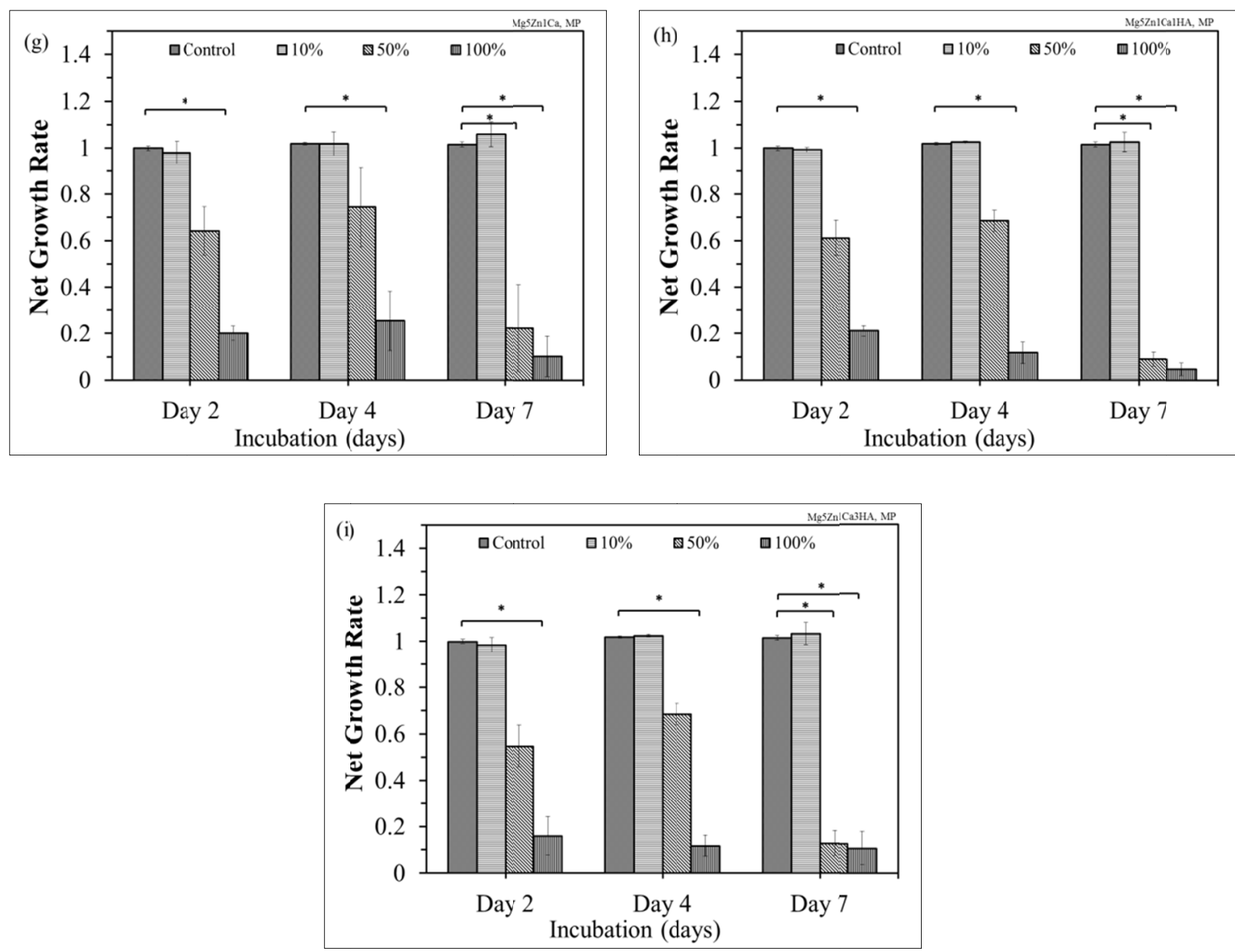

Figure 7.3: Net growth rate of osteoblast cells exposed to leached ions from mechanically polished samples during static immersion test (mean $\pm S D, n=3$ ): (a) MgIZn (ACI); (b) Mg1Zn1Ca (ACI); (c) Mg1Zn1Ca8Gd (ACI); (d) MglZn1Ca; (e) MglZnICalHA; (f) MglZn1Ca3HA; (g) Mg5Zn1Ca; (h) Mg5Zn1CalHA; and (i) Mg5Zn1Ca3HA. Statistical significance $(p<0.05)$ was analyzed using the Tukey test.

Figure 7.4 shows optical images of osteoblast cells cultured for 2, 4 and 7 days in the same control described above and in $10 \%$ extract media. Net cell growth was observed in the control and 10\% corrosion extracts from mechanically polished $\mathrm{Mg} 1 \mathrm{Zn}$, $\mathrm{Mg} 1 \mathrm{Zn} 1 \mathrm{Ca}$ and $\mathrm{Mg} 1 \mathrm{Zn} 1 \mathrm{Ca} 8 \mathrm{Gd}$. However, the number of dead cells in $10 \%$ corrosion extract appeared to increase after 4 days. 


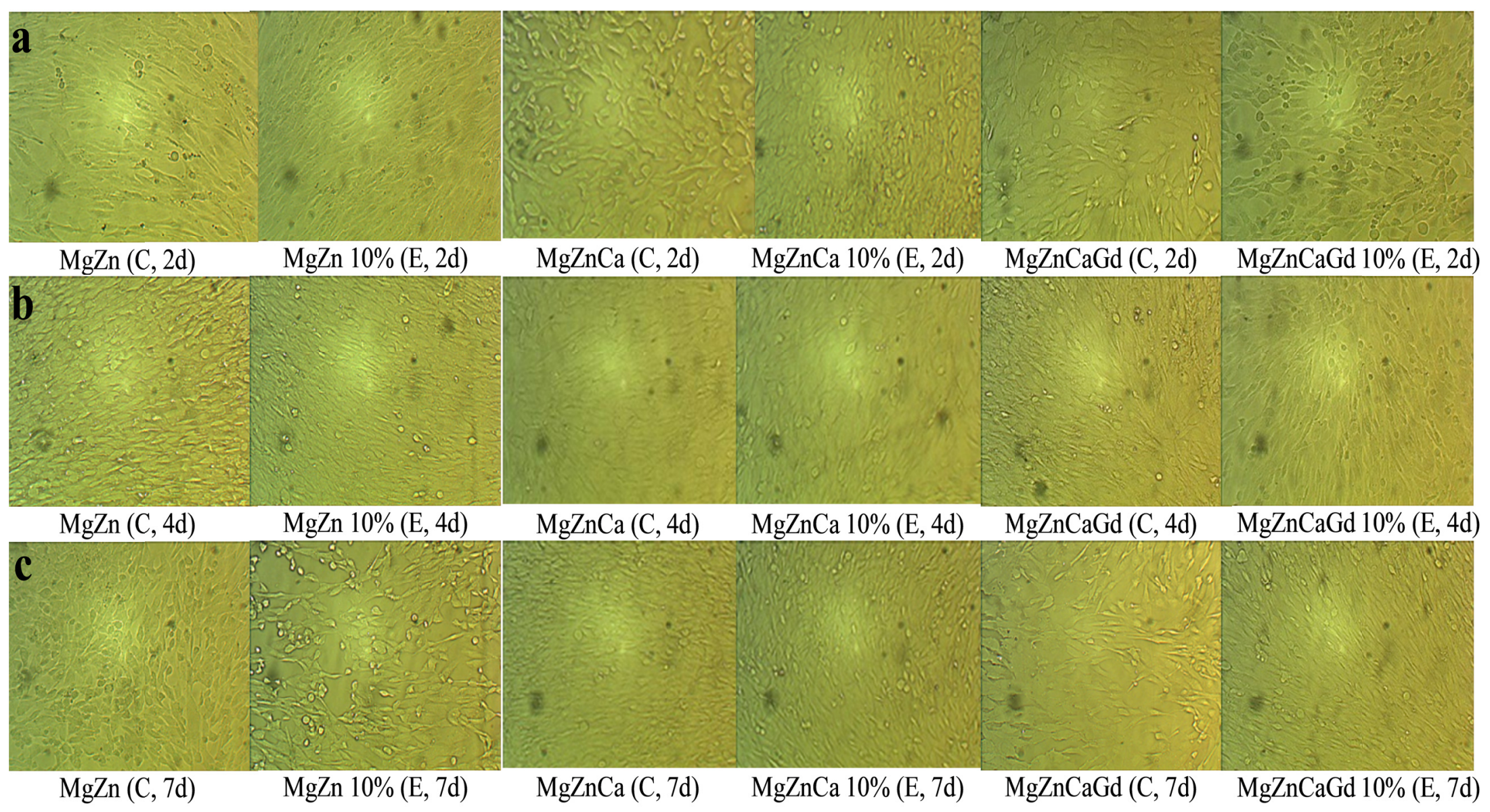

Figure 7.4: Optical morphologies of osteoblast cells that were cultured in the control (C) and 10\% extract (E) concentrations of $\mathrm{MgZn}, \mathrm{MgZnCa}$ and $\mathrm{MgZnCaGd}$ alloys from corrosion test runs in PBS for (a) 2 days, 4 days and (c) 7 days. 
The growth of osteoblast cells exposed to extracts from anodized samples during dynamic immersion in PBS at $37{ }^{\circ} \mathrm{C}$ was evaluated after 2, 4 and 7 days and is shown in Figure 7.5. There was no appreciable difference between the net growth rate of cells exposed to $10 \%$ corrosion extract and that of the control over time. However, there was $50 \%$ decrease in the net growth rate of cells exposed to $50 \%$ corrosion extract after day 2 ; followed by a slight decrease after day 4; and $80 \%$ decrease after day 7 . Cells exposed to $100 \%$ corrosion extract exhibited a net growth rate of $\sim 20 \%$ by day 2 with a slight decrease over time. Note that a similar trend was observed for mechanically polished samples under static conditions.
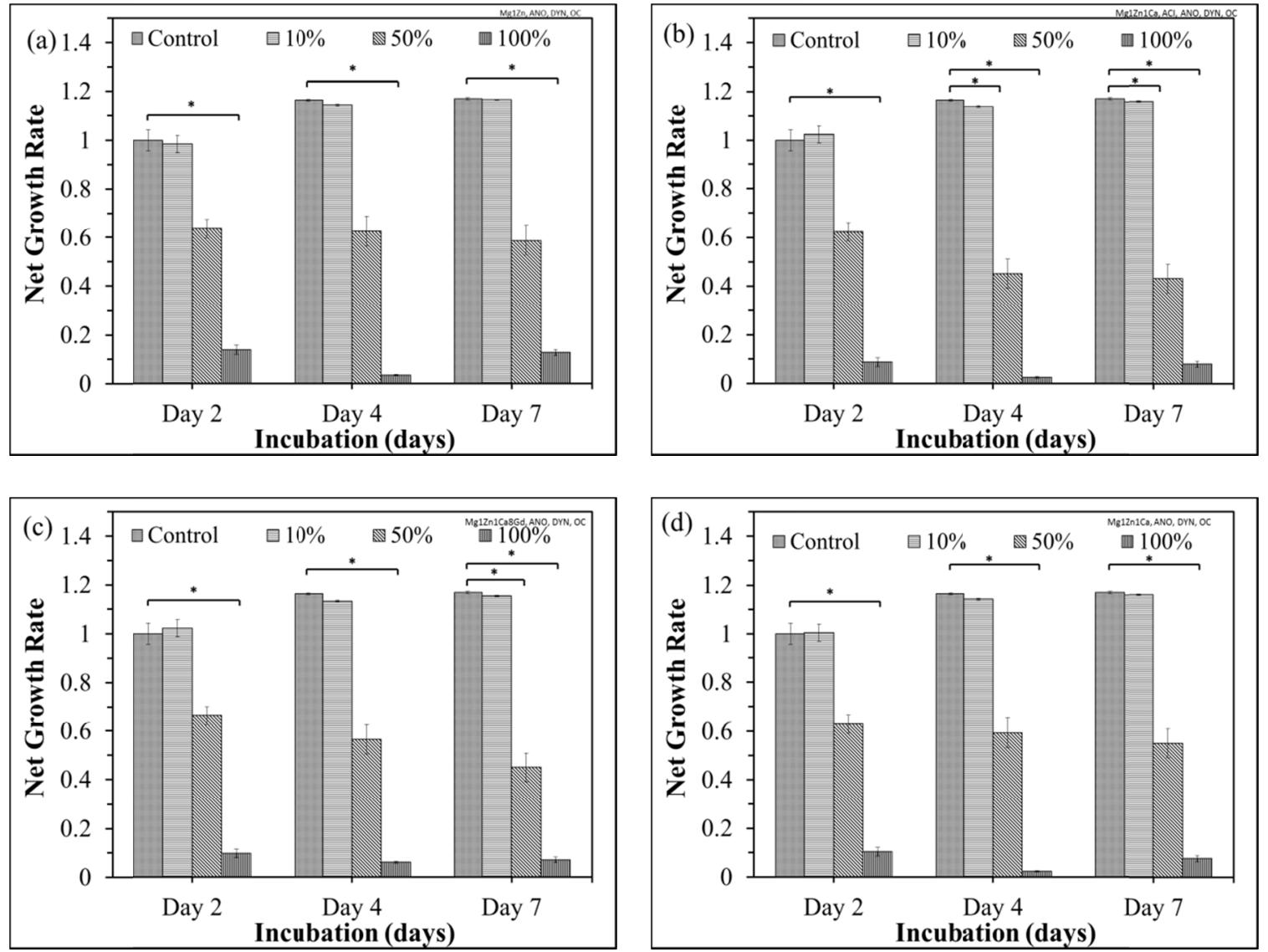

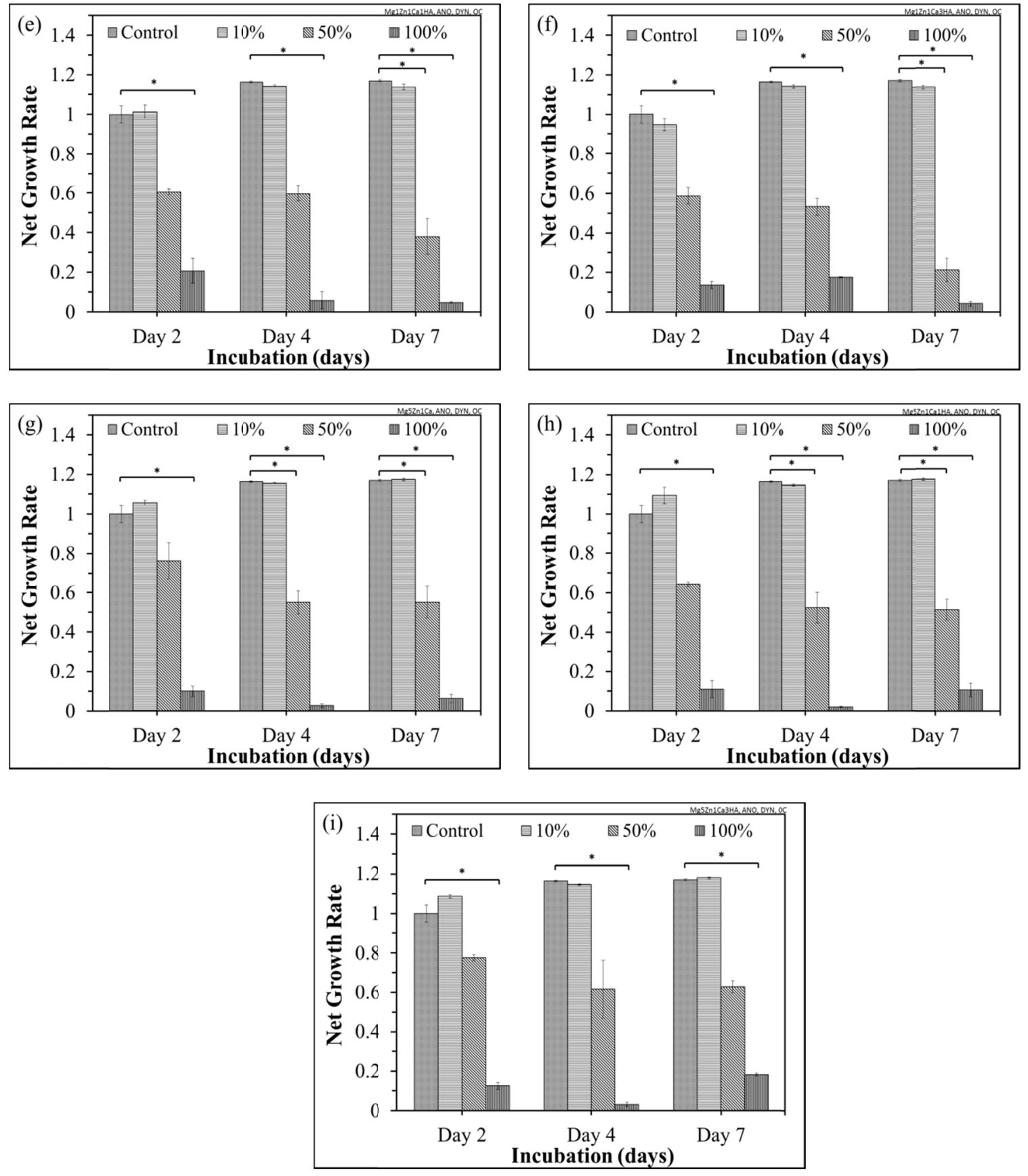

Figure 7.5: Net growth rate of osteoblast cells exposed to leached ions from anodized samples during dynamic immersion test (mean $\pm S D, n=3$ ): (a) MglZn (ACI); (b) MgIZn1Ca (ACI); (c) MglZn1Ca8Gd (ACI); (d) MglZn1Ca; (e) MglZn1CalHA; (f) MgIZn1Ca3HA; (g) Mg5Zn1Ca;

(h) Mg5Zn1CalHA; and (i) Mg5Zn1Ca3HA.Statistical significance $(p<0.05)$ was analyzed using the Tukey test. 


\section{Statistical Analysis}

A standard analysis was performed using SPSS software (IBM, Version 20, Armonk, New York) by comparing the significant differences in cytotoxicity of both endothelial and osteoblast cells and using a one-way analysis of variance (ANOVA) and post-hoc Tukey test. P values $<0.05$ were considered statistically significant. The tests were conducted with respect to control values of the respective time periods.

\subsection{Monitoring Osteoblast Cell Growth on Mg Alloys/MMCs - Electrochemical}

\section{Impedance Spectroscopy}

Electrochemical Impedance Spectroscopy (EIS) was used to monitor the osteoblast cell growth on the surface of $\mathrm{Mg} 1 \mathrm{Zn}$. During our previous attempts to grow cells on $\mathrm{Mg}$ alloys/MMCs, no cells were observed on the surface. This was attributed to simultaneous degradation, hydrogen evolution, localized $\mathrm{pH}$ increase and oxide formation. Hence, an electrochemical approach was adopted to monitor the cellular activity on Mg alloys/MMCs. The EIS data is presented in the form of Nyquist plots, where impedance at higher frequency corresponds to diffusion limited electron transfer process (solution resistance) and that at lower frequency corresponds to charge transfer limited process. Generally, the semicircle diameter signifies the magnitude of electron transfer resistance, which is controlled by surface modifications such as, coating, oxides, film, etc. In this investigation, adhesion of cells on the surface of sample (working electrode) delayed the interfacial electron transfer kinetics and increased the electron transfer resistance as shown in Table 7.3.

A three-electrode corrosion cell was used for EIS employing carbon as counter electrode, silver/silver chloride $(\mathrm{Ag} / \mathrm{AgCl})$ as the reference electrode and magnesium alloys with an exposed area of $0.50 \mathrm{~cm}^{2}$ as the working electrode. All tests were conducted at a scan rate of 1.0 
$\mathrm{mV} / \mathrm{s}$ in an incubator under $5 \% \mathrm{CO}_{2}$ at $34{ }^{\circ} \mathrm{C}$ in cell culture media. The frequency ranged from 1.0E- $02 \mathrm{~Hz}$ to $1.0 \mathrm{E}+05 \mathrm{~Hz}$ with 10 points per decade. Prior to conducting each experiment, the corrosion cells were first cleaned with detergent, then cleaned with acetone, ethanol and distilled water. Furthermore, the sterilization was performed by autoclaving at $126{ }^{\circ} \mathrm{C}$ for 30 minutes. Figure 7.6 ( $\mathrm{a}$ and $\mathrm{b}$ ) shows the Nyquist plots of Mg1Zn alloy before and after inoculation with osteoblast cells for 4 days (96 hours). Table 7.3 shows that the charge transfer resistance $\left(\mathrm{R}_{\mathrm{ct}}\right)$ increased gradually with increasing culture time. This indicated that cells adhered on the surface of the working electrode during the cell culturing process, which resulted in a higher electron transfer barrier. The double layer capacitance $\left(C_{\mathrm{dl}}\right)$ ranged between $9-16 \mu \mathrm{F} / \mathrm{cm}^{2}$, which indicated increase in the capacitative behavior at metal/oxide/cells interface. The value of the $\mathrm{C}_{\mathrm{dl}}$ depends on many variables including electrode potential, temperature, ionic concentrations, type of ions, oxides, electrode roughness, impurity adsorption, etc. In this study, an increase in $\mathrm{R}_{\mathrm{ct}}$ was observed with increased incubation time, confirming cellular adhesion on the surface of $\mathrm{Mg}$ alloys.

Table 7.3: The electrochemical impedance parameters of Mg1Zn in cell culture media with osteoblast cells at different time intervals

\begin{tabular}{ccc}
\hline $\mathrm{Mg} 1 \mathrm{Zn}$ & $\mathrm{R}_{\mathrm{ct}}\left(\Omega \cdot \mathrm{cm}^{2}\right)$ & $\mathrm{C}_{\mathrm{dl}}(\mu \mathrm{F} / \mathrm{cm} 2)$ \\
\hline Before Cell Culture, Day 4 & $1.36 \mathrm{E}+03$ & 16 \\
After Cell Culture, Day 1 & $2.28 \mathrm{E}+03$ & 9 \\
After Cell Culture, Day 2 & $3.87 \mathrm{E}+03$ & 13 \\
After Cell Culture, Day 3 & $3.97 \mathrm{E}+03$ & 14 \\
After Cell Culture, Day 4 & $4.09 \mathrm{E}+03$ & 14 \\
\hline
\end{tabular}


(a)

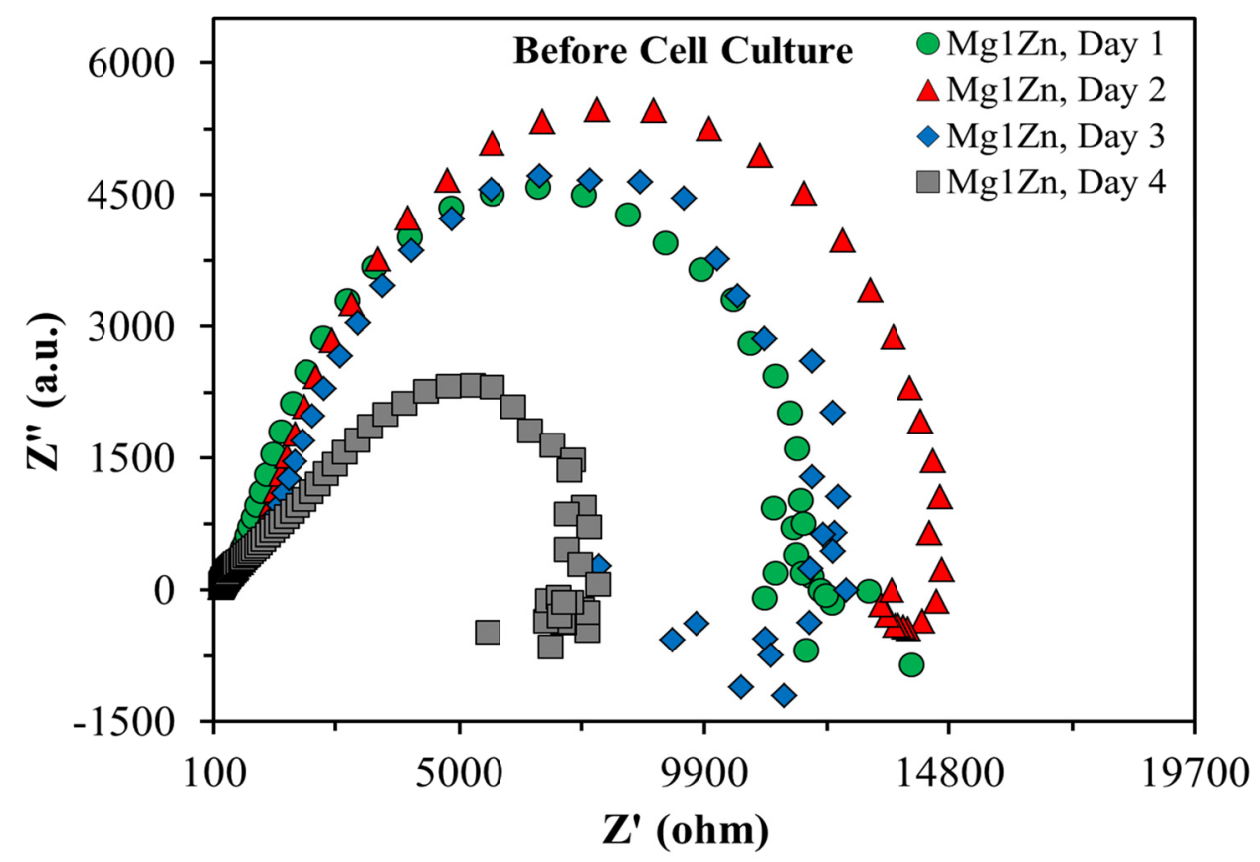

(b)

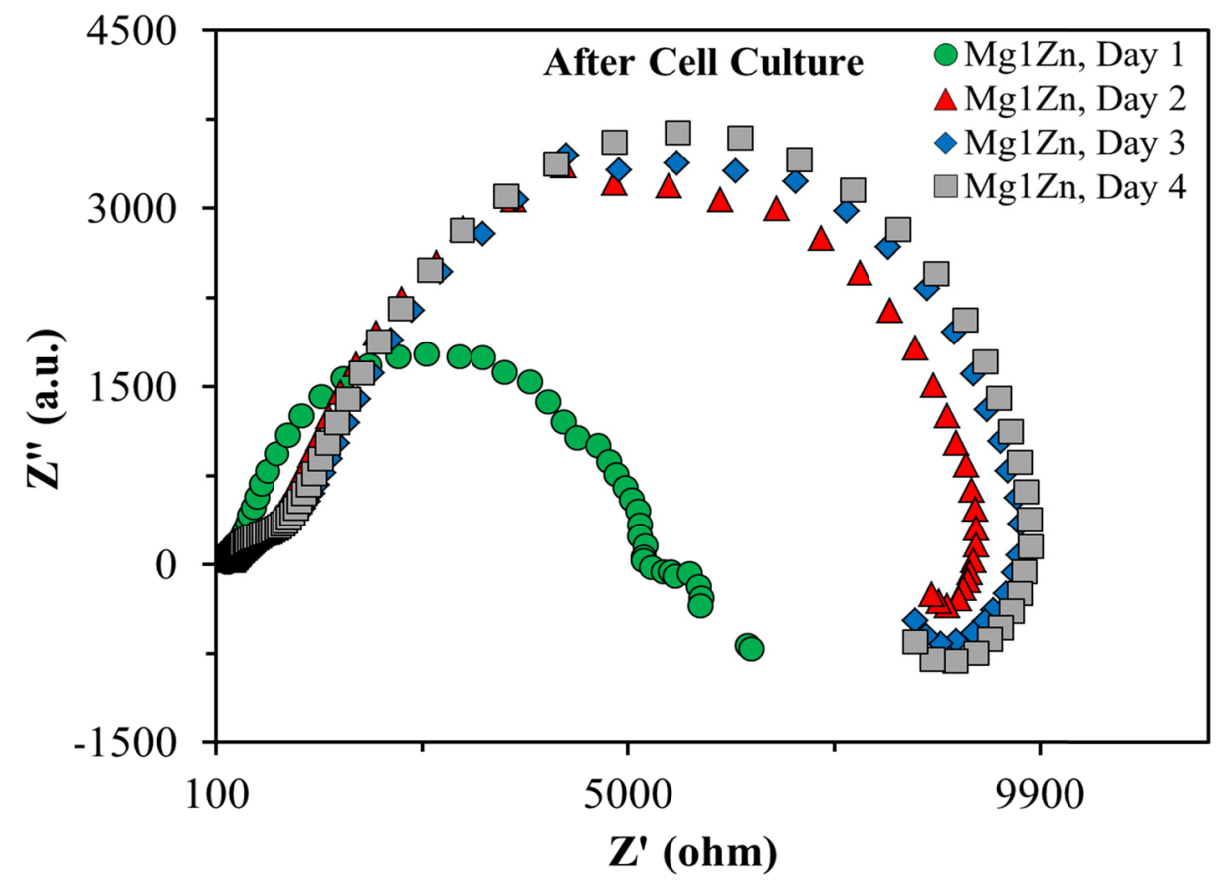

Figure 7.6: Effect of time on osteoblast cells growth on MgIZn by electrochemical impedance spectroscopy: (a) without cells and (b) with cells. 


\subsection{EFFECT OF SURFACE ROUGHNESS}

\subsection{Effect of Surface Roughness on Electrochemical Behavior and Wettability}

Surface defects and roughness are known to initiate corrosion. In most cases, pitting corrosion occurs in which an intense attack of chloride ions occur at localized sites on the surface of an implant, while the remainder of the surface corrodes at a much lower rate, either because of the formation of a protective oxide layer or due to physiological conditions. Another contributing factor is the presence of reactive sites, where a specific region on the surface behaves as if they are more anodic or cathodic in nature.

Cell adhesion and proliferation are essential properties of an implant, where such inefficiency could lead to poor integration with the tissue. Wettability, roughness, morphology, texture, charge and chemical composition also influence cellular activity on implants [109]. Several mechanical (polishing, coating) and chemical treatments (electropolishing, anodizing, etc.) have been employed to enhance the performance of magnesium (Mg) alloys for implant application. Nevertheless, surface roughness is an ideal parameter for assessing the performance of an implant. Roughness affects corrosion potential, and thus, the alloy's susceptibility to pitting corrosion [180]. Furthermore, the diffusion of the corrosion species (e.g. chloride ions) can be affect by surface roughness $[180,181,182]$. With the surface roughness it is possible to change the surface features mainly energy level and topography. It has been reported that implants success is not only dependent on surface physiochemical properties but also on its roughness $[144,145,146,147,148,149,150,151]$. The integration of these new class of alloys into the human body is complex and a challenge. SFE is an important parameter for cellular activity. The surface roughness and irregularity contribute to biomechanical interlocking, which are responsible for osseointegration reinforcement [154]. 
This chapter compares the contact angle (CA), surface free energy (SFE), fractional polarity (FP) and corrosion rate (CR) parameters at different surface roughness. As cast $\mathrm{Mg} 1 \mathrm{Zn} 1 \mathrm{Ca}$ (wt\%) alloys were mechanically polished to various degrees of surface roughness. Electrochemical techniques (potentiodynamic and electrochemical impedance spectroscopy, EIS) and wettability tests were performed to study the influence of surface roughness on electrochemical passivation and surface free energy, respectively. Furthermore, microstructure, and surface morphology of the alloys were assessed using SEM/EDS.

Ingots of $\mathrm{Mg} 1 \mathrm{Zn} 1 \mathrm{Ca}(\mathrm{wt} \%)$ were cut into cubes of dimensions $0.4 \mathrm{x} 0.4 \mathrm{x} 0.1$ (inch), which were then mechanically polished to achieve four different degrees of roughness. The roughness of the alloys was varied by polishing the alloy with Silicon Carbide ( $\mathrm{SiC})$ and carbimet surfaces. The abrasive sheets and diamond paste (DP) were purchased from Buehler ${ }^{\circledR}$ and lubricants (ethanol, 99.9\% and ethylene glycol) from Sigma-Aldrich. The usage of water based solutions was avoided during sample preparation, in order to prevent hydrolysis of the alloy. Instead of water, ethanol was used with $\mathrm{SiC}$ and a mixture of ethanol:ethylene glycol (3:1) with diamond paste on the carbimet surface. The surface roughness of the alloys was determined by optical profilometer and the data was analyzed by Scanning Probe Image Processor (SPIP).

Phosphate Buffered Saline (PBS, Sigma Aldrich) was used as the standard test solution for electrochemical studies. Potentiodynamic polarization and electrochemical impedance spectroscopy tests were performed at $37{ }^{\circ} \mathrm{C}$ in accordance with ASTM G 102-89 [160] and ASTM G 3-89 [183], respectively. Potentiodynamic polarization tests were conducted at a scan rate of $1.0 \mathrm{mV} / \mathrm{s}$. The electrolyte was purged with high purity nitrogen for 30 minutes prior to immersion of the sample, as well as continuously during the corrosion test. Faraday's law was 
used to calculate the corrosion rate (CR), in terms of penetration rate of the alloys, determined by:

$$
\mathrm{CR}=\left(\mathrm{I}_{\text {corr }} \cdot \mathrm{K} \cdot \mathrm{EW}\right) /(\rho \cdot \mathrm{A})
$$

Where, $I_{\text {corr }}$ is the corrosion current (amps), $\mathrm{K}$ is a constant for the corrosion rate (3272 $\mathrm{mm} / \mathrm{amp} . \mathrm{cm}$. year), $\mathrm{EW}$ is the equivalent weight in grams/equivalent, $\mathrm{A}$ is the sample area $(0.28$ $\left.\mathrm{cm}^{2}\right)$ and $\rho$ is the density $\left(1.69 \mathrm{~g} / \mathrm{cm}^{3}\right)$ of the alloy calculated by Archimedes principal.

EIS tests were also conducted in PBS under high purity nitrogen to determine the effect of alloying elements on the charge transfer resistance and were conducted in the frequency range from $1.0 \mathrm{E}-02 \mathrm{~Hz}$ to $1.0 \mathrm{E}+05 \mathrm{~Hz}$ with 10 points per decade.

Contact angles and surface free energy were measured using a Kyowa contact angle meter model DM-CE1 and adopting the sessile drop method. Surface morphologies of the alloys were studied by scanning electron microscopy (SEM, JEOL JSM 6330F), at an accelerated voltage of $20 \mathrm{kV}$. 


\subsubsection{Roughness Effect - Results and Discussion}

Table 8.1 shows the surface roughness $\left(\mathrm{S}_{\mathrm{a}}\right)$ and roughness mean $\left(\mathrm{S}_{\text {mean }}\right)$ values obtained from the optical profilometer. A decrease in surface roughness was observed with an increase in grit size of the grinding surface. Figure 8.1 and 8.2 shows the images of the alloy surfaces prepared at various roughnesses. A decrease in size and density of pores and scratches were observed with decreasing surface roughness.

Table 8.1:Lubricants and abrasives used during sample preparation and average roughness parameters

\begin{tabular}{|l|c|c|c|}
\hline Sample Finish & Lubricant & $\mathbf{S}_{\mathbf{a}}(\boldsymbol{\mu m})$ & $\mathbf{S}_{\text {mean }}(\boldsymbol{\mu m})$ \\
\hline SiC P-240 & Ethanol & 0.63 & -1.33 \\
\hline SiC P-320 & Ethanol & 0.37 & -0.14 \\
\hline SiC P-400 & Ethanol & 0.18 & 0.24 \\
\hline C-DP 0.05 $\mu \mathrm{m}$ & Ethanol-Ethylene Glycol (3:1) & 0.04 & -0.08 \\
\hline
\end{tabular}
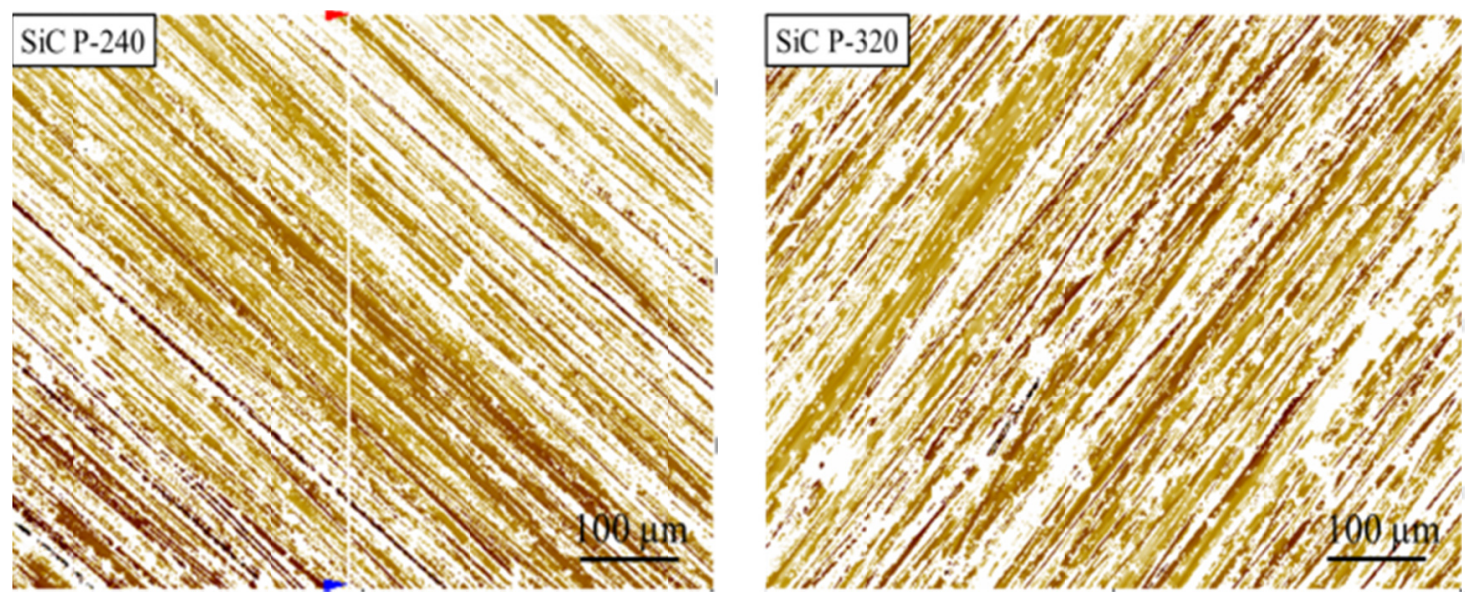

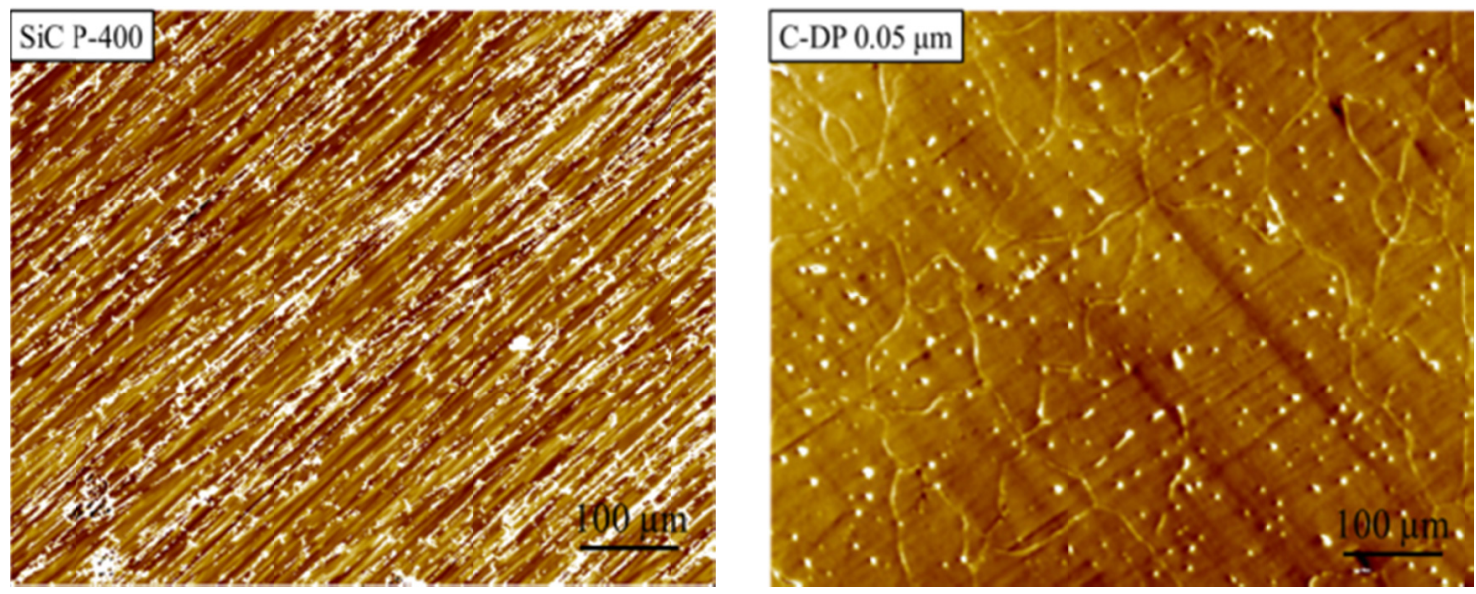

Figure 8.1: Interference microscope image representation of $\mathrm{Mg} 1 \mathrm{Zn} 1 \mathrm{Ca}$, scan area (640 x 860 $\mu m)$.
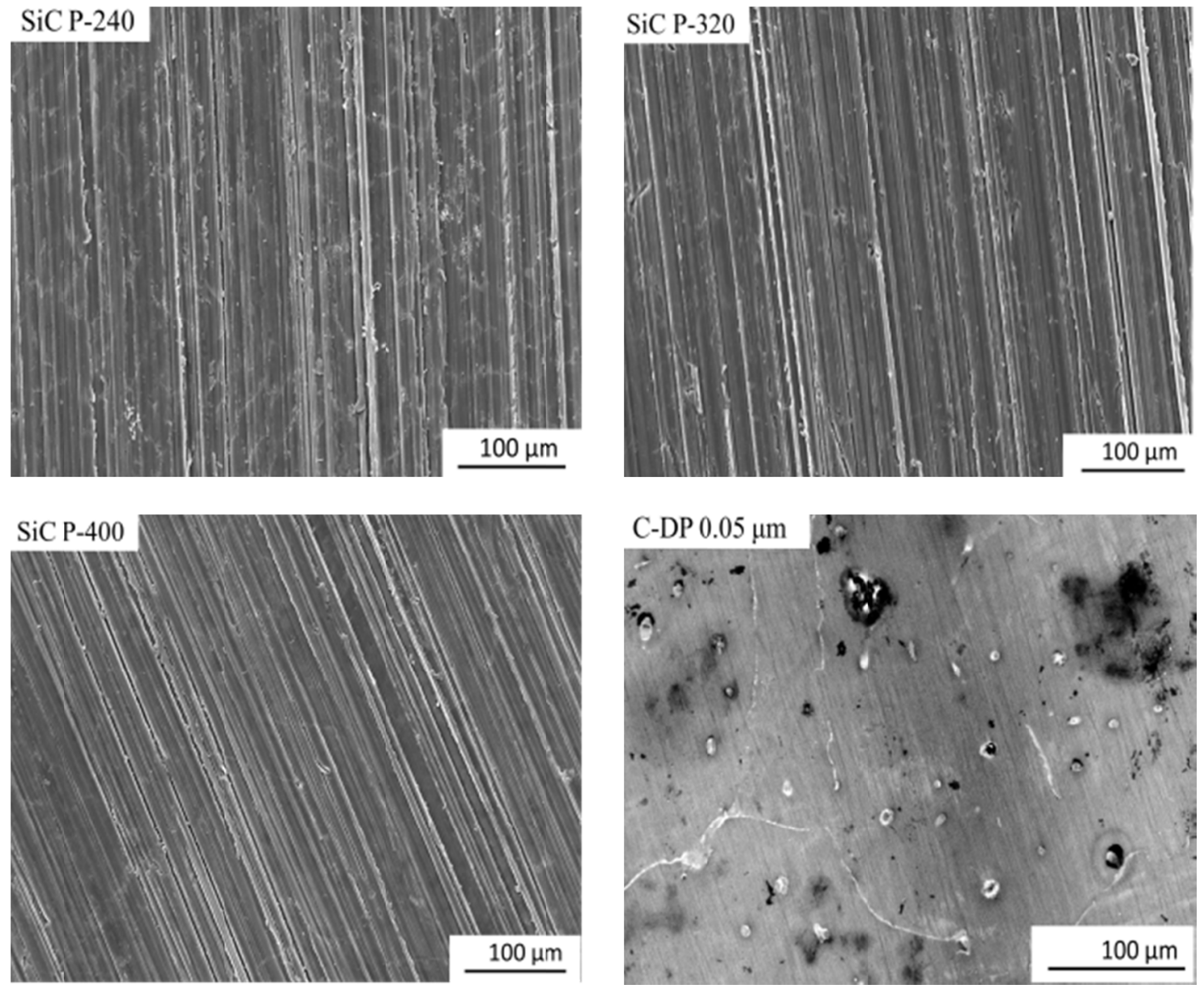

Figure 8.2: SEM micrographs of MgIZn1Ca alloys for different surface roughness. 
The potentiodynamic polarization corrosion and EIS tests were performed in PBS at 37 ${ }^{\circ} \mathrm{C}$. Table 8.2 summarizes the corrosion parameters, where the corrosion decreased with a decrease in surface roughness. This corresponded to a shift of the corrosion potential $\left(\mathrm{E}_{\mathrm{corr}}\right)$ in a more noble direction rates with decrease in roughness. The sample with lowest surface roughness of $0.04 \mu \mathrm{m}$ had a corrosion potential of $-1.5 \mathrm{~V}$ (vs. SCE); whereas that of the other samples ranged between -1.7 to $-1.9 \mathrm{~V}$. The corrosion current decreased from $48.4 \mu \mathrm{A}$ to $6.8 \mu \mathrm{A}$, as the roughness decreased from $0.63 \mu \mathrm{m}$ to $0.04 \mu \mathrm{m}$.

Potentiodynamic plot of the sample with lowest roughness (C-DP $0.05 \mu \mathrm{m}$ ) initially displayed distinct passivation as evidenced by the vertical straight line of the anodic curves, Figure 8.3. Furthermore, polarization resistance $\left(R_{p}\right)$ which evaluates the protective behavior of the surface was calculated by using the following formula:

$$
R_{p}=\beta_{a} \beta_{c} / 2.3 . I_{c o r r}\left(\beta_{a}-\beta_{c}\right)
$$

where $\beta_{a}$ and $\beta_{c}$ are anodic and cathodic slopes, respectively.

$\mathrm{R}_{\mathrm{p}}$ increased with decreasing roughness, due to the formation of a relatively uniform and compact oxide layer. This behavior was further confirmed with the EIS plots. The increased in $\mathrm{R}_{\mathrm{p}}$ may be attributed to the formation of mixed oxides of $\mathrm{Mg}$ and $\mathrm{Zn}$. 


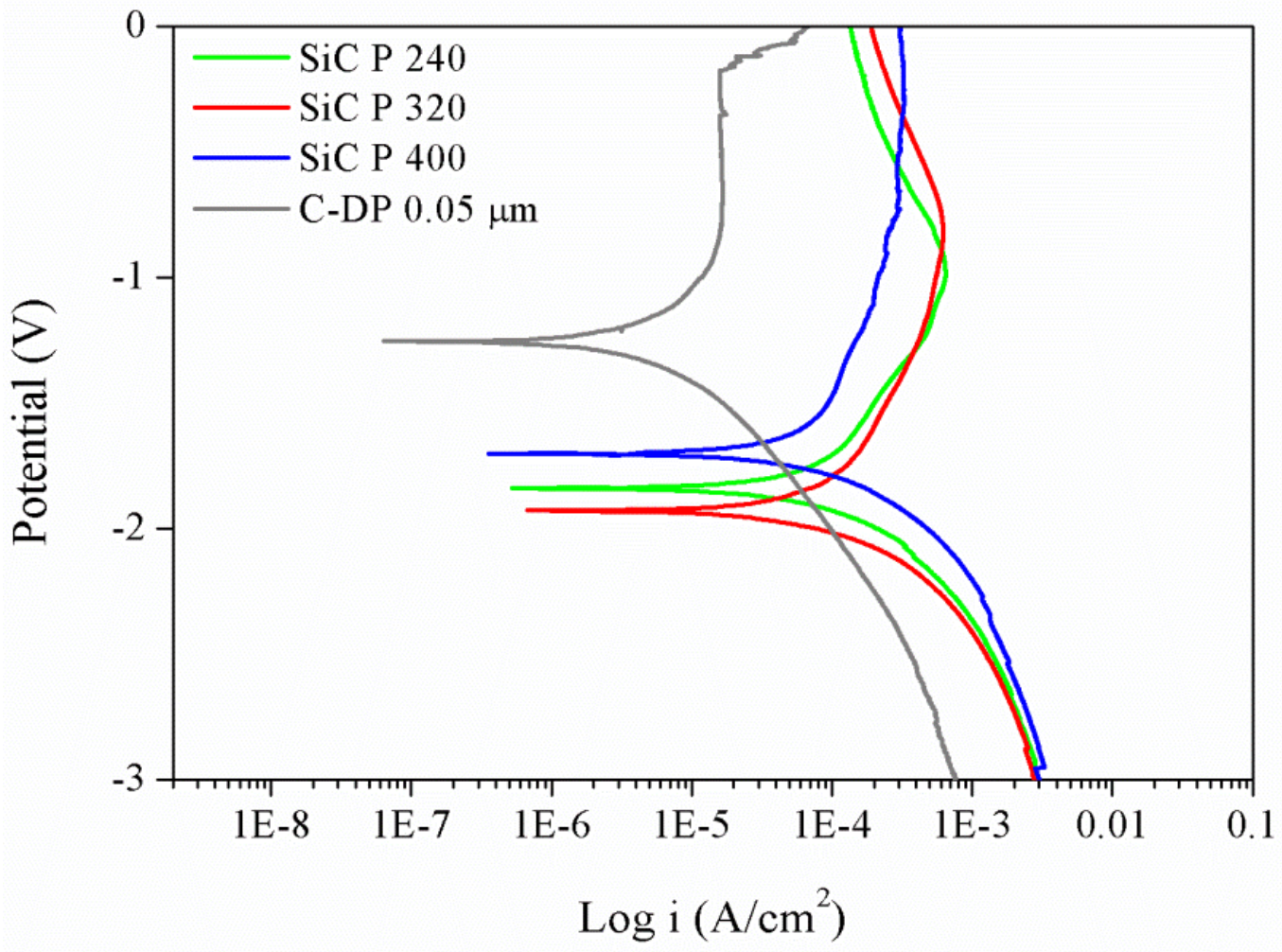

Figure 8.3: Potentiodynamic polarization curves of $\mathrm{Mg} 1 \mathrm{ZnICa}$ alloys at different roughness in PBS at $37^{\circ} \mathrm{C}$.

Table 8.2: Results of potentiodynamic corrosion tests of the samples in $P B S$ at $37^{\circ} \mathrm{C}$

\begin{tabular}{cccc}
\hline Sample Finish & $\mathrm{E}_{\text {corr }}(\mathrm{V})$ & $\mathrm{R}_{\mathrm{p}}\left(\Omega \mathrm{cm}^{2}\right)$ & $\mathrm{CR}(\mathrm{mm} /$ year $)$ \\
\hline SiC P 240 & -1.8 & 114.5 & 87.1 \\
SiC P 320 & -1.9 & 107.9 & 63.4 \\
SiC P 400 & -1.7 & 136.5 & 58.8 \\
C-DP 0.05 $\mu \mathrm{m}$ & -1.5 & 503.0 & 13.0 \\
\hline
\end{tabular}

The influence of surface roughness on the general corrosion resistance was investigated by EIS using a Gamry Echem Analyst software. Figure 8.4 shows the Randles equivalent circuit, 
where $\mathrm{R}_{\mathrm{s}}$, is the electrolyte resistance; $\mathrm{R}_{\text {corr }}$, the charge transfer resistance and $\mathrm{C}_{\mathrm{dl}}$, capacitance double layer. Figure 8.5 shows the Nyquist plot where the highest impedance was observed for the smoothest samples. This could be ascribed to the formation of various oxides, which act as an electric barrier. The capacitive arc provides an estimate of corrosion behavior of the material, in terms of the relative diameter of the capacitive arcs, which are directly proportional to the charge transfer resistance $\left(\mathrm{R}_{\mathrm{ct}}\right)$. Thus, an increase in semicircle diameter corresponds to an increase in corrosion resistance.

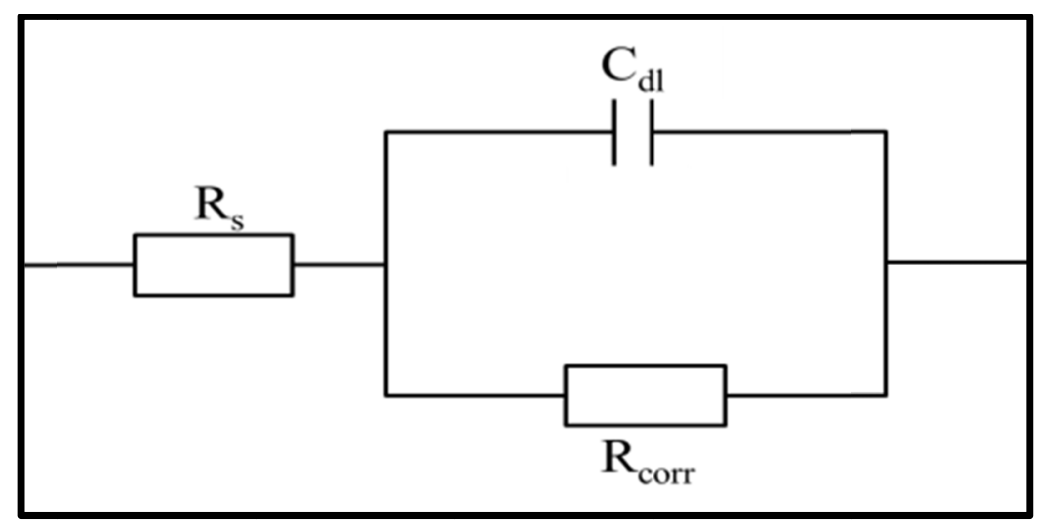

Figure 8.4: Equivalent circuit of the corrosion cell: $R_{s}=$ electrolyte resistance, $R_{\text {corr }}=$ charge transfer resistance and $C_{d l}=$ capacitance double layer.

Each sample displayed an inductive loop at low frequencies, which signifies that the alloys are susceptible to pitting corrosion. This occurs when $\mathrm{Cl}^{-}$ions diffuse through a breach in the passivating layer, resulting in the formation of hydrolyzed metal chlorides. At anodic sites, $\mathrm{Mg}^{++}$ions are produced; $\mathrm{Cl}^{-}$ions diffuse to such sites in order to establish electrical neutrality [184]. Moreover, the increase in concentration of ions compresses the double-layer and increases 
the potential, whereas a low overvoltage cathode facilitates hydrogen evolution and alkalization of solution, causing a substantial corrosion rate $[166,185]$.

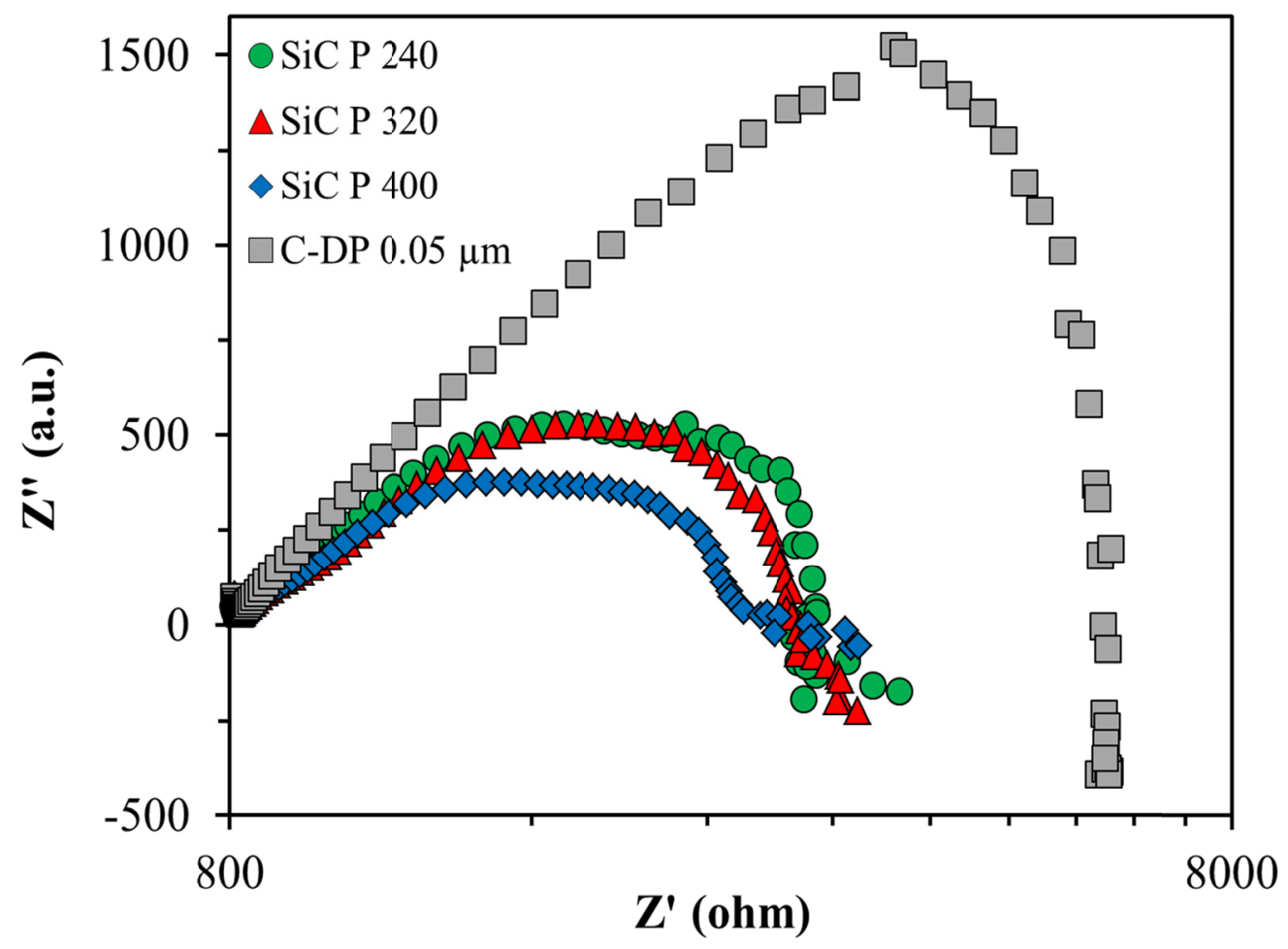

Figure 8.5: Nyquist plots of MglZnICa alloys, with different surface roughness, tested in PBS at $37^{\circ} \mathrm{C}$.

The charge transfer resistances derived from the Nyquist plots are given in Table 8.3. Increase in charge transfer resistance with decreased roughness was observed, which became more pronounced in case of $0.05 \mu \mathrm{m}$. This can attribute to reduced corrosion rates and uniformity of surface oxides. Overall capacitance double layer ranged between $15-28 \mu \mathrm{F} / \mathrm{cm}^{2}$.

Table 8.3: $R_{\text {corr }}$ and $C_{d l}$ values of Mg1Zn1Ca alloys in PBS at $37^{\circ} \mathrm{C}$

\begin{tabular}{lcc}
\hline Sample & $\mathrm{R}_{\text {corr }}\left(\Omega . \mathrm{cm}^{2}\right)$ & $\mathrm{C}_{\mathrm{dl}}\left(\mu \mathrm{F} / \mathrm{cm}^{2}\right)$ \\
\hline SiC P 240 & 511.8 & 17 \\
SiC P 320 & 495.3 & 23 \\
\hline
\end{tabular}


SiC P 400 405.2

28

C-DP $0.05 \mu \mathrm{m}$

1148.6

15 
Figure 8.6 shows the Bode plot, where the impedance modulus and the phase shift, as a function of frequency provide information on the nature of the electrochemical processes. In the case of impedance modulus vs frequency (Figure 8.6a), the high frequency domain represents the solution resistance $\left(\mathrm{R}_{\mathrm{s}}\right)$ and the low frequency domain represents the system resistance, which mainly depends on polarization resistance of the passivating film. Several oxides are produced, which resulted in a higher degree of phase shift at a frequency of $\sim 80 \mathrm{~Hz}$, Figure $8.6 \mathrm{~b}$. This is most likely due to an increase in surface film capacitance with an increase in the adsorbed amount of ions on the electrode surface. The oxide layers produced on the surface of the alloys act as an electric barrier (resistance) dependent upon the charge transfer, and the symmetry of the Bode plot is an indication of the uniformity of the surface oxides. The loop is depressed and shifts a loop towards high frequency, which could be associated to the adsorption and desorption phenomena occurring on the surface of the samples. A layer of corrosion products and salt deposits from the solution formed instigated the slow degradation process. The formation of these oxides can impart long term stability of an implant in biological environment and lead to slow degradation rates at the initial stage of implantation. Increase in concentration of ions in solution decrease modulus value, while phase shift to higher frequency. This could be due to increase in surface film capacitance with an increase in adsorbed ions on the electrode surface. 

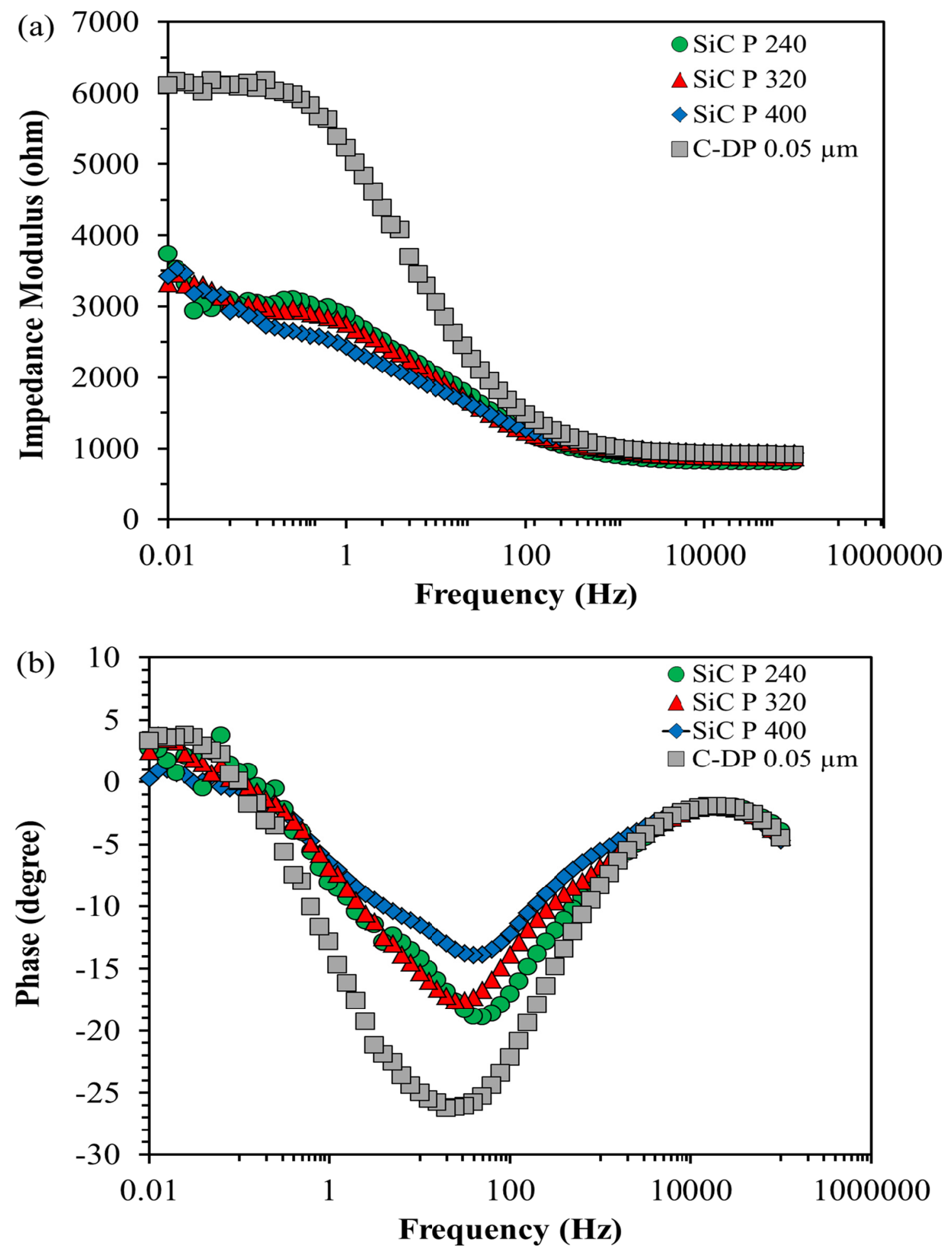

Figure 8.6: Bode representation of: (a) impedance modulus and (b) phase shift for $\mathrm{Mg} 1 \mathrm{Zn} 1 \mathrm{Ca}$ with different surface roughness in $P B S$ at $37^{\circ} \mathrm{C}$. 
Figure 8.7 compares the contact angle $(\mathrm{CA})$ and corrosion rate $(\mathrm{CR})$ parameters at different surface roughness. An, increase in contact angle was observed with a decrease in surface roughness, where it shifted from hydrophilic to hydrophobic (CA ranged 44 - 95 degree). The surface free energy $\left(\mathrm{mJ} / \mathrm{m}^{2}\right)$ components were calculated by using Kitazaki-Hata theory:

$$
\gamma^{\text {total }}=\gamma^{d}+\gamma^{p}+\gamma^{h}
$$

Where, $\gamma^{\text {total }}$ is the total SFE; $\gamma^{\mathrm{d}}$ is SFE dispersion component; $\gamma^{\mathrm{p}}$ is SFE polar component and $\gamma^{\mathrm{h}}$ is SFE hydrogen bond component.

Three liquids of different surface tensions (water, ethylene-glycol and diiodomethane) were used under ambient conditions. The SFE for $0.05 \mu \mathrm{m}$ surface finish was $29.7 \mathrm{~mJ} / \mathrm{m}^{2}$, whereas at higher roughness it ranged between $96.0-88.0 \mathrm{~mJ} / \mathrm{m}^{2}$ (Table 8.4 ). Studies have shown that cellular adhesion and cell activity are favorable on materials with low SFE ( $\sim 25-35$ $\mathrm{mJ} / \mathrm{m}^{2}$ ) [110,186,187]. Furthermore, fractional polarity (FP) was calculated, where Fractional Polarity $=$ polar $/($ polar + dipersion $)$. It was previously reported that a fractional polarity of less than 0.3 is a favorable parameter for good cellular adhesion [186,187]. In this study, a decrease in FP from 0.13 to 1.0 was observed with decreased roughness. Therefore, lower roughness is conducive to improved biocompatibility. 
Table 8.4: Surface free energy and fractional polarity components

\begin{tabular}{lcc}
\hline Sample & SFE $\left(\mathrm{mJ} / \mathrm{m}^{2}\right)$ & Fractional polarity, FP \\
\hline SiC P 240 & 88 & 0.79 \\
SiC P 320 & 184.5 & 0.97 \\
SiC P 400 & 96 & 0.79 \\
C-DP $0.05 \mu \mathrm{m}$ & 29.7 & 0.13 \\
\hline
\end{tabular}

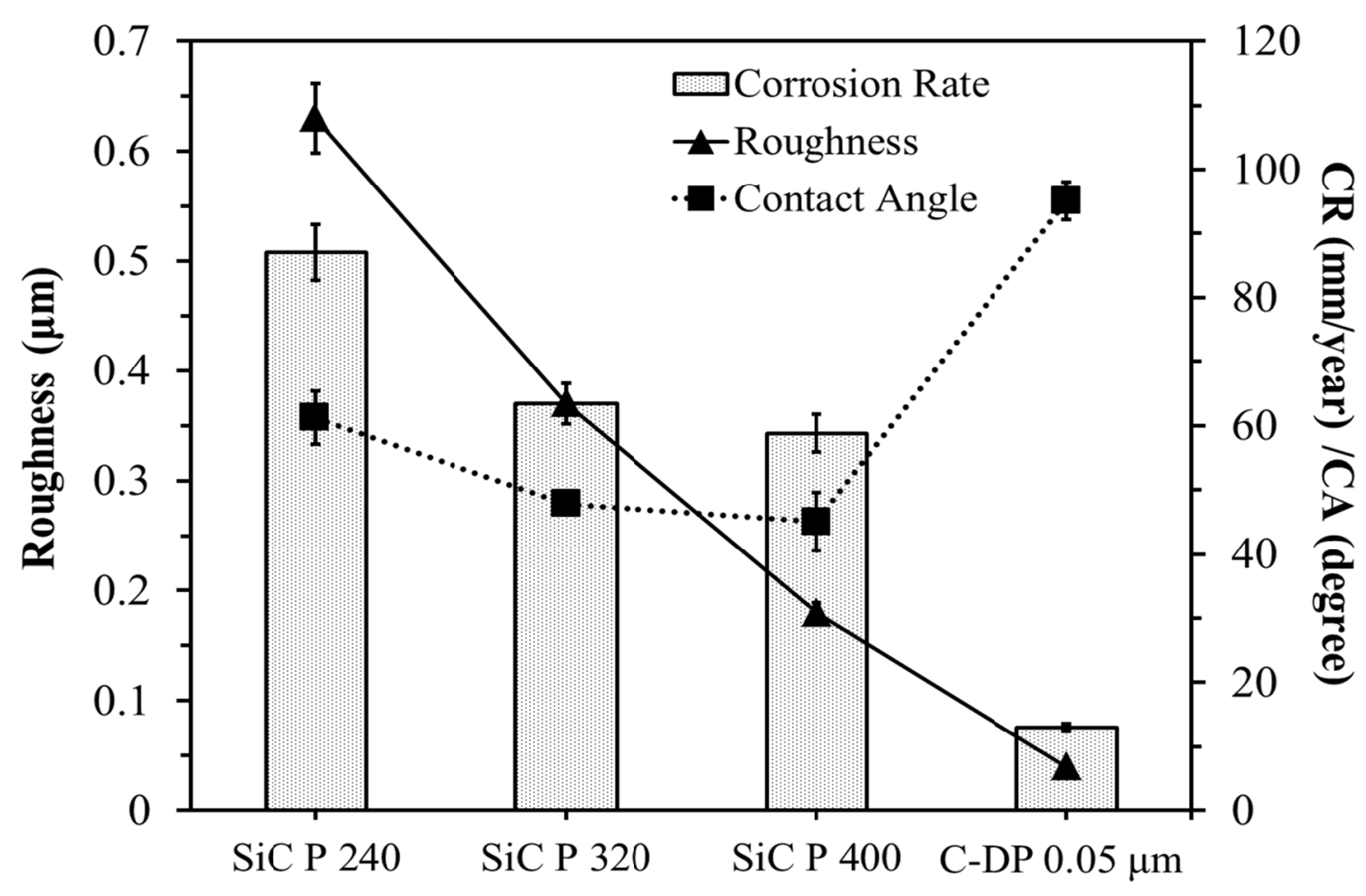

Figure 8.7: Plot showing the effect of roughness on corrosion rate (CR) and contact angle (CA). 


\subsection{DISCUSSION}

The development of $\mathrm{Mg}$ based alloys/MMCs is a challenge due to limitations of controlled and non-uniform degradation, hydrogen evolution, localized $\mathrm{pH}$ increase and biocompatibility as well as sustained mechanical integrity. The main function of biodegradable alloys/MMCs is spontaneous dissolution as new tissue develops and provision of required structural support. This has prompted a significant amount of research on the development of $\mathrm{Mg}$ based biodegradable alloys/MMCs. Although advances have been made in controlling the degradation rates of these implants, there is still a dearth of information on their biocompatibility. However, most Mg samples have their own characteristic behavior (mechanical integrity, degradation behavior, low density and biocompatibility) as a result of their unique microstructure and/or the existence of intermetallic phases. In this investigation, nine different compositions of Mg based alloys and MMCs were subjected to two types of surface treatments, mechanical polishing and anodization. Mechanical polishing results in the development of an oxide layer of $\sim 20-50 \mathrm{~nm}$, whereas anodization produces an oxide layer of thickness $\sim 5-10 \mu \mathrm{m}$. This passivating layer imparts enhanced corrosion resistance in both cases. Considering the aforementioned limitations of currently investigated metallic bioabsorbable materials, this investigation addresses the beneficial attributes of surface treatment and composition on mechanical properties and biocompatibility of Mg alloys/MMCs. The following discussion addresses each limitation and how any deleterious effect can be mitigated.

\section{(i) Effect of Microstructure on Mechanical and Degradation Properties of $\mathrm{Mg}$ Alloys/MMCs}


The main function of biodegradable alloys/MMCs is spontaneous dissolution as new tissue develops and the provision of adequate structural support. Pure magnesium (as-cast) has low overall yield strength (YS $\sim 27 \mathrm{MPa}$ ), tensile strength $(\mathrm{TS} \sim 90 \mathrm{MPa}$ ) and is susceptible to corrosion, which can lead to the loss of mechanical integrity before the surrounding implant tissue has fully healed [115]. Alloying is one method of improving the mechanical properties and corrosion resistance of $\mathrm{Mg}$ [66]. In this investigation, a reduced grain size was observed with the addition of alloying elements, which may be attributed to the precipitation of intermetallic phases $\left(\mathrm{Ca}_{2} \mathrm{Mg}_{6} \mathrm{Zn}_{3}, \quad \mathrm{MgCa}_{2}, \mathrm{CaZn}_{2}, \mathrm{Ca}_{5}\left(\mathrm{PO}_{4}\right)_{3}(\mathrm{OH})\right.$ and $\left.\mathrm{MgZn}_{2}\right)$ at grain boundaries. During solidification, alloying elements are rejected by the $\alpha-\mathrm{Mg}$ and restrict grain growth. Li et al. (2008) showed that $\alpha$-phase (matrix) and $\mathrm{Mg}_{2} \mathrm{Ca}$ phase precipitated along the grain boundaries [65]. Enhanced mechanical properties were attributed to a fine grain size of $60-100 \mu \mathrm{m}$ and a stable microstructure, that consisted of fine precipitates of $\beta{ }^{\prime}-\mathrm{Mg}_{15} \mathrm{RE}_{3}$, dispersed precipitates of $\mathrm{Mg}_{24} \mathrm{RE}_{5}$ (sheet-shaped) and $\mathrm{Mg}_{5} \mathrm{RE}$ (polygon-shapes) [93]. Zhang et al. (2010) [90] manufactured MgZn alloys by melting and casting, where $\alpha$ and $\gamma-\operatorname{MgZn}$ phases were observed to precipitate along the grain boundary. Pekguleryuz achieved an effective grain refinement with Zn, which was explained by its segregation and minimization of surface energy [129]. Tao et al. (2008) [87], manufactured $\mathrm{Mg}-6 \mathrm{Zn}-\mathrm{xCa}(\mathrm{x}=3,5,7.5,10 \mathrm{wt} \%)$ alloys by twin-roll rapid solidification that were subjected to rapid solidification and annealing at $200{ }^{\circ} \mathrm{C}$ for 1 hour. Improved strength, creep resistance and moderate ductility were observed during age hardening. This was attributed to the formation of various phases such as, $\mathrm{Mg}_{2} \mathrm{Ca}, \mathrm{Mg}_{2} \mathrm{Zn}_{3}, \mathrm{MgZn}_{2}$ and $\mathrm{Ca}_{2} \mathrm{Mg}_{6} \mathrm{Zn}_{3}$ [87]. Peng et al. manufactured $\mathrm{Mg}$-Gd based alloys and reported superior mechanical properties of YS $=280 \mathrm{MPa}$ and $\mathrm{TS}=310 \mathrm{MPa}$ were achieved at room temperature due to a microstructure composed of fine metastable precipitates dispersed in the matrix [89]. Li et al. 
showed that the addition of HA reduced the solid/liquid interfacial energy in Mg alloys [113]. Hort et al. (2010) investigated Mg2Gd, Mg5Gd, Mg10Gd, Mg15Gd (wt\%) manufactured by casting, where Gd was used to enhance the mechanical properties [93]. The yield strength and tensile strength of the as-cast alloy ( $\mathrm{YS}=37.99-127.65 \mathrm{MPa}$ and $\mathrm{TS}=103.73-175.22 \mathrm{MPa}$ ) increased with Gd content and solid solution formation [93].

In this investigation, an increase in tensile strength $(\sim 0.9-1.1 \mathrm{GPa})$ was observed with the addition of $\mathrm{Zn}$ and HA, which is comparable with those of cortical bone ( $0.5 \mathrm{GPa})$ as shown in Table 9.1. The modulus of Mg alloys/MMCs ranged between (41 - $52 \mathrm{GPa})$, which is also comparable with that of human bone $(3-20 \mathrm{GPa})$ and is lower than that of traditional metallic implants (73 - $230 \mathrm{GPa}$ ), see Table 9.1. Young's modulus of the AZ91D and Mg-MMC/HA was reported as $40 \mathrm{GPa}$ [177], which is comparable with the values obtained in the current study.

The formation of the aforementioned intermetallic phases, reduced grain size and anoidzation can be utilized to control the degradation rate of $\mathrm{Mg}$ alloys/MMCs. This was illustrated during potentiodynamic corrosion tests, where anodized samples exhibited smooth anodic curves that were indicative of strong passivation, whereas mechanically polished samples showed jagged anodic curves that were indicative of continuous breakdown (pitting corrosion) and repassivation. The anodized Mg1Zn1Ca8Gd, Mg5Zn1Ca, Mg1Zn1Ca1HA and Mg5Zn1Ca1HA exhibitted slowest degradation rates $(\sim 0.17-1.76 \mathrm{~mm} /$ year $)$ as shown in Table 9.1. The reduced corrosion rates in the aforementioned samples was mainly due to the formation of stable and uniform protective oxide layer, whereas composites with a higher concentration of HA displayed faster degradation due to agglomeration of HA particles in the composites. Such locations are prone to corrosive attacks. Similarly, Ling-Ling et al. (2008) investigated anodized 
AZ91 and reported an increase in corrosion resistance due to the formation of passivating oxide [166].

\section{(ii) Hydrogen evolution and $\mathrm{pH}$ from Anodized Mg Alloys/MMCs}

$\mathrm{Mg}$ alloys/composites were anodized in an attempt to improve the corrosion resistance and initial implant stability due to the formation of $\mathrm{Mg}$ oxide, which varied with processing parameters, such as exposure time, electrolyte and temperature. Anodization of biodegradable Mg alloys/MMCs imparts initial corrosion resistance and mechanical integrity after implantation and ensures sufficient time for the surgical region to heal. The oxide layer on anodized samples was approximately $5-10 \mu \mathrm{m}$. However, anodize coatings of Mg alloys have been reported to consist of two layers, ranging in thickness from $5-50 \mu \mathrm{m}[6,131,132]$. Shi et al. (2006) reported the initial occurrence of pitting corrosion on anodized specimens followed by filiform or general corrosion [130]. The anodize coating was hard and porous as compared with other conventional coating or fluoridated coating [114].

According to Zberg et al., hydrogen evolution from Mg based cardiovascular stents during clinical studies was of minimal concern and observed good biocompatibility with reduced inflammatory response [86]. In the case of orthopedic implants, hydrogen evolution was a major concern due to poor transport mechanisms $[122,123]$. Song (2007) reported both unanodized and anodized Mg alloys are susceptible to localized corrosion at which sites hydrogen is evolved [167]. In this investigation, a decrease in hydrogen evolution from the anodized samples was

attributed to the presence of various surface oxides. These oxides limit the exposure of substrate materials to the electrolyte. Additionally, the higher the concentration of $\mathrm{Zn}$ in MMC, the lower 
was the volume of hydrogen evolved. This was attributed to the formation of two type of oxides; those of light metals $\mathrm{Mg}$ and $\mathrm{Ca}$; and those of heavy metals, $\mathrm{Zn}$ and $\mathrm{Gd}$ [158].

Anodization limits the concentration of $\mathrm{Mg}(\mathrm{OH})_{2}$ ions in the electrolyte and restricts further increase in $\mathrm{pH}$. An increase in $\mathrm{pH}$ could affect not only the corrosion behavior of the implant but also cell viability or hemolysis $[115,124]$. The $\mathrm{pH}$ of PBS after corrosion of mechanically polished and anodized samples ranged between $\sim 7.2-8.4$ and $\sim 7.2-7.5$, respectively, due to greater passivation of the latter. Wang et al. reported the precipitation of less soluble products, such as magnesium phosphate, $\mathrm{Mg}_{3}\left(\mathrm{PO}_{4}\right)_{2}$; magnesium apatite; zinc phosphate, $\mathrm{Zn}_{3}\left(\mathrm{PO}_{4}\right)_{2}$; and calcium phosphate, $\mathrm{Ca}_{3}\left(\mathrm{PO}_{4}\right)_{2}$ due to a local increase in $\mathrm{pH}[127]$.

\section{(iii) Wettability Parameters Conducive for Cellular Proliferation}

Implant contact angle, wettability, interfacial free energy and surface free energy had significant influence on biocompatibility of implants [109]. In this investigation, all surfaces exhibited high electron donor (basic) character and low electron acceptor (acidic) character with polar solvent (water), which are reported to be conducive to cell viability [109]. Studies have shown that lower interfacial free energy can be associated with optimum biocompatibility for surfaces such that their water interfacial energies are minimized [109]. The minimal interfacial free energy obtained for the $\mathrm{Mg}$ samples in this investigation may correspond to good biocompatibility. Ponsonnet et al. reported that lower surface free energy corresponded to higher cell proliferation and indicated an inflection point in the range of $30-50 \mathrm{~mJ} / \mathrm{m}^{2}$ [109]. Mani et al. (2006) reported that high surface energy increased the risk of thrombogenicity [111]. The fractional polarity $(\mathrm{FP}=$ polar $/$ dispersion + polar $)$ of $\mathrm{Mg}$ alloys/MMCs used in this 
investigation ranged between $\sim 0-0.9$. It was reported that when FP is $>0.3$ good cellular adhesion was achieved [109].

\section{(iv) Low cytotoxicity with osteoblast and endothelial cells}

The cytotoxicity assessment by SRB assay of $10 \%$ extract from all samples on osteoblast and endothelial cells suggested that the concentration of dissolved ions released were non-toxic. There was no appreciable difference between the net growth rate of cells exposed to $10 \%$ corrosion extract and that of the control over time. The concentrations of $\mathrm{Mg}, \mathrm{Zn}, \mathrm{Ca}, \mathrm{Gd}$ and HA ions in the $10 \%$ extract had no cytotoxic effect on osteoblast and endothelial cells. However, the concentrations present in $50 \%$ and $100 \%$ corrosion extracts did have a deleterious effect. Osteoblast cell growth was observed to occur on $\mathrm{Mg} 1 \mathrm{Zn}$ samples, which was monitored by an increase in impedance in the Nyquist plots as shown in the in-vitro biocompatibility section of Table 9.1.

In summary, the results obtained from this work would serve as a useful tool in predicting the degradation behavior and mechanical properties of $\mathrm{Mg}$ alloys/MMCs under various physiological conditions. In addition, it provides information to enable the selection of the appropriate composition for a particular biodegradable implant. 
The following summarizes the limitations of $\mathrm{Mg}$ based alloys/MMCs and attempts to address their deleterious effects. In so doing, properties of materials currently employed in the manufacture of implant devices are compared with those of $\mathrm{Mg}$ based alloys/MMCs developed in this investigation. 
Table 9.1: Comparison of anodized Mg alloys/composites with literature [6, 37, 113]

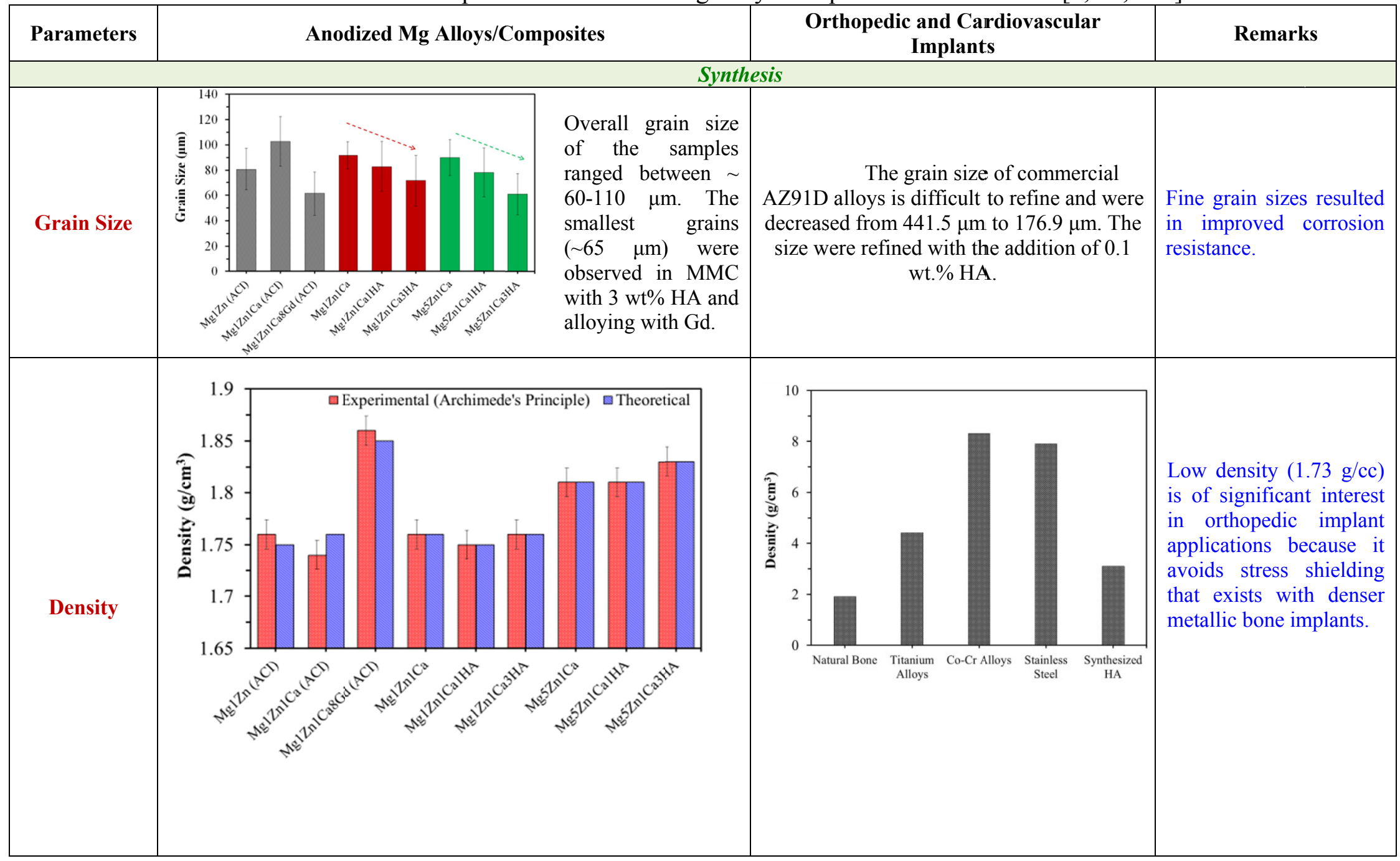




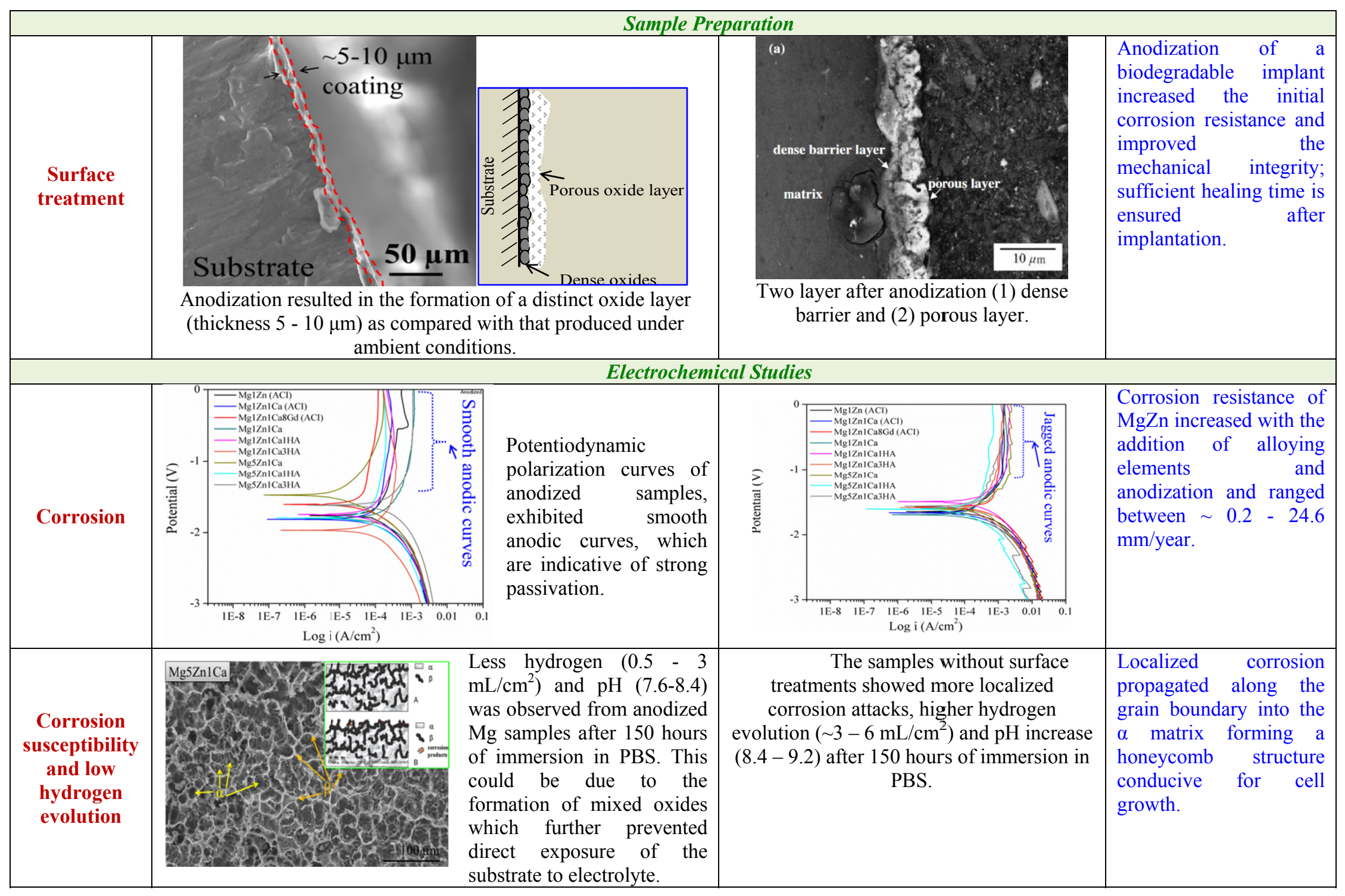




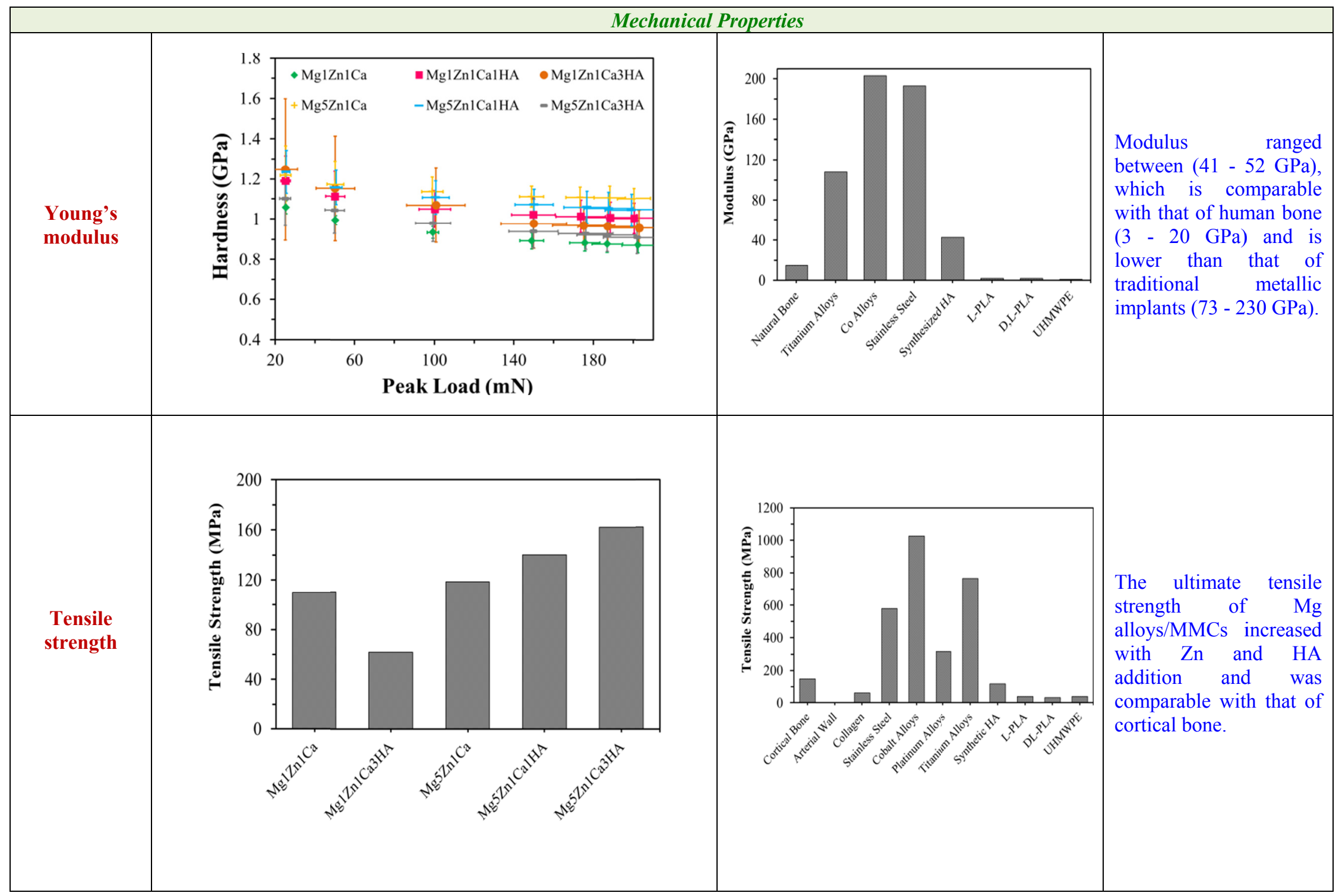




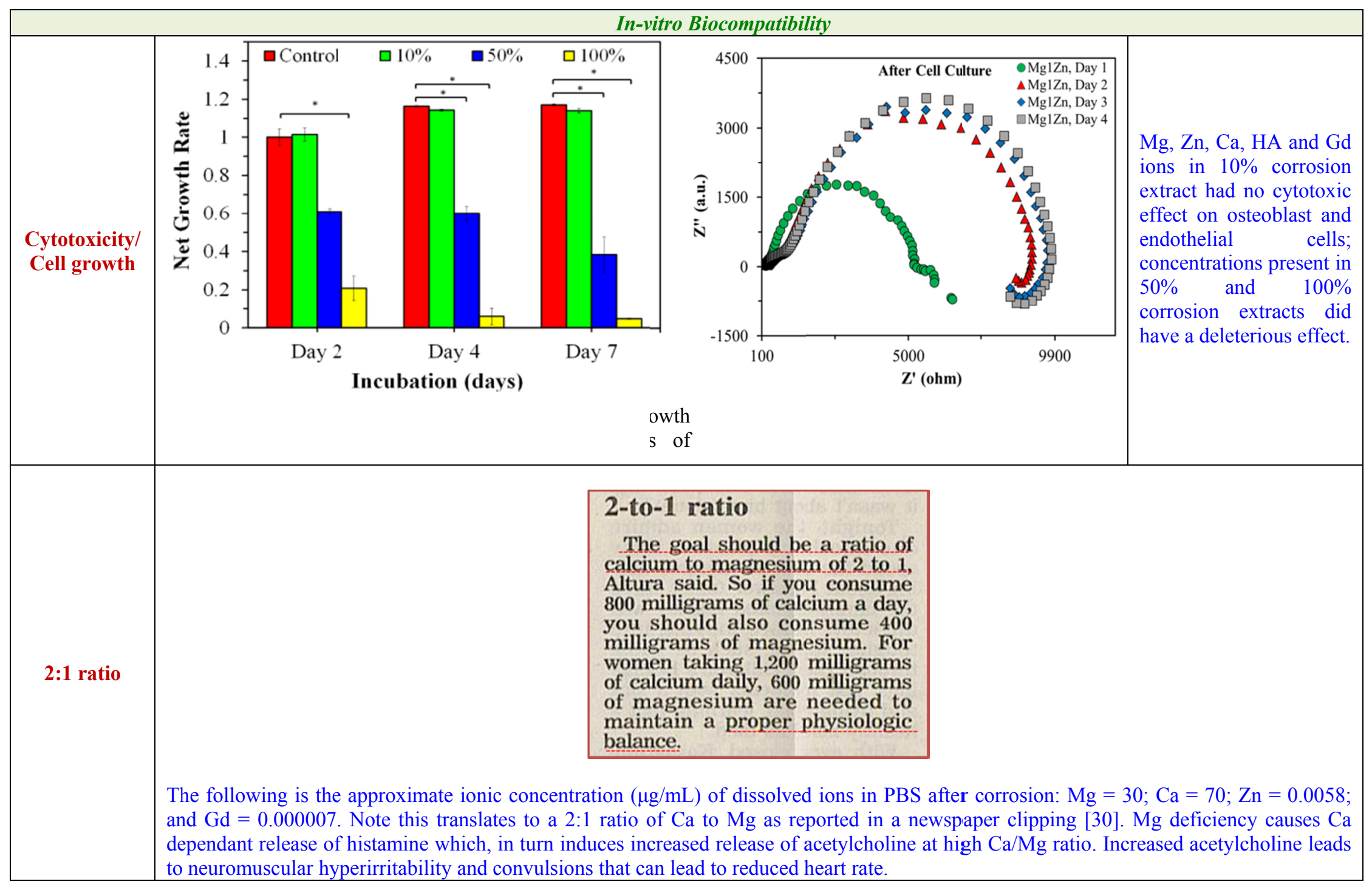




\subsection{CONCLUSION}

The Mg alloys/MMCs studied in this investigation appear to have tremendous potential as a biomaterial for the manufacture of surgical implants. However, these alloys/MMCs face major challenges of controlled and non-uniform degradation, hydrogen evolution, localized $\mathrm{pH}$ increase and biocompatibility as well as sustained mechanical integrity in physiological media. Of the aforementioned challenges, fast degradation and hydrogen evolution pose the greatest concern due to premature failure of the implant, the formation of subcutaneous gas bubbles and gangrene in clinical studies. Nevertheless, much research has been conducted worldwide to further improve the mechanical properties and biocompatibility of biosorbable materials by alloying and surface treatments. Among the surface treatments attempted, anodization has proven to be a good candidate for improving mechanical properties and corrosion resistance of biodegradable Mg alloys/MMCs.

The results obtained in this investigation have indicated that $\mathrm{MgZnCa} / \mathrm{nHA}$ has great potential as an implant material for orthopedic and cardiovascular applications especially when anodized. The following are conclusions derived from this research:

- In general, the microstructure of $\mathrm{Mg}$ alloys/MMCs consisted of $\alpha-\mathrm{Mg}$ solid solution, grain boundary segregation phases (enriched with $\mathrm{Zn}$ and $\mathrm{Ca}$ ), as well as binary and ternary intermetallics $\left(\mathrm{Mg}_{2} \mathrm{Ca}, \mathrm{CaZn} \mathrm{n}_{2}, \mathrm{MgZn}_{2}, \mathrm{CaZn}_{5}, \mathrm{Ca}_{2} \mathrm{Mg}_{6} \mathrm{Zn}_{3}\right.$ and $\left.\mathrm{Ca}_{5}\left(\mathrm{PO}_{4}\right)_{3}(\mathrm{OH})\right)$, all of which contributed to improved mechanical properties and corrosion resistance. 
- Mg alloys/MMCs manufactured utilizing the same procedure exhibited a reduction in the average grain (90 to $60 \mu \mathrm{m}$ ) size as the concentration of HA increased.

- Anodization resulted in the formation of a distinct oxide layer of thickness $\sim 5-10$ $\mu \mathrm{m}$ as compared with that produced on mechanically polished samples $(\sim 20-50$ $\mathrm{nm}$ ) under ambient conditions. The passivating layer resulted in a uniform degradation rate of $\sim 0.2-4.0 \mathrm{~mm} /$ year and hydrogen evolution of $1-3 \mathrm{~mL} / \mathrm{cm}^{2}$ as compared with $\sim 3-23 \mathrm{~mm} /$ year and $3-6 \mathrm{~mL} / \mathrm{cm}^{2}$ for mechanically polished samples.

- The range of modulus (45 - $53 \mathrm{GPa})$ and density $\left(1.69-1.76 \mathrm{~g} / \mathrm{cm}^{3}\right)$ of $\mathrm{Mg}$ alloys/MMCs were similar to those of human bone, which are instrumental for avoiding stress shielding. The modulus and micro hardness increased with the addition of alloying elements. The increase in hardness was much more significant with the addition of HA. At $3 \mathrm{wt} \% \mathrm{HA}$, inhomogeneous distribution of HA resulted in micro-hardness, which varied across the surface.

- The surface of Mg alloys/MMCs were generally hydrophobic (contact angle $~ 85-$ 110 degree); surface free energy $\left(25-35 \mathrm{~mJ} / \mathrm{m}^{2}\right)$; and fractional polarity $(0.0-0.7)$. These parameters have been reported to be favorable for cellular proliferation.

- $\quad \mathrm{Mg}, \mathrm{Zn}, \mathrm{Ca}, \mathrm{Gd}$ and HA ions at a total concentration of $114.8 \mu \mathrm{g} / \mathrm{mL}$ (individual concentrations: $\mathrm{Mg}=33.0 ; \mathrm{Zn}=1.0 ; \mathrm{Ca}=81.0$ and $\mathrm{Gd}=0.01 \mu \mathrm{g} / \mathrm{mL}$ ) were toxic to osteoblast and endothelial cells. This was the concentration of dissolved ions in the $100 \%$ corrosion extract. On an individual bases $1 \mu \mathrm{g} / \mathrm{mL}$ of $\mathrm{Zn}$ appeared to 
be the prime dissolved ion responsible for a decrease in the survivability of the cells.

- $\quad$ Smoother samples (roughness $\sim 0.05 \mu \mathrm{m}$ ) with surface parameters of surface free energy $\left(\sim 29.0 \mathrm{~mJ} / \mathrm{m}^{2}\right)$ and fractional polarity $(0.13)$ were generally more resistant to corrosion. Note that a surface free energy of $30-50 \mathrm{~mJ} / \mathrm{m}^{2}$ and $\mathrm{FP}>0.3$ has been reported to be conducive to good cellular adhesion.

The findings of this research will be useful for introducing a new class of $\mathrm{Mg}$ based biodegradable alloys/MMCs that will coincide with the emergence of innovative cardiovascular and orthopedic implant devices. The devices manufactured from these alloys such as, stents, pins, screws, nuts, etc. will provide greater efficacy for treating patients as compared with permanent implants currently available. The usage of $\mathrm{Mg}$ based biodegradable implants will therefore, negate repeat surgical procedures and reduce medical cost. 


\subsection{RECOMMENDATIONS FOR FUTURE RESEARCH}

The aim of the current research was to explore the potential of $\mathrm{Mg}$ alloys/MMCs and surface treatment for short-term applications for orthopedic and cardiovascular implants. The studies presented in this dissertation are preliminary and further research need to be conducted to elucidate platelet adhesion, clotting time, etc. for understanding thrombosis as well as in-vivo response.

The results obtained are very promising, however further investigation, especially in blood environment will determine the usefulness of proposed compositions and surface treatments for improving the initial stability and mechanical integrity of the implant. Some of the other recommendations for future work:

$\checkmark$ Grain size refinement and homogeneous distribution of HA in the matrix

$\checkmark$ Coating the implants with biodegradable drug eluting polymers

$\checkmark$ Design and manufacture for in-vivo implantation 


\section{REFERENCES}

1. Williams DF, Black J, Doherty PJ. Consensus report of second conference on definitions in biomaterials. Elsevier. 1992; 10:525-533.

2. Global Biomaterials Market (2010-2015). Report published by Markets and Markets, May 2011.http://www.marketsandmarkets.com/Market-

Reports/biomaterials-393.html. Accessed 17 Sept 2011.

3. Niinomi M. Recent research and development in titanium alloys for biomedical applications and health care goods. Science and Technology of Advanced Materials 2003; 4:445-454.

4. Gogotsi Y. Nanomaterials Handbook. CRC Taylor \& Francis, 2006.

5. Ratner BD, Hoffman AS, Schoen FJ, Lemons JE. Biomaterials science: An introduction to materials in medicine. Academic Press 1996.

6. Yunchang X. Degradation mechanism and surface modification of biomedical magnesium alloy. PhD thesis, City University of Hong Kong, August 2009.

7. Joining Joints, Austin Weber, Asssemblymag.com, December 22, 2008.

8. Suh H. Recent Advances in Biomaterials. Yonsei Medical Journal. 1998, 39:8796.

9. BCC Research, NAN017D, Published: November 2009.

http://www.sirim.my/amrec/biomat/history_of_biomaterials_applicat.htm

10. Gill P, Munroe N, Pulletikurthi C, Pandya S, Haider W. Effect of manufacturing process on the biocompatibility and mechanical properties of Ti-30Ta Alloy. Journal of Materials Engineering and Performance. 2011; 20:4-7.

11. Puleo DA, Huh WW. Acute toxicity of metal ions in cultures of osteogenic cells derived from bone marrow stromal cells. J Appl Biomater. 1995; 6:109-116.

12. Jacobs JJ, Gilbert JL, Urban RM. Corrosion of metal orthopaedic implants. J Bone Joint Surg. 1998; 80:268-282.

13. Lhotka C, Szekeres T, Steffan I, Zhuber K, Zweymuller K. Four-year study of cobalt and chromium blood levels in patients managed with two different metalon-metal total hip replacements. J Orthop Res. 2003; 21:189-195. 
14. Jacobs JJ, Skipor AK, Patterson LM, Hallab NJ, Paprosky WG, Black J, Galante JO. Metal release in patients who have had a primary total hip arthroplasty, J Bone Joint Surg. 1998; 80:1447-1458.

15. Jacobs JJ, Hallab NJ, Skipor AK, Urban RM. Metal degradation products: a cause for concern in metal-metal bearings?, Clin Orthop Relat Res. 2003. pp 139-147.

16. Granchi D, Ciapetti G, Stea S, Filippini AS, Zinghi G, Monteraro L. Cytokine release in mononuclear cells of patients with $\mathrm{Co}-\mathrm{Cr}$ hip prosthesis. Biomaterials. 1999; 20:1079-1086.

17. Niki Y, Matsumoto H, Suda Y, Otani T, Fujikawa K, Toyama Y, Hisamori N, Nozue A. Metal ions induce bone-resorption cytokyne production through the redox pathway in synoviocytes and bone marrow macrophages. Biomaterials. 2003; 24:1447-1457.

18. Haynes DR, Boyle SJ, Rogers SD, Howie DW, Vernon-Robert B. Variation in cytokines induced by particles from different prosthetic materials. Clin Orthop Relat Res. 1998; 352:223-230.

19. Wang JY, Wicklund BH, Gustilo RB, Tsukayama DT. Titanium, chromium and cobalt ions modulate the release of bone-associated cytokines by human monocytes/macrophages in vitro. Biomaterials. 1996; 17: 2233-2240.

20. Bi Y, Motter RR, Ragab AA, Goldberg VM, Anderson JM, Greenfield EM. Titanium particles stimulate bone resorption by inducing differentiation of murine osteoclasts. J Biomed Mater Res. 2001; 83:501-508.

21. Allen MJ, Myer BJ, Millet PJ, Rushton N. The effects of particulate cobalt, chromium and cobalt-chromium alloy on human osteoblast-like cells in vitro. J Bone Joint Surg. 1997; 79:475-482.

22. Wang ML, Nesti LJ, Tuli R, Lazatin J, Danielson KG, Sharkey PF, Tuan RS. Titanium particles suppress expression of osteoblastic phenotype in human messenchymal stem cells. J Orthop Res. 2002; 20:1175-1184.

23. http://asleepeasy.com/magnesium-sleep/, accessed December 19, 2011.

24. Park JB, Kim YK. Metallic biomaterials. In: Park JB and Bronzino JD, Editors, Biomaterials principles and application, CRC Press, Boca Raton; 2003.

25. Park B, Roderic S. Lakes Biomaterials: An introduction. Springer 2007.

26. Dong-Song Y, Er-Lin Z, Song-Yyan Z. Effect of Zn on mechanical property and corrosion property of extruded $\mathrm{Mg}-\mathrm{Zn}-\mathrm{Mn}$ alloy. Transactions of Nonferrous Metals Society of China. 2008; 18:763-768. 
27. Seal CK, Vince K, Hodgson MA. Biodegradable surgical implants based on magnesium alloys - A review of current research. Materials Science and Engineering. 2009; 4, 012011.

28. Grosland NM, Goel VK, Lakes RS. Techniques and Applications of Adaptive Bone Remodeling Concepts. CRC Press LCC. 2001.

29. Witte F. The history of biodegradable magnesium implants: A review. Acta Biomaterialia. 2010; 6:1680-1692.

30. http://george-eby-research.com/html/depression-anxiety.html, accessed July 14, 2012.

31. http://asleepeasy.com/magnesium-sleep/, accessed January 282012.

32. Mccarthy JT and Kumar R. Divalent Cation Metabolism: Magnesium. In: SCHRIER, R.W. (Ed.): Atlas of dieseases of the kidney Blackwell Science, Malden, 1999, 4.14 .8

33. Schumacher S. In-vitro-studies of the tissue compatibility of magnesium-based implants. Thesis, University of Veterinary Medicine Hannover 2011.

34. Rubin H. Magnesium: The missing element in molecular views of cell proliferation control. Bioessays, 2005; 27: 311320

35. Rubin H. The logic of the Membrane, Magnesium, Mitosis (MMM) model for the regulation of animal cell proliferation. Arch Biochem Biophys, 2007; 458:1623

36. Wester PO. 'Magnesium', The American Journal of Clinical Nutrition, 1987;45:1305-1312.

37. Zibiao L. Mg/Hydroxyapatite composites for potential bio-medical applications. Thesis submitted for the degree of M. Phil at the Brunel University, 2010.

38. Avedesian MM, Baker H. Magnesium and magnesium alloys. ASM International Handbook, 1999.

39. Mordike BL, Ebert T. Magnesium: properties-applications-potential.Mater.Sci. Eng. A, 2001; 302:37-45.

40. Kainer KU, Von Buch F. The Current State of Technology and Potential for further Development of Magnesium Applications. V. Kainer: Magnesium- Alloys and Technologies. Institut für Werkstofforschung, Translation by Frank Kaiser; Wiley-VCH Verlag GmbH \& Co, 2003:1-23.

41. Yang Z, Li JP, Zhang JX, Lorimer GW, Johnson J. Review on research and development of magnesium alloys, Acta Metallurgica Sinica. (Engl.Lett.) Vol. 21 
N0 5, pp. 313-328. Rostock P. Ist das Magnesium als Naht- und Schienungsmaterial für Knochenoperationen geeignet?, Arch Orthop Trauma Surg. 1937; 38:486-492.

42. Rude RK. Magnesium deficiency: A cause of heterogeneous disease in humans. J Bone Miner Res. 1998;13:749-58.

43. Shils ME. Magnesium. In: Shils ME, Olson JA, Shike M, editors, Modern nutrition in health and disease, 8th ed, Philadelphia: Lea \& Febiger. 1994. pp $164-84$.

44. Grubbs RD, Maguire ME. Magnesium as a regulatory cation: Criteria and evaluation. Magnesium. 1987; 6:113-127.

45. Wacker W, Parisi A. Magnesium metabolism. N Engl J Med. 1968; 278:658663.

46. Saris NEL, Khawaja JA. Interaction of $\mathrm{Mg} 2+$ and polyamines with membrane enzyme activities. In: M.J. Halpern and J. Durlach Editors, Current research in magnesium Libbey, London. 1996:205-209.

47. Beyenbach KW, Transport of magnesium across biological membranes. Magnes Trace Elem. 1990; 9:233-254.

48. Romani A, Scarpa A. Regulation of cell magnesium. Arch Biochem Biophys. 1992; 298:1-12.

49. What is magnesium and its essential function in the human body. September 2011. http://www.essortment.com/all/whatismagnesiu_rtca.htm

50. Quamme GA. Renal magnesium handling: New insights in understanding old problems. Kidney Int. 1997; 52:1180-95.

51. Grubbs RD, Maguire ME. Magnesium as a regulatory cation: Criteria and evaluation. Magnesium. 1987; 6:113-27.

52. Saris NE, Mervaala E, Karppanen H, Khawaja JA, Lewenstam A. Magnesium: an update on physiological, clinical, and analytical aspects. Clinica Chimica Acta. 2000; 294:1-26.

53. Institute of Medicine. Food and Nutrition Board. Dietary Reference Intakes: Calcium, Phosphorus, Magnesium, Vitamin D and Fluoride. National Academy Press. Washington, DC, 1999.

54. Chesley LC. A survey of management and case mortality', In: L.C. Chesley Editor, Hypertensive disorders in pregnancy Appleton-Century-Crofts, New York, 1978:309-340. 
55. Michael M, Avedesian N. Magnesium Inc. and Hugh Baker', Magnesium and Magnesium Alloys, ASM International, 1999.

56. Lahiri D. Hydroxyapatite-Nanotube Composites and Coatings for Orthopedic Applications. Florida Inetrnational University, Thesis, 2011.

57. Quach NC, Uggowitzer PJ, Schmutz P. Corrosion behaviour of an Mg-Y-RE alloy used in biomedical applications studied by electrochemical techniques. C. R. Chimie. 2008;11:1043-1054

58. Revie RW. Uhlig's Corrosion Handbook. John Wiley \& Sons, Inc; 2000:815.

59. Shaw BA. Corrosion resistance of magnesium alloys. ASM International 2003;13A.

60. Alvarez-Lopez M, Dolores Pereda M, Valle JA, Fernandez-Lorenzo M, GarciaAlonso MC, Ruano OA, Escudero ML. Corrosion behaviour of AZ31 magnesium alloy with different grain sizes in simulated biological fluids. Acta Biomaterialia. 2010;6:1763-1771.

61. Tunold R, Holtan H, Hagg Berfe M-B, Lasson A, Steen-Hansen R. Corr Sci 1977;17:353.

62. Makar GL, Kruger J, Joshi A. Advances in Magnesium Alloys and Composites (Eds: H. G. Paris, W. H. Hunt), International Magnesium Association and the Non- Ferrous Metals Committee, TMS, Phoenix, Arizona 1998:105-121.

63. Song GL, Atrens A. Corrosion mechanisms of magnesium alloys. Advanced Engineering Materials, 1999;1:11-33.

64. Witte F, Hort N, Vogt C, Cohen S, Kainer KU, Willumeit R, Feyerabend F. Degradable biomaterials based on magnesium corrosion. Current options in solid state and materials science. 2008;12:63-72.

65. Li Z, Gu X, Lou S, Zheng Y. The development of binary Mg-Ca alloys for use as biodegradable materials within bone. Biomaterials 2008;29:1329-44.

66. Kaesel VT, Bach PT, Haferkamp H, Witte F, Windhagen H. Approach to control the corrosion of magnesium by alloying, In: Kainer KU, editor. Proceedings of the sixth international conference magnesium alloys and their applications. New York: Wiley-Vch; 2004:534-539.

67. Huntsman RG, Hurn BA, Lehmann H. Paradoxical effect of magnesium ions on blood coagulation. Nature. 1960;19:185:852.

68. Haider W. Enhanced Biocompatibility of NiTi (NITINOL) Via Surface Treatment and Alloying. FIU Electronic Theses and Dissertations, 2010:177. 
69. Standing Committee on the Scientific Evaluation of Dietary Reference Intakes, Food and Nutrition Board, Institute of Medicine. Dietary Reference Intakes for Calcium, Phosphorus, Magnesium, Vitamin D and Fluoride. Washington, DC: National Academy Press 1997.

70. Weaver CM, Heaney RP. Calcium. In: Shils ME, Shike M, Ross AC, Caballero B, Cousins RJ. Modern Nutrition in Health and Disease. 10th ed. Baltimore, MD: Lippincott Williams \& Wilkins, 2006:194-210.

71. Institute of Medicine. Food and Nutrition Board. Dietary Reference Intakes for Vitamin A, Vitamin K, Arsenic, Boron, Chromium, Copper, Iodine, Iron, Manganese, Molybdenum, Nickel, Silicon, Vanadium and Zinc. Washington, DC: National Academy Press, 2001.

72. Dallman PR. Biochemical basis for the manifestations of iron deficiency. Annu Rev Nutr 1986;6:13-40.

73. Bothwell TH, Charlton RW, Cook JD, Finch CA. Iron Metabolism in Man. St. Louis: Oxford: Blackwell Scientific, 1979.

74. Andrews NC. Disorders of iron metabolism. The New England Journal of Medicine, 1999:341;1986-1995.

75. Haas JD, Brownlie T. Iron deficiency and reduced work capacity: a critical review of the research to determine a causal relationship. J Nutr. 2001;131:676-690.

76. Bhaskaram P. Immunobiology of mild micronutrient deficiencies. $\mathrm{Br} \mathrm{J}$ Nutr 2001;85:75-80.

77. Corbett JV. Accidental poisoning with iron supplements. The American Journal of Maternal/Child Nursing, 1995;20:234.

78. B. Smola, I. Stulı'kova, F. von Buch, B.L. Mordike. Structural aspects of high performance $\mathrm{Mg}$ alloys design. Materials Science and Engineering. 2002;324:113-117.

79. Peng QM, Wu YM, Fang DQ, Meng J, Wang LM. Microstructures and properties of $\mathrm{Mg}-7 \mathrm{Gd}$ alloy containing $\mathrm{Y}$. Journal of Alloys and Compounds. 2007;430:252-256.

80. Massalski ThB. Binary Alloy Phase Diagrams. ASM, Metals Park, OH, 1986.

81. Sandstead HH. Understanding zinc: recent observations and interpretations. J Lab Clin Med. 1994;124:322-327.

82. Institute of Medicine, Food and Nutrition Board. Dietary Reference Intakes for Vitamin A, Vitamin K, Arsenic, Boron, Chromium, Copper, Iodine, Iron, 
Manganese, Molybdenum, Nickel, Silicon, Vanadium, and Zinc. Washington, DC: National Academy Press 2001.

83. Gu XN, Zheng YF. A review on magnesium alloys as biodegradable materials, Front. Mater. Sci. China. 2010;4:111-115.

84. Sigel H. Metal Ions in Biological System. New York: Marcel Dekker Inc. 1986.

85. Seiler HG, Sigel H. Handbook on Toxicity of Inorganic Compounds. New York: Marcel Dekker Inc. 1988.

86. Zberg B, Uggowitzer PJ, Löffler JF. MgZnCa glasses without clinically observable hydrogen evolution for biodegradable implants. Nature Materials. 2009;8:887-891.

87. Tao Z, Ding C, Zhen-hua C. Microstructures and properties of rapidly solidified Mg-Zn-Ca alloys. Trans. Nonferrous Met. Soc. China. 2008;18:101-106.

88. Ye X, Chen M, Yang M, Wei J, Liu D. In vitro corrosion resistance and cytocompatibility of nano-hydroxyapatite reinforced $\mathrm{Mg}-\mathrm{Zn}-\mathrm{Zr}$ composites. J Mater Sci: Mater Med. 2010;21:1321-1328.

89. Peng Q, Hou X, Wang L, Wu Y, Cao Z, Wang L. Microstructure and mechanical properties of high performance $\mathrm{Mg}-\mathrm{Gd}$ based alloys. Materials and Design. 2009;30:292-296.

90. Zhang S, Zhang X, Zhao C, Li J, Song Y, Xie C, Tao H, Zhang Y, He Y, Jiang Y, Bian Y. Research on an $\mathrm{Mg}-\mathrm{Zn}$ alloy as a degradable biomaterial. Acta Biomaterialia. 2010;6:626-640.

91. Dubrovinskaia N, Dubrovinsky L, Kantor I, Crichton WA, Dmitriev V, Prakapenka V, Shen G, Vitos L, Ahuja R, Johansson B, Abrikosov IA. Beating the miscibility barrier between iron group elements and magnesium by highpressure alloying. Physical Review Letters, 2005;95:245-502.

92. Haitani T, Tamura Y, Motegi T, Kono N, Tamehiro H. Solubility of Iron in pure magnesium and cast structure of Mg-Fe alloys. Material Science Forum, 2003; 419-422:697-702.

93. Hort N, Huang Y, Fechner D, Störmer M, Blawert C, Witte F, Vogt C, Drücker $\mathrm{H}$, Willumeit R, Kainer KU, Feyerabend F. Magnesium alloys as implant materials - Principles of property design for Mg-RE alloys. Acta Biomaterialia, 2010;6:1714-1725.

94. Emley EF. Principles of magnesium technology, New York: Pergamon Press, 1966. 
95. Campbell J. Castings, 2nd ed. Oxford: Butterworth Heinemann, 2003.

96. Wang X, Wu W, Tang Y, Zeng X, Yao S. Early high temperature oxidation behaviors of Mg-10Gd-3Y alloys. Journal of Alloys and Compounds, 2009; 474:499-504.

97. ASM Metals Handbook, Desk Edition. 2nd ed. Metals Park, OH: ASM International; 1998.

98. Witte F, Kaese V, Haferkamp H, Switzer E, Lindenberg AM, Wirth CJ, Windhagen $\mathrm{H}$. In vivo corrosion of four magnesium alloys and the associated bone response. Biomaterials, 2005; 26:3557-3563.

99. Zhang E, Xu L, Yu G, Pan F, Yang K. In vivo evaluation of biodegradable magnesium alloy bone implant in the first 6 months implantation. DOI: 10.1002/jbm.a.32132.

100. Wu MK, Ashburn JR, Torng CJ, Hor PH, Meng RL, Gao L, Huang ZJ, Wang YQ, Chu CW. Superconductivity at $93 \mathrm{~K}$ in a New Mixed-Phase Y-Ba-Cu-O Compound System at Ambient Pressure. Physical Review Letters, 1987;58(9): 908-910.

101. McCarthy JT, Kumar R. Divalent Cation Metabolism: Magnesium. Blackwell Science, Malden, 1999: 4.1 - 4.8.

102. Rubin H. The logic of the Membrane, Magnesium, Mitosis (MMM) model for the regulation of animal cell proliferation. Archives of Biochemistry and Biophysics, 2007;458:16-23.

103. Abbott MB, Bathurst JC, Cunge JA, O'Connell PE, Rasmussen J. An introduction to the European hydrological system - Syste 'me Hydrologique Europe'en, SHE 1. History and philosophy of a physically based distributed modelling system. Journal of Hydrology, 1886;87:45-59.

104. Staiger MP, Pietak AM, Huadmai J, Dias G. Magnesium and its alloys as orthopedic biomaterials: A review. Biomaterials, 2006;27:1728-1734.

105. Zhou T, Chen D, Chen Z. Microstructures and properties of rapidly solidified MgZn-Ca alloys. Trans Nonferrous Met Soc China, 2008;18:101-106.

106. Seal CK, Vince K, Hodgson MA. Biodegradable Surgical Implants based onn Magnesium Alloys - A Review of Current Research. Materials Science and Engineering, 2009;4:012011.

107. Ngoc-Chang Q, Peter JU, Patrik S. Corrosion behaviour of an Mg-Y-RE alloy used in biomedical applications studied by electrochemical techniques. C. R. Chimie, 2008;11:1043-1054 
108. Subbiahdoss G, Grijpma DW, Henny C, Busscher HJ, Kuijer R. Microbial Biofilm Growth versus Tissue Integration on Biomaterials with Different Wettabilities and a Polymer-Brush Coating. Journal of Biomedical Materials Research Part A, 2010; 94: 533-538.

109. Ponsonnet L, Reybier K, Jaffrezic N, Comte V, Lagneau C, Lissac M, Martelet C. Relationship between surface properties (roughness, wettability) of titanium and titanium alloys and cell behavior. Materials Science and Engineering C, 2003;23:551-560.

110. Feng B, Chen JY, Qi SK, He L, Zhao JZ, Zhang XD. Characterization of surface oxide films on titanium and bioactivity. Journal of Materials Science: Materials in Medicine, 2002;13:457-464.

111. Mani G, Feldman MD, Patel D, Agrawal CM. Coronary stents: A materials perspective. Biomaterials, 2007;28:1689-1710.

112. Michiardi A, Aparicio C, Ratner BD, Planell JA, Gil J. The influence of surface energy on competitive protein adsorption on oxidized NiTi surfaces. Biomaterials, 2006;29:586-594.

113. Li Z. Mg/Hydroxyapatite composites for potential bio-medical applications, M. Phil, Brunel University, Brunel Center for Advanced Solidification Technology (BCAST), August 2010.

114. Song G, Song S. A possible biodegradable magnesium implant material. Advanced Engineering Materials, DOI: 10.1002/adem.200600252.

115. Gu X, Zheng Y, Cheng Y, Zhong S, Xi T. In vitro corrosion and biocompatibility of binary magnesium alloys. Biomaterials 2009;30:484-498.

116. Langö T, Morland T, Brubakk AO. Diffusion coefficients and solubility coefficients for gases in biological fluids and tissues: a review. Undersea Hyperb Med, 1996;23(4):247-72.

117. Erne P, Schier M., Resink TJ. The Road to Bioabsorbable Stents: Reaching Clinical Reality? Cardiovasc. Inter. Rad., 2006;29:11-16.

118. Heublein B, Rohde R, Kaese V, Niemeyer M, HartungW, Haverich A. Biocorrosion of magnesium alloys: a new principle in cardiovascular implant technology? Heart, 2003;89:651-656.

119. Erbel, R. et al. Temporary scaffolding of coronary arteries with bioabsorbable magnesium stents: a prospective, non-randomised multicentre trial. Lancet, 2007;369:1869-1875. 
120. Peeters P, Bosiers M, Verbist J, Deloose K, Heublein B. Preliminary results after application of absorbable metal stents in patients with critical limb ischemia. J. Endovasc. Ther., 2005;12:1-5.

121. Di Mario, C. et al. Drug-Eluting Bioabsorbable Magnesium Stent. J. Interv. Cardiol., 2004;17:391-395.

122. Witte F. et al. In vitro and in vivo corrosion measurements of magnesium alloys. Biomaterials. 2006;27:1013-1018.

123. Staiger MP, Pietak AM, Huadmai J, Dias G. Magnesium and its alloys as orthopaedic biomaterials: A review. Biomaterials, 2006;27:1728-1734.

124. Bodansky M. The effect of hydrogen ion concentration on saponin hemolysis.J Biol Chem, 1929;82(3):567-77.

125. http://www.material.ntnu.no/elektrokjemi/korrosjon/adhesion/, accessed January $15,2012$.

126. http://hansmalab.physics.ucsb.edu/afmbone.html, accessed date December 17, 2011.

127. Wang Y, Lim CS, Lim CV, Yong MS, Teo EK, Moh LN. In vitro degradation behavior of M1A magnesium alloy in protein-containing simulated body fluid. Materials Science and Engineering C, 2011;31:579-587.

128. http://www.buehler.com/technical_information/Buehler\%20Book/etching.pdf, accessed date December 17, 2011.

129. Pekguleryuz BM. Effects of zinc, lithium, and indium on the grain size of magnesium. J. Mater. Res., 2009;24:5.

130. Shi Z, Song G, Atrens A. The corrosion performance of anodized magnesium alloys. Corrosion Science, 2006;48:3531-3546.

131. Tian XB, Wei CB, Yang SQ, Fu FKY, Chu PK. Surf Coat. Technol, 2005;198:454.

132. Guo HF, An MZ, Liu RJ. Light Alloy Fabrication Technology. 2003:31-35.

133. Marinucci L, Balloni S, Becchetti E, Belacastro S, Guerra M, Calvitti M, Lilli C, Calvi EM, Locci P. Effect of Titanium Surface Roughness on Human Osteoblast Proliferation and Gene Expression In Vitro. International Journal of Oral \& Maxillofacial Implants, 2005: 719-725. 
134. Oh S, Daraio C, Chen LH, Pisanic TR, Finones RR, Jin S. Significantly accelerated osteoblast cell growth on aligned $\mathrm{TiO}_{2}$ nanotubes. Wiley InterScience, DOI: $10.1002 / \mathrm{jbm} . \mathrm{a} .30722$.

135. Kubásek J, Vojtěch D. Mechanical properties and corrosion behavior of biodegradable magnesium alloys. Metal, 2011;18:1-6.

136. Ye X, Chen M, Yang M, Wei J, Liu D. In vitro corrosion resistance and cytocompatibility of nano-hydroxyapatite reinforced $\mathrm{Mg}-\mathrm{Zn}-\mathrm{Zr}$ composites. J Mater Sci: Mater Med, 2010;21:1321-1328. DOI 10.1007/s10856-009-3954-3

137. Shabalovskaya S, Anderegg J,Van Humbeeck J. Critical overview of Nitinol surfaces and their modifications for medical applications. Acta Biomaterialia, 2008;4:447-467.

138. Maier JA, Malpuech-Brugère C, Zimowska W, Rayssiguier Y, Mazur A. Low magnesium promotes endothelial cell dysfunction: implications for atherosclerosis, inflammation and thrombosis, Biochim Biophys Acta. 2004;1689(1):13-21.

139. Pulletikurthi C. Enhancement of Biocompatibility of Porous Nitinol. Florida International University, Thesis, 2009.

140. Zhu, Trepanier, Fino, Pelton. Oxidation of Nitinol and Its Effect on Corrosion Resistance ASM Materials \& Processes for Medical Device Conference, 2003.

141. Tepe G, Schmehl J, Wendel HP, Schaffner S, Heller S, Gianotti M, Claus D, Duda SH. Reduced thrombogenicity of nitinol stents-In vitro evaluation of different surface modifications and coatings. Biomaterials, 2006;27:643-650.

142. Trigwell S, Hayden RD, Nelson KF, Selvaduray G. Effects of Surface Treatment on the Surface Chemistry of NiTi Alloy for Biomedical. Surface and Interface Analysis, 1998;26(7):483-489.

143. Rokicki R, Hryniewicz T, Rokosz K. Magnetoelectropolishing Metallic Implants. MDDI, 2008:102.

144. Murray DW, Rae T, Rushton N. The influence of the surface energy and roughness of implants on bone resorption. J. Bone Jt. Surg., 1989;71:632-637.

145. Hallab N, Bundy K, O'Connor K, Moses RL, Jacobs JJ. Evaluation of metallic and polymeric biomaterial surface energy and surface roughness characteristics for directed cell adhesion. Tissue Eng., 2001;71:55-71.

146. Schakenraad JM, Busscher HJ, Wildevuur CRH, Arends J. Thermodynamic aspects of cell spreading on solid substrata. J. Cell Biophys, 1988;13:75-91. 
147. Ruardy TG, Schakenraad JM, Van der Mei HC, Busscher HJ. Adhesion and spreading of human skin fibroblasts on physocochemically characterized gradient surfaces. J. Biomed. Mater. Res., 1995;29:1415-1423.

148. Georgi F, Grinnel T, Groth. Studies on the biocompatibility of materials: fibroblast reorganisation of substratum-bound fibronectin on surfaces varying in wettability. J. Biomed. Mater. Res., 1996;30:385-391.

149. K. Webb, V. Hlady, P.A. Tresco, Relative importance of surface wettabillity and charged functional groups on NIH 3T3 fibroblasts attachment, spreading, and cytosqueletal organisation, J. Biomed. Mater. Res. 241 (1998) 422- 430.

150. T. Groth, G. Altankov, Studies on cell-biomaterial interaction: role of tyrosine phosphorylation during fibroblasts spreading on surfaces varying in wettability, Biomaterials 17 (1995) 1227-1234.

151. Redey SA, Razzouk S, Rey C, Bernache-Assolant D, Leroy G, Nardin M, Gournot G. Osteoclasts adhesion and activity on synthetic hydroxyapatite, carbonated hydroxyapatite, and natural calcium carbonate: relationship to surface energies. J. Biomed. Mater. Res., 1999;45:140- 147.

152. Ponsonnet L, Reybier K, Jaffrezic N, Comte V, Lagneau C, Lissac M, Martelet C. Relationship between surface properties (roughness, wettability) of titanium and titanium alloys and cell behavior. Materials Science and Engineering C, 2003;23:551-560.

153. Den Braber ET, Ruijter JED, Smits HTJ, Ginsel LA, Recum AFV, Jansen JA. Effect of parallel surface microgrooves and surface energy on cell growth, J. Biomed. Mater. Res., 1995;29:511 -518.

154. Yao C, Webster T J. Anodization: a promising nano-modification technique of titanium implants for orthopedic applications. J. Nanosci. Nanotechnol., 2006;6: 2682-2692

155. Davis JR. Handbook of materials for medical devices. Edited by J. R. Davis. ASM International, 2003.

156. Fontana MG. Corrosion Engineering. Edited by 3rd. McGraw Hill, 1986.

157. Uhlig HH. The corrosion handbook (John Wiley \& Sons, Inc., 1948, 15.

158. Gill P, Munroe N. In-vitro corrosion studies of bioabsorbable alloys. Magnesium Technology, TMS, 2012.

159. Roberge PR. Handbook on Corrosion Engineering, McGraw Hill Handbooks, 1999:ISBN 0-07-076516-2. 
160. ASTM G102-89. Standard Practice for Calculation of Corrosion Rates and Related Information from Electrochemical Measurements. 1999. DOI: 10.1520/G0102-89R99.

161. ASTM G31-72. Standard Practice for Laboratory Immersion Corrosion Testing of Metals. 2004 DOI: 10.1520/G0031-72R04.

162. Xu L, Zhang E, Yin D, Zeng S, Yang K. In vitro corrosion behavior of Mg alloys in a phosphate buffered solution for bone implant application. J Mater Sci: Mater Med, 2008;19:1017-1025.

163. Gill P, Munroe N, Dua R, Ramaswamy S. Corrosion and Biocompatibility Assessment of Magnesium Alloys. Journal of Biomaterials and Nanobiotechnology, 2012;3:10-13.

164. Pound BG. Corrosion behavior of nitinol in blood serum and PBS containing amino acids. J Biomed Mater Res B Appl Biomater, 2010;2:287-295.

165. Schmidt M, Steinemann SG. XPS studies of amino acids adsorbed on titanium dioxide surfaces. J. Anal. Chem, 1991;314:412-415.

166. Ling-Ling L, Ying-Liang C, Hui-Min W, Zhao Z. Anodization of AZ91 magnesium alloy in alkaline solution containing silicate and corrosion properties of anodized films. Trans Nonferrous Met Soc China, 2008;18(3):722-727.

167. Song G. Control of biodegradation of biocompatable magnesium alloys. Corrosion Science, 2007;49(4):1696-1701.

168. Ambat R, Aung NN, Zhou W. Studies on the influence of chloride ion and $\mathrm{pH}$ on the corrosion and electrochemical behaviour of AZ91D magnesium alloy. Journal Applied Electrochemistry, 2000;30:865-874.

169. Song Y, Shan D, Chen R, Zhang F, Han EH. Biodegradable behaviors of AZ31 magnesium alloy in simulated body fluid. Materials Science and Engineering C, 2009; 29:1039-1045.

170. Wang H, Shi Z. In vitro biodegradation behavior of magnesium and magnesium alloy. J Biomed Mater Res B Appl Biomater, 2011;2:203-209. doi: 10.1002/jbm.b.31769.

171. Brubaker CO, Liu ZK. A computational thermodynamic model of the $\mathrm{Ca}-\mathrm{Mg}-\mathrm{Zn}$ system. J. Alloys Compd., 2004;370:114-122.

172. Oss CJV, Chaudhury M, Good RJ. Interfacial Lifshitz-van der Waals and polar interactions in macroscopic systems. Chem. Rev., 1988;88:927-941. 
173. Oliver WC, Pharr GM. An improved technique for determining hardness and elastic modulus using load and displacement sensing indentation experiments. J. Mater. Res., 1992;7:1564-1583.

174. ASTM E384-07 Standard Test Method for Microindentation Hardness of Materials.

175. http://www.gordonengland.co.uk/hardness/vickers.htm, assessed on January 31, 2012 .

176. Bolshakov A, Pharr GM. Influences of pileup on the measurement of mechanical properties by load and depth sensing indentation techniques. J. Mater. Res., 1998;13:1049-1058.

177. Witte F, Feyerabend F, Maier P, Fischer J, Stormer M, Blawert C, Dietzel W, Hort N. Biodegradable magnesium-hydroxyapatite metal matrix composites. Biomaterials, 2007;8:2163-2174.

178. Zhu, Trepanier, Fino, Pelton. Oxidation of Nitinol and Its Effect on Corrosion Resistance. ASM Materials \& Processes for Medical Device Conference, 2003.

179. Pelton AR, Mehta A, Zhu L, Trepanier C, Imbeni V, Robertson S, Barney M, Minor A. TiNi Oxidation: Kinetics and Phase Transformation. NDC, 2005.

180. Alvarez RB, Martin HJ, Horstemeyer MF, Chandler MQ, Williams N, Wang PT, Ruiz A. Corrosion relationships as a function of time and surface roughness on a structural AE44 magnesium alloy. Corrosion Science, 2010;52:1635-1648.

181. Zuo Y, Wang H, Xiong J. The aspect ratio of surface grooves and metastable pitting of stainless steel, Corros. Sci., 2002;44:25-35.

182. Suter T, Muller Y, Schmutz P, Trzebiatowski O. Microelectrochemical studies of pit initiation on high purity and ultra high purity aluminum. Adv. Eng. Mater., 2005;7:339-348.

183. ASTM G 3-89 (2004), Standard Practice for Conventions Applicable to Electrochemical Measurements in Corrosion Testing.

184. Macdonald JR. Impedance Spectroscopy. John Wiley and Sons, New York, 1987:1-26.

185. Song G. Recent progress in corrosion and protection of magnesium alloys. Advanced Engineering Materials, 2005;7:563-586 .

186. Gill P, Munroe N, Dua R, Ramaswamy S. In-vitro Degradation and Cytocompatibility Assessment of Mg-Zn and Mg-Zn-Ca Alloys. Materials and Processes for Medical Devices (MPMD), 2011, MN, USA. 
187. Hallab N, Bundy K, O’Connor K, Moses RL, Jacobs JJ. Evaluation of metallic and polymeric biomaterial surface energy and surface roughness characteristics for directed cell adhesion. Tissue Eng., 2001;71:55-71.

188. Tercero JE, Namin S, Lahiri D, Balani K, Tsoukias N, Agarwal A. Effect of carbon nanotube and aluminum oxide addition on plasma-sprayed hydroxyapatite coating's mechanical properties and biocompatibility. Materials Science and Engineering C, 2009;29:2195-2202.

189. Dulbecco R, Freeman G. Plaque formation by the polyoma virus. Virology, 1959;8:396.

190. Ham RG. Clonal growth of mammalian cells in a chemically defined synthetic medium. Proc. Natl. Acad. Sci., 1965;53:288.

191. Morton HJ A survey of commercially available tissue culture media. In Vitro, 1970;6(2):89.

192. Smith JD, Freeman G, Vogt M, et al.The nucleic acid of polyoma virus. Virology, 1960;12:185.

193. http://www.invitrogen.com/site/us/en/home/support/Product-TechnicalResources/media_formulation.56.html, accessed February 23, 2012.

194. Orazem ME, Tribollet B. Electrochemical Impedance Spectroscopy. John Wiley \& Sons, Hoboken, New Jersey, 2008.

195. www.gamry.com/assets/Application-Notes/Basics-of-EIS.pdf, Accessed April 6, 2012 .

196. Rukshin V, Azarbal B, Shah P, Tsang VT, Shechter M, Finkelstein A, Cercek B, Kaul S. Intravenous Magnesium in Experimental Stent Thrombosis in Swine. Journal of American Heart Association. 2001; 1544-1549.

197. Guo M, Chen J, Yun X, Chen K, Nie L, Yao S. Monitoring of cell growth and assessment of cytotoxicity using electrochemical impedance spectroscopy. Biochimica et Biophysica Acta. 2006;1760(3):432-439.

198. Guy G, Greene N. Corrosion Engineering. McGraw-Hill B0000CO3M7, 1978. 


\section{APPENDICES}

\section{A. Appendix - I}

Figure A.1 shows the relative bar graph representing a significant decrease in corrosion rates for anodized samples after 192 hours of static immersion in PBS at $37{ }^{\circ} \mathrm{C}$. $\mathrm{Mg} 1 \mathrm{Zn}$ (ACI) showed an increase in corrosion rate after anodization, which could be due to the formation of porous oxides on the surface.

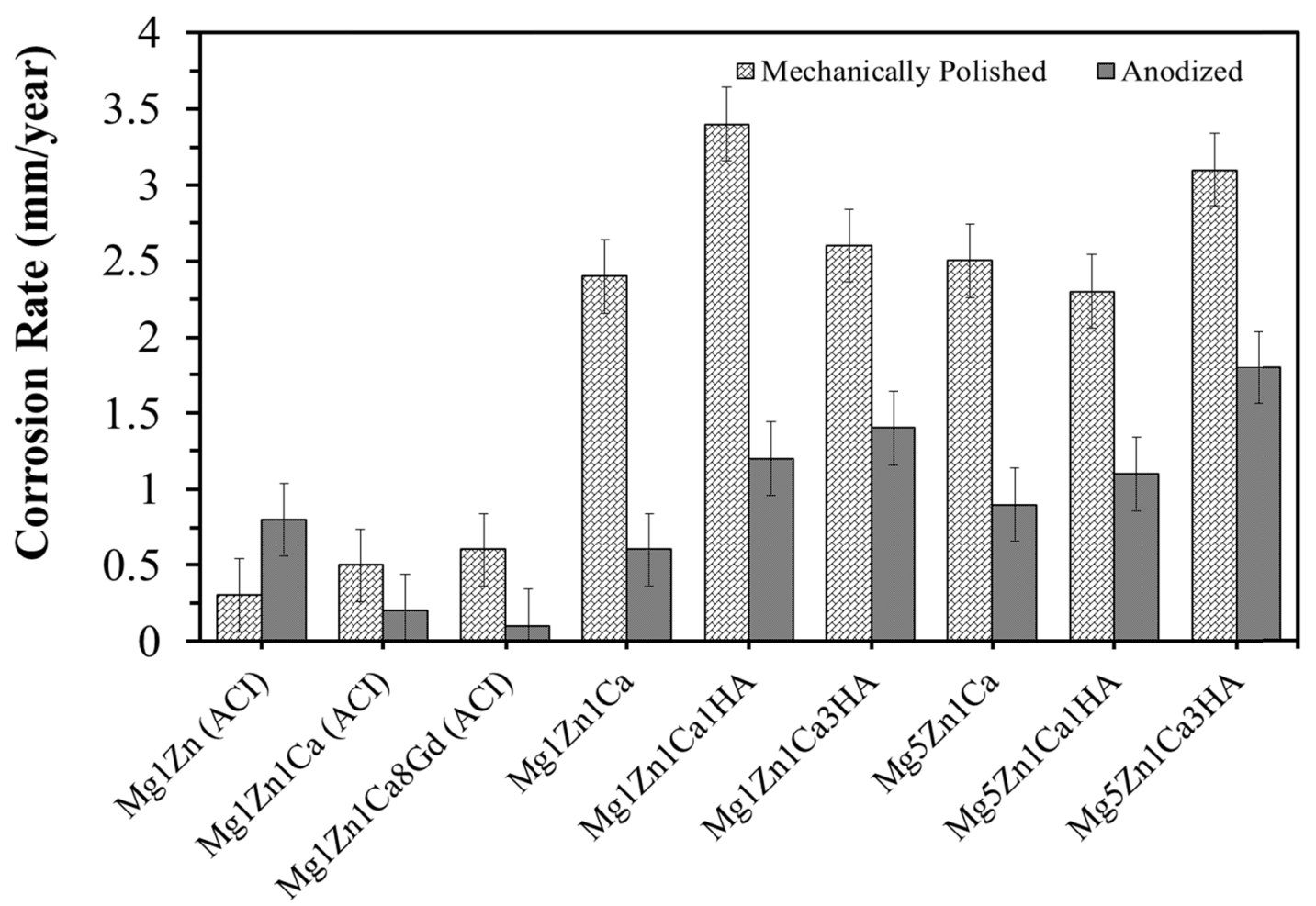

Figure A.1: Corrosion rates attained from immersion test on mechanically polished and anodized samples in PBS at $37^{\circ} \mathrm{C}$. 
Table A.1: Kitazaki Hata, average values of surface free energy components $\left(\mathrm{mJ} / \mathrm{m}^{2}\right)$ mechanically polished samples

\begin{tabular}{|c|c|c|c|c|c|}
\hline \multicolumn{7}{|c|}{ Surface Free Energy Components (mJ/m ) } \\
\hline $\begin{array}{c}\text { Mechanically Polished } \\
\text { Samples }\end{array}$ & Dispersion (d) & Polar (p) & $\begin{array}{c}\text { Hydrogen } \\
\text { component (h) }\end{array}$ & Total & $\begin{array}{c}\text { Fractional } \\
\text { polarity }\end{array}$ \\
\hline Mg1Zn (ACI) & 33.7 & 0.0 & 0.0 & 33.7 & 0 \\
\hline Mg1Zn1Ca (ACI) & 25.7 & 3.7 & 0.3 & 29.7 & 0.13 \\
\hline Mg1Zn1Ca8Gd (ACI) & 32.7 & 0.0 & 0.3 & 33.0 & 0 \\
\hline Mg1Zn1Ca & 14.9 & 46.1 & 3.4 & 64.4 & 0.76 \\
\hline Mg1Zn1Ca1HA & 19.1 & 10.7 & 3.8 & 33.6 & 0.36 \\
\hline Mg1Zn1Ca3HA & 14.0 & 26.9 & 2.2 & 43.1 & 0.66 \\
\hline Mg5Zn1Ca & 18.8 & 16.7 & 1.2 & 106.4 & 0.47 \\
\hline Mg5Zn1Ca1HA & 8.6 & 89.6 & 8.2 & 93.9 & 0.91 \\
\hline Mg5Zn1Ca3HA & 12.8 & 73.0 & 8.1 & & 0.85 \\
\hline
\end{tabular}

Table A.2: Kitazaki Hata, average values of surface free energy components $\left(\mathrm{mJ} / \mathrm{m}^{2}\right)$ anodized samples

\begin{tabular}{|c|c|c|c|c|c|}
\hline \multicolumn{6}{|c|}{ Surface Free Energy Components $\left(\mathrm{mJ} / \mathrm{m}^{2}\right)$} \\
\hline Anodized Samples & $\begin{array}{c}\text { Dispersion } \\
\text { (d) }\end{array}$ & $\begin{array}{c}\text { Polar } \\
\text { (p) }\end{array}$ & $\begin{array}{c}\text { Hydrogen } \\
\text { component } \\
\text { (h) }\end{array}$ & Total & $\begin{array}{c}\text { Fractional } \\
\text { polarity }\end{array}$ \\
\hline $\operatorname{Mg} 1 \mathrm{Zn}(\mathrm{ACI})$ & 21.9 & 24.1 & 0.2 & 46.2 & 0.53 \\
\hline $\mathrm{Mg} 1 \mathrm{Zn} 1 \mathrm{Ca}(\mathrm{ACI})$ & 24.4 & 9.2 & 0.0 & 33.6 & 0.27 \\
\hline Mg1Zn1Ca8Gd (ACI) & 25.0 & 0.0 & 0.0 & 25.0 & 0 \\
\hline $\mathrm{Mg} 1 \mathrm{Zn} 1 \mathrm{Ca}$ & 18.2 & 26.2 & 0.9 & 45.3 & 0.59 \\
\hline $\mathrm{Mg} 1 \mathrm{Zn} 1 \mathrm{Ca} 1 \mathrm{HA}$ & 21.0 & 16.5 & 2.6 & 40.1 & 0.44 \\
\hline $\mathrm{Mg} 1 \mathrm{Zn} 1 \mathrm{Ca} 3 \mathrm{HA}$ & 23.3 & 5.1 & 0.0 & 28.4 & 0.18 \\
\hline $\mathrm{Mg} 5 \mathrm{Zn} 1 \mathrm{Ca}$ & 15.1 & 50.5 & 1.0 & 66.6 & 0.77 \\
\hline Mg5Zn1Ca1HA & 29.0 & 2.7 & 0.0 & 31.7 & 0.09 \\
\hline $\mathrm{Mg} 5 \mathrm{Zn} 1 \mathrm{Ca} 3 \mathrm{HA}$ & 23.8 & 11.3 & 0.0 & 35.1 & 0.32 \\
\hline
\end{tabular}


Table A.3: Acid-Base, average values of mechanically polished samples: contact angle, interfacial free energy and work of adhesion

\begin{tabular}{|c|c|c|c|c|c|c|c|c|c|}
\hline \multirow{2}{*}{$\begin{array}{c}\text { Mechanically } \\
\text { Polished Samples }\end{array}$} & \multicolumn{3}{|c|}{ Contact Angle (Deg) } & \multicolumn{3}{c|}{ Interfacial Free Energy $\left(\mathrm{mJ} / \mathrm{m}^{2}\right)$} & \multicolumn{3}{c|}{ Work of Adhesion $\left(\mathrm{mJ} / \mathrm{m}^{2}\right)$} \\
\cline { 2 - 11 } & Water & $\begin{array}{c}\text { Ethylene } \\
\text { Glycol }\end{array}$ & $\begin{array}{c}\text { Diiodo- } \\
\text { methane }\end{array}$ & Water & $\begin{array}{c}\text { Ethylene } \\
\text { Glycol }\end{array}$ & $\begin{array}{c}\text { Diiodo- } \\
\text { methane }\end{array}$ & Water & $\begin{array}{c}\text { Ethylene } \\
\text { Glycol }\end{array}$ & $\begin{array}{c}\text { Diiodo- } \\
\text { methane }\end{array}$ \\
\hline Mg1Zn (ACI) & 99.5 & 64.4 & 57.3 & 42.5 & 9.8 & 3.1 & 60.8 & 68.6 & 78.2 \\
\hline Mg1Zn1Ca (ACI) & 95.1 & 72.7 & 59.8 & 35.2 & 14.5 & 3.1 & 66.3 & 62.1 & 76.4 \\
\hline Mg1Zn1Ca8Gd (ACI) & 93.0 & 65.6 & 56.7 & 35.2 & 11.6 & 3.5 & 69.0 & 67.7 & 78.7 \\
\hline Mg1Zn1Ca & 85.0 & 68.7 & 60.5 & 22.0 & 10.9 & 3.3 & 79.1 & 65.3 & 75.8 \\
\hline Mg1Zn1Ca1HA & 84.9 & 70.8 & 64.3 & 19.6 & 10.3 & 4.1 & 79.3 & 63.7 & 72.8 \\
\hline Mg1Zn1Ca3HA & 91.3 & 76.8 & 69.1 & 26.3 & 12.4 & 5.2 & 69.9 & 58.9 & 69.0 \\
\hline Mg5Zn1Ca & 93.1 & 74.1 & 63.8 & 30.3 & 13.2 & 4.0 & 68.9 & 61.1 & 73.2 \\
\hline Mg5Zn1Ca1HA & 78.0 & 68.0 & 64.7 & 10.8 & 8.0 & 4.2 & 87.9 & 65.8 & 72.5 \\
\hline Mg5Zn1Ca3HA & 73.7 & 61.3 & 56.5 & 10.2 & 7.6 & 2.5 & 93.2 & 70.9 & 78.9 \\
\hline
\end{tabular}

Table A.4: Kitazaki Hata, average values of mechanically polished samples: contact angle, interfacial free energy and work of adhesion

\begin{tabular}{|c|c|c|c|c|c|c|c|c|c|}
\hline \multirow{2}{*}{$\begin{array}{c}\text { Mechanically Polished } \\
\text { Samples }\end{array}$} & \multicolumn{3}{|c|}{ Contact Angle (Deg) } & \multicolumn{2}{c|}{ Interfacial Free Energy (mJ/m $)$} & \multicolumn{3}{c|}{ Work of Adhesion $\left(\mathrm{mJ} / \mathrm{m}^{2}\right)$} \\
\cline { 2 - 10 } & Water & $\begin{array}{c}\text { Ethylene } \\
\text { Glycol }\end{array}$ & $\begin{array}{c}\text { Diiodo- } \\
\text { methane }\end{array}$ & Water & $\begin{array}{c}\text { Ethylene } \\
\text { Glycol }\end{array}$ & $\begin{array}{c}\text { Diiodo- } \\
\text { methane }\end{array}$ & Water & $\begin{array}{c}\text { Ethylene } \\
\text { Glycol }\end{array}$ & $\begin{array}{c}\text { Diiodo- } \\
\text { methane }\end{array}$ \\
\hline Mg1Zn (ACI) & 98.0 & 70.4 & 55.7 & 43.9 & 17.7 & 5.1 & 62.6 & 63.7 & 79.4 \\
\hline Mg1Zn1Ca (ACI) & 95.2 & 74.8 & 58.9 & 36.3 & 17.2 & 3.4 & 66.2 & 60.2 & 77.1 \\
\hline Mg1Zn1Ca8Gd (ACI) & 93.1 & 65.7 & 57.3 & 37.0 & 13.4 & 5.6 & 68.8 & 67.3 & 78.2 \\
\hline Mg1Zn1Ca & 83.4 & 77.7 & 54.9 & 56.1 & 54.3 & 35.2 & 81.1 & 57.8 & 80.0 \\
\hline Mg1Zn1Ca1HA & 84.4 & 69.7 & 64.3 & 26.4 & 17.0 & 11.5 & 80.0 & 64.3 & 72.9 \\
\hline Mg1Zn1Ca3HA & 91.1 & 83.1 & 65.4 & 44.4 & 37.3 & 22.0 & 71.5 & 53.5 & 71.9 \\
\hline Mg5Zn1Ca & 92.1 & 79.2 & 60.6 & 39.1 & 27.6 & 11.8 & 70.4 & 56.8 & 75.7 \\
\hline Mg5Z1Ca1HA & 75.9 & 79.7 & 57.6 & 88.7 & 97.9 & 79.2 & 90.5 & 56.2 & 78.0 \\
\hline Mg5Zn1Ca3HA & 72.1 & 71.1 & 50.5 & 71.6 & 78.5 & 61.6 & 95.1 & 63.1 & 83.1 \\
\hline
\end{tabular}


Table A.5: Acid-Base, average values of anodized alloys: contact angle, interfacial free energy and work of adhesion

\begin{tabular}{|c|c|c|c|c|c|c|c|c|c|}
\hline \multirow{2}{*}{$\begin{array}{l}\text { Anodized } \\
\text { Samples }\end{array}$} & \multicolumn{3}{|c|}{ Contact Angle (Deg) } & \multicolumn{3}{|c|}{ Interfacial Free Energy $\left(\mathrm{mJ} / \mathrm{m}^{2}\right)$} & \multicolumn{3}{|c|}{ Work of Adhesion $\left(\mathrm{mJ} / \mathrm{m}^{2}\right)$} \\
\hline & Water & $\begin{array}{l}\text { Ethylene } \\
\text { Glycol }\end{array}$ & $\begin{array}{l}\text { Diiodo- } \\
\text { methane }\end{array}$ & Water & $\begin{array}{l}\text { Ethylene } \\
\text { Glycol }\end{array}$ & $\begin{array}{l}\text { Diiodo- } \\
\text { methane }\end{array}$ & Water & $\begin{array}{l}\text { Ethylene } \\
\text { Glycol }\end{array}$ & $\begin{array}{l}\text { Diiodo- } \\
\text { methane }\end{array}$ \\
\hline $\operatorname{Mg} 1 \mathrm{Zn}(\mathrm{ACI})$ & 95.6 & 70.9 & 56.1 & 37.9 & 15.1 & 2.5 & 65.7 & 63.6 & 79.1 \\
\hline $\mathrm{Mg} 1 \mathrm{Zn} 1 \mathrm{Ca}(\mathrm{ACI})$ & 100.3 & 74.7 & 59.4 & 41.9 & 16.3 & 3.1 & 59.8 & 60.5 & 76.6 \\
\hline $\begin{array}{l}\mathrm{Mg} 1 \mathrm{Zn} 1 \mathrm{Ca} 8 \mathrm{Gd} \\
(\mathrm{ACI})\end{array}$ & 107.0 & 82.0 & 67.5 & 45.5 & 17.6 & 4.8 & 51.6 & 54.6 & 70.3 \\
\hline $\mathrm{Mg} 1 \mathrm{Zn} 1 \mathrm{Ca}$ & 93.8 & 73.2 & 61.7 & 32.4 & 13.8 & 3.5 & 68.0 & 61.7 & 74.9 \\
\hline $\mathrm{Mg} 1 \mathrm{Zn} 1 \mathrm{Ca} 1 \mathrm{HA}$ & 85.2 & 67.5 & 58.2 & 23.6 & 11.3 & 2.8 & 78.8 & 66.2 & 77.6 \\
\hline $\mathrm{Mg} 1 \mathrm{Zn} 1 \mathrm{Ca} 3 \mathrm{HA}$ & 106.3 & 78.4 & 61.5 & 48.2 & 18.0 & 3.5 & 52.3 & 57.6 & 75.0 \\
\hline $\mathrm{Mg} 5 \mathrm{Zn} 1 \mathrm{Ca}$ & 93.6 & 72.8 & 61.2 & 32.5 & 13.8 & 3.4 & 68.2 & 62.0 & 75.3 \\
\hline Mg5Zn1Ca1HA & 99.5 & 72.7 & 56.3 & 42.7 & 16.5 & 2.5 & 60.8 & 62.1 & 79.0 \\
\hline Mg5Zn1Ca3HA & 106.0 & 74.3 & 54.2 & 52.0 & 19.0 & 2.2 & 52.7 & 60.8 & 80.5 \\
\hline
\end{tabular}

Table A.6: Kitazaki Hata, average values of anodized alloys: contact angle, interfacial free energy and work of adhesion

\begin{tabular}{|c|c|c|c|c|c|c|c|c|c|}
\hline \multirow{2}{*}{$\begin{array}{l}\text { Anodized } \\
\text { Samples }\end{array}$} & \multicolumn{3}{|c|}{ Contact Angle (Deg) } & \multicolumn{3}{|c|}{ Interfacial Free Energy $\left(\mathrm{mJ} / \mathrm{m}^{2}\right)$} & \multicolumn{3}{|c|}{ Work of Adhesion $\left(\mathrm{mJ} / \mathrm{m}^{2}\right)$} \\
\hline & Water & $\begin{array}{c}\text { Ethylene } \\
\text { Glycol }\end{array}$ & $\begin{array}{l}\text { Diiodo- } \\
\text { methane }\end{array}$ & Water & $\begin{array}{c}\text { Ethylene } \\
\text { Glycol }\end{array}$ & $\begin{array}{l}\text { Diiodo- } \\
\text { methane }\end{array}$ & Water & $\begin{array}{c}\text { Ethylene } \\
\text { Glycol }\end{array}$ & $\begin{array}{l}\text { Diiodo- } \\
\text { methane }\end{array}$ \\
\hline $\operatorname{Mg} 1 \mathrm{Zn}(\mathrm{ACI})$ & 94.2 & 81.1 & 49.7 & 51.5 & 38.8 & 13.3 & 67.5 & 55.1 & 83.7 \\
\hline $\begin{array}{l}\mathrm{Mg} 1 \mathrm{Zn} 1 \mathrm{Ca} \\
(\mathrm{ACI})\end{array}$ & 100.0 & 82.2 & 55.3 & 46.2 & 27.1 & 4.7 & 60.2 & 54.2 & 79.7 \\
\hline $\begin{array}{l}\mathrm{Mg} 1 \mathrm{Zn} 1 \mathrm{Ca} 8 \mathrm{Gd} \\
(\mathrm{ACI})\end{array}$ & 105.0 & 81.4 & 69.7 & 43.9 & 17.8 & 7.4 & 53.9 & 54.9 & 68.4 \\
\hline $\mathrm{Mg} 1 \mathrm{Zn} 1 \mathrm{Ca}$ & 92.2 & 81.5 & 56.5 & 48.0 & 38.2 & 17.3 & 70.1 & 54.8 & 78.8 \\
\hline $\mathrm{Mg} 1 \mathrm{Zn} 1 \mathrm{Ca} 1 \mathrm{HA}$ & 84.6 & 70.3 & 56.4 & 33.2 & 24.0 & 12.0 & 79.7 & 63.8 & 78.9 \\
\hline $\mathrm{Mg} 1 \mathrm{Zn} 1 \mathrm{Ca} 3 \mathrm{HA}$ & 102.4 & 83.7 & 61.5 & 44.0 & 23.1 & 4.1 & 57.2 & 53.0 & 75.1 \\
\hline $\mathrm{Mg} 5 \mathrm{Zn} 1 \mathrm{Ca}$ & 91.3 & 86.0 & 52.7 & 68.2 & 63.3 & 35.8 & 71.2 & 51.0 & 81.6 \\
\hline $\mathrm{Mg} 5 \mathrm{Zn} 1 \mathrm{Ca} 1 \mathrm{HA}$ & 98.7 & 76.2 & 54.6 & 42.7 & 20.3 & 2.2 & 61.8 & 59.1 & 80.3 \\
\hline Mg5Zn1Ca3HA & 99.9 & 83.0 & 54.6 & 47.6 & 29.3 & 5.7 & 60.3 & 53.5 & 80.2 \\
\hline
\end{tabular}




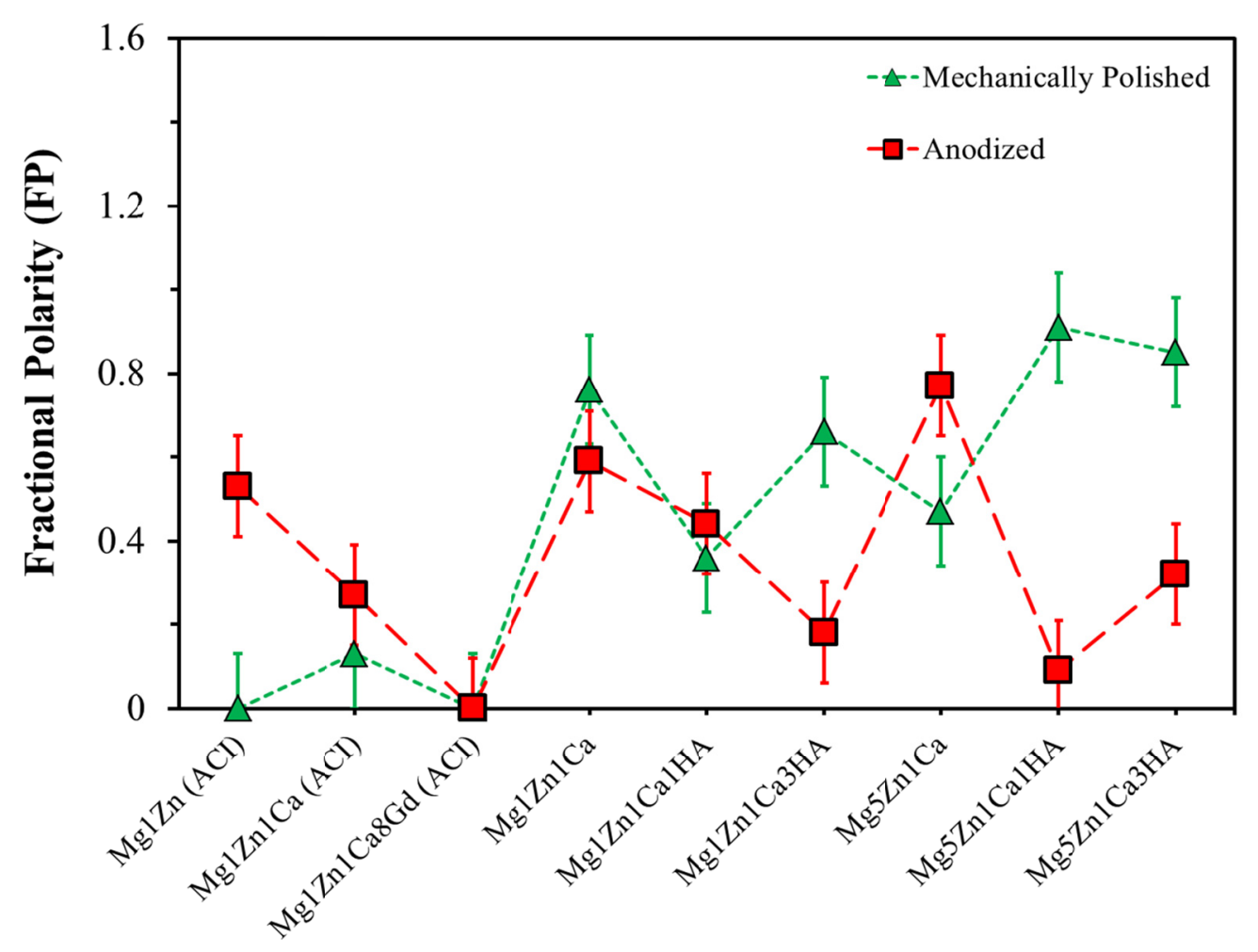

Figure A.2: Plot depicting the fractional polarity values for mechanically polished and anodized samples.

Table A.7: Acid-Base, average values of mechanically polished samples at different roughness: contact angle, interfacial free energy and work of adhesion

\begin{tabular}{|c|c|c|c|c|c|c|c|c|c|}
\hline \multirow{2}{*}{ Sample Finish } & \multicolumn{3}{|c|}{ Contact Angle (Deg) } & \multicolumn{3}{|c|}{ Interfacial Free Energy $\left(\mathrm{mJ} / \mathrm{m}^{2}\right)$} & \multicolumn{3}{|c|}{ Work of Adhesion $\left(\mathrm{mJ} / \mathrm{m}^{2}\right)$} \\
\hline & Water & $\begin{array}{c}\text { Ethylene } \\
\text { Glycol }\end{array}$ & $\begin{array}{l}\text { Diiodo- } \\
\text { methane }\end{array}$ & Water & $\begin{array}{c}\text { Ethylene } \\
\text { Glycol }\end{array}$ & $\begin{array}{l}\text { Diiodo- } \\
\text { methane }\end{array}$ & Water & $\begin{array}{c}\text { Ethylene } \\
\text { Glycol }\end{array}$ & $\begin{array}{l}\text { Diiodo- } \\
\text { methane }\end{array}$ \\
\hline SiC P-240 & 61.2 & 51.9 & 50.3 & -1.0 & 4.5 & 1.7 & 107.9 & 77.5 & 83.2 \\
\hline SiC P-320 & 47.8 & 52.1 & 59.6 & -20.1 & -0.6 & 3.1 & 121.7 & 77.3 & 76.5 \\
\hline $\mathrm{SiC} \mathrm{P}-400$ & 45.0 & 37.9 & 49.6 & -12.9 & 0.8 & 5.7 & 124.3 & 85.7 & 83.7 \\
\hline C-DP $0.05 \mu \mathrm{m}$ & 95.1 & 72.7 & 59.8 & 35.2 & 14.5 & 3.1 & 66.3 & 62.1 & 76.4 \\
\hline
\end{tabular}


Table A.8: Acid-Base, average values of surface free energy components $\left(\mathrm{mJ} / \mathrm{m}^{2}\right)$ of mechanically polished samples at different roughness

\begin{tabular}{|c|c|c|c|c|}
\hline \multicolumn{5}{|c|}{ Surface Free Energy Components $\left(\mathrm{mJ} / \mathrm{m}^{2}\right)$} \\
\hline Sample Finish & $\begin{array}{c}\text { Lifshitz-van } \\
\text { der Waals } \\
\text { LW }\end{array}$ & $\begin{array}{c}\text { Acidic (Electron } \\
\text { Acceptor) } \\
+\end{array}$ & $\begin{array}{c}\text { Basic (Electron } \\
\text { Donor) } \\
-\end{array}$ & Total \\
\hline SiC P-240 & 34.1 & 0.0 & 27.4 & 34.1 \\
\hline SiC P-320 & 28.8 & 0.0 & 50.2 & 28.8 \\
\hline SiC P-400 & 34.5 & 0.1 & 43.0 & 38.6 \\
\hline C-DP $0.05 \mu \mathrm{m}$ & 28.7 & 0.0 & 2.6 & 28.7 \\
\hline
\end{tabular}

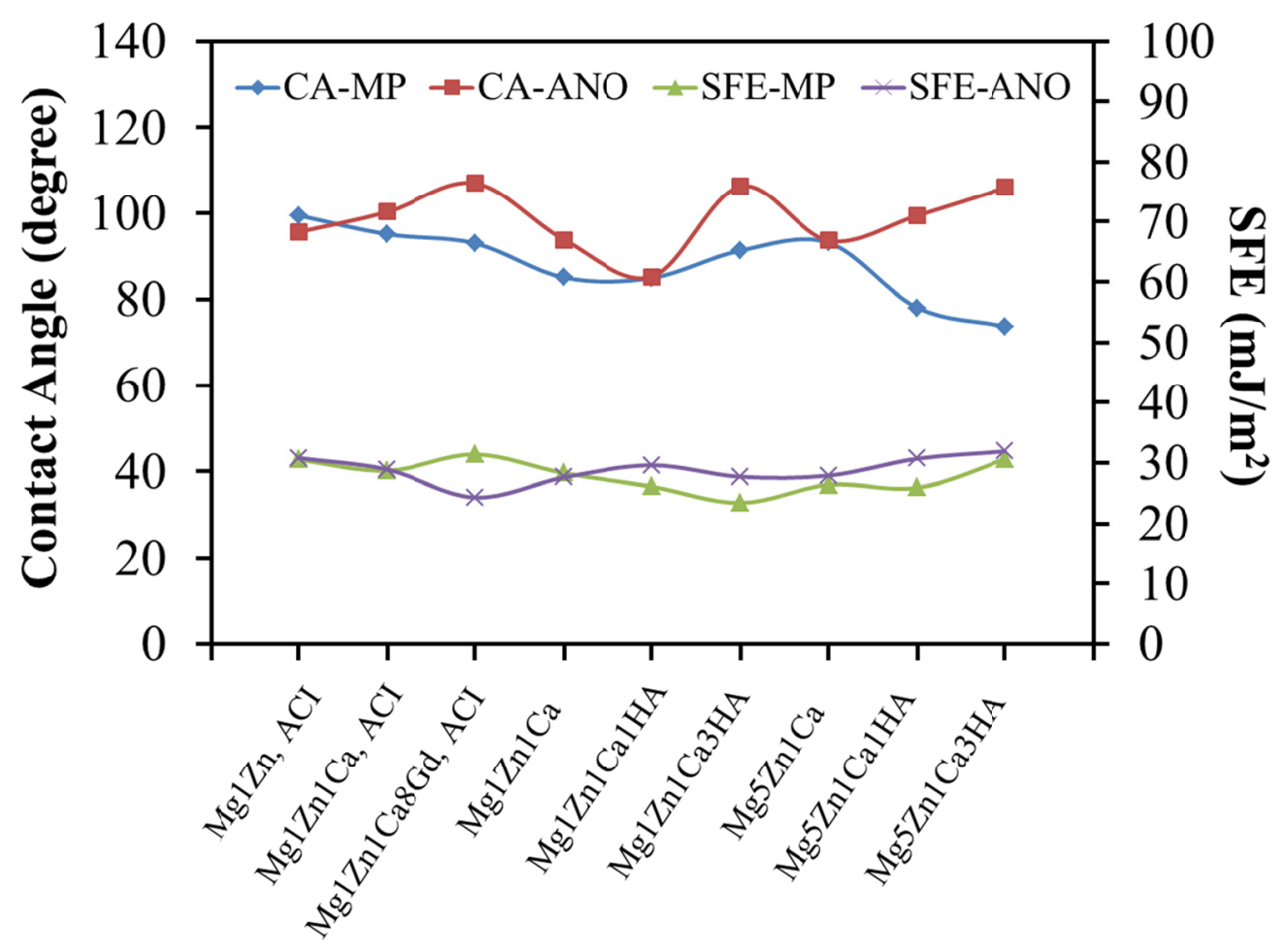

Figure A.3: Contact angle (water) and SFE values for both mechanically polished and anodized samples. 
Table A.9: Properties of elements used in this study

\begin{tabular}{|c|c|c|c|c|c|c|c|}
\hline Element & $\begin{array}{c}\text { Atomic } \\
\text { Radius } \\
\text { (nm) }\end{array}$ & Valency & $\begin{array}{c}\text { Crystal } \\
\text { Structure }\end{array}$ & $\begin{array}{c}\text { Density } \\
\mathbf{g} / \mathbf{c c}\end{array}$ & $\begin{array}{c}\text { Melting } \\
\text { Point } \\
\mathbf{}^{\mathbf{0}} \mathbf{C}\end{array}$ & $\begin{array}{c}\text { Standard } \\
\text { Electrode } \\
\text { Potential (V) }\end{array}$ & Magnetic Property \\
\hline $\mathbf{C a}$ & 0.197 & 2 & $\mathrm{FCC}$ & 1.55 & 839 & -2.868 & diamagnetic \\
\hline $\mathbf{M g}$ & 0.16 & 2 & $\mathrm{HCP}$ & 1.738 & 649 & -2.363 & paramagnetic \\
\hline $\mathbf{Z n}$ & 0.133 & 2 & $\mathrm{HCP}$ & 7.14 & 420 & -0.763 & Diamagnetic \\
\hline Gd & 0.18 & $1,2,3$ & $\mathrm{HCP}$ & 7.9 & 1312 & & Ferromagnetic/ \\
paramagnetic
\end{tabular}


Table A.10: Mean concentration values of Ca, Mg, Zn and Gd measured by ICP-MS. All concentrations and standard deviations were estimated for 3 replicates. Concentrations are reported in $\mathrm{ppm}(\mu \mathrm{g} / \mathrm{mL})$

\begin{tabular}{|c|c|c|c|c|c|c|c|c|c|}
\hline & \multirow{2}{*}{ Composition } & \multicolumn{2}{|c|}{ Magnesium } & \multicolumn{2}{|c|}{ Calcium } & \multicolumn{2}{|c|}{ Zinc } & \multicolumn{2}{|c|}{ Gadolinium } \\
\hline & & $\operatorname{ppm}(\mu \mathrm{g} / \mathrm{mL})$ & $\%$ RSD & $\operatorname{ppm}(\mu \mathrm{g} / \mathrm{mL})$ & $\% \mathrm{RSD}$ & $\operatorname{ppm}(\mu \mathrm{g} / \mathrm{mL})$ & $\%$ RSD & $\mathrm{ppm} \mu \mathrm{g} / \mathrm{mL}$ & $\%$ RSD \\
\hline \multirow{7}{*}{ 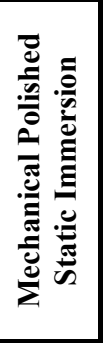 } & Mg1Zn (ACI) & 21 & 1 & NA & NA & 0.301 & 1 & NA & NA \\
\hline & Mg1Zn1Ca8Gd (ACI) & 2 & 3 & 59 & 3 & 0.225 & 1 & 0.0066 & 0.1 \\
\hline & $\mathrm{Mg} 1 \mathrm{Zn} 1 \mathrm{Ca}$ & 1.5 & 1 & 52 & 2 & 0.141 & 1 & NA & NA \\
\hline & Mg1Zn1Ca1HA & 1.5 & 1 & 70 & 1 & 0.111 & 1 & NA & NA \\
\hline & Mg1Zn1Ca3HA & 1 & 2 & 59 & 3 & 0.073 & 1 & NA & NA \\
\hline & Mg5Zn1Ca1HA & 0.6 & 2 & 69 & 2 & 0.539 & 1 & NA & NA \\
\hline & Mg5Zn1Ca3HA & 1.3 & 1 & 69 & 1 & 0.496 & 0.2 & NA & NA \\
\hline \multirow{8}{*}{ 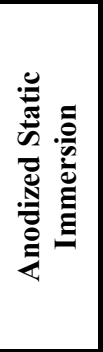 } & $\operatorname{Mg} 1 \mathrm{Zn}(\mathrm{ACI})$ & 23 & 0.2 & NA & NA & 0.012 & 2 & NA & NA \\
\hline & $\mathrm{Mg} 1 \mathrm{Zn} 1 \mathrm{Ca}(\mathrm{ACI})$ & 17 & 1 & 72 & 2 & 0.012 & 2 & NA & NA \\
\hline & Mg1Zn1Ca8Gd (ACI) & 23 & 2 & 70 & 1 & 0.011 & 3 & 0.0066 & 0.1 \\
\hline & $\mathrm{Mg} 1 \mathrm{Zn} 1 \mathrm{Ca}$ & 27 & 1 & 63 & 1 & 0.013 & 2 & NA & NA \\
\hline & Mg1Zn1Ca1HA & 12 & 2 & 68 & 4 & 0.009 & 1 & NA & NA \\
\hline & Mg1Zn1Ca3HA & 44 & 1 & 66 & 2 & 0.013 & 5 & NA & NA \\
\hline & $\mathrm{Mg} 5 \mathrm{Zn} 1 \mathrm{Ca} 1 \mathrm{HA}$ & 17 & 1 & 67 & 2 & 0.014 & 2 & NA & NA \\
\hline & $\mathrm{Mg} 5 \mathrm{Zn} 1 \mathrm{Ca} 3 \mathrm{HA}$ & 1.3 & 1 & 58 & 4 & 0.007 & 1 & NA & NA \\
\hline \multirow{9}{*}{ 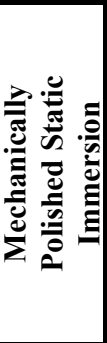 } & $\mathrm{Mg} 1 \mathrm{Zn}(\mathrm{PBS}+\mathrm{C})$ & 0.9 & 2 & NA & NA & 0.054 & 0.2 & NA & NA \\
\hline & Mg1Zn (PBS+Q) & 1 & 2 & NA & NA & 0.73 & 1 & NA & NA \\
\hline & Mg1Zn (PBS+W) & 0.8 & 3 & NA & NA & 0.574 & 1 & NA & NA \\
\hline & $\mathrm{Mg} 1 \mathrm{Zn} 1 \mathrm{Ca}(\mathrm{PBS}+\mathrm{C})$ & 1.1 & 5 & 82 & 2 & 0.165 & 1 & NA & NA \\
\hline & $\mathrm{Mg} 1 \mathrm{Zn} 1 \mathrm{Ca}(\mathrm{PBS}+\mathrm{Q})$ & 2.2 & 1 & 63 & 2 & 0.68 & 1 & NA & NA \\
\hline & $\mathrm{Mg} 1 \mathrm{Zn} 1 \mathrm{Ca}(\mathrm{PBS}+\mathrm{W})$ & 1 & 1 & 71 & 2 & 0.412 & 2 & NA & NA \\
\hline & Mg1Zn1Ca8Gd (PBS+C) & 1.8 & 2 & 58 & 3 & 0.239 & 0.4 & 0.0066 & 0.1 \\
\hline & Mg1Zn1Ca8Gd (PBS+Q) & 1 & 1 & 67 & 2 & 0.339 & 1 & 0.0066 & 0.1 \\
\hline & $\mathrm{Mg} 1 \mathrm{Zn} 1 \mathrm{Ca} 8 \mathrm{Gd}(\mathrm{PBS}+\mathrm{W})$ & 0.6 & 2 & 68 & 3 & 0.457 & 2 & 0.0066 & 0.1 \\
\hline \multirow{6}{*}{ 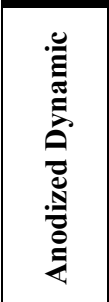 } & $\operatorname{Mg} 1 \mathrm{Zn}(\mathrm{ACI})$ & 20 & 2 & NA & NA & 0.012 & 1 & NA & NA \\
\hline & Mg1Zn1Ca8Gd (ACI) & 20 & 1 & 71 & 2 & 0.01 & 2 & 0.0078 & 0.3 \\
\hline & $\mathrm{Mg} 1 \mathrm{Zn} 1 \mathrm{Ca}$ & 26 & 2 & 87 & 3 & 0.004 & 6 & NA & NA \\
\hline & $\mathrm{Mg} 1 \mathrm{Zn} 1 \mathrm{Ca} 1 \mathrm{HA}$ & 29 & 5 & 67 & 8 & 0.012 & 2 & NA & NA \\
\hline & Mg1Zn1Ca3HA & 24 & 1 & 81 & 2 & 0.005 & 2 & NA & NA \\
\hline & $\mathrm{Mg} 5 \mathrm{Zn} 1 \mathrm{Ca}$ & 33 & 1 & 65 & 3 & 0.003 & 5 & NA & NA \\
\hline
\end{tabular}




\section{B. Appendix - II}

List of publications during Ph.D.

\section{JOURNAL ARTICLES}

1. P. Gill, N. Munroe, "Review on Magnesium Alloys as Biodegradable Implant Materials". International Journal of Biomedical Engineering and Technology. (Accepted)

2. P. Gill, N. Munroe, "Investigating Carbon Nanotubes in Cu-Cr Metal Matrix Composite", Journal of Materials Engineering and Performance Journal of Materials Engineering and Performance, 2012. DOI: 10.1007/s11665-012-0198-Z.

3. P. Gill, N. Munroe, R. Dua, S. Ramaswamy, "Corrosion and Biocompatibility Assessment of Magnesium Alloys". Journal of Biomaterials and Nanobiotechnology, 2012, 3 (1), p. 10-13. DOI: 10.4236/jbnb.2012.31002.

4. P. Gill, N. Munroe, C. Pulletikurthi, S. Pandya, W. Haider, "Effect of Manufacturing Process on the Biocompatibility and Mechanical Properties of Ti-30Ta Alloy". Journal of Materials Engineering and Performance, 2011, 20, p. 819-823, DOI: 10.1007/s11665-011-9874-7.

5. C. Pulletikurthi, N. Munroe, P. Gill, S. Pandya, D. Persaud, W. Haider, K. Iyer, A. McGoron, "Cytotoxicity of Ni from Surface-Treated Porous Nitinol (PNT) on Osteoblast Cells". Journal of Materials Engineering and Performance, 2011, 20, p. 824-829, DOI: 10.1007/s11665-011-9930-3.

6. W. Haider, N. Munroe, V. Tek, P. Gill, Y. Tang, A. J. McGoron, "Cytotoxicity of Metal Ions Released from Nitinol Alloys on Endothelial Cells". Journal of Materials Engineering and Performance, 2011, 20, p. 816-818, DOI: 10.1007/s11665-011-98845 .

7. W. Haider, N. D. Munroe, C. Pulletikurthi, P. Gill, S. Amruthaluri, "A Comparative Biocompatibility Analysis of Ternary Nitinol Alloys". Journal of Materials Engineering and Performance, 2009, 18, p. 760-764.

8. W. Haider, N. Munroe, V. Tek, C. Pulletikurthi, P. Gill, S. Pandya, "Surface Modifications of Nitinol". Journal of Long Term Effects of Medical Implants, 2009, 19 (2), p. 113-122.

9. P. Gill, N. Munroe, R. Dua, N. Hari-Babu, A. McGoron "Characterization and Degradation Behavior of Anodized Magnesium-Hydroxyapatite Metal Matrix 
Composites". Journal of Biomimetics, Biomaterials, and Tissue Engineering. (Submitted)

10. P. Gill, N. Munroe, A. Datye, "Assessing the Effect of Surface Roughness on Electrochemical Behavior of Biodegradable Magnesium Alloys". (Submitted)

11. P. Gill, N. Munroe, A. Datye, "Synthesis, Characterization and Mechanical Properties of Magnesium Based Biodegradable Alloys". Emerging Materials Research. (Submitted)

12. P. Gill, N. Munroe, A. Datye, N. Hari-Babu, "In-vitro Corrosion, Cytocompatibility and Mechanical Studies of MgZnCa/nHA Composites". (Under Preparation)

\section{CONFERENCE PROCEEDINGS}

1. P. Gill, N. Munroe, "In-vitro Corrosion Studies of Bioabsorbable Magnesium Alloys". TMS, Magnesium 2012.

2. P. Gill, N. Munroe, R. Dua, S. Ramaswamy, "In-vitro Degradation and Cytocompatibility Assessment of $\mathrm{Mg}-\mathrm{Zn}$ and $\mathrm{Mg}-\mathrm{Zn}$-Ca Alloys". Materials and Processes for Medical Devices (MPMD), Aug 8-10, 2011, MN, USA.

3. P. Gill, N. Munroe, C. Pulletikurthi, S. Pandya, V. Tek, W. Haider, "In-Vitro Localized Corrosion Studies of Ti-Ta Alloy". The International Conference for Shape Memory and Superelastic Technologies, May 16-20, 2010, Pacific Grove, California.

4. W. Haider, N. Munroe, V. Tek, A. J. McGoron, P. Gill, C. Pulletikurthi, S. Pandya, "An Assessment of Metal Ions Release from Ternary Nitinol Alloys under Static and Dynamic Conditions". The International Conference for Shape Memory and Superelastic Technologies, May 16-20, 2010, Pacific Grove, California.

5. W. Haider, N. Munroe, V. Tek, P. Gill, C. Pulletikurti and S. Pandya, "Influence of Surface Treatments on Corrosion Resistance and Metal Ion Leaching". The International Conference for Shape Memory and Superelastic Technologies, May 1620, 2010, Pacific Grove, California.

6. C. Pulletikurthi, N. Munroe, V. Tek, P. Gill, S. Pandya, W. Haider, "Assessing the Cytotoxicty of Ni from Porous Nitinol (PNT) on osteoblast cells". The International Conference for Shape Memory and Superelastic Technologies, May 16-20, 2010, Pacific Grove, California.

7. W. Haider, N. Munroe, P. Gill, C. Pulletikurthi, "The Electrochemical Characteristics of Surface Treated Nitinol Alloys". NACE-Corrosion 2010 
conference, Research in Progress Symposium, March 14-18, 52-54, 2010 San Antonio, Texas.

8. W. Haider, N. Munroe, C. Pulletikurthi, P. Gill, "Corrosion Behavior of Electropolished and Non-Electropolished Ternary Nitinol Alloys". 25th Southern Biomedical Engineering Conference, The International Federation for Medical and Biological Engineering (IFMBE) Proceedings, 24, 33-34, 2009.

9. N. Munroe, G. Philippidis, P. Gill, W. Haider, S. Amruthaluri, C. Pulletikurthi, S. Pandya, "Submerged Jet Mixing of Non-newtonian Fluids in Waste Tanks". International Mechanical Engineering Congress and Exposition (IMECE) Proceedings, Lake Buena Vista, Florida. IMECE2009 10379.

10. W. Haider, N. Munroe, C. Pulletikurthi, P. Gill, S. Shah, A. J. McGoron, "Cytotoxicity Assessment of Corrosion Products of Nitinol Alloys". Materials and Processes for medical devices-Conference and Exhibition, August 10-12, 2009, Minneapolis, Minnesota. 
VITA

PUNEET KAMAL SINGH GILL

\section{EDUCATION}

May 2009 - August 2012

August 2006 - December 2008

August 2001 - June 2005

PROFESSIONAL EXPERIENCE

January 2009 - April 2009

September 2005 - May 2006

July 2004 - September 2004

October 2004 - December 2004
Doctoral Candidate (Ph.D.) in Material Science and Engineering, Florida International University, Miami, USA (GPA 3.74/4.0)

Master of Science (M.S.) in Material Science and Engineering, Florida International University, Miami, Florida, USA (GPA 3.79/4.0)

Bachelor of Science (B.S.) in Material Science and Engineering, Shaheed Bhagat Singh College of Engineering and Technology, Punjab, India

\section{ACADEMIC AWARDS AND HONORS}

1. Selected for Marquis Who's Who in America, 2013 (67th Edition).

2. Dissertation Year Fellowship: University of Graduate School, Florida International University, Spring-Summer 2012.

3. First place, technical poster competition, Material advantage, FIU chapter, Spring-2012.

4. Nominated for membership of Sigma Xi, 'The Scientific Research Society' 2012-2013 by the Department of Mechanical and Materials Engineering, Florida International University.

5. Doctoral Evidence Acquisition Fellowship: University of Graduate School, Florida International University, Summer-Fall 2011.

6. Chair, Material Advantage Chapter at FIU, 2010-2011 (Chapter won "World Materials Day Award" at MS\&T 2011 )

7. Arthur E. Focke LeaderShape Award for the year 2011, sponsored by American Society of Metals (ASM) at University of Illinois, Champaign.

8. National Science Foundation (NSF) and the Army Research Office Travel Scholarship to present a student poster during 140th Annual Meeting \& Exhibition, TMS 2011, San Diego, California.

9. Member of The Phi Beta Delta and Golden Key International, honor society. 


\section{SELECTED PUBLICATIONS: JOURNAL (TOTAL 12) AND CONFERENCE}

PROCEEDINGS (TOTAL 19)

1. P. Gill, N. Munroe, "Review on Magnesium Alloys as Biodegradable Implant Materials". International Journal of Biomedical Engineering and Technology. (Accepted)

2. P. Gill, N. Munroe, R. Dua, S. Ramaswamy, "Corrosion and Biocompatibility Assessment of Magnesium Alloys". Journal of Biomaterials and Nanobiotechnology, 2012, 3 (1), p. 10-13. DOI: $10.4236 / \mathrm{jbnb} .2012 .31002$.

3. P. Gill, N. Munroe, "In-vitro Corrosion Studies of Bioabsorbable Magnesium Alloys". TMS, Magnesium 2012.

4. P. Gill, N. Munroe, R. Dua, S. Ramaswamy, "In-vitro Degradation and Cytocompatibility Assessment of $\mathrm{Mg}-\mathrm{Zn}$ and $\mathrm{Mg}-\mathrm{Zn}-\mathrm{Ca}$ Alloys". Materials and Processes for Medical Devices (MPMD), Aug 8-10, 2011, MN, USA.

(4 more papers are under review in peer reviewed journals)

\section{SELECTED POSTER PRESENTATIONS (TOTAL 18)}

1. P. Gill, N. Munroe, A. Dayte, R. Dua, S. Ramaswamy, "Mechanical and Biocompatibility Studies of Biodegradable Alloys". NanoFlorida Sept 30-Oct 1, 2011, Miami, Florida.

2. P. Gill, N. Munroe, A. Datye, "Corrosion susceptibility of magnesium based biodegradable alloys in simulated physiological solutions”. MS\&T, Oct 16-20, 2011, Columbus, Ohio.

\section{SELECTED CONFERENCE PRESENTATION (TOTAL 34)}

1. N. Munroe, P. Gill, S. Amruthaluri, "Recent Developments in the Design of Polymer Coated and Bioabsorbable Metal Alloys". BIT's $5^{\text {th }}$ Annual World Congress of Industrial Biotechnology, April 25-28, 2012, Xi'an, China.

2. P. Gill, N. Munroe, R. Dua, A. Datye, S. Ramaswamy, "Assessing Biocompatibility and Mechanical Properties of Degradable Metallic Biomaterials”. TMS, March 11-15, 2012, Orlando, Florida.

\section{REVIEW ACTIVITIES}

1. Editorial Board Member - Pure and Applied Biology (PAB).

2. Reviewer - Acta Biomaterialia and Journal of Materials Engineering and Performance.

3. Book - Mechanics of Biomaterials, Fundamental Principles for Implant Design: Lisa A. Pruitt and Ayyana M. Chakravartula, Cambridge Texts in Biomedical Engineering.

4. Book - Explosive Compaction of Powders \& Composites: R.A. Pruemmer, T. Balakrishna Bhat, K. Shiva Kumar and K. Hokamoto, Science Publishers ISBN 1-57808-270-6. Published in JOM February 2009, pp 66.

5. Book - Powder Metallurgy, The Preferred Metal-Forming Solution, Metal Powder Industries Federation, 105 College Road East, Princeton, New Jersey, USA. Published in JOM February 2011, pp 93. 